\title{
Complementarity in innovation and development : a cross-country comparison
}

Citation for published version (APA):

Hou, J. (2013). Complementarity in innovation and development : a cross-country comparison. [Doctoral Thesis, Maastricht University]. Datawyse / Universitaire Pers Maastricht. https://doi.org/10.26481/dis.20131011jh

Document status and date:

Published: 01/01/2013

DOI:

10.26481/dis.20131011jh

Document Version:

Publisher's PDF, also known as Version of record

\section{Please check the document version of this publication:}

- A submitted manuscript is the version of the article upon submission and before peer-review. There can be important differences between the submitted version and the official published version of record.

People interested in the research are advised to contact the author for the final version of the publication, or visit the DOI to the publisher's website.

- The final author version and the galley proof are versions of the publication after peer review.

- The final published version features the final layout of the paper including the volume, issue and page numbers.

Link to publication

\footnotetext{
General rights rights.

- You may freely distribute the URL identifying the publication in the public portal. please follow below link for the End User Agreement:

www.umlib.nl/taverne-license

Take down policy

If you believe that this document breaches copyright please contact us at:

repository@maastrichtuniversity.nl

providing details and we will investigate your claim.
}

Copyright and moral rights for the publications made accessible in the public portal are retained by the authors and/or other copyright owners and it is a condition of accessing publications that users recognise and abide by the legal requirements associated with these

- Users may download and print one copy of any publication from the public portal for the purpose of private study or research.

- You may not further distribute the material or use it for any profit-making activity or commercial gain

If the publication is distributed under the terms of Article $25 \mathrm{fa}$ of the Dutch Copyright Act, indicated by the "Taverne" license above, 
Complementarity in Innovation and Development A Cross-country Comparison 
(C) Jun Hou, Maastricht 2013

ISBN 9789461592521

Printed by Datawyse | Universitaire Pers Maastricht 


\section{Complementarity in Innovation and Development A Cross-country Comparison}

\section{DISSERTATION}

to obtain the degree of Doctor at Maastricht University, on the authority of the Rector Magnificus, Prof. dr. L.L.G. Soete, in accordance with the decision of the Board of Deans, to be defended in public on Friday October $11^{\text {th }} 2013$ at 12:00 hours

by

Jun Hou

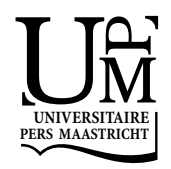




\author{
Supervisor: \\ Prof. Dr. Pierre Mohnen \\ Assessment Committee: \\ Prof. Dr. Robin Cowan (chair) \\ Prof. Dr. René Belderbos, KU Leuven \\ Prof. Dr. Elena Huergo Orejas, Universidad Complutense de Madrid \\ Dr. Boris Lokshin
}




\section{Acknowledgement}

First and foremost I would like to express my sincere gratitude to my supervisor, Professor Pierre Mohnen, who has given me valuable guidance, continuous help and consistent encouragement throughout my doctoral programme. His attitude to research inspired me to be a member of the academic family. And it goes without saying that without his support, this document would not have been possible.

Furthermore it gives me great pleasure in acknowledging the valuable advice given to me by the thesis committee members Prof. Robin Cowan, Prof. René Belderbos, Prof. Elena Huergo Orejas and especially Dr. Boris Lokshin. I am very grateful for their feedback and expertise.

This thesis would not have come to a successful completion without the help and support of all the other kind people around me. A special and warm thank you goes to Eveline in de Braek of UNU-MERIT for always providing prompt assistance in arranging many matters during the years I stayed at MERIT. And I am also very fortunate to know Lilia, Luciana, Asel and Nico, Can and Jinjin, Shuan, Daniel, Eileen, Mingqian, Anant and Kristen for their friendships. Looking back, I have come to realize that MERIT provided me with a stimulating and welcoming academic as well as a social environment, something I will dearly miss.

I am highly indebted to my friends Rogier, Brian, Han and Amber for their kindness and unfailing support in all my struggles. They are great and reliable friends who have never turned me a deaf ear during my ups and downs. I would like to thank them for questioning me about my ideas and helping me to think rationally.

Finally, I would like to thank my parents, my sister and my uncle for always supporting and believing in me, and for their unconditional love.

$$
\text { Jun Hou }
$$

Maastricht, July 2013 



\section{Table of Contents}

Table of Contents ................................................................................................... V

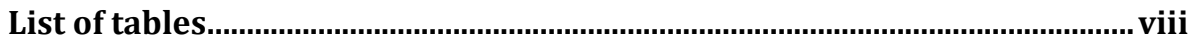

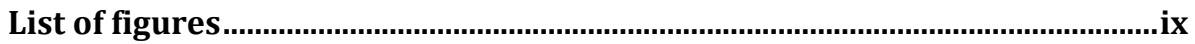

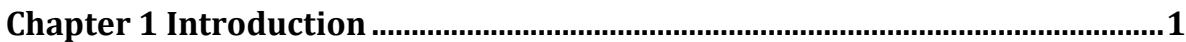

1.1 Motivation: innovation in developing countries ...................................1

1.2 Investment Climate Survey for innovation studies ..................................

1.3 Outline of thesis ............................................................................................. 7

Chapter 2 Complementarity in innovation studies........................................... 11

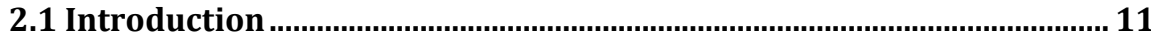

2.2 Definition and classification of complementarity............................... 12

2.2.1 Complementarity definition ......................................................................12

2.2.2 Complementarity classification: objective complementarity vs

behavioral complementarity ...................................................................................13

2.3 Approaches for testing complementarity ............................................ 16

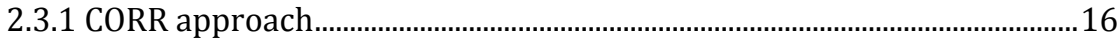

2.3.2 Production approach (PROD or system approach) ...................................17

2.4 Complementarity in innovation: patterns in the literature ................ 19

2.5 Summary: problems and limitations ...................................................... 23

Appendix 2A Studies of complementarity in innovation ............................. 26

Chapter 3 Complementarity between in-house R\&D and technology purchasing: evidence from Chinese manufacturing firms.............................. 29

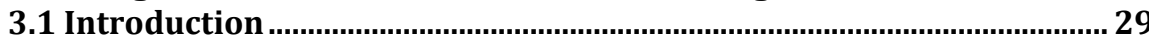

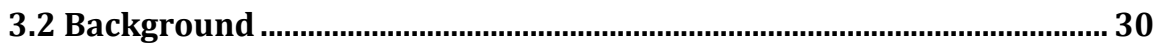

3.2.1 In-house R\&D and technology purchasing: complements or

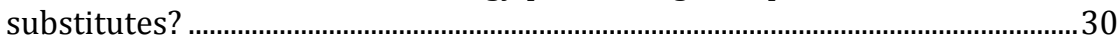

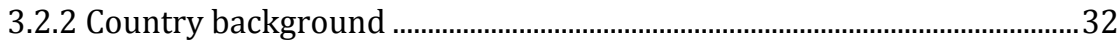

3.3. Empirical model and testing of complementarity............................... 34

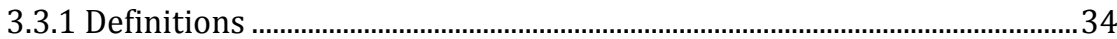

3.3.2 Testing complementarity in terms of innovation output............................36

3.3.3 Testing complementarity in terms of total factor productivity ...............37

3.4. Data and variables ................................................................................... 39

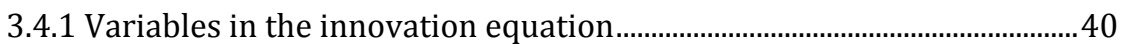

3.4.2 Variables in the production function ...........................................................42

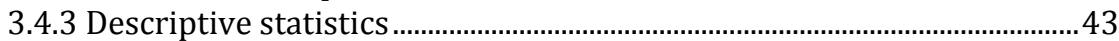

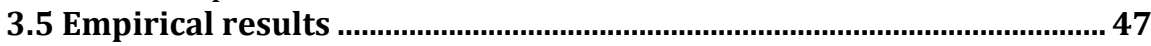

3.5.1 The role of R\&D and TP in stimulating innovation .....................................47

3.5.2 The role of $\mathrm{R} \& \mathrm{D}$ and TP in promoting productivity ...................................51

3.6 Conclusion ................................................................................................... 56

Appendix 3A Calculating the marginal effects of explanatory variables

on the unconditional expectation of new products sales per employee .57

Chapter 4 Complementarity between internal knowledge creation and external knowledge sourcing in developing countries ....................................59

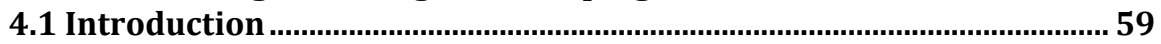


4.2 MAKE and BUY in developing countries: complements or substitutes?

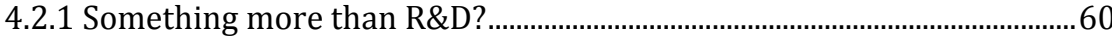

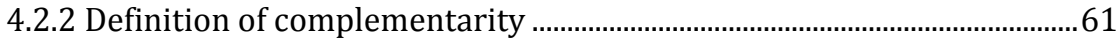

4.2.3 Evidence of complementarity in innovation studies .................................62

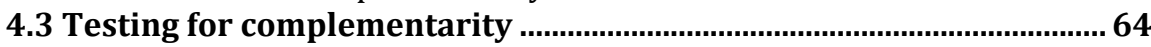

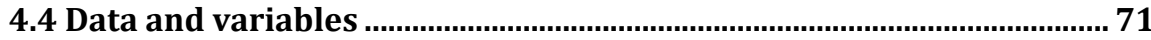

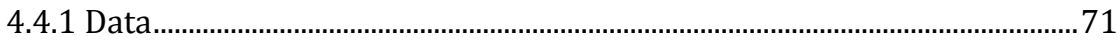

4.4.2 Specification of the production function .......................................................74

4.4.3 Specification of the knowledge acquisition equations ...............................75

4.5. Empirical results ..................................................................................... 79

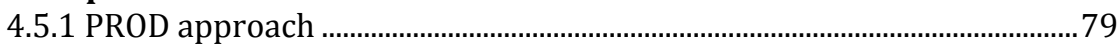

4.5.2 The Miravete and Pernías approach ...............................................................82

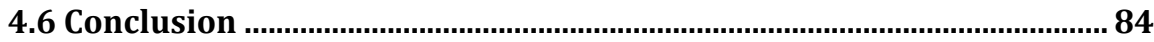

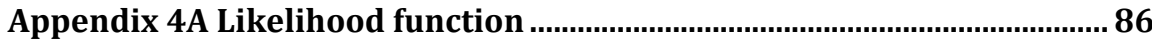

Appendix 4B Truncated bivariate probit with upper and lower bounds and the GHK simulator .......................................................................... 89

Chapter 5 Statistical inference with multiple inequality restrictions .......... 91

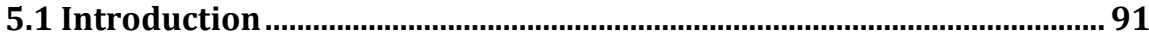

5.2 Complementarity with more than two activities................................ 92

5.2.1 Definition of pairwise complementarity .....................................................92

5.2.2 Studies of complementarity with more than two activities......................93

5.2.3 Modeling complementarity in a linear function...........................................94

5.2.4 The multivariate one-sided hypotheses .....................................................96

5.2.5 The hypothesis test method: likelihood ratio test ....................................99

5.3 A comparison of HT1 and HT2 in simulation experiments...............101

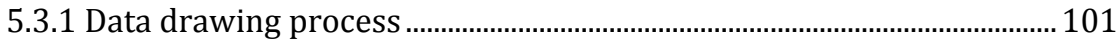

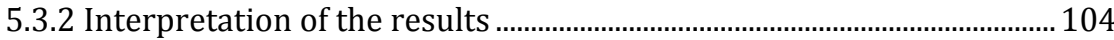

5.4 Final remarks ...............................................................................................110

Chapter 6 Innovation obstacles: evidence from Eastern European and

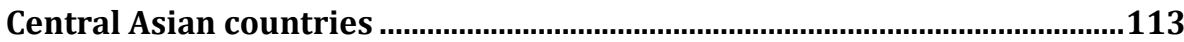

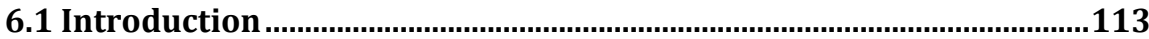

6.2 Obstacles in innovation ....................................................................114

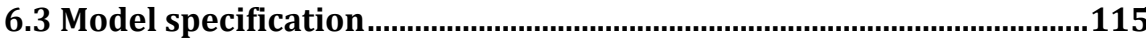

6.3.1 Complementarity between obstacles versus complementarity between

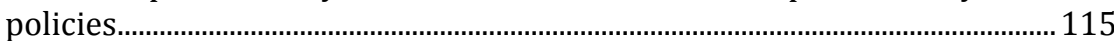

6.3.2 Model specification: obstacles in innovation function ............................116

6.3.3 Testing complementarity between pairs of obstacles............................. 118

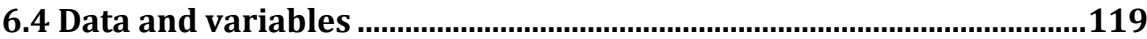

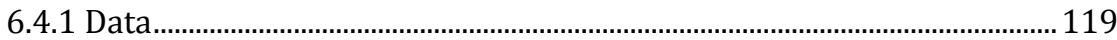

6.4.2 Measures for innovation performance........................................................ 122

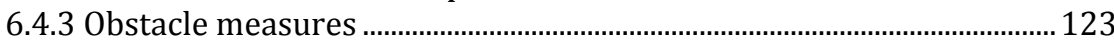

6.4.4 Patterns of obstacles .................................................................................. 126

6.4.5 Firm specificities.......................................................................................... 127

6.5 Obstacles to innovation: empirical results ..........................................132

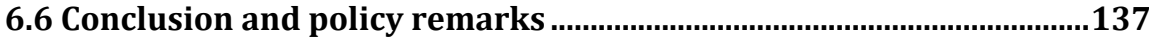

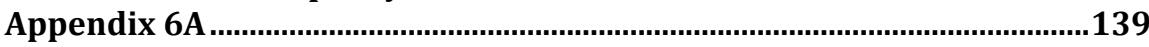

Chapter 7 Conclusion............................................................................................... 141 
7.1 Summary .............................................................................................141

7.2 Limitations and further research ............................................................144

References...................................................................................................147

Samenvatting …................................................................................157

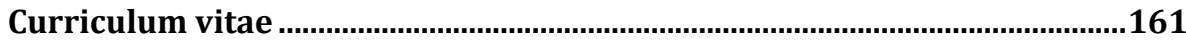




\section{List of tables}

Table 1.1 Regional coverage of the countries and firms in ICS ..........................................

Table 3.1 Literature on the complementarity in technology sourcing in China ..................34

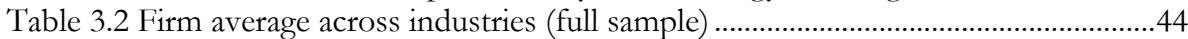

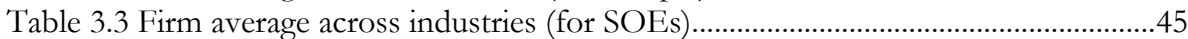

Table 3.4 Descriptive statistics of innovation inputs and outputs across industries (mean

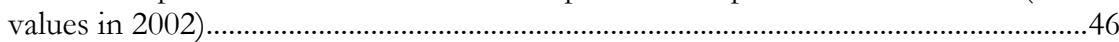

Table 3.5 Estimation results of innovation output (probit for process innovation, tobit type II for product innovation), marginal effects..............................................................4

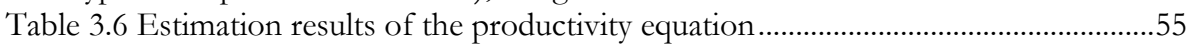

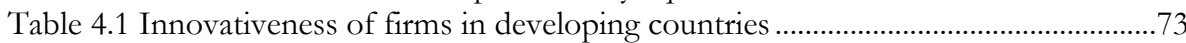

Table 4.2 "Make" and "Buy" strategies in low- and middle-income countries .....................74

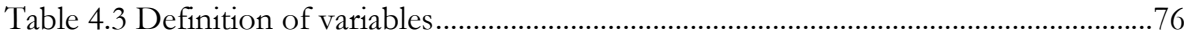

Table 4.4 Unconditional correlations between innovation strategies and scale of

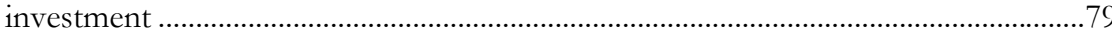

Table 4.5 PROD approach. OLS regression of equation (4.2) results with and without interaction term.

Table 4.6 Miravete and Pernías approach. MLE results.

Table 5.1 Complementarity in innovation studies with more than two activities or strategies

Table 5.2 Conditions for accepting or rejecting the Null of HT1 and HT2 in testing for complementarity....

Table 5.3 Monte Carlo results of testing pairwise complementarity in 3 activities $(10,000$ repetitions): decomposition statistics

Table 5.4 Monte Carlo results of testing pairwise complementarity in 4 activities $(10,000$ repetitions): decomposition statistics

Table 5.5 Monte Carlo results of testing pairwise complementarity/substitutability in 3 activities (10,000 repetitions): Sensitivity and Accuracy

Table 5.6 Monte Carlo results of testing pairwise complementarity in 4 activities $(10,000$ repetitions): Sensitivity and Accuracy.

Table 5.7 The preferable hypothesis between HT1 and HT2 across different sample sizes and R-square values (conclusions are based on the values of accuracy)................... 110

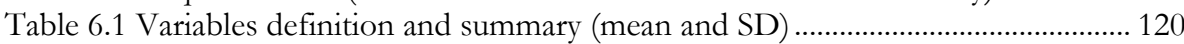

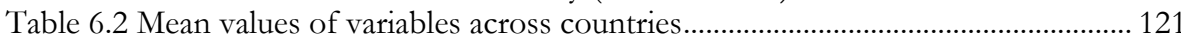

Table 6.3 R\&D and innovation output status of all and across each group (Mean values)

Table 6.4 Obstacles in innovators and non-innovators, (mean values and percentages) 126

Table 6.5 Obstacles across different sector, income and size groups (mean values and percentages)

Table 6.6 Generalized Tobit estimation results: full sample and across different sectors

Table 6.7 Generalized Tobit estimation results: across different income levels............... 130

Table 6.8 Generalized Tobit estimation results: across different size groups................... 131

Table 6.9 Summary of complementary/substitutive relationships between pairs of obstacles (at 95\% significant level) 


\section{List of figures}

Figure 2.1 Complementarity classifications

Figure 2.2 Percentage of studies reviewed across income-level, data unit and data nature

Figure 2.3 Number of studies on complementarity in innovation: patterns across activities concerned .21

Figure 4.1 Regions corresponding to strategy choices in the $\left(\varepsilon_{\mathrm{b}}, \varepsilon_{\mathrm{m}}\right)$ space .70

Figure 4.2 Innovation sourcing strategies, firm specificities and institutional characteristics in low-income and middle-income countries.

Figure 5.1 Orthogonal projection of to the Null parameter space for HT2 (equation 5.6)

Figure 6.1 Positive complementary versus negative complementary... 116

Figure 6.2 Complementarity/substitutability between obstacles to innovation propensity 



\section{Chapter 1}

\section{Introduction}

\subsection{Motivation: innovation in developing countries}

Under the intensive pace of the globalization and technological change, innovation has been widely recognized as the main source for developing countries to gain competitiveness and catch-up. Both challenges and opportunities emerge during this catch-up process. These challenges are accentuated by the fact that the catch-up process requires more knowledge and entrepreneurial spirit to compete in an environment of intensified global competition. The opportunities arise from the possibilities for modernization of traditional activities offered by new technologies.

While there is considerable experience accumulated in the field of innovation policy in developed economies, much of this is not directly applicable to developing countries due to the nature of the characteristics these countries have. The situation is rendered more complicated because the "developing world" presents very diverse situations in terms of levels of development, culture, institution etc. Consequently, innovation policy schemes have to be tailored to countries' specification in line with the recognized fact that "one size does not fit all”, and the recognized need for working much more on national peculiarities of development economics and policies.

The present thesis will try to investigate the potential synergistic effects which exist or might emerge among different aspects of the innovation process in developing countries. 


\section{Technological sourcing: something more than R\&D}

In the context of developing countries, new dimensions of the innovation concept are uncovered. Innovation should be understood as something new to a local context more than to a global context. On the one hand, it is still defined as the design and production of technologies of a worldwide significance - technology creation. On the other hand, innovation is also defined as local improvements based on the adoption of technologies, which are available from the domestic market or global market - technology adoption.

Innovation, which is mainly driven by research and development (R\&D) activities, has been considerably discussed in the endogenous growth theory (Aghion and Howitt, 1998; Grossman and Helpman, 1991) and a number of empirical studies (Griliches, 1984; Hall, Mairesse and Mohnen, 2010). Besides creating new knowledge, R\&D also presents another critical role for developing countries in building technological capacity (Cohen and Levinthal, 1989). However, with limited budget to allocate in R\&D and a lack of innovation experience, technology creation in developing countries in general is difficult to accomplish.

Technology adoption, by which is understood learning and imitation, has been recognized as another major channel for firms in developing countries to achieve technological advances. During the catch-up phase, external technological acquisition, domestic and international, together with in-house R\&D activities have a substantial influence on the speed of learning. Both internal and external sourcing are the major inputs in the innovation process. Freeman (1989) suggested that external knowledge sourcing has a significant influence on the learning process. He argued that for the most part even the most technologically advanced firms in developing countries are committed to be involved in external sourcing activities. External sourcing plays two important roles in this process: filling gaps in domestic technological capability and upgrading the existing technologies to international standards (Aggarwal, 2000). By enhancing technological capability, it consequently reinforces the return of doing in-house R\&D. At the same time, in-house $R \& D$ activities also present their dual function here: developing new innovation and building technological capacity. Cohen and Levinthal (1989) define "absorptive capacity" to describe the substantial role of a stock of prior knowledge in order to absorb external know-how. They argued that the in-house R\&D process would at the same time accommodate firms to build up their own technological capability. 
But which technological sourcing contributes most to firms' performance in developing countries? Are there any synergistic effects between these sourcing strategies? Answers to these questions are still inconclusive. The current research will conduct an insightful analysis of technological sourcing strategies in the context of developing countries.

\section{Individual policy or policy package?}

The success of innovation also associates with several other factors, such as the technological capability in the system and obstacles faced by firms. To gain a richer picture of innovation in development, we are not only concerned with the technological sourcing strategy, but also with the obstacles to innovation and learning. Obstacles in innovation are perceived as factors which have the potential to prevent innovation decision or increase the difficulties, timeframe and cost of the process. In fact, firms in less developed countries are more likely to face genuine barriers to innovation due to inadequate experience and this is precisely why they remain a low level of development.

The potential interactions between the obstacles require different forms of policy responses. Understanding the intrinsic relation between obstacles, complementary or substitutive, is essential to formulate efficient policies. A complementary relationship between obstacles to innovation suggests that if one obstacle is present and hampers innovation, the hampering effect of the second obstacles would be eased. It indicates a positive interaction between obstacles in enhancing innovation. This interpretation is in accordance with the standard notation of complementarity given by Milgrom and Roberts (1990a) - the presence of one activity increases the marginal return of the other activity. Based on this understanding, if obstacles are complementary, the corresponding policies that aim at removing obstacles are also complementary factors. Indeed, a complementary relationship between two obstacles suggests that policies aimed at solving both obstacles are optimal. To remove only one obstacle would amplify the hampering effects of the other. A substitutive relationship between obstacles, on the other hand, would indicate that obstacles need not be removed jointly, all policies should attempt is to avoid that obstacles appear simultaneously. With inadequate resources to solve all barriers together, this perspective would be especially valuable for developing countries.

An alternative (opposite) definition of complementary between innovation obstacles would be that of a negative interaction between them: if one obstacle is present and 
hampers innovation, the second obstacle's hampering effect is strengthened. This interpretation is in accordance with the terminology "negative complementarity" that we proposed earlier chapter 2.2). Thus, having a good understanding of the nature of innovation obstacles, their pattern and impacts on the innovation outcome and firm performance is crucial for the firm and the government to conceive efficient innovation strategies and policy responses, and consequently enhance economic competitiveness (Hadjimanolis, 2003; Ferriani et al., 2008).

\subsection{Investment Climate Survey for innovation studies}

The empirical analysis of this thesis uses firm-level data from the Investment Climate Survey (ICS) collected by the World Bank in 135 countries from different regions of the world between 2002 and 2011. The surveys are divided in several waves by the year at which they are conducted. According to the standardized questionnaire provided, two broad waves are defined: 2002-2005 and 2006-2011 ${ }^{1}$. For each wave, there is a standardized questionnaire that covers a set of questions that are addressed in every country's survey. In general, questionnaires used in the survey are the same, or at least very similar, within a region. Larger differences are detected across regions. The regional coverage of the countries is given in Table 1.1. The table shows the number of firms that are included from each region.

Table 1. 1 Regional coverage of the countries and firms in ICS

\begin{tabular}{|c|c|c|c|c|c|c|}
\hline \multirow[b]{2}{*}{ Region } & \multicolumn{3}{|c|}{$2002-2005$} & \multicolumn{3}{|c|}{ 2006-2011 } \\
\hline & $\begin{array}{l}\text { Number of } \\
\text { Countries }\end{array}$ & $\begin{array}{l}\text { Number } \\
\text { of firms }\end{array}$ & $\begin{array}{l}\text { Percentag } \\
\text { e of firms }\end{array}$ & $\begin{array}{l}\text { Number of } \\
\text { Countries }\end{array}$ & $\begin{array}{l}\text { Number } \\
\text { of firms }\end{array}$ & $\begin{array}{l}\text { Percentag } \\
\text { e of firms }\end{array}$ \\
\hline Sub-Saharan Africa & 12 & 3,258 & $7.73 \%$ & 37 & 15,276 & $24.18 \%$ \\
\hline $\begin{array}{l}\text { East Asia and Pacific } \\
\text { Eastern Europe and Central }\end{array}$ & 4 & 5,880 & $13.94 \%$ & 10 & 4,952 & $7.84 \%$ \\
\hline $\begin{array}{l}\text { Asia } \\
\text { Latin America and the }\end{array}$ & 28 & 19,558 & $46.38 \%$ & 30 & 13,286 & $21.03 \%$ \\
\hline Caribbean & 10 & 5,947 & $14.10 \%$ & 31 & 25,587 & $40.50 \%$ \\
\hline Middle East and North Africa & 5 & 3,281 & $7.78 \%$ & 1 & 477 & $0.76 \%$ \\
\hline South Asia & 4 & 4,245 & $10.07 \%$ & 5 & 3,592 & $5.69 \%$ \\
\hline Total & 63 & 42,169 & $100 \%$ & 114 & 63,170 & $100 \%$ \\
\hline
\end{tabular}

\footnotetext{
${ }^{1}$ Information regarding the full content and range of data can be found on the World Bank enterprise survey website: http://www.enterprisesurveys.org/
} 
The World Bank's ICS provide a unique source of information that can be used to measure finance, corruption, infrastructure, crime, competition, labor, obstacles to growth, and firms' performance across a large set of developing countries. In each country, the sample was designed to be representative of the population of firms according to their industry and location. Many recent studies have employed ICS for cross-country comparison analysis. The merits and weaknesses of these data for analysing firms' innovation behaviors in developing countries are discussed in Gonzales and Lamanna, 2007; Almeida and Fernandes, 2008; Saliola and Seker, 2011. Here, we highlight some of them.

First, for each wave, it is conducted by using a standardized questionnaire across countries located in the same region (see Table 1.1 for region categories), collecting comparable information on several innovation related aspects at the firm level. The data cover major two-digit manufacturing industries according to the International Standard Industrial Classification (ISIC), revision 3.1. Standardized survey instruments and a uniform sampling methodology are employed to minimize measurement error. The survey addresses question on whether the firm adopted a new technology during the year under review, in-house $\mathrm{R} \& \mathrm{D}$ or $\mathrm{R} \& \mathrm{D}$ co-operative works, technology-sourcing activities such as licensing, technology importing, and other important channels to acquire technology. The survey also contains questions which capture firm characteristics such as the firm's ownership structure, age, size, human capital composition, and whether it had import and export activities. Detailed information on infrastructure, institutional background and firms' operation environment also included.

Second, compared with the Community Innovation Survey (CIS) recently conducted in European countries by the OECD (Evangelista et al., 1997; Criscuolo et al., 2005; Damijan et al., 2005; Mohnen et al., 2005), the ICS has the advantage of collecting innovation characteristics for all firms in the sample. The CIS does not include this information for firms that do not innovate during the year under review, except for UK. This advantage potentially avoids the sample selection bias which might exist in CIS. ICS is also featured by its questions that are designed in the context of developing countries. It does so by considering the fact that innovation in developing or least developed countries is a catch-up process through learning, adoption and imitation. Great attentions are placed on learning activities for which firms have used to acquire technology, particularly in the wave of year 2002. The survey collects detailed 
information on the main channels used by firms to acquire technological source. These channels include importing new machinery, transferring from the parent company, or hiring key personnel or consultants, licensing from domestic or foreign sources, doing $\mathrm{R} \& \mathrm{D}$ internally, and doing $\mathrm{R} \& \mathrm{D}$ in cooperation with client firms, equipment and machinery suppliers, or other institutions (i.e., universities and public institutions, business or industry associations, trade fairs, or study groups). This unique information will assist us to do an insightful analysis about technological sourcing behavior of firms in developing countries.

Third, throughout all waves, one of the core questions covered by the ICS regards obstacles firms faced, such as factors related to finance, infrastructure, regulation, corruption, competition, labor, tax, and political instability etc. Respondents were asked to what extent each specific obstacle impeded their operation in the period under review. Dichotomous variables can be constructed to indicate whether a firm assesses them as major impediments (i.e. the corresponding variable takes the value 1 if the firm has rated an obstacle as major or very severe, and takes the value 0 otherwise). By tapping into the potential barriers of which exist in operation and innovation process, economist would gain a deeper understanding about firms' decision and activities. In addition, by investigating obstacles and their intrinsic relationship, we will be able to get a clear picture of how obstacles interact with each other and how they influence the innovation outcome. Findings will provide useful implications for government or enterprises to formulate efficient policies.

Last but not least, research on the comparison of innovation performance across developing countries has been limited due to the unavailability of a homogenous data source. The ICS collects information on innovation performance through surveys conducted across a large number of developing countries, which provides a unique opportunity to compare average innovation and productivity performance of firms across countries. In line with other survey, innovation is measured by several ways in ICS. Innovation can be indexed by a dummy - equal to one if a firm reports having introduced new technology or a significant improvement of the current technology during the period under review. Innovation can also be measured by other information such as the percentage of new products and services sales in total turnover. This sharein-sales indicator is the direct link between the innovation effort and the commercial success and has been widely used as output indicator in recent years (Mairesse and 
Mohnen, 2001; Klomp and Van Leeuwen, 1999). This definition captures the creation of new knowledge but also the adoption and adaptation of production processes. It should be noted that ICS only includes share-in-sales indicator in some countries and regions, such as China 2000-2002 and Eastern Europe and Central Asia 2006-2011.

There are several shortcomings in the ICS data though. First, due to methodological changes and evolution of the survey instrument across regions and years, it is not possible to match all variables in the dataset for every country. Second, firms are also largely unbalanced across each wave. There are many firms which drop out in the following survey and also lots of new firms that enter the dataset, which rules out the possibility of having panel analyses. Another major shortcoming is that even though there are always improvements of the quality and accuracy of the data, large amount of inconsistencies can be detected especially from 2002 to 2005, such as currency inconsistencies, missing values or unreasonable answers. Therefore, it is suggested to have a thorough familiarity with the questionnaires and a detailed check of the unstandardized data for each country before proceeding with the analysis.

\subsection{Outline of thesis}

The present chapter introduces the topic of inquiry in this thesis and describes the data used in the empirical analysis. It follows by giving a concise outline of the remaining chapters.

The second chapter is a step towards understanding the concept of complementarity and reviews previous innovation studies in the literature that adopts the complementarity approach. It presents an insightful interpretation of complementarity between pairwise economic activities by using a hierarchical classification. Complementarity is broadly classified into two types based on whether or not it is embedded in a specific objective function: objective complementarity and behavioral complementarity. Further classifications in the lower level of hierarchy are also defined. Apart from elaborating different types of complementarity, chapter 2 also introduces the approaches adopted in empirical studies to test complementarity/substitutability. Three approaches are distinguished: CORR (Correlation approach), MP (Miravete and Pernías approach) and PROD (Production approach). Moreover, reviewing the previous studies that try to 
investigate complementarity in the innovation process, it shows the problems and limitations that exist in literature. The chapter on literature review provides a detailed discussion on these problems and limitations. It also explains how they will be addressed in this thesis.

Chapter 3 investigates the existence of complementarity between in-house R\&D and external technology acquisition by using a panel data of Chinese manufacturing firms. It tries to explore the impact of internal and external technology sourcing on firms' innovation and productivity performance in Chinese small- and medium-sized manufacturing firms. In particular, it estimates the returns of $R \& D$ and external technology purchasing (TP) and their possible complementarity or substitutability. It does so by distinguishing two performance measures: innovation in products or processes and labor productivity. Since size may matter in this regard, we estimate separately the relationships for firms with fewer than 100, between 100 and 300, and more than 300 employees. The findings show that in-house $\mathrm{R} \& \mathrm{D}$ seems to accelerate the assimilation of external know-how whereas external technology sourcing enhances the efficiency of in-house innovation activities. The results also exhibit some evidence of complementarity between in-house R\&D and TP in raising the sales of new products per employee in small-sized Chinese manufacturing firms with 100 to 300 employees while $\mathrm{R} \& \mathrm{D}$ and TP are substitutes when it comes to raising labor productivity.

The fourth chapter is another empirical study to test potential synergistic effects between technological strategies by using firm cross-sectional data from 24 developing and least developed countries. In this chapter, we try to identify factors that determine the choice of a specific technological sourcing, as well as factors that foster the potential complementarity between them. It examines the roles of internal R\&D efforts and external technology sourcing in fostering productivity in manufacturing firms. Three testing approaches are compared and adopted in the empirical analysis, namely CORR, PROD and MP (Miravete and Pernías approach, see chapter 4). The analysis emphasizes that in a cross-sectional analysis, the MP approach stands out compared with the other two approaches by providing a structural framework, which effectively corrects the bias caused by the correlation between unobservables. The empirical finding highlights the critical role of external technology acquisition in manufacturing industries across developing countries and exhibits signs of complementarity only in middle-income countries. The results also show that different approaches give different results. 
Chapter 5 discusses different types of multivariate one-sided hypothesis defined to test pairwise complementarity among three or four activities. This chapter uses simulated datasets to compare the validity and efficiency of two types of hypotheses with different model specifications and sample sizes. The simulation results verify the potential bias which might exist in the non-exhaustive hypothesis formulation. Conclusions based on such hypotheses tend to be biased if the nature of the inequalities is not taken into account. Findings from this chapter also suggest that combing two tests of hypothesis always guarantees a more accurate conclusion in testing complementarity. In some situations, especially when the sample size is large and the R-square value is high for linear models, only one hypothesis testing can also provide adequate information to draw correct conclusions.

In order to gain a deeper understanding of the barriers to innovation, chapter 6 applies the complementarity approach to firm level data from the Investment Climate Survey 2009 Eastern European and Central Asian countries (EECA) to investigate if there exists complementarity or substitution among four types of obstacles to innovation across different sectors, income levels and size groups. The approach of testing pairwise complementarity when more than two activities occur, is borrowed from chapter 5 . Findings from this chapter provide a clear explanation of complementarity between obstacles to innovation: the presence of one obstacle eases the hampering effect of the second obstacle to innovation. The finding suggests that a policy package that attempts to tackle both obstacles is preferred. Policies that only eliminate one obstacle would amplify the deterring effects from the other. A substitutive relationship between obstacles, on the other hand, suggests removing one obstacle is enough because its presence would worsen the negative effects induced by the other.

The final chapter concludes the dissertation, providing a number of policy implications and it recommends avenues for future studies. 

Chapter 2

\section{Complementarity in innovation studies}

\subsection{Introduction}

Since Samuelson pointed it out in 1974, the notion of complementarity has been explained and adopted in different theories in economic research, such as comparative statics of optimal solutions (Topkis 1978; Topkis 1998); games with strategic complementarities (coincidence of normal-form solution concepts; oligopoly applications); comparative statics under uncertainty (behavior under risk; Bayesian games); and institutional complementarity (fit and synergies in organization theory; modern manufacturing; varieties of capitalism).

The notion of complementarity is commonly referred in standard price theory, where, for example, two goods are complements if raising the price of one lowers the consumption of the other. During the past two decades, this concept has been broadened to permit analyses of complex economic phenomena, organizational structures and government policies. A group of activities are defined as complements if doing more of any subset of them increases the return to doing more of any subset of the remaining activities (Milgrom and Roberts, 1990a; Matsuyama, 1995). However, complementarity may also cause deterring effects. For example, complementary factors in a system may have difficulties to adopt new organizational changes since change in one factor of the system would require change in other complementary factors in the system (Milgrom and Roberts, 1995). 
The perspective of complementarity is intriguing, yet it lacks the specificity about its definition, classification and testing approach framework. In this chapter, we aim to review the general definition of complementarity and its classifications, and thereby lay the basis for the empirical analysis in the following chapters.

\subsection{Definition and classification of complementarity}

\subsubsection{Complementarity definition}

Complementarity was first introduced into economics by Edgeworth (1881) and refers to the notion: gain from increasing all factors is more than sum of gains from increasing them separately. Topkis (1978) explained the theory of complementarity by using the subject of a branch of mathematics known as lattice theory. The intuition behind sublattices is that constraining a choice to lie in a sublattice expresses a kind of technical complementarity: it suggests that increasing the value of some variables never prevents one from increasing the others as well, it may actually require increasing some, and similarly that decreasing some variables never prevents one from decreasing others. In this sense, a sublattice could be very useful to model the idea that a set of activities is complementary.

Based on the concepts of Edgeworth complementairy and sublattice supermodularity, complementarity was formally modelled in economics by Milgrom and Roberts (1990b, 1994) and their approach provides an impetus for later empirical research. They argue that complementarity in economic terminology corresponds to positive mixed-partial derivatives of a specified payoff function in a differentiable framework. The marginal returns to one variable are increasing in the levels of the other variables, and therefore the economic performance by combining two or more complementary factors in a production system is expected to be better than what would be generated by applying these factors in isolation (Ennen and Richter, 2010). The notion of supermodularity enables economists to model, in a mathematically rigorous manner, the relationships among multiple economic activities or organizational elements of complex systems as something more than the sum of these elements. Beneficial effects of such relationships are often coined fit, which has a rich intellectual tradition in economic and organizational theory (Drazin and Van de Ven, 1985). 
Formally, a pair of economic activities is complementary if (1) adopting one does not preclude adopting the other and (2) whenever it is possible to implement each activity separately, the sum of the benefits to do just one or the other is no greater than the benefit of doing both together. Suppose there are two economic activities $X_{i}$ and $X_{j}$, and $\mathrm{Z}$ is a vector of exogenous variables. In a differentiable framework, the objective function $\mathrm{f}\left(X_{i}, X_{j}, Z\right)$ is supermodular if the incremental effect of one economic activity increases conditional on increasing another activity (Milgrom and Roberts, 1990a), which is equivalent to hold the following inequality for all values of the other arguments of $\mathrm{f}$ :

$$
\frac{\partial^{2} f\left(X_{i}, X_{j} \mid Z\right)}{\partial X_{i} \partial X_{j}}>0
$$

If $X_{i}$ and $X_{j}$ are discrete choices made by firm in adopting or implementing any economic activities, then the sum of adopting them separately is no greater than adopting them simultaneously with all other exogenous effects controlled:

$f\left(X_{i}=1, X_{j}=1 \mid Z\right)+f\left(X_{i}=0, X_{j}=0 \mid Z\right)>f\left(X_{i}=0, X_{j}=1 \mid Z\right)+f\left(X_{i}=1, X_{j}=0 \mid Z\right)$

In the case of substitutability, the inequality signs are reversed.

\subsubsection{Complementarity classification: objective complementarity vs behavioral complementarity}

In order to provide a more insightful interpretation of the inter-dependent relations between pairwise economics activities, we broadly classify the complementarity into two sub-categories: (a) objective complementarity and (b) behavioral complementarity. The former is the complementarity under the framework of achieving a specific economic goal, which is in accordance with the conceptual framework proposed by Milgrom and Roberts (1990b, 1994). It is a synergy between activities that foster a better performance with respect to a specific purpose. Examples are: complementarity between innovation sourcing strategies in productivity growth; complementarity between R\&D cooperation strategies in innovation output. The 'objective complementarity' plays a dominant role in the empirical studies of complementarity literature. One representative example is the study carried out by Mohnen and Röller (2005). The authors use the Community Innovation Survey (CIS) data from 4 European countries to test the complementarity between different kinds of innovation obstacles. Four obstacles faced by firms are 
interacted and embedded in the innovation function. By systematically estimating the complementary versus substitutive relationship between pairs of obstacles, their results show that lack of internal human capital is complementary to all the other obstacles regarding the probability of becoming an innovator. Another example is the 'Make and Buy' complementarity investigated by Cassiman and Veugelers, (2006) using Belgium manufacturing firms. The authors examined the relationship between firms' internal $\mathrm{R} \& \mathrm{D}$ and external technology acquisition in the production function. Their finding confirms the existence of complementarity between in-house R\&D and external sourcing strategy when it comes to productivity performance.

The other type of complementarity is the complementarity between economic activities in a general sense of a firm's recognition of utility or profit maximization. In this framework, no specific objective function is specified. It is based on the interpretation that a firm's choice of adopting activities simultaneously will in one way or another accomplish the optimal utility goal. Normally, empirical studies adopting this notation come with the assumption that firms are believed to undertake rational choices based on their individual understanding of maximizing utility. Due to the nature that it is a general behavior of adoption and decision-making, we define this type of mutual effects as 'behavioral complementarity'. A representative study in line with this notion was conducted by Arora and Gambardella (1990). They tested the synergetic effects among four different external sourcing strategies of large chemical and pharmaceutical firms by looking at the conditional correlation coefficients. After controlling for firms' specificities, the results show significant correlation coefficients between all types of external sourcing strategies. The authors conclude that if any two strategies are complementary then they are positively correlated. Several studies that try to investigate the innovation cooperation strategies also adopt the correlation coefficients (bivariate or multivariate analysis) as indicators for complementarity (Belderbos et al., 2004; Tether, 2008; Schmiedeberg, 2008). 
Figure 2.1 Complementarity classifications

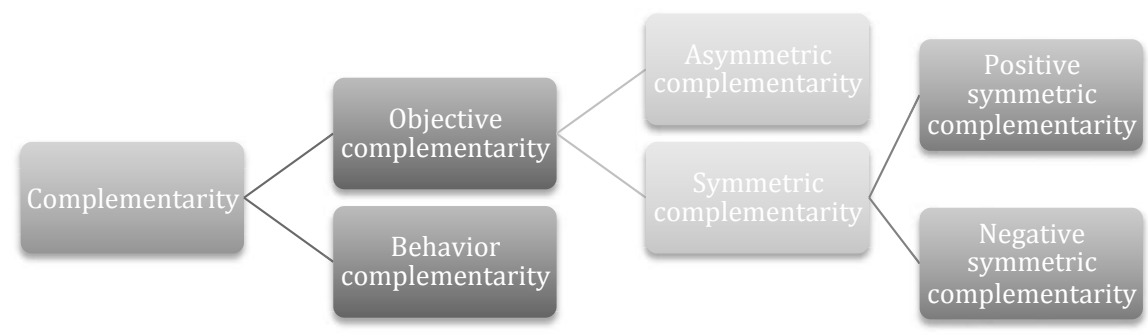

Symmetric complementarity vs asymmetric complementarity

As shown in figure 2.1, subcategories are further defined under the framework of objective complementarity. The symmetric complementarity and asymmetric complementarity were introduced by Choi and Poon (2008). If two or more economic activities affect the objective function in the same direction, then they are defined as 'symmetric complementary' activities. A further sub-classification can be made in the symmetric complementarity: 'positive symmetric complementarity' and 'negative symmetric complementarity'. The synergistic effect that arises from variables with positive estimated coefficients is referred to 'positive symmetric complementarity'. On the contrary, the synergistic effects that exist among variables with negative sign are referred to 'negative symmetric complementarity' (For more details, see Chapter 6.3.1). For example, for the innovation output function (patent or new products sales), strategies such as R\&D cooperation and technological sourcing are expected to stimulate innovation outcome while factors such as obstacles (finance, tax, regulation etc.) might inhibit innovation outcome. If $X_{i}$ and $X_{j}$ are in a differentiable form then:

with the presence complementarity $\frac{\partial^{2} f\left(X_{i}, X_{j} \mid Z\right)}{\partial X_{i} \partial X_{j}}>0$

$\left\{\begin{array}{l}\text { Positive complementary: if } \frac{\partial f\left(X_{i}, X_{j} \mid Z\right)}{\partial X_{i}}>0 \text { and } \frac{\partial f\left(X_{i}, X_{j} \mid Z\right)}{\partial X_{j}}>0 \\ \text { Negative complementary: if } \frac{\partial f\left(X_{i}, X_{j} \mid Z\right)}{\partial X_{i}}<0 \text { and } \frac{\partial f\left(X_{i}, X_{j} \mid Z\right)}{\partial X_{j}}<0\end{array}\right.$

In the case of $X_{i}$ and $X_{j}$ are both binary choice activities 
$f\left(X_{i}=1, X_{j}=1 \mid Z\right)+f\left(X_{i}=0, X_{j}=0 \mid Z\right)>f\left(X_{i}=0, X_{j}=1 \mid Z\right)+f\left(X_{i}=1, X_{j}=0 \mid Z\right)$

$\left\{\begin{array}{c}\text { Positive complementary: if } \frac{f\left(X_{i}=1, X_{j}=0 \mid Z\right)}{f\left(X_{i}=0, X_{j}=0 \mid Z\right)}>1 \text { and } \frac{f\left(X_{i}=0, X_{j}=1 \mid Z\right)}{f\left(X_{i}=0, X_{j}=0 \mid Z\right)}>1 \\ \text { Negative complementary: if } \frac{f\left(X_{i}=1, X_{j}=0 \mid Z\right)}{f\left(X_{i}=0, X_{j}=0 \mid Z\right)}<1 \text { and } \frac{f\left(X_{i}=0, X_{j}=1 \mid Z\right)}{f\left(X_{i}=0, X_{j}=0 \mid Z\right)}<1\end{array}\right.$

'Asymmetric complementarity' describes the situation that not all activities present positive effects in affecting the outcome under the objective function: at least one of the activities shows a negative sign or no effect on the outcome. In the case of only two activities $X_{i}$ and $X_{j}$, asymmetric complementarity is identified if only $X_{i}\left(X_{j}\right)$ positively influences outcome independently of the other, and the presence of $X_{j}\left(X_{i}\right)$ creates a catalysis effect that further enhances the positive impact of $X_{i}\left(X_{j}\right)$ instead of directly influencing the outcome.

If $X_{i}$ and $X_{j}$ are in a differentiable form then:

with $\frac{\partial f\left(X_{i}, X_{j} \mid Z\right)}{\partial X_{i} \partial X_{j}}>0$

Asymmetric complementary: if $\frac{\partial f\left(X_{i}, X_{j} \mid Z\right)}{\partial X_{i}}>0$ or $\frac{\partial f\left(X_{i}, X_{j} \mid Z\right)}{\partial X_{j}}>0$

In the case of $X_{i}$ and $X_{j}$ are binary choice activities,

$f\left(X_{i}=1, X_{j}=1 \mid Z\right)+f\left(X_{i}=0, X_{j}=0 \mid Z\right)>f\left(X_{i}=0, X_{j}=1 \mid Z\right)+f\left(X_{i}=1, X_{j}=0 \mid Z\right)$

Asymmetric complementary: if $\frac{f\left(X_{i}=1, X_{j}=0 \mid Z\right)}{f\left(X_{i}=0, X_{j}=0 \mid Z\right)}>1$ or $\frac{f\left(X_{i}=0, X_{j}=1 \mid Z\right)}{f\left(X_{i}=0, X_{j}=0 \mid Z\right)}>1$

Based on the classification introduced above, the next section will describe the approaches used to test complementary.

\subsection{Approaches for testing complementarity}

\subsubsection{CORR approach}

If the presence of one practice is likely to raise the marginal effect of other practices, then the joint adoption of two practices together should be encouraged. Therefore, if there is a co-movement phenomenon of two practices, it can be interpreted as the first 
evidence in favour of existing complementarity. This co-movement may be indexed by the positive correlation (negative if substitutes) between pairwise practices and the approach used to identify the correlation coefficient is defined as 'Correlation approach' $(\mathrm{CORR})^{2}$. This approach is easy to implement and mainly focuses on testing behavioral complementarity' in the sense that synergies between activities are captured without looking at the relative performance outcomes. Empirical studies that take this approach may use, as independent variables, either dichotomous variables (if an activity is implemented), rank-ordered or continuous measures of the factor concerned. The main statistical methods applied consist of the Pearson correlation coefficient, bivariate and multivariate conditional regressions. Some studies on complementarity use this approach as auxiliary evidence (Cassiman and Veugelers, 2006; Schmiedeberg, 2008).

Several drawbacks of the CORR approach should be noted here. First, using Pearson correlation can only provide very preliminary results with regard to the fact that heterogeneity always produces noise in the practice adoption process. Without holding the firm characteristics fixed, it is very unlikely that the pairwise correlation coefficient can generate consistent results. Second, in order to control for firm characteristics, bivariate probit or multinomial model have been used to test the complementarity by looking at the correlation between residuals. This method may successfully investigate factors which cause the correlation. For example, if the correlation coefficient decreases when factors are added, then one would argue that these factors are the causes of complementarity. However, the CORR approach is limited by the strong assumption imposed: firms are believed to make the optimal decision in adopting activities or choosing strategies concerned. Moreover, we do not know whether the correlation between residuals is the results of an actual complementarity or the association between unobserved errors (Athey and Stern, 1998; Miravete and Pernías, 2006).

\subsubsection{Production approach (PROD or system approach)}

In contrast, the approach that takes into account the performance outcomes with a specific objective function is defined as 'Production approach' (PROD) ${ }^{3}$. It has been widely applied to investigate complementarity in the economic and management literatures. The PROD approach looks directly at the cross partial returns in the objective

\footnotetext{
2 The CORR approach is also defined as 'Adoption approach' (Miravete and Pernias, 2006).

3 The PROD approach is also defined as 'System approach' (Enne and Richter, 2010).
} 
function and has been applied in several empirical studies (Cassiman and Veugelers, 2006; Mohnen and Röller, 2005; Belderbos et al., 2006).

First, in order to implement the PROD approach, an objective function needs to be established. Suppose there are two economic activities $X_{i}$ and $X_{j}$ and $\mathrm{Z}$ is a vector of exogenous variables in an objective function $\mathrm{f}\left(X_{i}, X_{j}, Z\right)$. The PROD approach regresses an objective on exclusive combinations of innovation activities.

$f\left(X_{i}, X_{j}, Z\right)=\theta_{00}\left(1-X_{i}\right)\left(1-X_{j}\right)+\theta_{10} X_{i}\left(1-X_{j}\right)+\theta_{01}\left(1-X_{i}\right) X_{j}+\theta_{11} X_{i} X_{j}+\theta_{z} Z+e$

where $X_{i}$ and $X_{j}$ are dichotomous choices that take value 1 if they are adopted by the firm. $\theta_{11}$ stands for the cross-partial returns of choosing both $X_{i}$ and $X_{j}$ jointly; $\theta_{10}$ for choosing $X_{i}$ only; $\theta_{01}$ for choosing $X_{j}$ only; $\theta_{00}$ for choosing none of them. The objective function is supermodular in $X_{i}$ and $X_{j}$ if

$\theta_{11}-\theta_{01}-\theta_{10}+\theta_{00}>0$

It demonstrates that the return to adopting both activities is greater than the sum of performing them in isolation. On the other hand, it is submodular and hence the choices are interpreted as substitutes if

$\theta_{11}-\theta_{01}-\theta_{10}+\theta_{00}<0$

Another alternative form to express the supermodularity in the objective function can be expressed as $\theta_{i j}>0$. The objective function now defined as

$f\left(X_{i}, X_{j}, Z\right)=\theta_{0}+\theta_{i} X_{i}+\theta_{j} X_{j}+\theta_{i j} X_{i} X_{j}+\theta_{z} Z+e$

where

$\theta_{0}=\theta_{00}$

$\theta_{i}=\theta_{10}-\theta_{00}$

$\theta_{j}=\theta_{01}-\theta_{00}$

$\theta_{i j}=\theta_{11}+\theta_{00}-\theta_{10}-\theta_{01}$

where the coefficient $\theta_{i}$ captures the non-exclusive partial effect of $X_{i} ; \theta_{i}$ the nonexclusive partial effect of $X_{j} ; \theta_{\mathrm{ij}}$ the return from adopting make and buy together; $\theta_{0}$ is 
constant. If we insert (2.7) into (2.6), we will get back to equation (2.4). Hence, the condition for the production function (2.5) to be supermodular can be simplified as oneside t-test on $\theta_{i j}>0$.It is clearly shown in function (2.6) that the marginal returns of either $X_{i}$ and $X_{j}$ will not be constant anymore if complementary or substitutive effects are observed (shown as $\theta_{\mathrm{ij}} \neq 0$ ). The complementarity coefficient appears in the estimation of partial effects of each of the strategy. The marginal returns of $X_{i}$ and $X_{j}$ to the performance outcome can be expressed respectively as

$\left[f \mid X_{i}=1\right]-\left[f \mid X_{i}=0\right]=\theta_{i}+\theta_{i j} X_{j}$ $\left[f \mid X_{j}=1\right]-\left[f \mid X_{j}=0\right]=\theta_{J}+\theta_{i j} X_{i}$

Athey and Stern (1998) explained that simply running OLS on the above function would deliver inconsistent results. They argued that the existence of firms' unobserved heterogeneity may have a substantial influence on the association between strategies even though complementarily may not exist at all. Consequently, the PROD approach might deliver biased results if there are unobserved factors in the error term that are correlated with the activities the firm adopted - the endogeneity problem.

In order to correct for this bias, a structural model should be developed, either using instruments in the cross sectional data or panel method if the panel data are available (Wooldridge, 2002). Cassiman and Veugelers (2006) have tried to adopt instrumental variables that were correlated with the adoption decision without affecting innovation output. However, the results can be refined only if the instrumental variables are properly identified. Therefore, the PROD approach possibly suffers from biases because of the endogeneity of input strategies.

\subsection{Complementarity in innovation: patterns in the literature}

Our review of the literature consists of forty-two empirical studies ${ }^{4}$ that reveal the substance of 'synergy' or 'fit' in innovation regarding both economic and management issues. The selected studies concern complementarity assets in different aspects of

\footnotetext{
4 This literature survey tries to include studies that address complementarity assets in innovation. However, the list is certainly not exhaustive.
} 
innovation and the selection is not exhaustive. Of the studies that investigate synergistic effects in innovation, the clear majority focuses on developed economies, thirty-seven out of forty-three studies (88.1per cent). Limited evidence exists in the context of developing or least developed countries. Except for three studies that used industry as their unit of analysis (Aggarwal, 2000; Rothaermel, 2005; Bin, 2008), most analyzes were based on firm level (organization level) data. We also noticed that almost 67 percentage of studies reviewed here adopt cross-sectional data on complementarities, using static measures of performance (e.g., productivity, patent or innovation sales) as their dependent variables. There are relatively fewer studies (about 33\%) taking a longitudinal perspective. To check the full list of studies reviewed in this chapter, please see Appendix $2 \mathrm{~A}$.

Figure 2.2 Percentage of studies reviewed across income-level, data unit and data nature

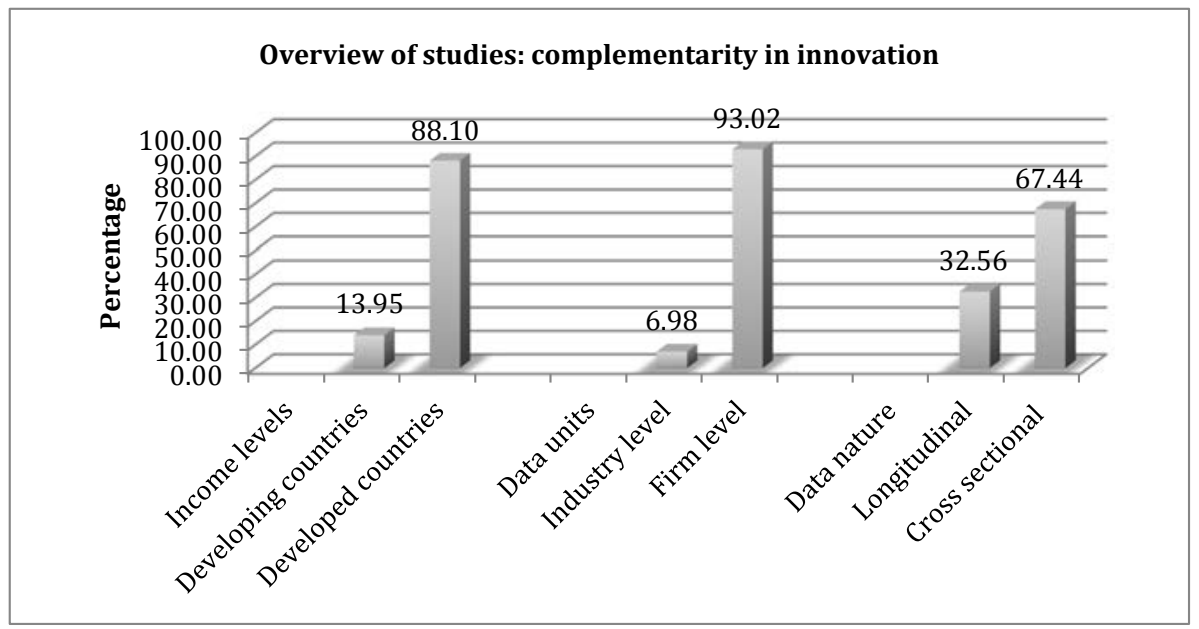

Types of activities concerned

Figure 2.2 classifies the studies according to the types of variables for which complementary was examined. In total, eight types of activities are allocated in different stages of the innovation process. The types of complementary factors are not restricted to only one stage of the innovation. For example, the innovation obstacles can also appear in the other two stages and firms' technological capabilities tend to influence the entire innovation process. Another issue regarding the groups of factors is that some studies address topics overlapping two groups. For example, complementarity between 
FDI and R\&D cooperation is associated with both the technological cooperation and technological sourcing group. But in our statistics, each of the studies reviewed will be included in only one group.

Figure 2.3 Number of studies on complementarity in innovation: patterns across activities concerned

\begin{tabular}{|l|l|}
\hline $\begin{array}{l}\text { Aquiring } \\
\text { technology }\end{array}$ & $\begin{array}{l}\text {-Technological sourcing : } 14 \text { (Basant and Fikkert, 1996; Cassiman and Veugelers, 2006; etc) } \\
\text {-Technology cooperation: } 8 \text { (Arora, 1990; Rothaermel, 2001; Belderbos et al., 2006; etc) }\end{array}$ \\
\hline $\begin{array}{l}\text { - Firm's technological capability: } 8 \text { (Moorman, 1999; Song et al., 2005; etc) } \\
\text { - IT and technological infrastructure: } 3 \text { (Powell, 1997; Bocquet and Brossard, 2007; etc) } \\
\text { - Organizational resources: } 3 \text { (Colombo and Mosconi, 1995; Gilsing et al., 2008; etc) }\end{array}$ \\
$\begin{array}{l}\text { - Human resrouces practises: } 4 \text { (Ichniowski, 1997; Lausen and Foss, 2003; etc) } \\
\text { - Innovation obstacles: } 2 \text { (Galia and Legros, 2004; Mohnen and Roller; 2005) } \\
\text { - innovation outcomes: } 1 \text { (Miravete and Penrías, 2006) }\end{array}$ \\
\hline Converting \\
innovation
\end{tabular}

Fourteen (32.5 percentage) of the forty-three studies analyzed the interplay between technological acquisition strategies such as internal and external, foreign direct investment and technology importing etc. The findings of these studies are mixed in terms of the synergistic effect among different types of technological sourcing strategies. An interesting pattern is that studies carried out in developed economies (Cassiman and Veugelers, 2006; Lokshin et al., 2008) are likely to confirm the complementary effects while some studies using samples from developing countries found evidence of substitutive effects (Basant and Fikkert, 1996). This pattern raises a question. Does the complementarity relationship between technological souring depend on the level of development?

Another set of relationship that has drawn a lot of attention at the technology acquisition stage are the R\&D cooperation activities. There are eight (18.6 per cent) studies in our sample that tried to search for complementarity between these co-operative activities. Of these studies, the majority found that the technological cooperation activities could create complementary values to the firm, associating with firm characteristics and specific types of cooperation. For example, Belderbos et al. (2006) analyzed the relationship among four types of R\&D co-operative activities (with competitors, clients, suppliers, and universities and research institutes) in Dutch firms. Their results suggest that small 
firms are likely to pursue co-operative strategies and cooperation with customers helps to increase market acceptance.

At the stage of assimilating knowledge, three groups of factors have received significant attention in the empirical literature regarding complementarity, firms' technological capability, technological infrastructure (e.g. IT) and organizational resources. Eight (18.6 per cent) of the forty-three studies have investigated synergistic effects among firms' technological capabilities such as product technology capability and product marketing capability (Moorman, 1999; Nerkar and Roberts, 2004); international R\&D and research capabilities (Penner, Hahn and Shaver, 2005) and absorptive capacity and networking capabilities (Tether and Tajar, 2008). Three studies included in our review searched for complementarity between innovation infrastructure factors. Powell (1997) studied the interdependent relationship between information technologies (ITs) and its complementary assets. The findings suggest that firms with complementary human and business resources such as flexible culture, strategic planning-IT integration, and supplier relationships, have gained advantages by using ITs. But ITs alone have not produced sustainable performance advantages in the retail industry. Similar evidence was also found by Zhu (2004), whose finding confirms complementarity between e-commerce capability and information technology infrastructure by looking at their interaction in firm performance in the retail industry. Equally, three of forty-three studies are included in the category of organization resources (Colombo and Mosconi, 1995; Chung and Singh, 2000; and Gilsing etc., 2008).

Four studies in our literature review regarding complementarity in innovation have investigated the synergistic effect in human resources practices. All of these four studies found complementary gains from combining different kinds of human resource strategies. Ichniowski, Shaw, and Prennushi (1997) found productivity gains from adopting a set of work practices simultaneously such as incentive pay, teams, flexible job assignments, employment security, and training etc. Laursen and Foss (2003) test complementarities among seven types of human resource management practices by using 1,900 Danish business firms and their findings confirm the existence of complementarity in affecting innovation performance positively. Colombo (2005) uses 506 Italian young firms that operate in high-tech industries in both manufacturing and finds evidence that there are synergistic gains from the combination of economic-managerial and scientifictechnical education, on the one hand, and technical and commercial industry-specific 
work experience, on the other hand. Bonaccorsi (2007) shows the institutional and human capital complementarities on patenting activity by employing patent data on NANO science from the year of 1989 to 1999.

Finally, a few studies (2 out of 43) address complementarity relationships between obstacles faced by a firm during the innovation process. Such as complementarity between financial and skilled labor obstacles, and complementarity between regulatory and institutional obstacles. To have a good understanding between innovation obstacles will consequently help the firm's managers or policy-makers to lay down effective policies for helping firms to achieve successful innovation. Galia and Legros (2004) showed that due to the existence of complementarity, adopting a package of policies increases the pace of innovation for French firms. More evidence in terms of complementarity in innovation obstacle was contributed from Mohnen and Röller (2005). They used a firm-level dataset from four European countries, and systematically estimated the pairwise complementarities between four types of innovation obstacles. The findings of their study provide the evidence regarding the existence of complementarity in innovation obstacles, but it depends on the phase of innovation that is targeted i.e. the probability of becoming an innovator and the intensity of innovation. Only one paper out of forty-three was testing the synergistic effect in innovation outcomes (Miravete and Pernías, 2006). The author adopted a structural equation system to distinguish the complementarity and correlation caused by unobserved heterogeneities of firms in Spanish ceramic tile industry.

\subsection{Summary: problems and limitations}

Our review has shown that a gradual development has been made with respect to investigating the role of complementarities in innovation studies from an empirical point of view. As indicated earlier, the findings of the forty-three studies analyzed here are relatively encouraging, with the studies covering various subjects and supporting the existence of complementarities throughout the innovation system, also with substitutive relationships unveiled or neither complementarity nor substitution.

In conclusion, we want to raise the limitations and the problems that might be encountered for future analysis. 
Gaps in the literature: the majority of studies of complementarity in innovation are focused on the developed economy context, few studies target developing countries

Overall, thirty-six studies (83.7 per cent) out of forty-three empirical studies showed evidence from developed economies. In comparison, we found substantially fewer studies (six in total, representing just 13.9 per cent of the forty-two papers) that used evidence from developing countries. In particular, all six studies were trying to investigate the potential complementarity in issues related to technological sourcing activities, topics of other aspects of innovation are relatively scarce $^{5}$. In order to build up their competitive advantages and foster productivity growth, firms in developing countries are trying to catch-up the technology frontier through learning and imitation. Synergistic effects among innovation activities or strategies play the role of catalysts that consequently contribute to the effectiveness of catch-up process. The current study is expected to fill this gap, which will mainly focus on investigating complementarities among economic activities along the innovation process in the context of developing countries. Chapter 3 and chapter 4 will discuss complementarity between technological sourcing strategies in Chinese manufacturing firms and in other developing countries respectively. A comparison of innovation obstacles across developed and developing countries will be studied in Chapter 6 .

\section{Empirical difficulties in testing 'objective complementarity' with more than 2 activities}

When testing 'objective complementarity' by using the PROD approach involving more than two activities, a system of equations that includes all the interaction terms is suggested in order to draw consistent conclusions. By only incorporating the cross-terms of two activities each time in the objective equation (Single cross-term) ${ }^{6}$ or including all pairs cross-terms (All cross-term) ${ }^{7}$ is likely to generate biased estimation due to the fact that these two tests ignore the cross partial effects between extra activities and the crossterms (including the third-order interactions, the fourth-order etc.).

With twenty-night out of forty-three studies reviewed that adopt the PROD approach, there are twenty studies that tried to test pairwise complementarity with more than 2 activities involved. Only two of them have adopted the equation with full cross terms

\footnotetext{
5 There might be studies that cover innovation complementarity issues in developing countries but these are not included in our review.

${ }^{6}$ See example from Bresnahan et al., 2002; Black and Lynch, 2001.

${ }^{7}$ See example from Caroli and Van Reenen, 2001.
} 
embedded (Mohnen and Röller, 2005; Belderbos et al., 2006). Due to the complexity of test statistics in multiple-inequality constrained equation, most of the studies suffer from the potential bias that might be caused by ignoring the full extra set of interaction terms (the third-order, the fourth-order etc.). Chapter 5 will try to address this issue in detail and discuss different types of one-sided tests of hypotheses adopted in an objective function with more than two activities. It highlights that it is essential to have two tests of hypotheses to guarantee a better statistical power in the case of multiple inequality constraints. A simulation experiment will be employed for the analysis. Chapter 6 adopts the findings to investigate the interplay relationship between four types of obstacles faced by a firm in the innovation process.

\section{Theoretical shortcomings}

Overall, the complementarity perspective allows identifying complementarities only ex post on the basis of their performance effects (Athey \& Stern, 1998). It does not provide the framework of ex ante with respect to the nature of activities among which synergistic effects exist or the conditions under which they emerge (Ennen et al., 2010). A number of papers adopt quantitative approaches and attempt to measure the distinct interplay relationship among activities in the innovation system. Normally, they use dichotomous variables to indicate whether particular factors concerned are in place or not. They provide little information on the strength of synergy caused by the level of activities. By employing continuous variables to measure firms' technological sourcing investment, chapter 3 of the current thesis tries to tackle this shortcoming.

The complementarity also raises some research challenges. One of them is to estimate empirically the depth and strength of the complementarity effects: how intense are various factors of the system linked with respect to the performance? Chapter 3 of this thesis tries to address this issue by estimating complementarity between continuous measures, and therefore the intensity of complementarity can be estimated. Another challenge is the potential endogeneity of complementarity. Chapter 4 explores this issue by differentiating the actual synergistic effects from the correlations between unobserved errors. 


\section{Appendix 2A Studies of complementarity in innovation}

\begin{tabular}{|c|c|c|c|c|}
\hline Authors & Activities concerned & Data sample & Method & Findings \\
\hline Arora, 1990 & $\begin{array}{l}\text { External linkage of the } \\
\text { large firms with other } \\
\text { parties }\end{array}$ & $\begin{array}{l}\text { Large chemical } \\
\text { and } \\
\text { pharmaceutical } \\
\text { producers }\end{array}$ & Corr & Complementary \\
\hline $\begin{array}{l}\text { Colombo and } \\
\text { Mosconi, } 1995\end{array}$ & $\begin{array}{l}\text { Flexible Automation } \\
\text { paradigm }\end{array}$ & $\begin{array}{l}\text { Italian metal } \\
\text { working industry, } \\
783 \text { plants }\end{array}$ & Corr & Complementary \\
\hline $\begin{array}{l}\text { Basant and Fikkert, } \\
1996\end{array}$ & $\begin{array}{l}\text { R\&D expenditures, } \\
\text { technology purchases, } \\
\text { and international and } \\
\text { domestic } R \& D \\
\text { spillovers }\end{array}$ & $\begin{array}{l}\text { Indian firms from } \\
1974-75 \text { to } 1981- \\
82\end{array}$ & Prod & Substitutive \\
\hline Helfat, 1997 & $\begin{array}{l}\text { R\&D capabilities and } \\
\text { complementary assets }\end{array}$ & $\begin{array}{l}\text { US petroleum } \\
\text { industry from } \\
1970 \text { s to early } \\
1980 \text { s. }\end{array}$ & Corr & Complementary \\
\hline Powell, 1997 & $\begin{array}{l}\text { ITs and human and } \\
\text { business resources }\end{array}$ & US retail industry & Corr & Complementary \\
\hline Moorman, 1999 & $\begin{array}{l}\text { Product technology } \\
\text { capability and product } \\
\text { marketing capability }\end{array}$ & $\begin{array}{l}22 \text { different } \\
\text { product categories. }\end{array}$ & Corr & Complementary \\
\hline Aggarwal, 2000 & $\begin{array}{l}\text { R\&D efforts and } \\
\text { technology imports }\end{array}$ & $\begin{array}{l}\text { India industry level } \\
\text { data 1982-1990 }\end{array}$ & Corr & Complementary \\
\hline Chung and Singh, 2000 & $\begin{array}{l}\text { Resource such as } \\
\text { investors, headquarters } \\
\text { location, geographical } \\
\text { strength and industry } \\
\text { strength) }\end{array}$ & $\begin{array}{l}\text { US investment } \\
\text { banking firms } \\
\text { during } 1980 \mathrm{~s}\end{array}$ & Prod & Complementary \\
\hline Rothaermel, 2001 & $\begin{array}{l}\text { Strategic exploration and } \\
\text { exploitation alliances }\end{array}$ & $\begin{array}{l}889 \text { strategic } \\
\text { alliances of } \\
\text { pharmaceutical } \\
\text { companies }\end{array}$ & Prod & Complementary \\
\hline Baer and Frese, 2003 & $\begin{array}{l}\text { Climates and adoption } \\
\text { of innovations }\end{array}$ & $\begin{array}{l}47 \text { mid-sized } \\
\text { German } \\
\text { companies }\end{array}$ & Prod & Complementary \\
\hline $\begin{array}{l}\text { Laursen and Foss, } \\
2003\end{array}$ & $\begin{array}{l}\text { Different human } \\
\text { resource management } \\
\text { practices }\end{array}$ & $\begin{array}{l}1,900 \text { Danish } \\
\text { business firms }\end{array}$ & Corr & Complementary \\
\hline $\begin{array}{l}\text { Miotti and Sachwald, } \\
2003\end{array}$ & $\begin{array}{l}\mathrm{R} \& \mathrm{D} \text { co-operation with } \\
\text { different partners }\end{array}$ & French CIS2 & Prod & Complementary \\
\hline Galia and Legros, 2004 & $\begin{array}{l}9 \text { types of innovation } \\
\text { obstacles }\end{array}$ & French CIS2 & Corr & Mixed \\
\hline Zhu, 2004 & $\begin{array}{l}\text { E-commerce capability } \\
\text { and information } \\
\text { technology (IT) } \\
\text { infrastructure }\end{array}$ & $\begin{array}{l}114 \text { companies in } \\
\text { the retail industry }\end{array}$ & Prod & Complementary \\
\hline $\begin{array}{l}\text { Nerkar and Roberts, } \\
2004\end{array}$ & $\begin{array}{l}\text { Technological and } \\
\text { product-market } \\
\text { experience }\end{array}$ & $\begin{array}{l}534 \text { 'significant' } \\
\text { new products }\end{array}$ & Prod & Complementary \\
\hline Colombo, 2005 & $\begin{array}{l}\text { The growth of new } \\
\text { technology-based firms } \\
\text { and the human capital of } \\
\text { founders }\end{array}$ & $\begin{array}{l}506 \text { Italian young } \\
\text { firms }\end{array}$ & Prod & Complementary \\
\hline
\end{tabular}


Penner Hahn and

Shaver, 2005

$\mathrm{Hu}$, Jefferson and

Jinchang, 2005

Mohnen and Röller, 2005

Rothaermel and Hill, 2005

Song, Droge, and

Hanvanich, 2005

Arora and Ceccagnoli, 2006

Miravete and Pernías, 2006

Cassiman and

Veugelers, 2006

Belderbos, Carree, and Lokshin, 2006

Colombo, Grilli, and Piva, 2006

Bocquet and Brossard, 2007

Bonaccorsi, 2007

Ichniowski, Shaw, and Prennushi, 2007

Rothaermel and Hess, 2007

Toole, 2007

Bin, 2008
International R\&D and research capabilities

omestic R\&D,

technology transfer, and

foreign direct

investment

Four types of obstacles

Generic assets and specialized assets

Marketing capabilities and technological capabilities

Technology licensing and the effectiveness of patent protection

Product and process innovation

Internal R\&D and external knowledge acquisition

$R \& D$ cooperation with different partners

Patent holding and commercial alliances

Strategies, organization and information technologies

Institutional and human capital practices

Among different types of work practices

Antecedents to innovation located at the intersections across different levels

Public basic and R\&D investment

$\mathrm{R} \& \mathrm{D}$, foreign transfer, domestic transfer, and inter-industry R\&D spillover
65 Japanese

Prod

Complementary

pharmaceutical

firms from 1980 to

1991

China's large and

Prod

Mixed

medium-sized

enterprises

CIS from four

Prod

Mixed

European

countries

Panel data over a Prod Mixed

26-year

U.S. joint ventures Prod Complementary

formed between

1990 and 1997

1994 Carnegie

Mellon survey in

the US

Spanish ceramic

$\mathrm{MP}$

tile industry

CIS 1,335 Belgian manufacturing

firms

Dutch CIS in 1998 Prod

Complementary

Italian young high- Corr tech observed

Complementary

from 1994 to 2003

French firms

Prod

Complementary

located in Haute-

Savoie

Patent data on

Prod

Complementary

NANO science, 1989-1999

36 homogeneous steel production lines owned by 17 companies

Penal data:

Prod

Mixed

pharmaceutical companies from

1980 to 2001

Panel of medical classes observed over 18 years

Chinese large- and medium-sized manufacturing enterprises over the period of 1996-2001 
Choi, Poon and Davis, 2006

Liu and Buck, 2007

Belderbos et al., 2008

Gilsing et al., 2008

Hashai and Almor, 2008

Lokshin, Belderbos, and Carree, 2008

Roper et al., 2008

Tether, 2008

King and Kesner, 2008

Schmiedeberg, 2008

Li, 2011
Different types of knowledge management strategies

Foreign R\&D activities and absorptive capacity

Intra-firm technology transfer and R\&D in foreign affiliates

Position, technological distance and network density

Integration of R\&D production and marketing activities

Internal and external $\mathrm{R} \& \mathrm{D}$

Horizontal, forwards, backwards, public and internal knowledge sourcing activities

Specialist knowledge providers

Marketing resources and target firm technology resources

Internal R\&D, R\&D contracting, and $\mathrm{R} \& \mathrm{D}$ cooperation

In-house $\mathrm{R} \& \mathrm{D}$, importing technology, and domestic technology
131 Korean firms

Corr

Mixed

Chinese high-tech

Prod

industries

enterprises

Japanese

Prod

multinational

firms: 1996-

1997,1999-2000.

Alliance networks in the

Prod

Complementary

pharmaceutical, chemical and automotive industries

52 firms out of

Prod

Complementary

140 Israeli

industrial firms in the year 2000

6-year panel of

Prod

Complementary

Dutch

manufacturing

firms (CIS)

Irish innovation panel (IIP) 1991

2002

UK's CIS3

Corr

Mixed

Prod

Complementary

German CIS 3

Corr

Complementary

Panel dataset of 21

Prod

Mixed 


\section{Chapter 3}

\section{Complementarity between in-house $R \& D$ and technology purchasing: evidence from Chinese manufacturing firms ${ }^{8}$}

\subsection{Introduction}

In order to catch up with the current technological frontier, firms in developing countries have been striving to promote technological advancement through internal research and development efforts (in-house $R \& D$ ) as well as through external technology purchasing (TP). In-house R\&D expenditure includes the capital, labor and design costs associated with research and development. TP involves purchasing, transferring or licensing new technologies from the domestic or the international market. For firms in developing countries, establishing efficient innovation strategies could accelerate their technological advance and contribute to their economic development.

In China, the central government has established a series of policy incentives to encourage firms to carry out in-house $\mathrm{R} \& \mathrm{D}$ activities ${ }^{9}$, and these policies have greatly increased China's capability to develop its own technology, and to assimilate and improve the technology transferred from advanced economies (Lu and Lazonick, 2001).

\footnotetext{
${ }^{8}$ This is a joint paper with Prof. P. Mohnen that was published in Oxford Development Studies, Volume: 41, Issue: 03, pages $343-371$.

9 Especially after 1995, policies were designed to accelerate indigenous science and technology development. The number of patent applications from domestic applicants was 10,011 in 1995, and it has increased dramatically ever since. The number reached 39,806 by 2002 and 255,832 by 2011 (China Patent Office, 2012). http://www.english.sipo.gov.cn/.
} 
With great emphasis placed on 'indigenous innovation'10, do Chinese firms still need external technology sourcing? Is there synergetic benefit from engaging in both internal R\&D and technology purchasing? The goal of this research is to answer these questions by testing whether there is a relationship of complementarity between the two sources of knowledge acquisition. In other words, do R\&D reinforce each other in achieving higher innovation output and/or higher levels of productivity?

The data on which the empirical analysis is based come from the World Bank Investment Climate Survey (ICS) ${ }^{11}$ relating to China in the year 2003. This dataset provides continuous data on $\mathrm{R} \& \mathrm{D}$ and technology purchases. The results exhibit some evidence of complementarity between in-house R\&D and TP in raising the sales of new products per employee in small-sized Chinese manufacturing firms with 100 to 300 employees. In-house R\&D seems to accelerate the assimilation of external expertise, while external technology sourcing enhances the efficiency of in-house innovation activities. However, we find that R\&D and TP are substitutes when it comes to raising labor productivity. Only for firms with fewer than 100 employees, is there a complementarity visible in terms of labor productivity.

The next section sets the background by reviewing the existing evidence on complementarity between internal and external technology acquisition in developing countries and by describing the evolution of the policy of technology acquisition in China. Section 3.3 defines the notion of complementarity and the specification of the model used in the empirical analysis. The data and the variables used will be presented in section 3.4. The results are interpreted in section 3.5. Section 3.6 summarizes and concludes.

\subsection{Background}

\subsubsection{In-house $R \& D$ and technology purchasing: complements or substitutes?}

A large number of empirical studies have estimated the relationship between innovation sourcing strategies in developing countries. Results are mixed. One group of studies concludes that internal $\mathrm{R} \& \mathrm{D}$ and external technology are substitutes for each other.

\footnotetext{
${ }^{10}$ Indigenous innovation means "to develop the capability of conducting R\&D or create innovation internally".

${ }^{11}$ For more information on the Investment Climate Survey, see http://www.worldbank.org
} 
Firms decide to develop technology by themselves and/or buy it from outside given a limited budget. An increase in either of the two options, therefore, tends to reduce the spending incurred on the other one. Mytelka (1987) found that external imports of technology discouraged Andean group countries from undertaking in-house innovation activities. Fikkert (1993) regressed technology imports on in-house R\&D efforts and also found a negative relationship between technology imports and R\&D efforts in Indian manufacturing firms. Basant and Fikkert (1996) estimated the returns on R\&D, technology imports and their interaction using Indian firm level panel data. They found substitutability between R\&D effort and external technology in the production of knowledge. Katrak (1997) found that the probability of importing technology is only weakly influenced by R\&D efforts, and Blonigen and Taylor (2000) also conclude that firms either make or buy technology.

Another group of studies concludes that in-house R\&D and external technology purchasing are complementary strategies. According to the notion of absorptive capacity proposed by Cohen and Levinthal (1989), the successful use of external technology requires the ability to assimilate external technology and apply it internally. As suggested by Fu, Pietrobelli and Soete (2010), a crucial condition for the effective transfer of technology to developing countries is their level of absorptive capacity. In this sense, parallel indigenous innovation efforts are complementary to international technology diffusion. The studies by Desai (1989), Lall (1989) and Mowery and Oxley (1995) confirm the view that technological capability is needed in order to understand the tacit components of foreign technology. Besides, acquiring technology externally helps to improve the efficiency of doing in-house R\&D. As Aggarwal (2000) points out, external technology sourcing plays two important roles in developing economies: filling gaps in domestic technological capability and upgrading the existing technologies to international standards. By enhancing technological capability, it may consequently stimulate in-house R\&D. Braga and Willmore (1991) found that there is a robust complementary relationship between technology buying and firm technology effort in Brazilian industry. Deolalikar and Evenson (1989) and Kim and Nelson (2000) come to the same conclusion on the basis of Indian data. A number of studies have tested a slightly different but related hypothesis based on data from developed countries, namely the existence of complementarity between internal and external R\&D: Arora and Gambardella (1990) for large US, European, and Japanese biotechnology firms, 
Cassiman and Veugelers (2006) and Veugelers (1997) for Belgian manufacturing firms, Bönte (2003) for West-German industry data, and Belderbos et al. (2008) for Dutch firm data. Most of the studies share the view that internal and external R\&D are complementary, although Audretsch, Menkveld and Thurik (1996) find that the complementarity applies only for high-technology industries.

\subsubsection{Country background}

China has been the fastest growing major economy in the past 30 years with an average annual GDP growth greater than 10 per cent. Around 8 per cent of the total manufacturing output in the world comes from China, and it ranks third worldwide in industrial output ${ }^{12}$. The extraordinary performance of the Chinese economy makes it very interesting to study its technology acquisition behavior and to examine whether such acquisition contributed to the growth performance of its manufacturing firms.

In the 1950s, China began to acquire technology externally. At first, the major source of technology was the former Soviet Union. Then, western countries and Japan became the main suppliers of technology to heavy industry. After the economic open-door policy launched in 1976, importing external technology constituted an essential component of the Four Modernisation Programmes (Zhao, 1995). Technology transfer became diversified through the purchase of turnkey plants and equipment, through foreign direct investment (FDI), and in the form of disembodied technology including licensing, technical consulting, technical service and co-production. Another feature is that the source of technology widened. Five countries - the USA, Japan, Germany, France and the UK - dominated the supply of technology to China at that time. After the economic reform of 1978, other industrial countries and regions, such as Canada, Italy, Taiwan and Hong Kong, played an increasing role in providing technology to China (Zhang, 1990; Liu, 1992; Zhao, 1995). In 1985, the central government initiated the science and technology system reform, which defined the acquisition of foreign technology as one of the main technology sourcing strategy for promoting technological development. After 1995, policies were designed to accelerate indigenous science and technology development by creating incentives and providing support for firms to establish R\&D departments. As a result, these units increased dramatically, from 7000 in 1987 to over

\footnotetext{
${ }^{12}$ For more detailed information the reader is referred to http://en.wikipedia.org/wiki/Economy_of_the_People\%27s_Republic_of_China
} 
24,000 by 1998 (China Science and Technology Statistics, 1992, 1998) ${ }^{13}$, and the R\&D expenditure grew annually by more than 20 per cent from 1995 to 2003 (OECD, 2006). However, when set against China's rapid economic growth, its ratio of R\&D to GDP still remarkably low (1.13 per cent in 2003) compared with the OECD countries (2.25per cent in 2003) ${ }^{14}$.

The reform of Chinese state-owned enterprises ("SOEs") was a critical part of establishing the indigenous innovation system. Unlike the private sector with no government financial support since the reforms began in the 1980s, the SOEs have remained a persistent drain on government resources (Steinfeld, 1998; White, 2000). In order to encourage SOEs to introduce new products rather than simply producing more of their existing products, the government introduced investment tax incentives (Rawski, 1994; White, 2000). Particularly since 1993, the innovation policy was sharply focused on reforming SOEs. Evidence has shown that SOEs became more strategic and dynamic in innovation in reacting to competitive pressures (Luo et al., 1998). Managers of SOEs were being granted greater responsibility and decision making power (Child, 1994; Guthrie, 1997; Walder, 1989), especially for meeting profit-based and efficiency-based measures of performance (Groves et al., 1994; White and Liu, 1998).

Like other developing countries, China has two main objectives in acquiring foreign technology: to enhance technological capability and to facilitate economic growth by increasing productivity. It is interesting to examine these issues after China's transition to a market economy, a period during which it experienced unprecedented changes in its social, legal, and economic institutions (Zhou, Yim and Tse, 2005). Table 3.1 presents some selected studies which analys the relationship of internal and external technological sourcing in China. Although the external technology alone does not always have a significant impact on innovation, in general, the findings confirmed the complementary relationship between in-house R\&D and external technology sourcing (e.g. Liu and Buck, 2007; Liu and Zou, 2008; Bin, 2008; Li, 2011; Li and Wu, 2010).

\footnotetext{
13 Source: Ministry of Science and Technology of the People's Republic of China: http://www.most.gov.cn/eng/

${ }^{14}$ Main source: OECD library, http://www.oecd-ilibrary.org/economics/oecd-factbook-2005_factbook2005-en
} 
Table 3.1 Literature on the complementarity in technology sourcing in China

\begin{tabular}{|c|c|c|c|c|c|}
\hline Study by & Data & $\begin{array}{l}\text { Dependent } \\
\text { variables }\end{array}$ & $\begin{array}{l}\text { Technology } \\
\text { sourcing }\end{array}$ & Method $^{15}$ & Findings \\
\hline Zhao, 1995 & $\begin{array}{l}\text { Heavy industries, } \\
\text { firm level data, } \\
1960-1991\end{array}$ & $\begin{array}{l}\text { Output; } \\
\text { export } \\
\text { value }\end{array}$ & $\begin{array}{l}\text { R\&D and } \\
\text { technical } \\
\text { upgrading }\end{array}$ & CORR & $\begin{array}{l}\text { Imported } \\
\text { technology } \\
\text { complements R\&D }\end{array}$ \\
\hline $\begin{array}{l}\text { Liu and } \\
\text { White, } 1997\end{array}$ & $\begin{array}{l}\text { Industry level data, } \\
1987-1993\end{array}$ & $\begin{array}{l}\text { New } \\
\text { product } \\
\text { sales }\end{array}$ & $\begin{array}{l}\text { R\&D personnel } \\
\text { and technology } \\
\text { imports }\end{array}$ & $\begin{array}{l}\text { PROD } \\
\text { OLS }\end{array}$ & $\begin{array}{l}\text { R\&D complements } \\
\text { technology transfer }\end{array}$ \\
\hline $\begin{array}{l}\text { Hu et al., } \\
2005\end{array}$ & $\begin{array}{l}\text { Large and medium- } \\
\text { sized enterprises, } \\
1995-1999\end{array}$ & $\begin{array}{l}\text { Produc- } \\
\text { tivity }\end{array}$ & $\begin{array}{l}\text { R\&D, } \\
\text { technology } \\
\text { transfer and FDI }\end{array}$ & $\begin{array}{l}\text { PROD } \\
\text { IV }\end{array}$ & $\begin{array}{l}\text { R\&D complements } \\
\text { technology transfer }\end{array}$ \\
\hline $\begin{array}{l}\text { Liu and } \\
\text { Buck, 2007; } \\
\text { Liu and Zou, } \\
2008\end{array}$ & $\begin{array}{l}\text { High-tech industry, } \\
\text { with annual } \\
\text { turnover above } 5 \\
\text { million RMB, 1997- } \\
2002\end{array}$ & $\begin{array}{l}\text { New } \\
\text { product } \\
\text { sales }\end{array}$ & $\begin{array}{l}\text { Foreign R\&D } \\
\text { and domestic } \\
\text { R\&D }\end{array}$ & $\begin{array}{l}\text { PROD } \\
\text { GMM }\end{array}$ & $\begin{array}{l}\text { Domestic R\&D } \\
\text { complements } \\
\text { foreign R\&D }\end{array}$ \\
\hline Bin, 2008 & $\begin{array}{l}\text { Large and medium- } \\
\text { sized manufacturing } \\
\text { enterprises, } \\
\text { 1996-2001 }\end{array}$ & $\begin{array}{l}\text { Labor } \\
\text { produc- } \\
\text { tivity and } \\
\text { number of } \\
\text { patents }\end{array}$ & $\begin{array}{l}\text { In-house R\&D, } \\
\text { foreign transfer, } \\
\text { domestic } \\
\text { transfer, and } \\
\text { inter-industry } \\
\text { R\&D spillovers }\end{array}$ & $\begin{array}{l}\text { PROD } \\
\text { FE, RE }\end{array}$ & $\begin{array}{l}\text { In-house R\&D } \\
\text { complements inter- } \\
\text { industry R\&D } \\
\text { spillover and foreign } \\
\text { transfer }\end{array}$ \\
\hline Li, 2011 & $\begin{array}{l}\text { Large and medium- } \\
\text { sized SOEs in high- } \\
\text { tech industry, } \\
1995-2004\end{array}$ & $\begin{array}{l}\text { Number } \\
\text { of patents }\end{array}$ & $\begin{array}{l}\text { R\&D, domestic } \\
\text { technology and } \\
\text { foreign } \\
\text { technology }\end{array}$ & $\begin{array}{l}\text { PROD } \\
\text { Negative } \\
\text { binomial }\end{array}$ & $\begin{array}{l}\text { Foreign technology } \\
\text { complements R\&D }\end{array}$ \\
\hline $\begin{array}{l}\mathrm{Li} \text { and } \mathrm{Wu}, \\
2010\end{array}$ & $\begin{array}{l}\text { Large and medium- } \\
\text { sized firms in } 4 \\
\text { high-tech } \\
\text { industries, } \\
\text { 1995-2004 }\end{array}$ & $\begin{array}{l}\text { Number } \\
\text { of patents }\end{array}$ & $\begin{array}{l}\text { R\&D, domestic } \\
\text { technology and } \\
\text { foreign } \\
\text { technology }\end{array}$ & $\begin{array}{l}\text { PROD } \\
\text { Negative } \\
\text { binomial }\end{array}$ & $\begin{array}{l}\text { Foreign technology } \\
\text { complements R\&D }\end{array}$ \\
\hline
\end{tabular}

\subsection{Empirical model and testing of complementarity}

\subsubsection{Definitions}

A pair of economic activities is complementary if (1) adopting one does not preclude adopting the other one, and (2) the sum of the benefits of implementing each activity separately is not greater than the benefit of implementing both together. An equivalent understanding of the second condition is that the incremental return to implementing any one of the activities is greater if the other one is already implemented. A theorem states that if each pair of activities in a group is complementary, then implementing any subset of the activities in the group raises the incremental return to implementing the

${ }^{15}$ For the methods of testing complementarity, see section 3.2. 
remaining ones (Topkis, 1978). Complementarity between activities in economic models was by Vives (1990) and Milgrom and Roberts (1990b, 1995).

More formally, suppose there are two technology acquisition practices, R\&D and TP, and $\mathrm{Z}$ is a vector of exogenous variables. If $\mathrm{R} \& \mathrm{D}$ and TP are discrete variables, they are complementary if the presence of one strategy (say, R\&D) increases the marginal return of adopting the other strategy (TP) controlling for other effects. In other words, the objective function $\mathrm{f}(\mathrm{R} \& \mathrm{D}, \mathrm{TP}, \mathrm{Z})$ is supermodular meaning that the following inequality holds for all values of the other arguments of $\mathrm{f}($.$) (Milgrom and Roberts, 1990a):$

$\mathrm{f}(1,1 ; Z)-\mathrm{f}(1,0 ; Z)>\mathrm{f}(0,1 ; Z)-\mathrm{f}(0,0 ; Z)$

If $\mathrm{R} \& \mathrm{D}$ and $\mathrm{TP}$ are continuous variables, this inequality restriction implies that the incremental effect on the objective function of increasing one practice increases conditionally on increasing another practice:

$\frac{\partial^{2} f(R, T, Z)}{\partial R \partial T}>0$; where R stands for R\&D and T for TP.

Conversely, R\&D and TP are substitutes if the inverse of inequality (3.1) or (3.2) holds.

Testing complementarity among activities in maximizing an objective function has been done in several empirical studies (Cassiman and Veugelers, 2006; Mohnen and Röller, 2003; Belderbos et al., 2008). This approach is known as the production function approach (PROD). It refers to a synergistic effect between activities which that will lead to a better performance in terms of a stated goal. Another approach to test complementarity, known as the correlation approach (CORR), consists in checking the sign of the correlation coefficient between strategies conditional on certain other determinants. In Table 3.1, methods adopted in testing complementarity are shown in column 5. The current study will focus only on the PROD. We shall consider two kinds of performance objectives: innovation output and total factor productivity (TFP). If there is complementarity between in-house $\mathrm{R} \& \mathrm{D}$ and technology purchase, it can show up in greater innovation output and indirectly in higher TFP levels through the effect of innovation output on TFP. Given the way in which innovation output and TFP are measured, we have to resort to different econometric models to test complementarity with respect to each of these two objectives. 


\subsubsection{Testing complementarity in terms of innovation output}

Innovation output can refer to different kinds of innovation and can be measured in a qualitative or in a quantitative way. We shall consider two kinds of innovation output: new products and new processes. Based on the questionnaire, process innovation can be measured only by its incidence whereas product innovation will be measured by its incidence and its intensity. Hence for process innovation we specify a probit model, i.e. we observe a dichotomous variable $\operatorname{Pr} o c_{i}$ which equals 1 when the firm claims to have introduced a new process in the period under review, and zero otherwise. The values one and zero correspond respectively to a positive and a negative value of a latent variable $\operatorname{Pr} o c_{i}^{*}$, which is itself determined by innovation inputs and firm-specific variables:

$$
\operatorname{Pr} o c_{i}^{*}=v_{b} I_{b i}+v_{m} I_{m i}+\delta_{b} I_{b i} \ln r_{b i}+\delta_{m} I_{m} \ln r_{m i}+\delta_{b m} I_{b i} \ln r_{b i} I_{m i} \ln r_{m i}+\varphi W_{i}^{*}+\eta_{i}
$$

where $r_{b, i}$ and $r_{m, i}$ are the levels of innovation inputs (TP and R\&D respectively), expressed in expenditure per employee, so that a marginal effect of an increase in their levels depends on the size of the firm. ${ }^{16}$ It is unreasonable to assume that the marginal effect of 1000 additional RMB spent on R\&D or TP would be the same for large and small firms. $W_{i}^{*}$ is a vector of exogenous variables that affect the probability of innovating. $v_{b}, v_{m}, \delta_{b}, \delta_{m}, \delta_{b m}$, and $\phi$ are coefficients to be estimated. $\eta$ is a random error term due to measurement errors and omitted variables. Since R\&D and TP have many zeros (around 60 per cent for R\&D and 80 per cent for TP), we model them first as dichotomous variables $\left(I_{b i}=1\right.$ if TP is different from zero and $I_{m i}=1$ if $R \& D$ is different from zero, and zero otherwise) and, if they are both present, we allow for complementarity or substitutability between them in their continuous variations. If $\delta_{b m}$ is positive (negative) and statistically significant, then there is complementarity (substitutability) between R\&D and TP. Since there are only six cases ${ }^{17}$ where firms purchase technology without doing their own $R \& D$, we cannot reasonably identify any complementarity or substitutability with the discrete variables.

\footnotetext{
${ }^{16}$ Index b refers to "buy", i.e. technology purchases, index m refers to "make", i.e. own R\&D.

${ }^{17}$ Among these six cases, two are in the electronic equipment industry, two in electronic parts making industry, one in the garment and leather products industry and one in the metallurgical products industry.
} 
For product innovation, we observe, on the one hand, a dichotomous variable $\operatorname{Pr} o d_{i}$ equal to one if a new product has been introduced on the market and zero otherwise, and on the other hand, a continuous variable Innosale ${ }_{i}$, which measures the sales of new products per employee. Since this variable is only measured for firms that have introduced a new product on the market, OLS estimates would suffer from a potential selection bias. To correct for this bias, we shall specify a tobit type II model composed of a main equation of interest (3.3.2) and a selection equation (3.3.3):

$\ln \left(\right.$ Innosale $\left._{i}\right)=v_{b}^{o} I_{b i}+v_{m}^{o} I_{m i}+\delta_{b}^{o} I_{b i} \ln r_{b i}+\delta_{m}^{o} I_{m i} \ln r_{m, i}+\delta_{b m}^{o} I_{b i} \ln r_{b i} I_{m i} \ln r_{m i}+\phi^{o} W_{i}+\eta_{i}^{o}$

$\operatorname{Pr} o d_{i}^{*}=v_{b}^{*} I_{b i}+v_{m}^{*} I_{m i}+\delta_{b}^{*} I_{b i} \ln r_{b i}+\delta_{m}^{*} I_{m i} \ln r_{m i}+\delta_{b m}^{*} I_{b i} \ln r_{b i} I_{m i} \ln r_{m i}+\varphi W_{i}^{*}+\eta_{i}^{*}$,

$$
\left\{\begin{array}{l}
\operatorname{Pr} o d_{i}=1 \text { if } \operatorname{Pr} o d_{i}^{*}>0 \\
\operatorname{Pr} o d_{i}=0 \text { if } \operatorname{Pr} o d_{i}^{*} \leq 0
\end{array}\right.
$$

where $\operatorname{Pr} o d_{i}^{*}$ in the selection equation (3.3.3) is a latent variable which indicates if a firm had any product innovation or not in the period under review depending on whether its

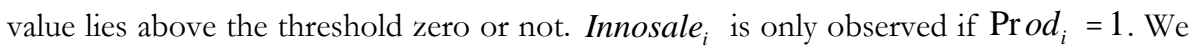
assume that the error terms $\eta_{i}^{o}$ and $\eta_{i}^{*}$ follow a joint normal distribution with $\operatorname{var}\left(\eta_{i}^{*}\right)=1, \operatorname{var}\left(\eta_{i}^{0}\right)=\sigma_{2}^{2}, \operatorname{cov}\left(\eta_{i}^{0}, \eta_{i}^{*}\right)=\rho \sigma_{2}$. In order to identify the effects of the explanatory variables $W_{i}$ and $W_{i}^{*}$, the latter will contain at least one extra exogenous variable not included in $W_{i}$. Due to the fact that the innovation output indicator is only available for the year 2002, the probit model (3.3.1) and the generalized tobit model (3.3.2) and (3.3.3) will be estimated on cross-sectional data.

\subsubsection{Testing complementarity in terms of total factor productivity}

In addition to looking at the effect of technology-sourcing strategies on innovation output, we will go one step further and also investigate whether there is a synergy between R\&D and TP in promoting firms' productivity performance. We start from a general production function:

$$
Y_{i t}=g\left(T F P_{i t}\right) h\left(K_{i t}, L_{i t}, M_{i t}\right)+\varepsilon_{i t}
$$


where $\mathrm{Y}_{\mathrm{it}}$ stands for total sales, $K_{\mathrm{it}}, L_{\mathrm{it}}$ and $M_{\mathrm{it}}$ represent respectively. the inputs physical capital, labor and materials, $\mathrm{TFP}_{\mathrm{it}}$ is the total factor productivity, which is driven by the innovation inputs, industry specificities and ownership characteristics, and $\varepsilon_{\mathrm{it}}$ is a random error term. Here we index all variables by subscripts $i$ for firms and $t$ for time, because now we have panel data. TFP is supposed to be a function of the innovation inputs $r_{b, i t}$ (TP per employee) and $r_{m, i t}$ (R\&D expenditure per employee), other explanatory variables $V_{i t}$ (ownership dummies, export dummies and age of the firm), industry dummies $\left(\mathrm{I}_{\mathrm{i}}\right)$ to capture differences in technological opportunities, and time dummies ( $\left.\mathrm{T}_{t}\right)$ to capture year-to-year fluctuations in productivity. We assume that the functions $\mathrm{g}($.$) and \mathrm{h}($.$) are separable and that both are second-order approximations after a$ logarithmic transformation of (3.4).

After rewriting (3.4) in terms of labor productivity, so as to estimate directly the extent of scale economies, we obtain the labor productivity function (3.5):

$\ln \left(Y_{i t} / L_{i t}\right)=\gamma_{0}+\beta_{k} \ln \left(K_{i t} / L_{i t}\right)+\left(\beta_{l}+\beta_{k}+\beta_{m}-1\right) \ln L_{i t}+\beta_{m} \ln \left(M_{i t} / L_{i t}\right)$

$+0.5 \beta_{k k}\left(\ln \left(K_{i t} / L_{i t}\right)\right)^{2}+0.5 \beta_{m m}\left(\ln \left(M_{i t} / L_{i t}\right)\right)^{2}+\beta_{k m} \ln \left(K_{i t} / L_{i t}\right) \ln \left(M_{i t} / L_{i t}\right)$

$+I_{b i t}\left(\alpha_{b}+\gamma_{b} \ln r_{b i t}+0.5 \gamma_{b b}\left(\ln r_{b i t}\right)^{2}\right)+I_{m i t}\left(\alpha_{m}+\gamma_{m} \ln r_{m i t}+0.5 \gamma_{m m}\left(\ln r_{m i t}\right)^{2}\right)+I_{b i t} I_{m i t}\left(\alpha_{b m}+\gamma_{b m}\left(\ln r_{b i t}\right)\left(\ln r_{m i t}\right)\right)$

$+\gamma_{v} V_{i t}+\Sigma_{j} \gamma_{j} I_{j}+\Sigma_{t} \gamma_{t} T_{t}+\omega_{i}+\varepsilon_{i t}$

As in equations (3.3) we model the effects of R\&D and TP first as a step function with different levels of TFP for the observations where R\&D or TP is present and secondly in a continuous way only for the cases where both are present. In (3.5) we have expressed $\mathrm{R} \& \mathrm{D}$ and TP in logarithms assuming constant elasticities. The disturbance term has two orthogonal components: the time-invariant individual effects $\omega_{i}$, which are unobserved by the econometrician but known to the firm (such as managerial ability or organizational ability), and the idiosyncratic productivity shocks $\varepsilon_{i t}$, which are unobserved by the econometrician and by the firm. We assume the idiosyncratic error term to be uncorrelated with past values of the explanatory variables.

The problem here is that the inputs, especially the traditional inputs, labor, capital and materials, but also the innovation related inputs $r_{b, i t}$ and $r_{m, i t}$ may be correlated with $\omega_{i}$. The endogeneity of input practices makes OLS fail to generate consistent estimators. To tackle the endogeneity problem we use the system-GMM estimator (Arellano and Bond, 
1991, Blundell and Bond, 1998). ${ }^{18}$ Taking the first differences of equation (3.5) will remove the unobserved individual effect $\omega_{\mathrm{i}}$, thus eliminating a potential source of omitted variable bias in the estimation. Then, the differenced variables that are not strictly exogenous are instrumented with all their available lagged levels (Difference GMM). However, lagged levels are poor instruments for first differences if the variables are close to a random walk (Holtz-Eakin, Newey, and Rosen, 1988; Arellano and Bover, 1995). Therefore, Blundell and Bond (1998) suggest adding another set of orthogonality conditions, namely between the levels of the error term and the first-differences in the exogenous variables under the assumption of stationarity. This is the idea behind System GMM.

\subsection{Data and variables}

The data used in our empirical analysis are from the World Bank Investment Climate Survey (ICS) $)^{19}$ - China 2003. The survey is conducted in 24 industrial cities and provides us with a wide range of information about the economic environment and activities of the firms. The majority of firms included in the ICS China 2003 are of small or medium size $^{20}$. After removing missing values, cleaning for outliers and removing the large size firms, we are left with 3332 observations of small and medium-sized firms from 18 cities and 10 manufacturing industries for the period 2000 to $2002^{21}$. Several aspects of firms'

\footnotetext{
18 We prefer to use the dynamic panel GMM approach to the proxy-based approach introduced by Olley and Pakes (1996). Ackerberg et al (2006) compare the two approaches and discuss their respective advantages and disadvantages.

${ }^{19}$ See footnote 13 .

20 According to the National Bureau of Statistics of China, small-sized firms have fewer than 300 employees, medium-sized firms have between 300 and 2000 employees, and large size firms have more than 2000 employees. The classification is based on the number of long-term employees according to "The classification of small, medium and large Chinese manufacturing firms" from the National Bureau of Statistics of China: http://www.stats.gov.cn/. The large size firms included in the sample, after dropping missing values, represent about 3.5 per cent of the total sample (33 firms). We decided to drop these firms and look only at the small and medium-sized firms. Meanwhile, there are about 40 per cent of firms with fewer than 100 employees. It is interesting to look at their technological sourcing behavior separately since the t-tests in Table 3.2 and Table 3.4 show that their characteristics are significantly differently from those of other firms. In total, our sample is divided into three categories: firms with fewer than 100 employees (40.1per cent), firms with a number of employees between 100 and 300 (30.37 per cent) and firms with more than 300 employees (29.53 per cent).

${ }^{21}$ Firms with no information on financial outcomes are omitted. The service sector is not included because the innovation outputs are not reported. Furthermore, following Hall and Mairesse (1995), we keep only cases in which the capital-labor ratio is within three times the inter-quartile range (the difference between the 75 per cent value and the 25 per cent value) above or below the median. This removed 129 observations, or 2.1 per cent of the sample. The remaining sample is an unbalanced panel with 3332 observations for the period 2000 to 2002.
} 
innovation activity are covered in the survey; such as the firms' innovative input strategies and innovation outputs. We deflate annual sales, profits, capital, materials and innovation expenditure to convert them into values expressed in year 2000 prices $^{22}$.

\subsubsection{Variables in the innovation equation}

The dependent variable in the innovation equation (3.3.1) is a dichotomous variable equal to 1 if the firm claims to have had either a product or a process innovation in the years 2000 to 2002. In equation (3.3.2) the dependent variable is the log of sales of new products per employee. There are two categories of variables that might affect the probability of having a successful innovation and the intensity of innovative sales.

The first category captures firm specificities. With more profits in previous periods, firms have more cash available and are therefore more likely to invest in innovation and be successful innovators (Katrak, 1997). PROFIT per employee is the average ratio of profit (before tax) per employee from 2000 to 2002. CAPITAL per employee, which is the average capital/labor ratio from 2000 to 2002, serves as an indicator of the capital intensity, but it also to some extent reflects the size of a firm. Larger firms are expected to have more resources to allocate to innovation activities, which leads to better innovation performance. Company ownership can be a crucial variable in innovation performance in the case of China, as it affects the motivation to innovate and the continuity of business strategy. State-owned enterprises (SOEs) are usually reluctant to undertake changes. However, with investment and tax incentives from the government, they might have more resources to carry out innovation activities. So the effect of SOEs on innovation output is ambiguous. Foreign-controlled firms tend to concentrate their research and development in their home countries (OECD, 2003). A negative sign is expected. SOE and FOREIGN indicate respectively state and foreign ownership. The dummy EXPORT indicates if firms have positive exports in 2002. On the one hand, the point of learning-by-exporting suggests that technology flows from international buyers help to improve the performance of exporters (Salmon and Shaver, 2005; Liu and Zou., 2008). Furthermore, fierce competition on the international market stimulates firms to be innovative. On the other hand, especially in the case of China, exporting firms compete successfully in the international market by relying on the price advantage of alreadyexisting products due to the relatively low material and labor costs. This might inhibit

22 For the annual sales and profits, we use the wholesale price deflators at the industry level. For capital, material and innovation expenditure, the industry input deflators are used (Chinese Bureau of Statistics, 2000-2003). 
innovation, especially product innovation. So the sign of EXPORT is ambiguous. AGE is calculated as the number of years evolved since the enterprise started production up to 2002. Young firms are expected to be more dynamic and innovative all other things equal (Katrak, 1997), and therefore a negative effect is expected. Innovation activities tend to be relatively more intensive in the technologically more advanced industries, such as pharmaceuticals, electrics and electrical equipment, and electronics. Industry specificities are controlled for by industry dummies.

The second category of explanatory variables is the set of innovation inputs. The survey contains information on two technology-sourcing strategies. Firms are asked to report their annual in-house R\&D expenditure. In-house R\&D spending comprises capital, labor and design costs associated with research and development. The other way for firms to increase their technological expertise is to buy technology directly from external channels, on the domestic or the international market. Technology purchasing is defined in the questionnaire as the amount that firms spend on purchasing technology externally. The two variables are respectively denoted by $\mathrm{R} \& \mathrm{D}$ and TP. Both are measured in average spending per employee in 2000-2002. More investment in in-house R\&D and external technology purchasing will strengthen the firms' technological capability and contribute to raising their innovation output. We expect both marginal effects to have a positive sign. The sign of the interaction term of R\&D and TP indicates their complementarity or substitutability. Dummy variables R\&D_PRI, R\&D_UNI, and R\&D_FIRM are equal to 1 if firms have any R\&D cooperation with public research institutes, universities, or other firms. The Chinese government has strongly encouraged Public Research Institutes (PRIs) and universities to create more effective links with industry since the 1980s. In 2004, about one-third of large and medium-sized companies' R\&D spending went to universities and PRIs as contracted R\&D (National Bureau of Statistics of China, 2006). We use these three variables as proxies for technological opportunity. Any form of co-operation constitutes an information source for new technologies and could lead to innovativeness. The benefits drawn from co-operative activities might only show up in the probability of innovation but not in new product sales, since most of the innovations carried out in universities and research institutes focus on basic science research that will not be immediately commercialized in the market. 
Additional variables are included in the selection equation (3.3.3) in order to avoid identification problems. These variables are expected to influence the occurrence of product innovation, but not the intensity. In reality, such variables are difficult to define (Puhani, 2000; Vella, 1998). City dummies will be used here as proxies for the location of a firm. In China, being located in a developed industrial city (such as in the coastal area) may provide firms with greater policy-oriented opportunities to undertake innovation activities. However, location may not affect the intensity of innovation, which depends rather on variables reflecting the market structure (as shown by Sasidharan and Kathuria, 2011).

\subsubsection{Variables in the production function}

In the production function, the dependent variable is PRODUCTIVITY. It is measured in sales per employee. The three conventional inputs are CAPITAL, measured as the total book value of fixed assets, LABOR, measured as the number of full-time employees, and MATERIAL, measured as the costs of raw materials, energy and other related costs reported by the firm ${ }^{23}$. The innovation inputs R\&D and TP and their interaction will also enter the productivity equation as endogenous variables. We control for several variables (FOREIGN, SOE, and EXPORT) that capture the firms' competitiveness and technological capability. Foreign-owned firms are characterized by higher capital intensity, high quality of human capital and efficient management. Many previous studies suggest that foreign-owned firms are more productive (Globerman et al., 1994; Doms and Jensen, 1998; Kimura and Kiyota, 2007). State-owned enterprises (SOEs) are usually characterized by redundant workers and inefficient management. As we can see from Table 3.2, SOEs are mostly medium-sized firms (hence above the sample average with respect to the number of employees) while their productivity is below the sample average. They are not motivated to perform efficiently because the local government takes full responsibility for their production and profit. For this reason, we expect SOEs to have a negative effect on the productivity performance. EXPORT activities are expected to enhance economic growth and improve the productivity of involved firms (Beckerman, 1962; Bhagwati, 1988). Firms participating in international markets are exposed to more intense competition. More vigorous competition exerts discipline on firms. It therefore tends to strengthen their efficiency, and we expect a

\footnotetext{
23 The capital and material inputs are logarithmically transformed and expressed in 1000 RMB per employee.
} 
positive effect. We also control for industry and year specificities by using industry and year dummies.

\subsubsection{Descriptive statistics}

Tables 3.2 to 3.4 provide descriptive statistics on the conventional inputs, the productivity performance, the technology sourcing and the control variables across industries. As Table 3.2 shows, high-tech industries such as electronic equipment, household electronics and biotechnology have a higher capital/labor ratio, are more productive and more active in collaborative research. Enterprises in household electronics and garments are more likely to sell their products abroad and to be foreignowned. Firms with fewer than 100 employees are on average younger, less collaborative in research, less capital intensive, less often foreign- or state-owned, less export-oriented and less productive. Table 3.3 provides the descriptive statistics across industries for SOEs. Except for the transportation equipment industry, SOEs have lower laborproductivity level than the other firms in the corresponding industry confirming the OECD (2007) report. In contrast, SOEs are more capital-intensive and bigger (in terms of number of employees). They are more numerous in electronic parts, auto parts, metallurgical products and the garment industry. They are less likely to export and their average age is 28 years, which is almost twice the average age of the whole sample. They are more likely to collaborate in research. Notice that almost half of the SOEs in the biotechnological industry claim to have $\mathrm{R} \& \mathrm{D}$ cooperation with public research institutions.

Table 3.4 presents the innovation outputs and inputs of Chinese small and medium-sized manufacturing firms. Approximately 46 per cent of the firms claim to have introduced a new product and 25 per cent have introduced a new process in the period under review. Technology intensive industries such as electronics and biotech are more likely to be innovators, and they also perform better in terms of new product sales as shown by column four in Table 3.4. It should be noted that the product and process innovations in developing countries are not conventionally defined as new to the market, but rather as new to the firm. 
Table 3. 2 Firm average across industries (full sample)

\begin{tabular}{|c|c|c|c|c|c|c|c|c|c|c|c|c|}
\hline Industry & $\begin{array}{l}\text { N. } \\
\text { obs }\end{array}$ & $\begin{array}{c}\text { Producti } \\
\text { vity }\end{array}$ & $\begin{array}{c}\text { Capita } \\
1\end{array}$ & $\begin{array}{c}\text { Materia } \\
1\end{array}$ & Labor & $\begin{array}{c}\text { SOE } \\
\text { dummy }\end{array}$ & $\begin{array}{c}\text { Foreig } \\
n \\
\text { dummy }\end{array}$ & $\begin{array}{c}\text { Export } \\
\text { dumm } \\
y\end{array}$ & Age & $\begin{array}{c}\text { R\&D_- } \\
\text { UNI }\end{array}$ & $\begin{array}{c}\text { R\&D } \\
- \\
\text { PRI }\end{array}$ & $\begin{array}{l}\text { R\&D } \\
\text { FIRM }\end{array}$ \\
\hline $\begin{array}{l}\text { Garment \& } \\
\text { leather }\end{array}$ & 778 & 3.871 & 3.091 & 3.059 & 4.953 & 0.090 & 0.193 & 0.391 & 12.772 & 0.042 & 0.035 & 0.063 \\
\hline $\begin{array}{l}\text { Electronic } \\
\text { equipment }\end{array}$ & 375 & 5.044 & 3.851 & 4.080 & 4.957 & 0.200 & 0.224 & 0.195 & 9.523 & 0.237 & 0.187 & 0.205 \\
\hline $\begin{array}{l}\text { Electronic } \\
\text { parts }\end{array}$ & 614 & 4.210 & 3.690 & 3.321 & 4.860 & 0.259 & 0.137 & 0.176 & 16.614 & 0.155 & 0.137 & 0.164 \\
\hline $\begin{array}{l}\text { Household } \\
\text { electronics }\end{array}$ & 128 & 4.525 & 3.825 & 3.273 & 5.216 & 0.047 & 0.367 & 0.445 & 11.461 & 0.172 & 0.102 & 0.188 \\
\hline $\begin{array}{l}\text { Auto \& auto } \\
\text { parts }\end{array}$ & 734 & 4.344 & 3.716 & 3.560 & 5.261 & 0.228 & 0.113 & 0.108 & 16.634 & 0.082 & 0.105 & 0.178 \\
\hline $\begin{array}{l}\text { Food } \\
\text { processing }\end{array}$ & 144 & 4.483 & 3.624 & 3.603 & 4.898 & 0.250 & 0.146 & 0.069 & 15.708 & 0.188 & 0.181 & 0.125 \\
\hline $\begin{array}{l}\text { Chemical } \\
\text { product }\end{array}$ & 134 & 4.287 & 3.935 & 2.980 & 4.865 & 0.261 & 0.045 & 0.104 & 14.985 & 0.082 & 0.194 & 0.157 \\
\hline $\begin{array}{l}\text { Biotech } \\
\text { products }\end{array}$ & 60 & 4.764 & 4.106 & 2.986 & 4.901 & 0.200 & 0.050 & 0.067 & 11.400 & 0.417 & 0.417 & 0.133 \\
\hline $\begin{array}{l}\text { Metallurgical } \\
\text { product }\end{array}$ & 327 & 3.601 & 3.534 & 2.601 & 4.765 & 0.312 & 0.092 & 0.064 & 17.294 & 0.055 & 0.086 & 0.150 \\
\hline $\begin{array}{l}\text { Transportation } \\
\text { equipment }\end{array}$ & 38 & 3.100 & 2.565 & 1.887 & 4.216 & 0.237 & 0.079 & 0.000 & 11.816 & 0.000 & 0.000 & 0.132 \\
\hline $\begin{array}{l}\text { SOE firms }{ }^{24} \\
\text { Non-SOEs }\end{array}$ & $\begin{array}{c}671 \\
2661\end{array}$ & $\begin{array}{l}3.845 \\
4.313\end{array}$ & $\begin{array}{l}4.066 \\
3.439\end{array}$ & $\begin{array}{l}2.901 \\
3.402\end{array}$ & $\begin{array}{l}5.666 \\
4.808\end{array}$ & $\begin{array}{l}1.000 \\
0.000\end{array}$ & $\begin{array}{l}0.000 \\
0.171\end{array}$ & $\begin{array}{l}0.107 \\
0.225\end{array}$ & $\begin{array}{l}28.261 \\
11.079\end{array}$ & $\begin{array}{l}0.142 \\
0.107\end{array}$ & $\begin{array}{l}0.137 \\
0.107\end{array}$ & $\begin{array}{l}0.168 \\
0.139\end{array}$ \\
\hline Employees & & & & & & & & & & & & \\
\hline $\begin{array}{l}<100 \\
\text { Employees }>=\end{array}$ & 1304 & 3.972 & 3.215 & 3.097 & 3.743 & 0.112 & 0.079 & 0.080 & 10.888 & 0.080 & 0.070 & 0.110 \\
\hline $100 \&<300$ & 1026 & 4.361 & 3.533 & 3.455 & 5.126 & 0.151 & 0.188 & 0.252 & 12.901 & 0.112 & 0.110 & 0.148 \\
\hline $\begin{array}{l}\text { Employees } \\
>=300\end{array}$ & 1002 & 4.393 & 4.054 & 3.409 & 6.443 & 0.369 & 0.215 & 0.306 & 20.967 & 0.161 & 0.172 & 0.187 \\
\hline Total & 3332 & 4.219 & 3.565 & 3.301 & 4.981 & 0.201 & 0.153 & 0.201 & 14.539 & 0.114 & 0.113 & 0.145 \\
\hline
\end{tabular}

Notes: Productivity is in logarithm of sales (in $1000 \mathrm{RMB}$ ) per employee;

Capital and material are also logarithmically transformed and in 1000RMB/employee;

Labor is the logarithm of the number of employees in the firm;

R\&D_UNI: dummy variable $=1$ if a firm reports co-operation with universities;

R\&D_PRI: dummy variable $=1$ if a firm reports cooperation with public research institutes;

R\&D_FIRM: dummy variable $=1$ if a firm reports co-operation with other firms.

\footnotetext{
24 -tests have been used to test the differences in means between SOEs and Non-SOEs for our main variables. The differences are significant (at 90 per cent level) for all variables in table 3.2 except for R\&D_UNI, R\&D_RES and R\&D_FIRM. Similar t-tests have been conducted to compare the means of main variables for different size classes. The differences are always significant (at 90 per cent level) for firms with fewer than 100 and those with between 100 and 300 employees. For firms with 100 to 300 and above 300 employees, the only two variables where the differences are not significant at 90 per cent level are MATERIAL and R\&D_UNI.
} 
Table 3. 3 Firm average across industries (for SOEs)

\begin{tabular}{|c|c|c|c|c|c|c|c|c|c|c|}
\hline Industry & N. obs & Productivity & Capital & Material & Labor & $\begin{array}{l}\text { Export } \\
\text { dummy }\end{array}$ & Age & $\begin{array}{c}\text { R\&D_- } \\
\text { UNI }\end{array}$ & $\begin{array}{r}\text { R\&D } \\
\text { PRI }\end{array}$ & $\begin{array}{l}\text { R\&D_ } \\
\text { FIRM }\end{array}$ \\
\hline $\begin{array}{l}\text { Garment \& } \\
\text { leather }\end{array}$ & 70 & 3.376 & 3.814 & 2.439 & 5.141 & 0.257 & 26.014 & 0.029 & 0.029 & 0.057 \\
\hline $\begin{array}{l}\text { Electronic } \\
\text { equipment } \\
\text { Electronic }\end{array}$ & 75 & 4.513 & 3.833 & 3.578 & 5.456 & 0.120 & 18.600 & 0.280 & 0.267 & 0.240 \\
\hline $\begin{array}{l}\text { parts } \\
\text { Household }\end{array}$ & 159 & 3.808 & 4.094 & 2.823 & 5.520 & 0.164 & 28.843 & 0.189 & 0.214 & 0.257 \\
\hline electronics & 6 & 2.383 & 4.717 & 1.762 & 6.159 & 0.000 & 3.000 & 0.000 & 0.000 & 0.000 \\
\hline $\begin{array}{l}\text { Auto \& auto } \\
\text { part }\end{array}$ & 167 & 4.068 & 4.351 & 3.312 & 6.258 & 0.072 & 33.413 & 0.126 & 0.072 & 0.137 \\
\hline $\begin{array}{l}\text { Food } \\
\text { processing }\end{array}$ & 36 & 3.818 & 4.176 & 2.851 & 5.181 & 0.000 & 35.833 & 0.083 & 0.028 & 0.083 \\
\hline $\begin{array}{l}\text { Chemical } \\
\text { products }\end{array}$ & 35 & 3.964 & 4.168 & 2.911 & 5.541 & 0.114 & 24.971 & 0.029 & 0.057 & 0.228 \\
\hline $\begin{array}{l}\text { Biotech } \\
\text { products }\end{array}$ & 12 & 4.034 & 4.351 & 2.832 & 5.438 & 0.000 & 31.500 & 0.333 & 0.500 & 0.083 \\
\hline $\begin{array}{l}\text { Metallurgical } \\
\text { product }\end{array}$ & 102 & 3.459 & 3.758 & 2.413 & 5.684 & 0.029 & 27.676 & 0.127 & 0.147 & 0.117 \\
\hline $\begin{array}{l}\text { Transportation } \\
\text { equipment }\end{array}$ & 9 & 3.225 & 3.970 & 1.138 & 5.285 & 0.000 & 22.000 & 0.000 & 0.000 & 0.333 \\
\hline Total & 671 & 3.845 & 4.066 & 2.901 & 5.666 & 0.107 & 28.261 & 0.142 & 0.137 & 0.168 \\
\hline
\end{tabular}

Notes: Productivity is in logarithm of sales (in 1000 RMB) per employee;

Capital and material are also in logarithmically transformed and in 1000RMB/employee;

Labor is the logarithm of the number of employees in the firm;

R\&D_UNI: dummy variable $=1$ if a firm reports co-operation with universities;

R\&D_PRI: dummy variable $=1$ if a firm reports co-operation with public research institutes;

R\&D_FIRM: dummy variable $=1$ if a firm reports co-operation with other firms.

It has been postulated that new and dynamic industries in developing countries can most readily catch up (Gerschenkron, 1962). Under the R\&D, TP, R\&D and TP headings we report the observed incidences ${ }^{25}$ and corresponding expenditure statistics. As is shown in Table 3.4, the electronic equipment, auto and auto parts and biotech industries spend more on technology acquisition, both internally and externally, than traditional industries such as chemicals, garment and leather and food processing. The relatively lower innovation efforts might explain why most Chinese firms in low-tech industries have not been able to catch up with technology advances, as argued by Fu and Gong (2010).

25 The percentage of firms that claimed to have positive expenditures of R\&D and TP in the period under review. 
Table 3. 4 Descriptive statistics of innovation inputs and outputs across industries (mean values in 2002)

\begin{tabular}{|c|c|c|c|c|c|c|c|c|c|}
\hline \multirow[b]{2}{*}{ Industry } & \multicolumn{2}{|c|}{ Innovation } & \multirow{2}{*}{$\begin{array}{c}\text { New product } \\
\text { sales per } \\
\text { employee }\end{array}$} & \multicolumn{2}{|c|}{$\mathrm{R} \& \mathrm{D}$} & \multicolumn{2}{|c|}{$\mathrm{TP}$} & \multicolumn{2}{|c|}{ R\&D \&TP } \\
\hline & Products & Process & & $\begin{array}{l}\text { Inci- } \\
\text { dence }\end{array}$ & $\begin{array}{c}\text { Expen- } \\
\text { diture }\end{array}$ & $\begin{array}{l}\text { Inci- } \\
\text { dence }\end{array}$ & $\begin{array}{c}\text { Expen- } \\
\text { diture }\end{array}$ & $\begin{array}{l}\text { Inci- } \\
\text { dence }\end{array}$ & $\begin{array}{l}\text { Expen } \\
\text { diture }\end{array}$ \\
\hline Garment \& leather & 0.246 & 0.123 & 2.344 & 0.264 & -0.186 & 0.078 & -0.180 & 0.074 & 0.256 \\
\hline Electronic equipment & 0.643 & 0.384 & 3.123 & 0.616 & 0.746 & 0.256 & -0.001 & 0.240 & 0.749 \\
\hline Electronic parts & 0.542 & 0.316 & 2.116 & 0.485 & 0.196 & 0.223 & 0.000 & 0.214 & 0.362 \\
\hline Household electronics & 0.648 & 0.438 & 2.625 & 0.581 & -0.031 & 0.256 & -0.042 & 0.256 & 1.212 \\
\hline Auto \& auto part & 0.527 & 0.260 & 2.151 & 0.482 & 0.079 & 0.215 & -0.167 & 0.215 & 0.655 \\
\hline Food processing & 0.553 & 0.261 & 2.420 & 0.396 & -0.233 & 0.229 & -0.210 & 0.229 & 0.341 \\
\hline Chemical product & 0.425 & 0.224 & 1.365 & 0.304 & 0.005 & 0.217 & -0.089 & 0.217 & 0.245 \\
\hline Biotech products & 0.700 & 0.222 & 2.407 & 0.600 & 0.693 & 0.350 & 0.288 & 0.350 & 1.039 \\
\hline Metallurgical product & 0.385 & 0.220 & 1.530 & 0.312 & -0.072 & 0.128 & -0.199 & 0.119 & 0.443 \\
\hline $\begin{array}{l}\text { Transportation } \\
\text { equipment }\end{array}$ & 0.143 & 0.086 & 0.424 & 0.154 & 0.484 & 0.077 & 0.031 & 0.077 & 0.030 \\
\hline SOE firms ${ }^{26}$ & 0.563 & 0.328 & 1.294 & 0.485 & -0.142 & 0.203 & -0.247 & 0.194 & 0.440 \\
\hline Non-SOEs & 0.440 & 0.231 & 2.761 & 0.405 & 0.155 & 0.179 & -0.071 & 0.175 & 0.502 \\
\hline Employees $<100$ & 0.353 & 0.194 & 2.970 & 0.278 & 0.143 & 0.106 & 0.005 & 0.101 & 0.229 \\
\hline $\begin{array}{l}\text { Employees }>=100 \quad \& \\
<300\end{array}$ & 0.476 & 0.242 & 2.852 & 0.411 & 0.103 & 0.192 & -0.094 & 0.183 & 0.557 \\
\hline $\begin{array}{l}\text { Employees } \\
>=300\end{array}$ & 0.608 & 0.331 & 1.635 & 0.614 & 0.024 & 0.275 & -0.262 & 0.272 & 0.753 \\
\hline Total & 0.464 & 0.251 & 2.278 & 0.422 & 0.094 & 0.184 & -0.107 & 0.178 & 0.489 \\
\hline
\end{tabular}

Note: Innovation (products/process): dummy variable equal to 1 if a firm has introduced a new product (process) in the period of 2000 to 2002;

New product sales: sales of new product per employee, in logarithms;

$\mathrm{R} \& \mathrm{D}$ expenditure (RD) and technology purchases (TP) are expressed in 1000 RMB per employee, in logs;

$R \& D \& T P$ is the product of $R \& D$ and TP.

The lack of efficiency of Chinese SOEs is also shown in the innovation input and output data. The proportion of firms that do in-house R\&D is higher for SOEs than for the total sample and the same goes for technology purchasing. As a result, the innovation propensities in terms of products and processes are above the overall averages. However, the intensities of R\&D and TP expenditures per employee are lower for SOEs than for the overall sample and the average value of new product sales per employee, which takes

\footnotetext{
${ }^{26} \mathrm{t}$-tests have been used to test the differences in means between SOEs and Non SOEs for our main variables. The differences are significant (at 90 per cent level) for all variables in table 3.4 except for TP. Similar t-tests have been conducted to compare the means of main variables for different size classes. The differences are always significant (at 90 per cent level) for firms with 100 to 300 and above 300 employees. For firms with fewer than 100 and those between 100 and 300 employees, the only variable where the differences are not significant at 90 per cent level is PROCESS.
} 
into account the relative level and the market success of innovation, is substantially below the overall sample average. A similar pattern holds in terms of firm size. Enterprises with fewer than 100 employees are lower in terms of engaging in R\&D and TP and introducing new products and processes, but higher in R\&D, TP and product innovation intensities compared with other two groups (firms with 100 to 300 employees and firms with more than 300 employees).

\subsection{Empirical results}

We now turn to the results of the econometric analysis regarding how the two technology-sourcing strategies, R\&D and TP, affect the innovation and productivity performances of small and medium-sized Chinese manufacturing firms, and the questions of whether they are substitutes or complements. We have divided the sample into three groups, the set of firms with fewer than 100 employees (very small-sized firms), the set of those with more than 100 and fewer than 300 employees (small-sized firms), and the set of those with more than 300 employees (medium-sized firms), because there are some clear differences between the three groups.

\subsubsection{The role of $R \& D$ and TP in stimulating innovation}

Table 3.5 presents the marginal effects of the regressors in the Probit model (equation 3.3.1) and the tobit type II model (equations (3.3.2) and (3.3.3)). The observed frequencies of $\mathrm{R} \& \mathrm{D}$ performers and technology purchasers are 42 per cent and 18 per cent per cent respectively, and only six firms that bought knowledge from outside did not perform their own R\&D. We had difficulties identifying a separate intercept for firms with their own $R \& D$ and external technology purchases and therefore did not introduce the interaction of the two dummies in the model. 
Table 3. 5 Estimation results of innovation output (probit for process innovation, tobit type II for product innovation), marginal effects

\begin{tabular}{|c|c|c|c|c|c|c|}
\hline \multirow{3}{*}{ VARIABLES } & \multicolumn{3}{|c|}{$<100$ employees } & \multicolumn{3}{|c|}{$>=100$ employees } \\
\hline & \multirow{2}{*}{$\begin{array}{c}\text { Probit } \\
\text { Process } \\
\text { innovat. }\end{array}$} & \multicolumn{2}{|c|}{ Tobit type II } & \multirow{2}{*}{$\begin{array}{c}\text { Probit } \\
\text { Process } \\
\text { innovat. }\end{array}$} & \multicolumn{2}{|c|}{ Tobit type II } \\
\hline & & $\begin{array}{l}\text { New product } \\
\text { sales/person }\end{array}$ & $\begin{array}{l}\text { Product } \\
\text { innovat. }\end{array}$ & & $\begin{array}{l}\text { New product } \\
\text { sales/person }\end{array}$ & $\begin{array}{l}\text { Product } \\
\text { innovat. }\end{array}$ \\
\hline & $(1)$ & $(2)$ & (3) & $(4)$ & (5) & $(6)$ \\
\hline \multirow[t]{2}{*}{$\mathrm{I}_{\mathrm{m}}$} & 0.108 & $0.439 * * *$ & $0.225^{* * *}$ & $0.112^{* *}$ & $0.296^{* * *}$ & $0.258^{* * *}$ \\
\hline & $(0.068)$ & $(0.127)$ & $(0.083)$ & $(0.048)$ & $(0.164)$ & $(0.056)$ \\
\hline \multirow[t]{2}{*}{$\mathrm{I}_{\mathrm{b}}$} & -0.013 & $0.266^{*}$ & -0.047 & $-0.099 * *$ & $0.252^{*}$ & 0.020 \\
\hline & $(0.088)$ & $(0.147)$ & $(0.125)$ & $(0.050)$ & $(0.141)$ & $(0.076)$ \\
\hline \multirow[t]{2}{*}{$\mathrm{I}_{\mathrm{m}} \ln (\mathrm{R} \& \mathrm{D} /$ labor $)$} & 0.017 & 0.064 & -0.016 & 0.029 & $0.201 * * *$ & $0.037^{*}$ \\
\hline & $(0.024)$ & $(0.042)$ & $(0.032)$ & $(0.018)$ & $(0.047)$ & $(0.022)$ \\
\hline \multirow[t]{2}{*}{$\mathrm{I}_{\mathrm{m}} \ln (\mathrm{R} \& \mathrm{D} / \text { labor })^{2} / 2$} & 0.002 & 0.002 & 0.039 & -0.006 & $0.014^{* * *}$ & 0.002 \\
\hline & $(0.019)$ & $(0.003)$ & $(0.026)$ & $(0.012)$ & $(0.004)$ & $(0.015)$ \\
\hline \multirow[t]{2}{*}{$\mathrm{I}_{\mathrm{b}} \ln (\mathrm{TP} /$ labor $)$} & 0.080 & 0.119 & -0.036 & 0.027 & $0.149 * * *$ & 0.061 \\
\hline & $(0.057)$ & $(0.100)$ & $(0.067)$ & $(0.031)$ & $(0.074)$ & $(0.046)$ \\
\hline \multirow[t]{2}{*}{$\mathrm{I}_{\mathrm{b}} \ln (\mathrm{TP} / \text { labor })^{2} / 2$} & 0.032 & 0.004 & 0.017 & -0.002 & 0.008 & -0.014 \\
\hline & $(0.055)$ & $(0.004)$ & $(0.079)$ & $(0.026)$ & $(0.014)$ & $(0.032)$ \\
\hline \multirow{2}{*}{$\begin{array}{l}\mathrm{I}_{\mathrm{bm}} \ln (\mathrm{R} \& \mathrm{D} / \text { labor }) \\
\quad{ }^{\prime} \ln (\mathrm{TP} / \text { labor })\end{array}$} & -0.029 & 0.005 & 0.009 & 0.023 & $0.016^{* * *}$ & 0.023 \\
\hline & $(0.056)$ & $(0.003)$ & $(0.053)$ & $(0.029)$ & $(0.004)$ & $(0.034)$ \\
\hline \multirow[t]{2}{*}{ SOE } & -0.057 & 0.090 & 0.105 & $0.173^{* * *}$ & -0.067 & $0.146^{* *}$ \\
\hline & $(0.056)$ & $0.128)$ & $(0.094)$ & $(0.057)$ & $0.135)$ & $(0.061)$ \\
\hline \multirow[t]{2}{*}{ FOREIGN } & 0.073 & $0.304^{* *}$ & 0.083 & 0.019 & -0.041 & -0.042 \\
\hline & $(0.089)$ & $(0.126)$ & $(0.106)$ & $(0.050)$ & $(0.125)$ & $(0.062)$ \\
\hline \multirow[t]{2}{*}{ AGE } & -0.002 & $-0.012^{* * *}$ & $-0.006^{* *}$ & -0.001 & $-0.016^{* * *}$ & -0.001 \\
\hline & $(0.002)$ & $(0.004)$ & $(0.003)$ & $(0.001)$ & $(0.004)$ & $(0.002)$ \\
\hline \multirow{2}{*}{$\begin{array}{l}\text { CAPITAL/labor } \\
\text { (avg 2000-2002) }\end{array}$} & 0.000 & 0.001 & -0.000 & -0.000 & -0.001 & -0.001 \\
\hline & $(0.000)$ & $(0.001)$ & $(0.001)$ & $(0.000)$ & $(0.001)$ & $(0.000)$ \\
\hline \multirow{2}{*}{$\begin{array}{l}\text { PROFIT/labor } \\
\text { (avg 2000-2002) }\end{array}$} & $-0.001 *$ & $0.003 * * *$ & 0.001 & 0.000 & $0.017^{* * *}$ & $0.007 * * *$ \\
\hline & $(0.001)$ & $(0.001)$ & $(0.001)$ & $(0.000)$ & $(0.001)$ & $(0.002)$ \\
\hline \multirow[t]{2}{*}{ EXPORT } & 0.042 & -0.152 & -0.000 & $0.140 * * *$ & -0.139 & 0.037 \\
\hline & $(0.084)$ & $(0.133)$ & $(0.102)$ & $(0.052)$ & $(0.118)$ & $(0.060)$ \\
\hline \multirow[t]{2}{*}{ R\&D_UNI } & $0.203^{* *}$ & $0.616^{* * *}$ & $0.197 *$ & $0.111^{*}$ & 0.076 & 0.074 \\
\hline & $(0.098)$ & $(0.124)$ & $(0.110)$ & $(0.058)$ & $(0.130)$ & $(0.067)$ \\
\hline \multirow[t]{2}{*}{ R\&D_PRI } & -0.017 & $0.636 * * *$ & 0.038 & 0.059 & 0.099 & 0.048 \\
\hline & $(0.073)$ & $(0.120)$ & $(0.109)$ & $(0.056)$ & $(0.127)$ & $(0.068)$ \\
\hline \multirow[t]{2}{*}{ R\&D_FIRM } & 0.069 & $0.688^{* * *}$ & $0.390 * * *$ & $0.128^{* *}$ & $0.370^{* * *}$ & $0.285^{* * *}$ \\
\hline & $(0.072)$ & $(0.112)$ & $(0.088)$ & $(0.051)$ & $(0.134)$ & $(0.052)$ \\
\hline$\rho$ & & 0.079 & & & $-0.765^{* * *}$ & \\
\hline$\sigma_{\eta}$ & & 1.233 & & & 1.751 & \\
\hline Nb observations & 435 & 159 & 435 & 680 & 372 & 680 \\
\hline
\end{tabular}

$* * *$ p-value $0.01, * * \mathrm{p}$-value $0.05,{ }^{*} \mathrm{p}$-value 0.1 . Industry dummies are included. City dummies are included in the probit for process innovation and in the selection equation for the product innovation. New product sales per employee is in logarithms. Ib indicates that $\mathrm{R} \& \mathrm{D}>0$, Im indicates that $\mathrm{TP}>0$, Ibm indicates that both R\&D and TP are positive.

In columns (1) and (4) we report the marginal effects of the explanatory variables on the incidence of process innovations, in columns (3) and (6) the marginal effects on the incidence of product innovations. In columns (2) and (4) we report the marginal effects of the explanatory variables on the unconditional expectation of new product sales per employee. Calculations of unconditional marginal effects/elasticities are based on (3.a10)-(3.a14) in appendix A. When computing the marginal effects of Ib or Im we take into account all the terms where these two dummies appear (i.e. four terms in total). For $\mathrm{Imln}(\mathrm{R} \& \mathrm{D} / \mathrm{labor}$ ) and Ibln(TP/labor), we include in the computation of the elasticities the effects of the square term and the interaction term. The marginal effects of $\operatorname{Im} \ln (\mathrm{R} \& \mathrm{D} /$ labor $) 2 / 2$ and $\mathrm{Ibln}(\mathrm{TP} /$ labor $) 2 / 2$ represent secondorder derivatives and the marginal effect of $\operatorname{Im} \ln (\mathrm{R} \& \mathrm{D} / \mathrm{labor}) * \mathrm{Ib} \ln (\mathrm{TP} /$ labor $)$ represents the secondorder cross derivative of the unconditional expectation of new product sales/employee. Standard Errors are computed using the Delta method. 
In Table 3.5 we report the marginal effects of the explanatory variables for the probit regression for process innovation and the selection equation for product innovation and the marginal effects on the unconditional expected value of new product sales per employee. In Appendix 3A we derive the marginal effects of the regressors on the conditional (equation 3.a7) and unconditional expectations of new product sales per employee (equations (3.a10)-(3.a14)). When computing the marginal effects of dummy $\mathrm{I}_{\mathrm{b}}$ or $\mathrm{I}_{\mathrm{m}}$ we take into account all the terms where these two dummies appear (i.e. four terms in total). For $\mathrm{I}_{\mathrm{m}} \ln (\mathrm{R} \& \mathrm{D} /$ labor $)$ and $\mathrm{I}_{\mathrm{b}} \ln (\mathrm{TP} /$ labor $)$, we include in the computation of the elasticities the effects of square term and the interaction term. The marginal effects of $I_{m} \ln (R \& D / \text { labor })^{2} / 2$ and $I_{b} \ln (T P / \text { labor })^{2} / 2$ represent second-order derivatives and the marginal effect of $I_{m} \ln (\mathrm{R} \& D /$ labor $) * I_{b} \ln (T P /$ labor $)$ represents the second-order cross derivative of the unconditional expectation of new product sales/employee. Standard Errors are computed using the Delta Method $^{27}$.

$\mathrm{R} \& \mathrm{D}$ is found to have a significant positive effect on process innovation only for firms with more than 300 employees. Firms that do R\&D have a 21.3 percentage-points higher incidence of process innovation than those that do no R\&D (coefficient of $\left.\mathrm{I}_{\mathrm{m}}\right)^{28}$. Our data do not allow us to conclude anything regarding the marginal effect of a quantitative increase in $\mathrm{R} \& \mathrm{D}$ on process innovation, except for small firms where a 10 per cent increase in R\&D per employee increases the probability of innovating by 0.7 percentage points. Technology purchasing has a negative and significant effect on process innovation, again only in a certain size class, this time medium-sized firms: technology purchasing firms have there on average a 15.8 percentage points lower incidence of process innovation than non-technology purchasing firms. For all other firms we cannot conclude anything about how TP affects process innovation. Our two sources of technology have a clearer effect on product innovation. In very small firms (fewer than 100 employees), $R \& D$ performing firms have a 22.5 percentage points higher probability of being product innovators and a 43.9 per cent higher sales of new products per employee than non-R\&D performing firms. In medium-sized firms the incidence is 35.7 percentage points higher, and the sales of new products per employee are 54 per cent higher for R\&D firms than for non-R\&D firms. In small firms (between 100 and 300

\footnotetext{
27 The Delta method is based on the first order approximation around the mean. For more details, see Oehlert (1992).

${ }^{28}$ When computing the marginal effects of $\mathrm{I}_{\mathrm{b}}$ or $\mathrm{I}_{\mathrm{m}}$ we take into account all the terms where these two dummies appear (i.e. four terms in total).
} 
employees), these magnitudes are not precisely estimated, but the new product sales elasticity with respect to $\mathrm{R} \& \mathrm{D}$ is 0.404 . Technology purchasing has also a positive effect on product innovation. In very small firms, TP firms have on average a 26.6 percent higher sales figure per employee than non-TP firms; small TP firms are on average 32.4 percentage points more likely to innovate in products than non-TP firms, and their sales per employee are 86.1 per cent higher, which, however, declines by 2.1 per cent as TP expenditure per employee increase by 10 percent (coefficient of $\mathrm{I}_{\mathrm{b}} \ln (\mathrm{TP} /$ labor $\left.)\right)^{29}$; and finally in medium sized firms new product sales per employee rise by 3.8 per cent as TP per employee increases by 10 per cent. The only significant sign of complementarity between R\&D and TP is visible for small firms, where the elasticity of new product sales per employee with respect to $R \& D$ increases by 0.22 per cent as technology purchasing increases by 10 per cent. ${ }^{30}$ The synergy between own R\&D and external technology purchasing, at least as it is evident in small Chinese manufacturing firms (between 100 and 300 employees), is in line with the argument of absorptive capacity (Cohen and Levinthal, 1990) and the results reported by Li and Wu (2010), Liu and White (1997), Liu and Buck (2007) and Liu and Zou (2008).

Among the control variables, characteristics such as being an exporter, a young firm, or a foreign-owned firm, a firm that co-operates in $\mathrm{R} \& \mathrm{D}$ positively affect the probability or the intensity of innovating. Exporting firms with 100 to 300 and more than 300 employees have a 16 and 14 percentage-points higher probability of process innovation. Old firms are expected to be less dynamic and innovative (Katrak, 1997). Indeed, they have 1.2 to 2.7 percentage-points lower sales of new products per employee in very small and small-sized firms. Foreign-owned firms with fewer than 100 employees have a 30 percentage points higher product innovation intensity. Due to the high costs and uncertainties connected with innovation, firms with profits are more likely to have the adequate financial resources to innovate. An increase of 1000 RMB in profit per employee increases by 0.3 percentage points the sales of new products per employee for firms with fewer than 100 employees and by 1.7 and 1.8 percentage points for small and medium-sized firms. State-owned enterprises have a 21 percentage-points higher probability to innovate in processes if they have more than 300 employees. They

\footnotetext{
${ }^{29}$ When computing the marginal effects of $I_{m} \ln (R \& D /$ labor $)$ and $I_{b} \ln (T P /$ labor), we include in the computation of the elasticities of the square term and the interaction term.

${ }^{30} \mathrm{As} \mathrm{Ai}$ and Norton (2003) pointed out, complementarity should be based on a positive sign of the crosselasticity and not the interaction term alone.
} 
probably benefit from more financial and policy support from government. R\&D collaborations with other firms, public research institutes and universities increase the probability to innovate and the intensity of product innovations especially for the very small firms (see Boeing, Mueller and Sandner, 2012). Those with fewer than 100 employees that benefit from any kind of $\mathrm{R} \& \mathrm{D}$ collaboration have a 60 percentage points higher sales of new products per employee. For firms with 100 to 300 employees, it is mostly collaborations with other firms and universities that affect the innovation intensity, increasing it by 59.6 and 53.5 percentage points. Collaborations with universities seem to decrease sales of new products per employee by 36.3 per cente in medium-sized firms.

\subsubsection{The role of $R \& D$ and $T P$ in promoting productivity}

We now go a step further and examine the issue of complementarity or substitutability between in-house $\mathrm{R} \& \mathrm{D}$ and technology purchasing in terms of achieving a better productivity performance, since in the end innovation serves to improve productivity. Table 3.6 presents the results of the productivity equation (3.5) obtained using ordinary least squares (OLS) and the system GMM method. The system GMM exploits the orthogonality conditions between the first differences in the error term and the explanatory variables in levels lagged by one period, once for 2002 and once for 2001, and the orthogonality conditions between the error terms in levels and the lagged first differences of the explanatory variables. Hence in total there are 85 orthogonality conditions, 29 estimated coefficients, and consequently 56 overidentifying restrictions ${ }^{31}$. The OLS estimates are likely to be inconsistent because of the endogeneity of the conventional inputs and the innovation strategy variables. They are only shown as a benchmark. In the presence of a positive productivity shock we expect firms to increase

\footnotetext{
31 The number of orthogonality conditions equals the number of instruments used for the endogenous variables plus the number of pre-determined variables (used as their own instruments). In the GMM case, 14 variables are considered to be endogenous (the first fourteen independent variables in the table). We consider the first differences in the error term of the productivity equation to be orthogonal to the one and two-period lagged levels of the endogenous variables for the year 2002 and to the one-period lagged levels of the endogenous variables for the year 2001 (remember, we have no data prior to 2000). That makes 42 orthogonality conditions so far. As to the level of the error term, we consider it to be orthogonal to the first differences in the endogenous variables for 2002 and for 2001. That makes 28 additional orthogonality conditions (14 for each year). So, in total the system GMM exploits 70 orthogonality conditions to instrument for the endogenous variables, plus 15 orthogonality conditions using the predetermined variables of our model (the time, industry, ownership and exporting status dummies) in the first difference equations, which makes a grand total of 85 orthogonality conditions. The number 56 in the Hansen overidentification test equals the total number of orthogonality conditions (85) minus the number of estimated parameters (29).
} 
their inputs, but the existence of adjustment costs for labor and capital will have them increase materials more than the two quasi-fixed inputs. Hence we would expect an upward bias in the estimate of the output elasticity of the inputs, more for materials than for labor and capital. R\&D is probably more quasi-fixed than technology purchases and hence we expect a stronger upward bias for the latter than for the former. The directions of bias are partly confirmed by our estimates. Yet, the OLS estimates are not very different from the GMM estimates, which is a sign that the latter are not unreasonable. Our interpretation will be based on the system GMM estimation, which tackles the endogeneity problem. The instruments used in the GMM estimation are acceptable by the Hansen test of overidentifying restrictions, which is only significantly different from zero at a p-value of 38 (resp. 16) per cent for firms with fewer (resp. more) than 100 employees. The Difference-in-Hansen test also accepts the 28 additional orthogonality conditions of the level equations that differentiate the System GMM from the Firstdifference GMM estimates. ${ }^{32}$

We have chosen a translog approximation to a general production function in the conventional inputs (the $\mathrm{h}($.$) function in equation (3.4)) as well as a translog$ approximation of the total factor productivity expression in the two technology variables (the $\mathrm{g}($. ) function in equation (3.4)). We have normalized the conventional inputs, capital and material, and the technology inputs, R\&D and TP, by labor and introduced a separate labor term to capture the departure from constant returns to scale with respect to all the inputs. ${ }^{33}$ The point of approximation is around unit values of the input/output ratios, which is out of the sample for the conventional inputs (see Table 3.2) but quite reasonable for the technology inputs (see Table 3.4). We have also accounted for the fact that many firms have no R\&D or no technology purchase by including dummy indicators for these two variables and by interacting these dummy variables with their respective amounts when they are positive.

We cannot reject the null hypothesis of constant returns to scale (the ln(labor) coefficient is not significantly different from 0). Capital and material are substitutes. In the bottom subpanel of Table 3.6, we report the output elasticities of physical capital, materials,

\footnotetext{
32 The two-step system GMM performed in STATA 11, using the xtabond2 command, automatically corrects the standard errors for heteroskedasticity and autocorrelation (Roodman, 2006).

33 By dividing all the inputs by labor and dividing output by labor, we have imposed that the second-order parameters of the translog approximation sum up to zero and the first-order terms sum up to 1 , so as to impose constant returns to scale. We have then allowed the sum of the first-order terms to deviate from 1 by allowing for a labor first-order term to appear on the right-hand side.
} 
$\mathrm{R} \& \mathrm{D}$ and TP evaluated at the means of the variables ${ }^{34}$. The elasticities for capital are quite reasonable, around .12 to .18 for capital and .57 to .62 for material.

The results in Table 3.6 show that firms with in-house R\&D/employee at its mean value and no TP have a 29 (resp 18 per cent) higher labor productivity than firms with no $\mathrm{R} \& \mathrm{D}$ in the small (resp. medium-sized firms and no significant difference in labor productivity for very small firms (coefficients of $\mathrm{I}_{\mathrm{m}}$ ). In contrast the effect of technology purchases is visible mainly in very small firms and small firms, but not in medium-sized firms. With technology purchases are at their mean value and no R\&D, very small (resp. small) firms have a 69 (resp. 39) per cent higher labor productivity than firms with no technology purchasing. Medium-sized firms show no significant difference in labor productivity between TP and non-TP firms. For firms that do both R\&D and TP, labor productivity is significantly lower than for firms that do neither of them. In this sense, the two means of knowledge accumulation are at odds with each other. Since their respective effect on innovation (product and process) is generally positive, the average negative effect on labor productivity for firms that pursue both strategies must be due to some excessive cost, a possible duplication of knowledge acquisition, or some correlation of those activities with other associated characteristics, such as lack of experience or age of the firm. For instance, one could imagine that young, non technology-based firms, are less efficient because they lack know-how or technological capabilities, which they try to acquire by all possible means from inside or outside the firm.

The elasticity of output with respect to $\mathrm{R} \& \mathrm{D}$ (for $\mathrm{R} \& \mathrm{D}$-performing firms) shows significance only for small firms, where we obtain an elasticity of 0.11 , which is quite consistent with the elasticities reported in the literature (see Hall, Mairesse, Mohnen, 2010). The elasticity of output with respect to TP (for firms with TP) is significant at 0.10 (coefficient of $\mathrm{I}_{\mathrm{b}} \ln (\mathrm{TP} /$ labor $)$ ) in medium-sized firms and not significant elsewhere. A complementarity between R\&D and TP actually shows up in very small firms (coefficient of $\mathrm{I}_{\mathrm{bm}} \ln (\mathrm{R} \& \mathrm{D} /$ labor $) \ln (\mathrm{TP} /$ labor $\left.)\right)$, while in the other firms the cross-elasticity of output with respect to R\&D and TP is not significant. This means that in very small firms the returns from investing in one source of knowledge, R\&D or technology purchasing, increases with the investment in the other source. In that sense the two strategies are

\footnotetext{
34 When the marginal effects were computed, we include the elasticities of the square term and the interaction term. For computing the marginal effects of $\ln$ (capital/labor) and $\ln$ (material/labor), the square term and the interaction term are also accounted.
} 
complements. As for the control variables the results are not surprising. In China, the majority of foreign-invested firms are in the high-tech industry and in general characterized by the higher average technical efficiency compared with domestic firms (Fu and Gong, 2010). As expected, foreign-owned firms are more productive than the reference category of firms in terms of ownership structure, i.e. domestic, non-stateowned firms. In contrast to foreign firms, SOEs tend to be less productive compared with firms with other ownership structures. This evidence reflects the inefficiency of Chinese SOEs. This finding is consistent with studies in other developing countries (Braga and Willmore, 1991). Exporting firms in China, at least those with more than 300 employees, are more productive than non-exporting firms. This may indicate that the pressure on international markets enables firms to foster their productivity or that the higher productivity enables firms to export.

We must be cautious when we compare our results with others in the literature. $\mathrm{Hu}$ et al (2005) found complementarity between domestic R\&D and technology transfer. But their results are based on large and medium size Chinese enterprises which probably involve a different pattern of innovation sourcing strategies. Bönte (2003) and Belderbos et al (2008) showed to a complementarity between internal (i.e. in-house) and external (i.e. contracted-out) R\&D in West-Germany and the Netherlands respectively. But our study is not comparable to theirs because our measure of purchased technology relates to the purchase of existing technology, from domestic or foreign sources, and not to the execution of $R \& D$ outside of the firm's R\&D facilities. We investigate the complementarity not between ways of performing $R \& D$ but between $R \& D$ and the purchase of existing technology. Fikkert (1993) and Basant and Fikkert (1996) found substitutability between R\&D and TP for Indian firms, but that was in a regime where there were controls on the external sourcing of technology, whereas in the period that we are examining Chinese firms were actually encouraged to import technology. ${ }^{35}$

\footnotetext{
35 We thank an anonymous referee for this remark.
} 
Table 3. 6 Estimation results of the productivity equation

\begin{tabular}{|c|c|c|c|c|c|c|}
\hline & \multicolumn{2}{|c|}{$<100$ employees } & \multicolumn{2}{|c|}{$\begin{array}{c}>=100 \&<300 \\
\text { employees }\end{array}$} & \multicolumn{2}{|c|}{$>=300$ employees } \\
\hline & OLS & GMM & OLS & GMM & OLS & GMM \\
\hline \multirow[t]{2}{*}{$\ln$ (capital/labor) } & $0.084^{* * *}$ & $0.182^{* * *}$ & $0.131 * * *$ & $0.082^{* *}$ & $0.183^{* * *}$ & $0.079 * *$ \\
\hline & $(0.016)$ & $(0.049)$ & $(0.023)$ & $(0.038)$ & $(0.027)$ & $(0.032)$ \\
\hline \multirow[t]{2}{*}[\operatorname{ln}(\text{capital}/\text{labor})]{$^{2} / 2$} & 0.001 & -0.010 & -0.009 & 0.019 & 0.019 & 0.029 \\
\hline & $(0.011)$ & $(0.022)$ & $(0.027)$ & $(0.019)$ & $(0.031)$ & $(0.060)$ \\
\hline \multirow[t]{2}{*}{$\ln ($ labor) } & 0.042 & 0.026 & 0.059 & -0.000 & -0.037 & 0.128 \\
\hline & $(0.035)$ & $(0.073)$ & $(0.071)$ & $(0.093)$ & $(0.042)$ & $(0.104)$ \\
\hline \multirow[t]{2}{*}{$\ln ($ material/labor) } & $0.657 * * *$ & $0.619 * * *$ & $0.620 * * *$ & $0.627 * * *$ & $0.521 * * *$ & $0.527 * * *$ \\
\hline & $(0.013)$ & $(0.025)$ & $(0.017)$ & $(0.040)$ & $(0.015)$ & $(0.041)$ \\
\hline \multirow[t]{2}{*}[\operatorname{ln}(\text{material}/\text{labor})]{$^{2} / 2$} & $0.130 * * *$ & $0.105^{* * *}$ & $0.075^{* * *}$ & $0.107 * * *$ & $0.121 * * *$ & $0.050^{* *}$ \\
\hline & $(0.009)$ & $(0.017)$ & $(0.014)$ & $(0.014)$ & $(0.011)$ & $(0.019)$ \\
\hline \multirow{2}{*}{$\begin{array}{l}\ln (\text { capital/labor) } \\
\quad * \ln (\text { material/labor })\end{array}$} & $-0.070^{* * *}$ & -0.029 & $-0.039 * * *$ & 0.011 & $-0.041 * * *$ & -0.017 \\
\hline & $(0.008)$ & $(0.024)$ & $(0.015)$ & $(0.025)$ & $(0.014)$ & $(0.025)$ \\
\hline \multirow[t]{2}{*}{$\mathrm{I}_{\mathrm{m}}$} & $0.112^{*}$ & 0.147 & $0.247^{* * *}$ & $0.294^{* * *}$ & $0.269 * * *$ & $0.177^{*}$ \\
\hline & $(0.060)$ & $(0.092)$ & $(0.074)$ & $(0.101)$ & $(0.074)$ & $(0.089)$ \\
\hline \multirow[t]{2}{*}{$\mathbf{I}_{\mathrm{b}}$} & 0.222 & $0.692^{* * *}$ & -0.157 & $0.387^{* * *}$ & 0.269 & 0.476 \\
\hline & $(0.270)$ & $(0.261)$ & $(0.182)$ & $(0.117)$ & $(0.284)$ & $(0.796)$ \\
\hline \multirow[t]{2}{*}{$\mathbf{I}_{\mathrm{bm}}$} & -0.197 & $-0.939 * * *$ & -0.016 & $-0.498^{* * *}$ & -0.692 & $-0.581 * * *$ \\
\hline & $(0.283)$ & $(0.288)$ & $(0.316)$ & $(0.148)$ & $(0.658)$ & $(0.196)$ \\
\hline \multirow[t]{2}{*}{$\mathrm{I}_{\mathrm{m}} \ln (\mathrm{R} \& \mathrm{D} /$ labor $)$} & 0.013 & 0.051 & 0.037 & $0.110^{* * *}$ & $0.037^{*}$ & 0.049 \\
\hline & $(0.024)$ & $(0.035)$ & $(0.026)$ & $(0.036)$ & $(0.021)$ & $(0.031)$ \\
\hline \multirow[t]{2}{*}{$\mathrm{I}_{\mathrm{m}} \ln (\mathrm{R} \& \mathrm{D} / \text { labor })^{2} / 2$} & 0.024 & -0.006 & 0.003 & -0.008 & -0.012 & -0.005 \\
\hline & $(0.019)$ & $(0.018)$ & $(0.018)$ & $(0.016)$ & $(0.014)$ & $(0.015)$ \\
\hline \multirow{2}{*}{$I_{b} \ln (T P /$ labor $)$} & 0.005 & -0.080 & 0.069 & 0.004 & 0.057 & $0.100^{* * *}$ \\
\hline & $(0.058)$ & $(0.054)$ & $(0.045)$ & $(0.050)$ & $(0.036)$ & $(0.032)$ \\
\hline \multirow[t]{2}{*}{$\mathrm{I}_{\mathrm{b}} \ln (\mathrm{TP} / \text { labor })^{2} / 2$} & 0.015 & -0.036 & 0.039 & -0.016 & 0.011 & $0.031 * *$ \\
\hline & $(0.063)$ & $(0.035)$ & $(0.045)$ & $(0.029)$ & $(0.021)$ & $(0.014)$ \\
\hline \multirow{2}{*}{$\begin{array}{c}\mathrm{I}_{\mathrm{bm}} \ln (\mathrm{R} \& \mathrm{D} / \text { labor }) \\
* \ln (\mathrm{TP} / \text { labor })\end{array}$} & 0.014 & $0.073^{* *}$ & 0.002 & 0.013 & 0.006 & 0.005 \\
\hline & $(0.037)$ & $(0.029)$ & $(0.028)$ & $(0.021)$ & $(0.012)$ & $(0.009)$ \\
\hline \multirow[t]{2}{*}{ SOE } & -0.080 & -0.137 & $-0.228 * * *$ & -0.072 & $-0.362^{* * *}$ & $-0.336 * * *$ \\
\hline & $(0.058)$ & $(0.107)$ & $(0.069)$ & $(0.106)$ & $(0.049)$ & $(0.075)$ \\
\hline \multirow[t]{2}{*}{ FOREIGN } & $0.221 * * *$ & $0.286^{* * *}$ & $0.221 * * *$ & $0.215^{* * *}$ & $0.132^{* *}$ & $0.171^{* *}$ \\
\hline & $(0.070)$ & $(0.088)$ & $(0.064)$ & $(0.067)$ & $(0.055)$ & $(0.069)$ \\
\hline \multirow[t]{2}{*}{ EXPORT } & 0.019 & 0.007 & $0.111^{*}$ & 0.076 & $0.202^{* * *}$ & $0.150^{* *}$ \\
\hline & $(0.069)$ & $(0.081)$ & $(0.061)$ & $(0.062)$ & $(0.053)$ & $(0.062)$ \\
\hline \multirow[t]{2}{*}{ Constant } & $1.602 * * *$ & $1.576^{* * *}$ & $1.542 * * *$ & 1.152 & $2.278^{* * *}$ & 0.628 \\
\hline & $(0.209)$ & $(0.395)$ & $(0.412)$ & $(0.906)$ & $(0.418)$ & $(0.967)$ \\
\hline R-squared & 0.775 & - & 0.707 & - & 0.744 & - \\
\hline \multirow{3}{*}{$\begin{array}{l}\text { Hansen } \\
\text { overidentification test } \\
\text { Prob > chi2 }\end{array}$} & & chi2(56): & & chi2(56): & & chi2(56): \\
\hline & & 57.46 & & 56.34 & & 66.07 \\
\hline & & 0.384 & & 0.462 & & 0.091 \\
\hline Difference-in-Hansen & & chi2(28): & & chi2(28): & & chi2(28): \\
\hline test & & 32.02 & & 31.80 & & 24.10 \\
\hline Prob $>$ chi 2 & & 0.231 & & 0.283 & & 0.625 \\
\hline Nb observations & 1,304 & 1,304 & 1,026 & 1,026 & 1,002 & 1,002 \\
\hline $\begin{array}{l}\text { *** } \mathrm{p}-\text { value } 0.01, * * \\
\text { computing the margina } \\
\text { appear (i.e. five terms } \mathrm{i} \\
\text { of the elasticities the } \\
\mathrm{Im} \ln (\mathrm{R} \& \mathrm{D} / \mathrm{labor}) 2 / 2 \\
\text { of } \mathrm{Im} \ln (\mathrm{R} \& \mathrm{D} / \mathrm{labor})^{*} \mathrm{I} \\
\text { expectation of new } \\
\ln (\mathrm{material} / \mathrm{labor}) \text {, squa } \\
\text { using the Delta Metho } \\
\text { positive values for } \mathrm{R} \& \mathrm{I}\end{array}$ & $\begin{array}{l}\text { alue } 0.05 \text {, } \\
\text { fects of } \mathrm{Ib} \\
\text { tal). For In } \\
\text { ects of the } \\
\text { Ibln(TP/la } \\
\text { (TP/labor) } \\
\text { duct sales, } \\
\text { erm and the } \\
\text { The margin } \\
\text { d TP. }\end{array}$ & $\begin{array}{l}\text { p-value } 0 . \\
\text { Im we tak } \\
\text { (R\&D/labc } \\
\text { quare term } \\
\text { r) } 2 / 2 \text { repre } \\
\text { presents th } \\
\text { mployee. F } \\
\text { nteraction te } \\
\text { effects are }\end{array}$ & $\begin{array}{l}\text { Industry at } \\
\text { hto account } \\
\text { and Ibln(TI } \\
\text { nd the inte } \\
\text { at second-o } \\
\text { econd-orde } \\
\text { the marg } \\
\text { are also ac } \\
\text { aluated at tl }\end{array}$ & $\begin{array}{l}\text { year dumn } \\
\text { the terms } \\
\text { abor), we in } \\
\text { tion term. } \\
r \text { derivative } \\
\text { ross derivat } \\
1 \text { effects } \\
\text { inted. Stan } \\
\text { means of } t\end{array}$ & $\begin{array}{l}\text { are incluc } \\
\text { ere these tw } \\
\text { ude in the cc } \\
\text { he marginal } \\
\text { and the mar } \\
\text { e of the un } \\
\ln \text { (capital/l } \\
\text { rd Errors are } \\
\text { variables an }\end{array}$ & $\begin{array}{l}\text { d. When } \\
\text { dummies } \\
\text { fputation } \\
\text { ffects of } \\
\text { al effect } \\
\text { nditional } \\
\text { or) and } \\
\text { omputed } \\
\text { only for }\end{array}$ \\
\hline
\end{tabular}




\subsection{Conclusion}

This paper explores the impact of internal and external technology sourcing on firms' innovation and productivity performance in Chinese small- and medium-sized manufacturing firms. In particular, it investigates the returns of $R \& D$ and external technology purchasing (TP) and their possible complementarity or substitutability. It does so by distinguishing two performance measures: innovation in products or processes and labor productivity. Since size may matter in this regard, we estimate separately the relationships for firms with fewer than 100, between 100 and 300, and more than 300 employees.

Do Chinese firms need both $\mathrm{R} \& \mathrm{D}$ and TP in order to grow and catch up with technological frontier? Our evidence suggests (1) that firms with $\mathrm{R} \& \mathrm{D}$ are more innovative; (2) that firms with TP are (with the exception of process innovations in medium-sized firms) more innovative than non-TP firms; (3) that the elasticities or semielasticities of process or product innovation with respect to R\&D and TP are positive whenever they are significant (with the exception of TP on product innovation intensity in small firms); (4) that the output elasticities of $\mathrm{R} \& \mathrm{D}$ and $\mathrm{TP}$ are always positive whenever they are significant and of a reasonable order of magnitude (around 0.10); and (5) that whenever there are significant estimates a complementarity exists between R\&D and TP in promoting innovation or labor productivity.

External technology purchasing complements internal R\&D in fostering innovation and labor productivity. To the extent that firms might not be sufficiently informed of this synergy in technology acquisition, it might be useful for the Chinese government to promote the adoption of both sources of technology acquisition. The somewhat surprising result is that firms that do both do not necessarily have the highest productivity performance. The exact reasons for this phenomenon, which could be duplication in knowledge acquisition, short-term adjustment costs, or other characteristics of those particular firms, would be worth exploring further. 


\section{Appendix 3A Calculating the marginal effects of explanatory variables on the unconditional expectation of new products sales per employee}

The conditional expected value of $y_{2}$ is:

$\mathrm{E}\left(\mathrm{y}_{2} \mid \mathrm{y}_{1}^{*}>0\right)=\beta_{2}^{\prime} \mathrm{X}_{2}+\mathrm{E}\left(\varepsilon_{2} \mid \varepsilon_{1}>-\beta_{1}^{\prime} \mathrm{X}_{1}\right)=\beta_{2}^{\prime} \mathrm{X}_{2}+\varrho \sigma_{2} \frac{\phi\left(\beta_{1}^{\prime} \mathrm{x}_{1}\right)}{\Phi\left(\beta_{1}^{\prime} \mathrm{x}_{1}\right)}$

$\mathrm{E}\left(\mathrm{y}_{2} \mid \mathrm{y}_{1}=1\right)=\beta_{2}^{\prime} \mathrm{X}_{2}+\mathrm{E}\left(\varepsilon_{2} \mid \varepsilon_{1}>-\beta_{1}^{\prime} \mathrm{X}_{1}\right)=\beta_{2}^{\prime} \mathrm{X}_{2}+\varrho \sigma_{2} \frac{\phi\left(\beta_{1}^{\prime} \mathrm{X}_{1}\right)}{\Phi\left(\beta_{1}^{\prime} \mathrm{X}_{1}\right)}$

Using the inverse Mills Ratio $\lambda(\mathrm{a})=\frac{\phi(a)}{1-\Phi(a)}=\frac{\phi(-a)}{\Phi(-a)}=\frac{\phi\left(\beta_{1}^{\prime} X_{1}\right)}{\Phi\left(\beta_{1}^{\prime} X_{1}\right)}$

where $a=\frac{-\beta_{1}^{\prime} X_{1}-E\left(\varepsilon_{1}\right)}{\sigma_{1}}=-\beta_{1}^{\prime} X_{1}$

$\phi$ and $\Phi$ are, respectively, the normal density function and the normal distribution function, $y_{2}$ represents new product sales per employee (innosale $\mathrm{e}_{\mathrm{i}}$ ), $\mathrm{X}_{\mathrm{i}}$ are the regressors of equation $\mathrm{i}$ where $\mathrm{i}=1,2$ (index 1 refers to the selection equation (3.3.3) and index 2 to the intensity equation (3.3.2)), we can rewrite the conditional expected value of $y_{2}$ is:

$\mathrm{E}\left(\mathrm{y}_{2} \mid \mathrm{y}_{1}^{*}>1\right)=\beta_{2}^{\prime} \mathrm{X}_{2}+\mathrm{E}\left(\varepsilon_{2} \mid \varepsilon_{1}>-\beta_{1}^{\prime} \mathrm{X}_{1}\right)=\beta_{2}^{\prime} \mathrm{X}_{2}+\varrho \sigma_{2} \lambda(a)$

The conditional marginal effects:

$$
\begin{aligned}
& \frac{\partial \mathrm{E}\left(\mathrm{y}_{2} \mid \mathrm{y}_{1}^{*}>1\right)}{\partial \mathrm{x}_{\mathrm{i}}}=\beta_{2 \mathrm{i}}+\varrho \sigma_{2} \frac{\partial}{\partial \mathrm{a}}\left[\frac{\phi(a)}{1-\Phi(a)}\right] \frac{\partial(a)}{\partial \mathrm{x}_{\mathrm{i}}}=\beta_{2 \mathrm{i}}-\varrho \sigma_{2} \beta_{1 \mathrm{i}} \frac{\phi^{\prime}(a)[1-\Phi(a)]+[\phi(a)]^{2}}{[1-\Phi(a)]^{2}} \\
& \phi^{\prime}(a)=-(a) * \phi(a) \\
& \lambda(a)^{\prime}=-\beta_{1 j} \lambda(a)[\lambda(a)-a] \\
& \frac{\partial E\left(y_{2} \mid y_{1}^{*}>0\right)}{\partial x_{i}}=\beta_{2 i}-\varrho \sigma_{2}\left(\beta_{1 i}\right)\left\{\frac{[\phi(a)]^{2}}{[1-\Phi(a)]^{2}}-\frac{(a) * \phi(a) *[1-\Phi(a)]}{[1-\Phi(a)]^{2}}\right\} \\
& =\beta_{2 i}-\varrho \sigma_{2}\left(\beta_{1 i}\right) \frac{\phi(-a)}{\Phi(-a)}\left[\frac{\phi(-a)}{\Phi(-a)}-a\right] \\
& =\beta_{2 i}-\varrho \sigma_{2} \beta_{1 i} \lambda(a)[\lambda(a)-a]
\end{aligned}
$$

This is the marginal effect of $x_{i}$ on the conditional expected value of $y_{2}$. Here, we are considering only the effect of $x_{i}$ on the value of $y_{2}$ for those having product innovation. Notice that the conditional marginal effect in (3.a7) depends on the vector $\mathrm{X}_{1}$, since $\mathrm{a}=-\beta_{1}^{\prime} \mathrm{X}_{1}$. In general, the conditional marginal effect of a variable $\mathrm{x}_{\mathrm{i}}$ will be different for each observation (individual). We shall evaluate it at the means of the observations for each variable.

The unconditional expected value of new product sales per employee is given by:

$E\left(y_{2} \mid X\right)=\mathrm{E}\left(\varepsilon_{2} \mid \varepsilon_{1}>-\beta_{1}^{\prime} X_{1}\right) \Phi\left(\beta_{1}^{\prime} X_{1}\right)+\mathrm{E}\left(\varepsilon_{2} \mid \varepsilon_{1}<-\beta_{1}^{\prime} X_{1}\right) \Phi\left(-\beta_{1}^{\prime} X_{1}\right)$

Since $\mathrm{y} 2=0$ if a firm has no product innovation: $\varepsilon_{1}<-\beta_{1}^{\prime} X_{1}$. Then (3.a8) can be 
written as

$E\left(y_{2}\right)=\mathrm{E}\left(\varepsilon_{2} \mid \varepsilon_{1}>-\beta_{1}^{\prime} X_{1}\right) \Phi\left(\beta_{1}^{\prime} X_{1}\right)$

The unconditional effect is:

$$
\begin{aligned}
& \frac{\partial \mathrm{E}\left(\mathrm{y}_{2}\right)}{\partial \mathrm{x}_{\mathrm{i}}}=\Phi\left(\beta_{1}^{\prime} \mathrm{X}_{1}\right) \frac{\partial\left(\mathrm{y}_{2} \mid \mathrm{y}_{1}^{*}>1\right)}{\partial \mathrm{x}_{\mathrm{i}}}+\beta_{1 \mathrm{i}} \mathrm{E}\left(\varepsilon_{2} \mid \varepsilon_{1}>-\beta_{1}^{\prime} \mathrm{X}_{1}\right) \phi\left(\beta_{1}^{\prime} \mathrm{X}_{1}\right) \\
& =\Phi\left(\beta_{1}^{\prime} X_{1}\right)\left\{\beta_{2 i}-\varrho \sigma_{2} \beta_{1 i} \lambda(a)[\lambda(a)-a]\right\}+\beta_{1 i}\left[\beta_{2}^{\prime} X_{2}+\varrho \sigma_{2} \lambda(a)\right] \phi\left(\beta_{1}^{\prime} X_{1}\right)
\end{aligned}
$$

Following (3.a10), the second-order derivative with respect to $x_{j}$ is:

$$
\begin{aligned}
& \frac{\partial^{2} E\left(y_{2}\right)}{\partial x_{i} \partial x_{j}}=\phi\left(\beta_{1}^{\prime} X_{1}\right) * \beta_{1 j} *\left\{\beta_{2 i}-\varrho \sigma_{2} \beta_{1 i} \lambda(a)[\lambda(a)-a]\right\}-\Phi\left(\beta_{1}^{\prime} X_{1}\right) * \varrho \sigma_{2} \beta_{1 i} W \\
& +\beta_{1 i}\left\{\left[\beta_{2}^{\prime} X_{2}+\varrho \sigma_{2} \lambda(a)\right] *\left[-\beta_{1}^{\prime} X_{1} * \phi\left(\beta_{1}^{\prime} X_{1}\right) * \beta_{1 j}\right]+\phi\left(\beta_{1}^{\prime} X_{1}\right) * Q\right\}
\end{aligned}
$$

where

$$
\begin{aligned}
W & =\left[\lambda(a)^{2}-\lambda(a) * a\right]^{\prime}=2 \lambda(a) * \lambda(a)^{\prime}-\left[\lambda(a)^{\prime} * a+a^{\prime} * \lambda(a)\right] \\
& =2 \lambda(a) *\left\{\beta_{1 j} \lambda(a)[a-\lambda(a)]\right\}-\left\{\beta_{1 j} \lambda(a)[a-\lambda(a)] * a-\beta_{1 j} \lambda(a)\right\} \\
& =2 \beta_{1 j} \lambda(a)^{2}[a-\lambda(a)]-\beta_{1 j} \lambda(a)\{[a-\lambda(a)] * a-1\} \\
Q & =\left[\beta_{2}^{\prime} X_{2}+\varrho \sigma_{2} \lambda(a)\right]^{\prime}=\beta_{2 j}+\varrho \sigma_{2} \beta_{1 j} \lambda(a)[a-\lambda(a)] .
\end{aligned}
$$




\section{Chapter 4}

\section{Complementarity between internal knowledge creation and external knowledge sourcing in developing countries $^{36}$}

\subsection{Introduction}

Much of the economic and social progress of the past few centuries has benefited from technological progress. Innovation has been considerably discussed in the endogenous growth theory (Aghion and Howitt, 1998; Grossman and Helpman, 1991), where it is modelled as being driven by an R\&D sector. Although the number of studies examining the influence of innovation on productivity is increasing, most of the empirical studies on innovation and productivity have been conducted on developed country data (see Mairesse et al., 2011 for a review). In developing countries, innovation is more a process of learning and assimilation of knowledge in an effort to catch-up with the technological frontier than a process of creation and discovery (Fransman and King, 1984).

The current study will focus on knowledge sourcing strategies in developing countries. Two types of technology sourcing are distinguished. Firms can obtain new technologies by conducting their own R\&D (MAKE) or they can acquire new technologies through licensing, hiring new personnel, or investing in new machinery (BUY). We shall address two questions: What are the comparative returns of the two sources of knowledge? And are the two substitutes or complements, i.e. is there a choice between one or the other, or should they be conducted jointly?

36 This chapter leads to a joint working paper with Prof. P. Mohnen. UNU-MERIT WP 2013-10 
The analysis is based on firm level data from 24 low- and middle-income countries ${ }^{37}$. We test the existence of complementarity between MAKE and BUY by estimating demand equations for the two knowledge sourcing strategies, which are derived from a production function that allows for a synergy between them. This way of testing complementarity, which is borrowed from Miravete and Pernías (2006), allows the separate identification of a synergy between the two strategies and the unexplained correlation between the error terms in the respective demand equations. The result suggests that firms in low-income countries rely more on external sourcing and firms in middle-income countries more on in-house $\mathrm{R} \& \mathrm{D}$, while a synergy between internal and external knowledge sourcing exists in middle-income countries but not in low-income countries.

This paper proceeds as follows. The next section sets the background by reviewing the feature of innovation strategies in developing countries and existing evidence on complementarity in innovation studies. Section 4.3 presents the empirical model and methods to estimate complementarity. The data and the variables used will be presented in section 4.4. The results are interpreted in section 4.5. The last section summarises and concludes.

\subsection{MAKE and BUY in developing countries: complements or substitutes?}

\subsubsection{Something more than $R \& D$ ?}

Cooper (1989) explained the differences in characteristics between innovation in industrialized economies and developing countries. As he pointed out it is a rather limited view of innovation theories to be only concerned with the initial introduction of products or processes. Most firms in developing countries attempt to reach the technological frontier instead of achieving inventions that are new to the market.

At a low stage of development, firms normally face obstacles such as inadequate human capital and poor infrastructure. In-house innovative activities are severely constrained for a majority of firms. Freeman (1989) suggested that external knowledge sourcing has a significant influence on the learning process. He argued that for the most part even the most technologically advanced firms in developing countries are committed to be

\footnotetext{
${ }^{37}$ The classification into middle-income and low-income countries is taken from "World Bank country classification 2005". See: http://www.worldbank.org
} 
involved in external sourcing activities. Aggarwal (2000) explained that external technology plays two important roles in developing economies: filling gaps in domestic technological capability and upgrading the existing technologies to international standards. By enhancing the technological capability, external technology sourcing benefits in-house R\&D.

However, acquiring external knowledge per se does not guarantee that a firm will achieve successful learning (Matusik, 2000). For external knowledge to be exploited effectively, it has to be combined with a complementary knowledge base within the firm. Cooper (1989) mentioned that failure to learn is in fact quite common in developing countries because the firms there that receive technology via external sources are quite often unconcerned about how to develop and appropriate this internal technological capability. Cohen and Levinthal (1989) define "absorptive capacity" to describe the substantial role of a stock of prior knowledge in order to absorb external know-how. They argue that the in-house $R \& D$ process would at the same time accommodate firms to build up their own technological capability. This technological capability within firms is needed in order to understand the tacit components of the technology (Desai, 1989; Lall, 1989; Mowey and Oxley, 1995).

The paradigm of open innovation demonstrates that firms should make the best use of internal and external knowledge (Chesbrough, 2003). This perspective not only emphasizes the significant value of external knowledge; it also indicates that firms organize their internal $\mathrm{R} \& \mathrm{D}$ in part in order to absorb the wealth of available external knowledge. Such a mutual interaction implies the possible complementary between own and external sources of knowledge.

\subsubsection{Definition of complementarity}

A pair of economic activities is complementary if (1) adopting one activity does not preclude adopting the other and if (2), whenever it is possible to implement each activity separately, the sum of the benefits of doing each separately is not greater than the benefit of doing both together (Milgrom and Robert; 1990a). The theorem states that if each pair of activities in a group is complementary, then implementing any subset of the activities in the group raises the incremental return to implementing the remaining ones (Topkis 1978). This notion of complementarity between activities was first introduced in 
economics by Vives (1990) and then further developed by Milgrom and Roberts (1990b, 1995).

More formally, suppose there are two discrete technology acquisition practices, MAKE and BUY. $\mathrm{Z}$ is a vector of exogenous variables. The objective function $\mathrm{f}(\mathrm{MAKE}, \mathrm{BUY}$, $\mathrm{Z}$ ) is supermodular if the following inequality holds for all values of the other arguments of $f$ :

$\mathrm{f}(1,1 ; Z)-\mathrm{f}(1,0 ; Z)>\mathrm{f}(0,1 ; Z)-\mathrm{f}(0,0 ; Z)$

MAKE and BUY are complementary if the presence of one strategy (e.g. MAKE) increases the marginal return of adopting the other strategy (BUY), after controlling for other exogenous effects ${ }^{38}$ (Milgrom and Robert, 1990b). Conversely, MAKE and BUY are substitutes if the inverse inequality holds for (4.1).

\subsubsection{Evidence of complementarity in innovation studies}

The notion of complementarity is commonly refer to cross-price effects in demand theory. During the past decades, many studies have broadened this concept to analyse more complex economic phenomena, organizational structures and government policies. Here, we briefly review some key studies in both economic and management literature that have estimated the complementarity versus substitutability in ways of technology sourcing.

In emerging economies, complementarity in innovation mainly focuses on investigating the inter-dependent relation between in-house $\mathrm{R} \& \mathrm{D}$ and imported technology. Braga and Willmore (1991) found that there is a robust complementary relationship between technology buying and firm technology effort in Brazilian industry. Deolalikar and Evenson (1989) showed that technology transferred from abroad and in-house R\&D are complementary rather than substitutive avenues of technology acquisition. Kim and Nelson (2000) also argued that the process of learning through the external technology sourcing serves as an effective experience that paves the way for indigenous technological innovation in Indian firms.

\footnotetext{
38 If MAKE and BUY are continuous variables, an equivalent inequality restriction would imply that the incremental effect of one practice on the objective function increases with an increase in the other practice:

$\frac{\partial^{2} f\left(r_{b}, r_{m}, Z\right)}{\partial r_{b} \partial r_{m}}>0$; where $r_{b}$ is BUY and $r_{m}$ is MAKE.
} 
Besides, complementarity in innovation has also been shared by lots of studies across developed economies. Arora and Gambardella (1990) test the synergetic effects among four different external sourcing strategies of large American chemical and pharmaceutical firms. The results show that there is complementarity between all types of external sourcing strategies. Veugelers (1997) finds that the external sourcing strategy stimulates internal research activities in Belgian manufacturing firms. It seems that external knowledge sources leverage the innovative power of in-house $\mathrm{R} \& \mathrm{D}$. This result is also found in a study undertaken by Lokshin, Belderbos and Carree (2008). In a recent study Cassiman and Veugelers (2006) found a strong synergy relationship between firms' internal R\&D and disembodied knowledge sourcing strategies in Belgian manufacturing firms.

On the other hand, some studies have found evidence on substitutability between innovation activities. Mytelka (1987) found that external imports of technology discourage Andean group countries to undertake in-house innovation activities. Fikkert (1993) used the Indian manufacturing firm data to regress the technology imports on inhouse R\&D efforts. Their findings support the hypothesis of negative relationship between technology imports and R\&D efforts. Basant and Fikkert (1996) estimated the return of $R \& D$, technology imports and their interaction term in the production function by using Indian firm level panel data. They found that the estimated rate of return of technology imports is much higher than the return to in-house R\&D. The results also imply a substitutive relation between $R \& D$ efforts and external technology in the production of knowledge. Katrak (1997) also found that the probability of importing technology was only weakly influenced by R\&D efforts and the external sourcing had a significant negative effect on the R\&D labor intensity in Indian electrical and electronics industries.

Despite the rich literature on technology making and buying in developing countries, the results are far from conclusive. What distinguishes this study from the previous studies is, first of all, the use of a recent methodology for testing complementarity that controls for the correlation between unobservables in the strategy equations, and, secondly, the use of a unique dataset of 24 developing countries that allows to investigate differences in complementarity at different levels of development. 


\subsection{Testing for complementarity}

In this section we explain the way complementarity in technology acquisition strategies can be identified and tested.

In empirical studies, the most popular approach applied to investigate complementarity between economic activities consists in directly estimating the cross partial derivatives in the production function. This approach is defined as the Production approach (PROD). It aims at testing the complementarily for a specific objective function. It has been applied in several empirical studies (Cassiman and Veugelers, 2006; Mohnen and Röller, 2005; Belderbos et al., 2006).

Suppose that firm i uses two knowledge acquisition strategies, $\mathrm{y}_{\mathrm{mi}}$ referring to MAKE or internal knowledge acquisition, and $\mathrm{y}_{\mathrm{bi}}$, referring to BUY or external knowledge acquisition. The technology is represented by a standard Cobb-Douglas production function $\mathrm{Q}_{\mathrm{i}}=\mathrm{f}\left(\mathrm{K}_{\mathrm{i}}, \mathrm{L}_{\mathrm{i}}, \mathrm{y}_{\mathrm{mi}}, \mathrm{y}_{\mathrm{bi}}, \mathrm{Z}_{\mathrm{i}}\right)$, where $\mathrm{K}$ and $\mathrm{L}$ represent respectively capital and labor, and $\mathrm{Z}$ stands for a group of control variables that capture the firm- and organization-specific characteristics. In logarithmic terms, denoting logarithmically transformed continuous variables by small letters, we have

$q=\alpha k_{i}+\beta l_{i}+\theta_{00}\left(1-y_{b i}\right)\left(1-y_{m i}\right)+\theta_{10} y_{b i}\left(1-y_{m i}\right)+\theta_{01}\left(1-y_{b i}\right) y_{m i}+\theta_{11} y_{b i} y_{m i}+\chi Z_{i}+e_{i}$

where $\alpha$ and $\beta$ are the output elasticities of capital and labor, $\mathrm{y}_{\mathrm{ji}}(\mathrm{j}=\mathrm{b}, \mathrm{m})$ are binary choice variables taking the value 1 if the corresponding strategies are adopted by firm $i$, $\theta_{11}, \theta_{01}, \theta_{10}$, and $\theta_{00}$ captures the productivity obtained when respectively MAKE and BUY, only BUY, only MAKE and neither MAKE nor BUY are chosen, and $\mathrm{e}_{\mathrm{it}}$ is a random error term.

The PROD approach estimates the existence of complementarity directly by regressing the objective function on exclusive combinations of innovation activities. The production function is supermodular in $\mathrm{y}_{\mathrm{bi}}$ and $\mathrm{y}_{\mathrm{mi}}$ if

$\theta_{11}-\theta_{01}-\theta_{10}+\theta_{00}>0$

The inequality expresses the fact that the presence of one innovation activity increases the marginal return of adopting another activity. Conversely, the two activities are substitutive if 
$\theta_{11}-\theta_{01}-\theta_{10}+\theta_{00}<0$

An alternative form can be written in the follow way:

$q=\alpha k_{i}+\beta l_{i}+\theta_{0}+\theta_{b} y_{b i}+\theta_{m} y_{m i}+\theta_{b m} y_{b i} y_{m i}+\chi Z_{i}+e_{i}$

where

$\theta_{0}=\theta_{00}$

$\theta_{b}=\theta_{10}-\theta_{00}$

$\theta_{m}=\theta_{01}-\theta_{00}$

$\theta_{b m}=\theta_{11}+\theta_{00}-\theta_{10}-\theta_{01}$.

Coefficient $\theta_{\mathrm{m}}$ captures the non-exclusive partial effects of MAKE, $\theta_{\mathrm{b}}$ the non-exclusive partial effect of BUY, $\theta_{\mathrm{bm}}$ the returns of adopting MAKE and BUY together; $\theta_{0}$ is constant. The condition for supermodularity now simplifies to:

$\theta_{b m}=\theta_{11}+\theta_{00}-\theta_{10}-\theta_{01}>0$

It is worth noting under (4.5) the marginal returns to either MAKE or BUY will not be constant anymore if complementarity or substitutability is observed $\left(\theta_{\mathrm{bm}} \neq 0\right)$. Henceforth, the marginal returns of MAKE and BUY should be expressed respectively as

$\left[f \mid y_{m}=1\right]-\left[f \mid y_{m}=0\right]=\theta_{m}+\theta_{b m} y_{b}$

$\left[f \mid y_{b}=1\right]-\left[f \mid y_{b}=0\right]=\theta_{b}+\theta_{b m} y_{m}$

Athey and Stern (1998) explain that simply running OLS on the above function would deliver inconsistent results. They argue that the existence of firms' unobserved heterogeneity correlated with the strategy decisions may make the PROD approach fail to generate consistent estimators.

In order to correct for this bias, one should either use instrument variables with cross sectional data or control for the unobserved heterogeneity if panel data are available (Wooldridge, 2002). Cassiman and Veugelers (2006) have tried to adopt instrumental variables that were correlated with the adoption decisions without affecting innovation output. However, the results can be refined only if the instrumental variables are properly identified. In the current case, neither the input price (especially for BUY) that 
each firm faces in adopting innovation practices nor factors that affect the return to those practices are observed by the econometrician.

In the following part, we introduce another approach of testing for complementarity, which was originally developed by Miravete and Pernías (2006 and 2010) and later extended in Kretschmer, Miravete and Pernías (2012). This approach tests for "behavioral complementarity" and can be classified somewhere between the PROD approach introduced above and what is known in the literature as the CORR approach. The latter tests whether there remains a correlation between the error terms of the reduced forms of two strategy equations, which are derived without necessarily specifying any objective function. In contrast, in the Miravete and Pernías (MP) approach we specify an objective function, although in the end the estimation is based on the parameterization of the individual returns of each strategy ${ }^{39}$. Compared with the PROD approach we model explicitly the endogeneity of the strategy choices ${ }^{40}$. Table below compares three approaches. Apart from not specifying an objective function, the CORR approach imposes two assumptions: firms are assumed to make rational choices and there are no correlations between the unobserved factors that affect the activities concerned. The MP approach differs from the CORR approach by releasing the second assumption.

Different approaches to test complementarity in cross sectional analysis

\begin{tabular}{l|lll}
\hline Approach & Category & $\begin{array}{l}\text { Objective } \\
\text { function }\end{array}$ & Assumptions \\
\hline PROD & Objective & Yes & $\begin{array}{l}\text { No unobservables } \\
\text { CORR }\end{array}$ \\
Behavior & No & $\begin{array}{l}\text { Optimal choices \& No } \\
\text { unobservables }\end{array}$ \\
$\begin{array}{l}\text { MP (Miravete and } \\
\text { Pernías) }\end{array}$ & Objective/Behavior & Yes & Optimal choices \\
\hline
\end{tabular}

Here, we start from the production function (4.8) by introducing both observed and unobserved factors, $W_{j i}$ and $\varepsilon_{j i}$ respectively, which are both interacted with input

\footnotetext{
${ }^{39}$ In Kretschmer, Miravete and Pernías (2012) the objective function is estimated together with the strategy choice equations.

40 The simple version is using the Pearson correlation or conditional correlation between the residuals to test for the association between two or more activities. A number of empirical studies use this approach as auxiliary evidence. For example: Arora and Gambardella (1990) introduce a formal analysis of CORR as a test for complementarity. Brickley (1995) explicitly uses CORR as a test for the comparative static predictions of Holmström and Milgrom (1994) in the context of franchising contract provisions. A critical assumption underlying this approach is the absence of covariance between the residuals of the strategy equations conditional on the characteristics of the firm.
} 
strategies MAKE and BUY in determining the productivity performance. The $W_{j i}$ $(j=b, m)$ are observed factors, which capture things like the firms' past innovation experience and its absorptive capacity that can influence the return from the corresponding innovation strategy. Control variables are defined differently in determining the return of MAKE and BUY in order to avoid the identification problem. The $\varepsilon_{j i}$ 's $(j=b, m)$ capture unobserved factors that can influence the choice of MAKE and/or BUY, such as the appropriation regime or management practices, and factors that cannot be quantitatively or qualitatively identified. The production function is now given as

$q_{i}=\alpha k_{i}+\beta l_{i}+\left(\theta_{b} W_{b i}+\delta_{b m} y_{m i}+\varepsilon_{b i}\right) y_{b i}+\left(\theta_{m} W_{m i}+\delta_{b m} y_{b i}+\varepsilon_{m i}\right) y_{m i}+\chi Z_{i}+e_{i}$

Let

$\lambda_{b i}=\theta_{b} W_{b i} ; \lambda_{m i}=\theta_{m} W_{m i}$

On the right-hand side of equation (4.8), $\left(\lambda_{b i}+\delta_{b m} y_{m i}+\varepsilon_{b i}\right)$ and $\left(\lambda_{m i}+\delta_{b m} y_{b i}+\varepsilon_{m i}\right)$ measure respectively the percentage differences in productivity level when choosing 1 instead of 0 for each of the two strategies, holding the other one fixed. Specification (4.8) is borrowed from Lewbel (2007). He shows that a specification like (4.8) eliminates the incoherency and incompleteness problems in simultaneous equations with binary variables, by specifying as an objective function that incorporates the individual returns derived from each individual strategy. Equation (4.8) differs from the PROD approach in that it captures not only the possible interaction between the input strategy variables and the technological capability $\lambda_{j i}$, but also the potential endogeneity of the strategy choices by including $\varepsilon_{j i}$, which is possibly correlated with $y_{j i}$. The existence of complementarity can only be concluded when controlling for both observed and unobserved characteristics.

We shall estimate equation (4.8) by maximum likelihood. Before we derive the likelihood function, two important assumptions need to be made. Because of the absence of information regarding the cost associated to the two innovation strategies, we are not able to derive a cost function, hence we assume that firms behave optimally by maximizing their productivity. Second, in order to avoid an identification problem, we 
assume that the unobserved error terms $\left(\varepsilon_{\mathrm{bi}}, \varepsilon_{\mathrm{mi}}\right)$ follow a standard bivariate normal distribution with a correlation coefficient $\rho_{b m}$.

The firm has to decide on whether to adopt or not each of the two innovation strategies (MAKE and/or BUY). Therefore, four choice combinations are possible: $\mathrm{D}(1,1), \mathrm{D}(1,0)$, $\mathrm{D}(0,1), \mathrm{D}(0,0)$. The firm will choose the combination that yields the highest productivity. For each of the four possible choices we will get a corresponding set of inequality restrictions as follows ${ }^{41}$ :

$$
\begin{gathered}
D_{(1,1)} \Rightarrow\left\{\begin{array}{l}
f(1,1)>f(0,1) \\
f(1,1)>f(1,0) \\
f(1,1)>f(0,0)
\end{array}\right\}=\left\{\begin{array}{c}
\varepsilon_{b i}>-\lambda_{b i}-2 \delta_{b m} \\
\varepsilon_{m i}>-\lambda_{m i}-2 \delta_{b m} \\
\varepsilon_{m i}>-\lambda_{b i}-\lambda_{m i}-2 \delta_{b m}-\varepsilon_{b i} *
\end{array}\right\} \\
D_{(1,0)} \Rightarrow\left\{\begin{array}{l}
f(1,0)>f(1,1) \\
f(1,0)>f(0,1) \\
f(1,0)>f(0,0)
\end{array}\right\}=\left\{\begin{array}{c}
\varepsilon_{m i}<-\lambda_{m i}-2 \delta_{b m} \\
\varepsilon_{m i}<\lambda_{b i}-\lambda_{m i}+\varepsilon_{b i} * \\
\varepsilon_{b i}>-\lambda_{b i}
\end{array}\right\} \\
D_{(0,1)} \Rightarrow\left\{\begin{array}{l}
f(0,1)>f(1,1) \\
f(0,1)>f(1,0) \\
f(0,1)>f(0,0)
\end{array}\right\}=\left\{\begin{array}{c}
\varepsilon_{b i}<-\lambda_{b i}-2 \delta_{b m} \\
\varepsilon_{m i}>\lambda_{b i}-\lambda_{m i}+\varepsilon_{b i} * \\
\varepsilon_{m i}>-\lambda_{m i}
\end{array}\right\} \\
D_{(0,0)} \Rightarrow\left\{\begin{array}{c}
f(0,0)>f(1,1) \\
f(0,0)>f(1,0) \\
f(0,0)>f(0,1)
\end{array}\right\}=\left\{\begin{array}{c}
\varepsilon_{m i}<-\lambda_{b i}-\lambda_{m i}-2 \delta_{b m}-\varepsilon_{b i} * \\
\varepsilon_{b i}<-\lambda_{b i} \\
\varepsilon_{m i}<-\lambda_{m i}
\end{array}\right\}
\end{gathered}
$$

If $\mathrm{D}(1,1)$ is the optimal choice, the first set of inequality restrictions in (4.10) automatically satisfy the supermodular condition (4.1). This can be proved by:

First, adding the first two inequality for $\mathrm{D}(1,1)$ in $(4.10)$, we will have

$$
\varepsilon_{b i}+\varepsilon_{m i}+\lambda_{b i}+\lambda_{m i}+4 \delta_{b m}>0
$$

then rearranging the third inequality of $\mathrm{D}(1,1)$ and putting the left sequence to the right,

$$
\varepsilon_{b i}+\varepsilon_{m i}+\lambda_{b i}+\lambda_{m i}+2 \delta_{b m}>0
$$

\footnotetext{
${ }^{41} \mathrm{f}\left(\mathrm{ybi}, \mathrm{y}_{\mathrm{mi}}\right)$ is derived from equation (8). Here, the form of $\mathrm{D}(1,1)$ is the sum of returns in choosing both MAKE and BUY: $\left(\lambda_{b i}+\delta_{b m} y_{m i}+\varepsilon_{b i}\right)+\left(\lambda_{m i}+\delta_{b m} y_{b i}+\varepsilon_{m i}\right)$. This specific form for $\mathrm{D}(1,1)$ enables us to avoid the incoherency and incompleteness problems (Lewbel, 2007).
} 
finally, subtracting (4.12) from (4.11), we obtain the supermodularity condition

$$
\begin{aligned}
& D(1,1)-D(1,0)>D(0,1)-D(0,0) \\
& \Rightarrow\left(\lambda_{b i}+\delta_{b m}+\varepsilon_{b i}\right)+\left(\lambda_{m i}+\delta_{b m}+\varepsilon_{m i}\right)-\left(\lambda_{b i}+\varepsilon_{b i}\right)>\left(\lambda_{m i}+\varepsilon_{m i}\right)-0 \Rightarrow 2 \delta_{b m}>0 .
\end{aligned}
$$

In the structural from, firms need to reach decisions by considering both the expected returns of doing MAKE/BUY and their possible synergy. If there is a synergistic effect, firms will engage in both activities together and we expect to see the existence of complementarity, which will be exhibited as $2 \delta_{\mathrm{bm}}>0$. What is important to notice is that the estimation will control for the presence of the correlation between error terms, $\rho_{b m}$, which may cause the two strategies to be adopted jointly but for other reasons than complementarity between them.

In order to write the likelihood function, there are three situations that should be considered separately. First, if $\delta_{\mathrm{bm}}=0$, which implies that there is no complementarity MAKE and BUY, (4.10) will be transformed into a likelihood function that corresponds to the standard bivariate probit model. There is no interaction between the returns of individual strategies, and hence each strategy is separately chosen depending on whether its return is above a certain threshold. Second, if $\delta_{\mathrm{bm}}>0$, the inequalities for $\mathrm{D}(1,1)$ and $\mathrm{D}(0,0)$ in (4.10) that are marked with an asterisk are binding. Last, if $\delta_{\mathrm{bm}}<0$, it is the inequalities marked with an asterisk for $\mathrm{D}(1,0)$ and $\mathrm{D}(1,0)$ in (4.10) that are binding. Figure 4.1 adapted from Miravete and Pernias (2006), which represents the regions of strategy choices in the space of $\left(\varepsilon_{\mathrm{b}}, \varepsilon_{\mathrm{m}}\right)$ gives us a clear picture of the difference between the regions of strategy choices in the bivariate probit model and in the presence of complementarity (or substitutability). If $\delta_{\mathrm{bm}}=0$, the regions corresponding to the strategy profiles are in a rectangular fashion orthogonal to each other. If $\delta_{\mathrm{bm}}>0$, the regions contours will no longer be rectangular as in the bivariate probit model. Even for some values below the individual thresholds pertinent to the adoption of individual strategies, the two strategies (MAKE and BUY) can be adopted jointly because of their complementarity. Conversely, if $\delta_{\mathrm{bm}}<0$, the space for individual (non-joint) strategy adoption is much larger than when $\delta_{\mathrm{bm}}>0$ because strategies are substitutes for each other. 
Figure 4.1 Regions corresponding to strategy choices in the $\left(\varepsilon_{\mathrm{b}}, \varepsilon_{\mathrm{m}}\right)$ space
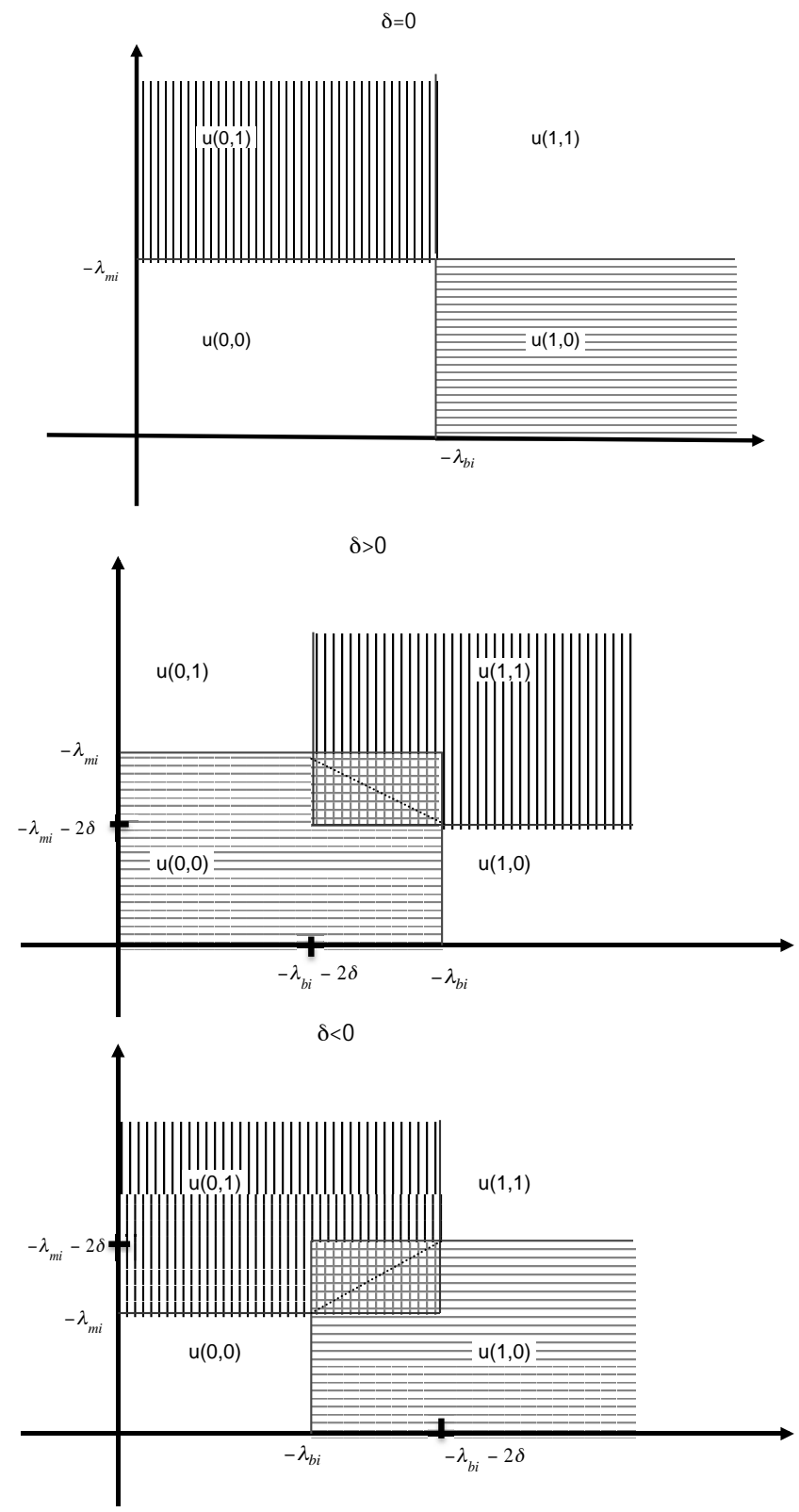
The likelihood function will reproduce the probability of observing pairs of strategies that are determined by the inequality constraints in (4.10).

$L_{i}\left(\alpha, \beta, \chi, \theta_{b}, \theta_{m}, \delta_{b m}, \rho_{b m} ; y_{b i}, y_{m i}, Z_{i}\right)$

$=\sum_{i=1}^{n}\left\{y_{b i} y_{m i} \ln P_{(1,1)}+y_{b i}\left(1-y_{m i}\right) \ln P_{(1,0)}+\left(1-y_{b i}\right) y_{m i} \ln P_{(0,1)}+\left(1-y_{b i}\right)\left(1-y_{m i}\right) \ln P_{(0,0)}\right\}$

where

$$
\begin{aligned}
& P_{(1,1)}=\int_{-\lambda_{b i}-2 \delta_{b m}}^{\infty} \int_{\max \left[\left(-\lambda_{m i}-2 \delta_{b m}\right),\left(-\lambda_{b i}-\lambda_{m i}-2 \delta_{b m}-\varepsilon_{b i}\right)\right]}^{\infty} \phi_{2 m}\left(\varepsilon_{b i}, \varepsilon_{m i}, \rho_{b m}\right) d \varepsilon_{b i} d \varepsilon_{m i} \\
& P_{(1,0)}=\int_{-\lambda_{b i}}^{\infty} \int_{-\infty}^{\min \left[\left(-\lambda_{m i}-2 \delta_{b m}\right),\left(\lambda_{b i}-\lambda_{m i}+\varepsilon_{b i}\right)\right]} \phi_{2}\left(\varepsilon_{b i}, \varepsilon_{m i}, \rho_{b m}\right) d \varepsilon_{b i} d \varepsilon_{m i} \\
& P_{(0,1)}\left.=\int_{-\infty}^{-\lambda_{b i}-2 \delta_{b m}} \int_{-\infty}^{\infty} \int_{\max \left[\left(-\lambda_{m i}\right),\left(\lambda_{b i}-\lambda_{m i}\right.\right.}^{\infty} \phi_{2}\left(\varepsilon_{b i}\right)\right] \\
& P_{(0,0)}\left.=\int_{-\infty}^{-\lambda_{b i} \min \left[\left(-\lambda_{b i}\right),\left(-\lambda_{b i}-\lambda_{m i}+2 \delta_{b m}-\varepsilon_{b i}\right)\right]}, \rho_{b m}\right) d \varepsilon_{b i} d \varepsilon_{m i} \\
& \int_{-\infty}^{\infty} \phi_{2}\left(\varepsilon_{b i}, \varepsilon_{m i}, \rho_{b m}\right) d \varepsilon_{b i} d \varepsilon_{m i}
\end{aligned}
$$

where $\mathrm{P}_{(1,1)}$, for instance, denotes the probability of observing the strategy pair $(1,1)$. The same goes for the other pairs. In addition to the parameters in the production function (4.8), the correlation coefficient $\rho_{\mathrm{bm}}$ will also be estimated. The estimation of a truncated bivariate probit with upper and lower bounds is achieved by adopting the maximum simulated likelihood estimator using the GHK simulator (Hajivassiliou and Ruud, 1994; Greene, 2003) ${ }^{42}$.

\subsection{Data and variables}

\subsubsection{Data}

The data that we use in our empirical analysis come from the World Bank Investment Climate Surveys (ICS) ${ }^{43}$. These surveys have been conducted mostly in developing countries and provide us a wide range of information about innovative performance, economic activities and the investment environment of firms. Several aspects referring to

\footnotetext{
42 The estimation of likelihood function (4.14) is conducted by using statistical program STATA 10.2. The corresponding programming code is available upon request.

${ }^{43}$ For more information and the methodology of the survey, please see http://www.worldbank.org
} 
firms' innovation behavior are covered in the survey, in particular firms' R\&D input, licensing and other external sourcing channels.

After removing missing values and cleaning for outliers, we are left with 9,086 firms across 24 countries in the manufacturing sector in the pooled cross-sectional dataset from the period 2002-2005 ${ }^{44}$. Due to differences in the size of the economies and the survey methods adopted across countries and regions, the number of firms in the samples varies considerably across countries. Only countries with more than 50 observations are included ${ }^{45}$. Table 4.1 presents descriptive statistics about the countries and their innovativeness. Innovativeness here means having introduced a product or a process innovation.

As shown in Table 4.1, innovation is rather pervasive across countries with approximately 58 per cent of them claiming to have been innovative during the period under review. It should be noted again that these numbers do not represent inventions nor introductions of products or processes new to the market. They are more likely to be innovations new to the firm, sometimes considered as imitative innovations. Among all countries in our sample, Brazil is the most innovative country with 86 per cent of firms having had product or process innovations in the period under survey. In second place comes South Africa with 82 per cent. Ethiopia and Pakistan have no information with respect to innovation output ${ }^{46}$.

The survey contains two main questions regarding firms' knowledge acquisition strategies. First, firms were asked to choose the three most important methods of knowledge sourcing out of a total of twelve options. The dummy variable BUY gets value 1 if firms chose at least one of the following three technological sources: importing machinery and equipment, hiring key personnel or licensing from abroad or domestically. Second, the survey has questions related to firms' R\&D spending in the last year of the

\footnotetext{
$44 \mathrm{We}$ did not use the standardized dataset provided by the World Bank due to inconsistencies in the questionnaires and measurements (e.g. currencies). Instead, we cleaned the data country by country because the standardized dataset does not always cover all the information provided by firms. Additionally, the currency unit in the standardized data also caused some confusion, which needed to be traced back to each country's questionnaire. Furthermore, the service sector is not included because the innovation inputs (R\&D and external sourcing) are not reported. Furthermore, following Hall and Mairesse (1995), we only keep observations for which the capital-labor ratio was within three times the inter-quartile range (the difference between the $75 \%$ value and the $25 \%$ value) above or below the median, which is about 6 percentage of total sample.

${ }^{45} \mathrm{~A}$ sample with fewer than 50 observations is unlikely to give us consistent estimates of the country specific effect. We also dropped firms with fewer than 5 permanent employees and growth of sales per person above 300 per cent. In total we eliminated in this way about $3 \%$ of all the observations.

${ }^{46}$ This is not problematic to our further analysis since our main concern is the productivity performance.
} 
survey period. R\&D expenditures cover all outlays (labor costs, materials, expenditures on tangible fixed assets) incurred for research activities that comprise "creative work undertaken on a systematic basis in order to increase the stock of knowledge, including knowledge of man, culture and society, and the use of this stock of knowledge to devise new applications" (OECD, 2011). The dichotomous variable MAKE takes value 1 if firms claim to have positive R\&D spending during the period of the survey, 0 otherwise.

Table 4. 1 Innovativeness of firms in developing countries

\begin{tabular}{|c|c|c|c|c|c|c|c|}
\hline Country & Year & $\begin{array}{c}\text { Observ } \\
\text { ation } \\
\text { (firms) }\end{array}$ & Income $^{47}$ & $\begin{array}{c}\text { Percentage } \\
\text { of } \\
\text { innovators }\end{array}$ & $\begin{array}{c}\text { Output per } \\
\text { worker (log, } \\
1000 \\
\text { USD/perso } \\
\text { n) } \\
\end{array}$ & $\begin{array}{c}\text { Capital per } \\
\text { worker (log, } \\
1000 \\
\text { USD/perso } \\
\text { n) } \\
\end{array}$ & $\begin{array}{c}\text { Labor (log, } \\
\text { person) }\end{array}$ \\
\hline Brazil & 2003 & 1463 & Lower-Middle income & $85.99 \%$ & 2.58 & 2.03 & 4.00 \\
\hline Chile & 2004 & 306 & Higher-Middle income & $51.31 \%$ & 3.70 & 3.69 & 3.90 \\
\hline Costa Rica & 2005 & 88 & Higher-Middle income & $78.41 \%$ & 3.01 & 2.74 & 3.47 \\
\hline Ecuador & 2003 & 273 & Lower-Middle income & $75.46 \%$ & 2.92 & 2.71 & 3.67 \\
\hline Egypt & 2004 & 582 & Lower-Middle income & $11.51 \%$ & 1.47 & 1.46 & 3.37 \\
\hline E1 Salvador & 2003 & 280 & Lower-Middle income & $80.71 \%$ & 2.69 & 2.60 & 3.79 \\
\hline Ethiopia & 2002 & 243 & Low income & missing & 1.51 & 2.16 & 3.64 \\
\hline Guatemala & 2003 & 371 & Lower-Middle income & $72.78 \%$ & 2.41 & 2.19 & 3.58 \\
\hline Guyana & 2004 & 97 & Lower-Middle income & $54.64 \%$ & 2.52 & 2.73 & 3.09 \\
\hline Honduras & 2003 & 323 & Lower-Middle income & $66.25 \%$ & 2.19 & 1.98 & 3.28 \\
\hline Indonesia & 2003 & 466 & Lower-Middle income & $46.35 \%$ & 1.86 & 1.76 & 5.23 \\
\hline Lithuania & 2004 & 74 & Higher-Middle income & $39.19 \%$ & 2.18 & 0.94 & 3.79 \\
\hline Madagascar & 2005 & 79 & Low income & $60.76 \%$ & 1.50 & 1.65 & 4.11 \\
\hline Malawi & 2005 & 84 & Low income & $64.29 \%$ & 2.34 & 2.03 & 4.15 \\
\hline Mauritius & 2005 & 98 & Higher-Middle income & $72.45 \%$ & 2.70 & 2.40 & 4.12 \\
\hline Nicaragua & 2003 & 308 & Low income & $75.00 \%$ & 1.77 & 1.73 & 2.95 \\
\hline Pakistan & 2002 & 845 & Low income & missing & 2.31 & 2.29 & 3.30 \\
\hline Philippines & 2003 & 582 & Lower-Middle income & $59.79 \%$ & 1.97 & 1.57 & 4.16 \\
\hline South Africa & 2003 & 513 & Lower-Middle income & $82.85 \%$ & 3.47 & 2.85 & 4.69 \\
\hline Syria & 2003 & 75 & Lower-Middle income & $36.00 \%$ & 1.83 & 2.70 & 2.23 \\
\hline Tanzania & 2003 & 73 & Low income & $49.32 \%$ & 2.09 & 2.21 & 3.51 \\
\hline Thailand & 2004 & 1336 & Lower-Middle income & $64.97 \%$ & 2.85 & 2.49 & 4.96 \\
\hline Turkey & 2005 & 454 & Higher-Middle income & $69.16 \%$ & 3.54 & 3.32 & 4.20 \\
\hline Zambia & 2002 & 73 & Low income & & 2.54 & 2.24 & 4.07 \\
\hline Total & & 9086 & & $57.67 \%$ & 2.50 & 2.26 & 4.02 \\
\hline
\end{tabular}

Table 4.2 shows the count statistics of the appearance of each strategy and their interactions. We do not distinguish between higher- and lower-middle income countries,

47 Countries are divided according to 2011 GNI per capita, calculated using the World Bank Atlas method (http://data.worldbank.org/about/country-classifications/world-bank-atlas-method). Low-income countries: 1,025 USD or less; lower middle-income countries: 1,026 - 4,035 USD; upper middle-income countries: 4,036 - 12,475 USD; and high-income countries: 12,476 USD or more. We have aggregated low-middle and higher-middle into one group: middle-income countries. 
only between the union of those two and low-income countries. The statistics show that the main technology sourcing in low- and middle-income countries is external. Given the low levels of financial and human resources, firms seek innovation sources from external channels. There is about a 9 per cent higher frequency in pursuing the non-exclusive BUY strategy and a slightly lower probability of adopting the non-exclusive MAKE strategy in middle-income compared with low-income countries. Turning to the exclusive strategies (columns 3 to 6 ), we see that firms are more likely to adopt MAKE and BUY in middle-income than in low-income countries, 21.8 per cent versus 17.5 per cent. At a relatively higher level of development firms have probably accumulated some knowledge stocks and have gained experience that make them capable of doing in-house R\&D and external BUY simultaneously. One should note that there are also other existing knowledge sourcing strategies, such as knowledge transfer from mother companies, learning from international conferences or study trips. We will not address these strategies here.

Table 4. 2 "Make" and "Buy" strategies in low- and middle-income countries

\begin{tabular}{|c|c|c|c|c|c|c|c|}
\hline $\begin{array}{c}\text { Income } \\
\text { level }\end{array}$ & MAKE & BUY & $\begin{array}{c}\text { MAKE } \\
\text { ONLY }\end{array}$ & $\begin{array}{c}\text { BUY } \\
\text { ONLY }\end{array}$ & $\begin{array}{c}\text { MAKE } \\
\text { AND } \\
\text { BUY }\end{array}$ & $\begin{array}{c}\text { NO } \\
\text { MAKE } \\
\text { OR BUY }\end{array}$ & Innovation \\
\hline $\begin{array}{c}\text { Low- } \\
\text { income } \\
\text { countries }\end{array}$ & $31.09 \%$ & $56.54 \%$ & $13.55 \%$ & $39.00 \%$ & $17.54 \%$ & $29.91 \%$ & $24.75 \%$ \\
\hline $\begin{array}{c}\text { Middle- } \\
\text { income } \\
\text { countries }\end{array}$ & $28.84 \%$ & $67.05 \%$ & $7.02 \%$ & $45.22 \%$ & $21.83 \%$ & $25.93 \%$ & $65.28 \%$ \\
\hline Total & $29.26 \%$ & $65.08 \%$ & $8.24 \%$ & $44.06 \%$ & $21.02 \%$ & $26.68 \%$ & $57.67 \%$ \\
\hline
\end{tabular}

\subsubsection{Specification of the production function}

Table 4.3 provides the definition for each variable used in our empirical analysis. Two sets of variables will be introduced in accordance with the two methods adopted in the empirical analysis, one for the PROD approach and the other one is for the MP approach. The dependent variable in the PROD approach is productivity, measured by sales per employee, in natural logarithmic terms. The standard explanatory variables in the production function (4.5) are: physical capital (total end-of-year capital per person in $\operatorname{logs}$ ), labor (log of permanent workers at the end of the year). Sales and capital are converted in 1000 USD. Besides the standard explanatory variables, we also control for differences in capacity utilization (in percentage) because firms are likely to be more 
productive with the same amount of inputs when they operate at a relatively high level of capacity utilization.

Variable EXPORT indicates whether firms had positive export sales during the last year. Here, we use EXPORT to indicate the level of openness of the economy. Openness has generally led to greater competition in the product markets and increasingly also in the market for services. More vigorous competition exerts discipline on firms in developing countries. It therefore tends to strengthen incentives for development in their economy. So we expect a positive relation between export activities and firm performance.

The ICS survey contains a series of information about the business environment in which firms operate. The business environment consists of government regulations, institutional background, or social conventions, which are believed to have a substantial impact on firms' production decisions and performance (Coase, 1998). Questions are asked about obstacles to innovation on a four-point Likert scale. We select the infrastructure, regulation, and financial innovation hindrances and transform these variables in binary variables. The dummy variables Infra_obs, Regu_obs and Finance_obs take value 1 if the answer is marked as a major or very severe obstacle (scores 3 and 4). It is believed that these economic and institutional obstacles can play a significant role in explaining the heterogeneous performance in productivity across countries (Mohnen and Röller, 2005). Size ${ }^{48}$, industry and country dummies ${ }^{49}$ are used to capture the heterogeneities due to size, industries and countries.

\subsubsection{Specification of the knowledge acquisition equations}

Two categories of variables are expected to affect firms' knowledge sourcing strategies. The first category is firm specific. It includes size and foreign ownership (Foreignowner). Larger firms are expected to be more innovative and hence have more often internal R\&D activities and external technology purchases. Most of the foreign firms in developing countries are more competitive than the domestic firms. However, empirical evidence has shown that in joint ventures the core technologies remain generally under the control of the foreign partners or of company headquarters abroad (OECD, 2007). So, in general, foreign-owned companies are expected to be less likely to engage in innovation activities than domestic firms.

\footnotetext{
48 Small firms: < 20 employees; medium size firms: 21-99 employees, large size firms > 100 employees.

${ }^{49}$ Four regions are included: European, African, Asian and Latin American countries.
} 
Table 4. 3 Definition of variables

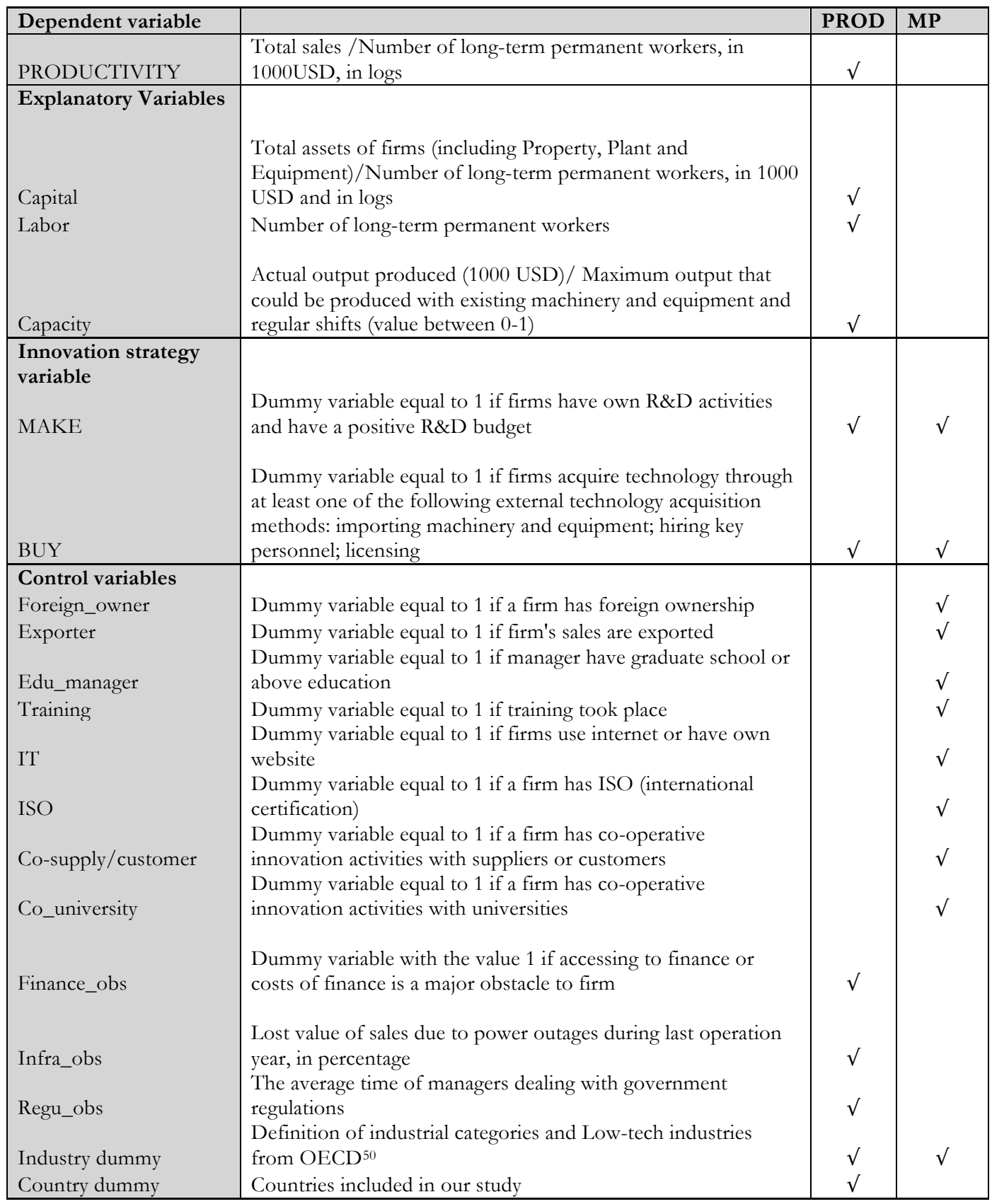

50 See http://www.oecd.org 
The second category of variables is intended to capture the technological capability that affects firms' innovation strategy decisions. Because information technology is commonly recognized as an important technological infrastructure to improve communication and logistics efficiency, IT is included in both the returns of MAKE and BUY. Dummy variable ISO with value 1 indicates that the firm has received international certificates, for example ISO9000, ISO9002 or ISO14000. ISO standards in general represent a reservoir of technology. In developing countries, ISO standards are an important means both of acquiring technological know-how and of raising the capability to compete in global markets. ISO certifications to some extent reflect the technological capability and experience of firms. Training will be included only in the MAKE function. It gets value 1 if firms carry out a training program for their employees. Skilled labor is an essential part of firms' innovation capacity to accommodate and integrate the new knowledge into production and ultimately transform it into new products or processes. Dummy variable Edu_manager has a value 1 if the average education level of senior managers is above the university level. It will only be included in the BUY equation.

Dummy variable Co_supply/customer indicates collaboration with suppliers and customers, which is believed to be associated with input quality improvements aimed at cost reductions or market expansion (Von Hippel, 1988; Tether, 2002). Co_university indicates if firms cooperate with universities and research institutes. It is generally associated with radical, breakthrough innovations that may open up entire new markets or market segments (Tether, 2002; Monjon and Waelbroeck, 2003). These two indicators are also widely used to measure a firm's absorptive capacity (Zahra and George, 2002; Schmidt, 2005; Freel and Harrison, 2006).

Figure 4.1 depicts the differences in the mean values of the explanatory variables between low-income and middle income countries. Clearly, technological capability and institutional environment are heterogeneous across levels of development. The pattern exhibits that the mean values of technology-related variables is generally higher in middle-income than in the low-income countries. One exception in our sample is the managers' education that is higher in the low-income group, which might be due to the differences in the education across different countries.

It is worth highlighting the pattern of technological capability across different income groups here. Lane and Lubatkin (1998) suggest that firms learn from firms that have 
similar characteristics. Dussauge et al. (2000) and Cohen and Levinthal (1990) use the path-dependency theory to conclude that a firm is better able to acquire and use knowledge sourcing if it has some prior experience or higher technological capability. With low levels of development firms might be constrained by generally low levels of technological capability. Hence, firms in low-income countries might rely mainly on external technology acquisitions. Additionally, the synergy effect of MAKE_and_BUY on productivity performance will be undermined by factors such as weak infrastructure, scarce financial resources, etc. The increase of technological capability will catalyze the speed and efficiency of absorbing external know-how; hence we argue that the complementarity between in-house and external knowledge sourcing strategies is expected to appear as the level of development increases. The last three columns in figure 4.2 show the mean values of the infrastructure, financial and regulation obstacles that firms face. At least the infrastructure and finance related obstacles are more severely felt in low-income countries.

Figure 4.2 Innovation sourcing strategies, firm specificities and institutional characteristics in low-income and middle-income countries

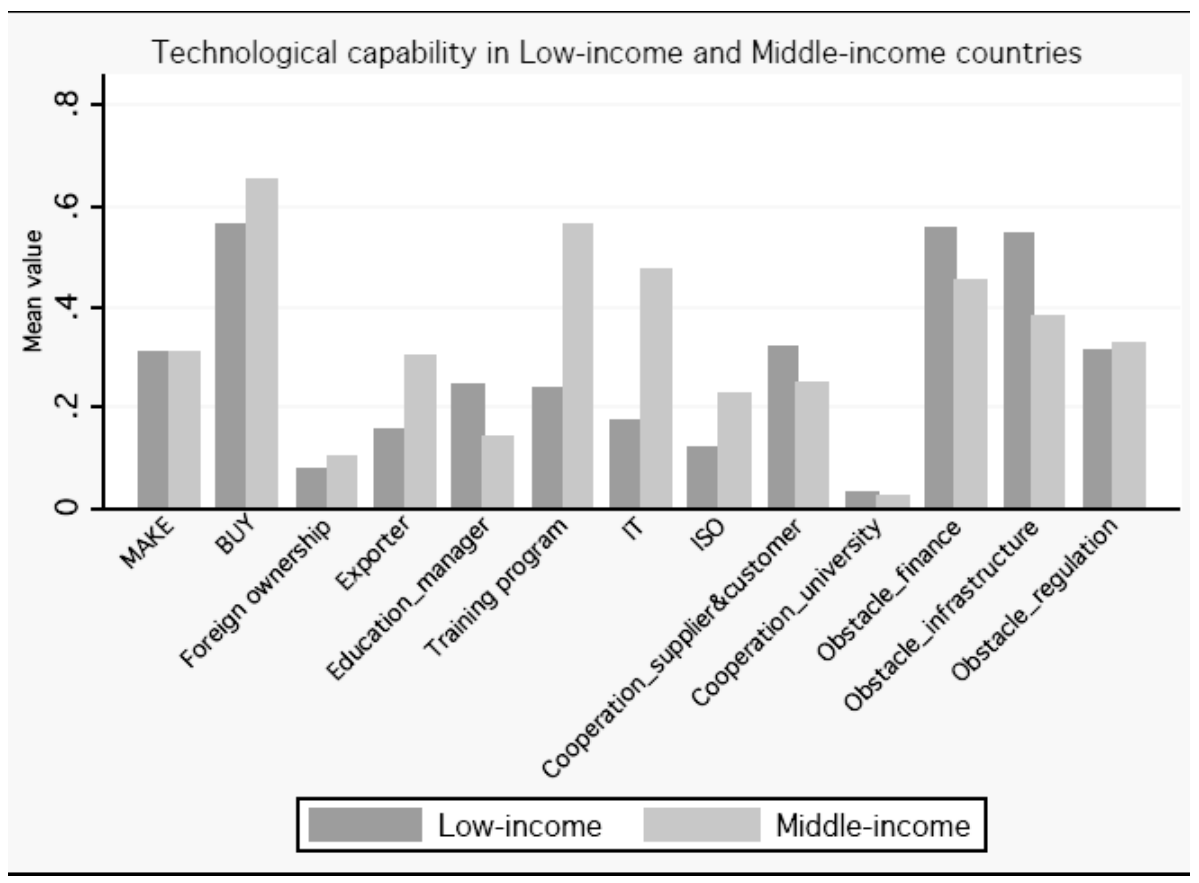




\subsection{Empirical results}

This section discusses the result of empirical analysis on the role of technologysourcingstrategies in affecting firms' performance. In particular, we would like to see whether there are synergy effects between them. As shown in Table 4.4, a simple correlation between MAKE and BUY regardless of any other differences in firms' characteristics gives a Pearson coefficient of -0.0017 (non-significant at 10 per cent) for the low-income countries and 0.1167 (significant at 1 per cent) for the middle-income countries. This finding suggests an association between innovation sourcing strategies in middle-income countries. However, as stated before, the correlation observed here may be caused by firm specificities. It is unwarranted to draw a conclusion at this stage.

Table 4. 4 Unconditional correlations between innovation strategies and scale of investment

\begin{tabular}{|l|c|c|c|c|}
\hline & \multicolumn{2}{|c|}{ Low-income countries } & \multicolumn{2}{c|}{ Middle-income countries } \\
\hline & MAKE & BUY & MAKE & BUY \\
\hline MAKE & 1 & & 1 & 1 \\
BUY & -0.0017 & 1 & $0.1167^{* * *}$ & 1 \\
\hline
\end{tabular}

$* * *$ indicates the results is significant at 0.01 .

\subsubsection{PROD approach}

Based on equation 4.5, we regress firms' productivity (in logarithm) on the innovation strategies MAKE and BUY while controlling for other firm, industry and country specificities, which may affect the productivity performance. The results are given in Table 4.5 .

We separate the sample into two groups according to their income levels. The first two columns of Table 4.5 are the results without interaction term between MAKE and BUY while the last two columns include it. Except for the technological sourcing variables, the estimated coefficients of the other variables do not differ considerably when controlling or not for the interaction term.

As shown in Table 4.5, different patterns are observed across different income levels with respect to the determinants of productivity performance. The findings suggest that the elasticity of capital stock elasticity (Capital) of production is positive and does not differ considerably, 0.44 and 0.46 respectively for low- and middle-income countires. We find that there are in general increasing returns to scale in middle-income countries and, 
on the contrary, decreasing returns to scale in the low-income group at a 95 per cent significant level. Firms with higher utilization of resources and production capacity are more productive in both groups. And it is reflected by the highly significant coefficients of Capacity.

Table 4. 5 PROD approach. OLS regression of equation (4.2) results with and without interaction term

\begin{tabular}{|c|c|c|c|c|}
\hline \multirow[b]{2}{*}{ Productivity } & \multicolumn{2}{|c|}{ Without interaction } & \multicolumn{2}{|c|}{ With interaction } \\
\hline & $\begin{array}{c}\text { Low-income } \\
\text { countries }\end{array}$ & $\begin{array}{l}\text { Middle-income } \\
\text { countries }\end{array}$ & $\begin{array}{c}\text { Low-income } \\
\text { countries }\end{array}$ & $\begin{array}{l}\text { Middle-income } \\
\text { countries }\end{array}$ \\
\hline Capital & $\begin{array}{c}0.443^{* * *} \\
0.020\end{array}$ & $\begin{array}{c}0.469^{* * *} \\
0.007\end{array}$ & $\begin{array}{c}0.443^{* * *} \\
0.020\end{array}$ & $\begin{array}{c}0.468^{* * *} \\
0.007\end{array}$ \\
\hline Labor & $\begin{array}{c}-0.103^{* *} \\
0.044\end{array}$ & $\begin{array}{c}0.064 * * * \\
0.016\end{array}$ & $\begin{array}{c}-0.102^{* * * *} \\
0.044\end{array}$ & $\begin{array}{c}0.064^{* * *} \\
0.016\end{array}$ \\
\hline Capacity & $\begin{array}{c}0.517^{* * * *} \\
0.139\end{array}$ & $\begin{array}{c}0.514^{* * * *} \\
0.054\end{array}$ & $\begin{array}{c}0.522^{* * * *} \\
0.139\end{array}$ & $\begin{array}{c}0.511^{* * * *} \\
0.054\end{array}$ \\
\hline Exporter & $\begin{array}{c}0.548^{* * *} \\
0.073\end{array}$ & $\begin{array}{c}0.205^{* * *} \\
0.026\end{array}$ & $\begin{array}{c}0.541^{* * *} \\
0.074\end{array}$ & $\begin{array}{c}0.204^{* * *} \\
0.026\end{array}$ \\
\hline Finance_obs & $\begin{array}{c}-0.153^{* * *} \\
0.053\end{array}$ & $\begin{array}{c}-0.105^{* * *} \\
0.024\end{array}$ & $\begin{array}{c}-0.152^{* * *} \\
0.053\end{array}$ & $\begin{array}{c}-0.105^{* * *} \\
0.024\end{array}$ \\
\hline Infra_obs & $\begin{array}{l}0.055 \\
0.051\end{array}$ & $\begin{array}{r}-0.013 \\
0.022\end{array}$ & $\begin{array}{l}0.056 \\
0.051\end{array}$ & $\begin{array}{r}-0.013 \\
0.022\end{array}$ \\
\hline Regu_obs & $\begin{array}{l}0.045 \\
0.056\end{array}$ & $\begin{array}{c}0.084 * * * \\
0.023\end{array}$ & $\begin{array}{l}0.044 \\
0.056\end{array}$ & $\begin{array}{c}0.084^{* * * *} \\
0.023\end{array}$ \\
\hline MAKE & $\begin{array}{l}0.015 \\
0.057\end{array}$ & $\begin{array}{c}0.160^{* * * *} \\
0.024\end{array}$ & $\begin{array}{c}-0.074 \\
0.082\end{array}$ & $\begin{array}{c}0.207^{* * *} \\
0.045\end{array}$ \\
\hline BUY & $\begin{array}{c}0.183^{* * *} \\
0.051\end{array}$ & $\begin{array}{c}0.041^{*} \\
0.023\end{array}$ & $\begin{array}{c}0.133^{* *} \\
0.061\end{array}$ & $\begin{array}{c}0.057 * * \\
0.027\end{array}$ \\
\hline MAKE\&BUY & & & $\begin{array}{l}0.156 \\
0.104\end{array}$ & $\begin{array}{r}-0.064 \\
0.051\end{array}$ \\
\hline Size_medium & $\begin{array}{c}0.364 * * * \\
0.077\end{array}$ & $\begin{array}{c}0.225^{* * *} \\
0.034\end{array}$ & $\begin{array}{c}0.369 * * * \\
0.077\end{array}$ & $\begin{array}{c}0.224^{* * * *} \\
0.034\end{array}$ \\
\hline Size_large & $\begin{array}{c}0.510^{* * * *} \\
0.158\end{array}$ & $\begin{array}{c}0.318^{* * * *} \\
0.058\end{array}$ & $\begin{array}{c}0.515^{* * *} \\
0.158\end{array}$ & $\begin{array}{c}0.319 * * * \\
0.058\end{array}$ \\
\hline Constant & $\begin{array}{c}0.494^{* * * *} \\
0.177\end{array}$ & $\begin{array}{c}0.620 * * * \\
0.075\end{array}$ & $\begin{array}{c}0.512^{* * *} \\
0.178\end{array}$ & $\begin{array}{c}0.616^{* * *} \\
0.075\end{array}$ \\
\hline Obs. & 1705 & 7381 & 1705 & 7381 \\
\hline Adj_R2 & 0.379 & 0.5434 & 0.3794 & 0.5434 \\
\hline
\end{tabular}

Note: "No make or buy" is the base category. Industry, country dummies are included.

*** Significant level $1 \%$, ** at $5 \%$, * at $10 \%$.

Not surprisingly, when firms face severe obstacles in their production process, their production performance is likely to be hampered or delayed and the productivity performance is expected to be lower. Financial constraints (Finance_obs) depress productivity of firms in both groups, especially in the low-income countries, the estimated coefficient being -0.153 and -0.105 respectively. Infra_obs does not differ significantly from zero in both groups. The estimated coefficients of Regu_obs show a 
positive impact on the productivity across firms in middle-income countries. It might be due to the fact that firms that face more regulations are more likely to spend more time in dealing with the regulation authorities (Mohnen and Röller, 2005). As a result, they may learn how to overcome these barriers more efficiently and benefit in terms of productivity performance. It may also be that obstacles are better perceived by more innovating firms, in which case obstacles might reflect innovation with more innovating firms being more productive. Exporting firms in low- and middle-income countries are respectively 54.8 per cent and 20.5 per cent more productive than non-exporting firms. Entering international markets may enable these firms to boost their productivity by interacting with buyers and by coping with intensive competition in the export market.

Regarding the effect of innovation sourcing strategies in firms' performance, the results of Table 4.5 present us the marginal contribution of MAKE, BUY and their interaction effect. Regardless of whether the interaction term is included or not, the estimators for BUY are all positive and significant in both groups. Especially for low-income countries, firms adopting external technological sourcing are more productive compared with those that participate in in-house $\mathrm{R} \& \mathrm{D}$ and those that are not involved in any innovation investment. The result implies that in the context of a low level of development, firms investing in innovation through external channels are more productive and external sourcing strategies play a critical role in contributing to their performance. However, in the case of middle-income countries, in-house R\&D becomes significant.

Turning to the potential synergistic effects between MAKE and BUY, the last two columns of Table 4.5 show that interaction coefficients of MAKE and BUY are not significant in both groups. This result suggests that there is no complementarity observed between MAKE and BUY in fostering productivity. The return of adopting in-house $\mathrm{R} \& \mathrm{D}$ and external technology buying together does not differ from the sum of the returns from adopting them individually. Assuming there are no unobserved factors across firms, we can conclude at this stage that no complementarity is confirmed between MAKE and BUY. With the presence of an interaction term, external sourcing still plays a significant role across low-income countries while investing in in-house R\&D seems to be more efficient in fostering productivity improvements across firms in middle-income countries.

Practically, it is very difficult for economists to identify and control all the possible 
sources of heterogeneity across firms. So far our estimations of complementarity (or substitutability) are based on the assumption that no unobserved heterogeneities exist in the returns to MAKE and BUY. This assumption will be released in the next section. The Miravete and Pernías approach will enable us to distinguish complementarity and the association due to unobserved heterogeneity.

\subsubsection{The Miravete and Pernías approach}

The first two columns of Table 4.6 give the bivariate probit results of conditional correlation between internal and external innovation sourcing. The bivariate probit analysis assumes no synergy $\left(\boldsymbol{\delta}_{\mathrm{bm}}=0\right.$ in equation (4.8)). After controlling for observed heterogeneities, the magnitude of the correlation coefficients between MAKE and BUY decisions do not differ much from the simple Pearson correlation coefficients that we obtained at the beginning of our analysis.

The last two columns of Table 4.6 report the results from MP approach. In the presence of complementarity and correlation due to unobserved heterogeneities, the estimated coefficients of the exogenous variables are in line with those of the bivariate probit estimation but slightly different in magnitudes. In the interpretation underlying equation (4.8) these variables explain the adoption of MAKE and BUY and their marginal return.

The firm specific factors exert a significant influence on firms' knowledge sourcing strategies. Firms with more employees seem to be more motivated to participate in both in-house and external innovating activities.Large firms are likely to have more resources to dedicate to innovation activities. Since in joint ventures technologies remain controlled by the foreign company headquarters abroad, foreign-invested companies are reluctant to engage in innovation activities by themselves. The estimated coefficients of Foreign-owner are negative but only significant in affecting MAKE for the group of middle-income countries. 
Table 4. 6 Miravete and Pernías approach. MLE results

\begin{tabular}{|c|c|c|c|c|}
\hline & \multicolumn{2}{|c|}{ no complementarity } & \multicolumn{2}{|c|}{ Complementarity } \\
\hline & $\begin{array}{c}\text { Low-income } \\
\text { countries }\end{array}$ & $\begin{array}{l}\text { Middle-income } \\
\text { countries }\end{array}$ & $\begin{array}{c}\text { Low-income } \\
\text { countries }\end{array}$ & $\begin{array}{l}\text { Middle-income } \\
\text { countries }\end{array}$ \\
\hline \multicolumn{5}{|l|}{ BUY } \\
\hline \multirow[t]{2}{*}{ Foreign_owner } & 0.204 & $-0.111^{*}$ & 0.204 & -0.087 \\
\hline & 0.140 & 0.063 & 0.140 & 0.060 \\
\hline \multirow[t]{2}{*}{ ISO } & -0.078 & 0.063 & -0.078 & 0.047 \\
\hline & 0.110 & 0.045 & 0.110 & 0.042 \\
\hline \multirow[t]{2}{*}{ Internet } & 0.137 & $0.349^{* * *}$ & 0.137 & $0.281 * * *$ \\
\hline & 0.093 & 0.034 & 0.093 & 0.039 \\
\hline \multirow[t]{2}{*}{ Co_supply/client } & $-0.322 * * *$ & $-0.223^{* * *}$ & $-0.322^{* * *}$ & $-0.232^{* * *}$ \\
\hline & 0.070 & 0.036 & 0.070 & 0.033 \\
\hline \multirow[t]{2}{*}{ Co_university } & -0.261 & $-0.366^{* * *}$ & -0.261 & $-0.373^{* * *}$ \\
\hline & 0.194 & 0.101 & 0.194 & 0.094 \\
\hline \multirow[t]{2}{*}{ Edu_manager } & -0.037 & $0.288^{* * *}$ & -0.037 & $0.285^{* * *}$ \\
\hline & 0.067 & 0.034 & 0.067 & 0.032 \\
\hline \multirow[t]{2}{*}{ Size_Medium } & 0.063 & $0.245^{* * *}$ & 0.063 & $0.208^{* * *}$ \\
\hline & 0.072 & 0.041 & 0.072 & 0.041 \\
\hline \multirow[t]{2}{*}{ Size_Large } & $0.258^{* *}$ & $0.324 * * *$ & $0.258^{* * *}$ & $0.262^{* * *}$ \\
\hline & 0.102 & 0.048 & 0.102 & 0.049 \\
\hline \multirow[t]{2}{*}{ Constant } & 0.100 & -0.063 & 0.100 & -0.037 \\
\hline & 0.092 & 0.060 & 0.092 & 0.058 \\
\hline \multicolumn{5}{|l|}{ MAKE } \\
\hline \multirow[t]{2}{*}{ Foreign_owner } & -0.202 & $-0.205^{* * *}$ & -0.202 & $-0.201 * * *$ \\
\hline & 0.147 & 0.063 & 0.147 & 0.064 \\
\hline \multirow[t]{2}{*}{ ISO } & 0.102 & 0.058 & 0.102 & 0.040 \\
\hline & 0.109 & 0.044 & 0.109 & 0.045 \\
\hline \multirow[t]{2}{*}{ Internet } & 0.064 & $0.513^{* * *}$ & 0.064 & $0.452^{* * *}$ \\
\hline & 0.095 & 0.035 & 0.095 & 0.041 \\
\hline \multirow[t]{2}{*}{ Co_supply/client } & -0.069 & $0.171 * * *$ & -0.069 & $0.193^{* * *}$ \\
\hline & 0.073 & 0.037 & 0.073 & 0.038 \\
\hline \multirow[t]{2}{*}{ Co_university } & -0.281 & $0.326^{* * *}$ & -0.281 & $0.383^{* * *}$ \\
\hline & 0.222 & 0.105 & 0.222 & 0.108 \\
\hline \multirow[t]{2}{*}{ Training } & 0.069 & $0.530 * * *$ & 0.069 & $0.541 * * *$ \\
\hline & 0.086 & 0.037 & 0.086 & 0.037 \\
\hline \multirow[t]{2}{*}{ Size_Medium } & $0.287 * * *$ & $0.243^{* * *}$ & $0.287^{* * *}$ & $0.184 * * *$ \\
\hline & 0.077 & 0.048 & 0.077 & 0.052 \\
\hline \multirow[t]{2}{*}{ Size_Large } & $0.336^{* * *}$ & $0.331 * * *$ & $0.336^{* * *}$ & $0.256^{* * *}$ \\
\hline & 0.107 & 0.053 & 0.107 & 0.059 \\
\hline \multirow[t]{2}{*}{ Constant } & $-0.450 * * *$ & $-1.679 * * *$ & $-0.450 * * *$ & $-1.776^{* * *}$ \\
\hline & 0.091 & 0.070 & 0.091 & 0.074 \\
\hline \multirow[t]{2}{*}{ Complementarity } & & & 0.000 & $0.279 * * *$ \\
\hline & & & 0.004 & 0.084 \\
\hline \multirow[t]{2}{*}{ Correlation } & 0.035 & $0.101 * * *$ & 0.035 & $-0.198 * *$ \\
\hline & 0.043 & 0.022 & 0.043 & 0.089 \\
\hline obs. & 1705 & 7381 & 1705 & 7381 \\
\hline Likelihood ratio & -2069.274 & -8311.584 & -2069.2744 & -8306.2234 \\
\hline
\end{tabular}

Note: Industry dummies are included. *** Significant level $1 \%$, ** at $5 \%$, * at $10 \%$. 
Firms with more technological capability earn more profit from adopting either of the two innovation strategies. This effect is reflected in the coefficients of the technological variables. In the middle-income countries, IT and Edu_manager are positively correlated with BUY whereas IT and Training encourage firms to adopt in-house R\&D. ISO coefficients are not significant anywhere and for the low-income group, none of the technological indicators is significant. Co-operative activities, (Co_supplier/customer and Co_university) are observed to stimulate firms' MAKE decision in the middle-income countries and to reduce the purchase of external knowledge in the low-income countries.

Collaboration seems to enhance knowledge, encourage own R\&D efforts and reducing the need for external knowledge, substituting in a sense for technology purchasing. After including the complementarity coefficient in the system, the correlation coefficient between residuals is unchanged and insignificant in the low-income countries as it shown in $\delta_{\mathrm{bm}}$, the correlation coefficient between the unobserved effects remains, insignificant in the low-income countries and becomes negative in the middle-income countries. No sign of complementarity exists in low-income countries. However, in the middle-income countries the complementarity coefficient is positive and statistically significant at the 99 per cent confidence level. Hence in those countries it pays to do both MAKE and BUY simultaneously as is generally found in developed countries.

\subsection{Conclusion}

The lack of advanced technological competencies in developing countries requires innovation to occur through the absorption of existing knowledge and the adoption of existing technologies. In the least developed countries, the low levels of technological capability severely constrains firms in their efforts to build up their own R\&D stock of knowledge and make them rely instead on external knowledge acquisitions such as licensing, hiring skilled labor and purchasing technology embedded in machinery and collaborating with foreign firms. Our results highlight the significant contribution of external technological sourcing for productivity performance in the low-income countries. In the middle-income countries it is the combination of internal R\&D and external knowledge acquisition that leads to better productivity performance.

These findings suggest that at different levels of development, governments formulate different policies in order to achieve optimal productivity performance. At a low level of 
development, external sourcing strategies are essential for local firms to integrate the global market. Governments should develop policies that encourage external sourcing, such as providing technological information and financial support for technology import. In middle-income countries, where firms have sufficiently built up their technological capabilities and gathered enough innovation experience, government policies should focus on encouraging firms to invest in both internal and external technological sourcing because of the existence of a complementarity between them. This finding is consistent with the conclusion drawn from chapter 3, which suggests that a certain level of innovation capability, such as prior accumulated $R \& D$, may be necessary for firms to utilize external know-how and for the existence of synergetic effect.

By adopting three different methods in the empirical analysis, heterogeneous results are exhibited. Due to its several limitations (see chapter 4.3), the CORR approach is suggested to apply as an auxiliary text. PROD is an effective approach to test complementarity if there is no unobserved heterogeneity correlated with potential complementary strategies. PROD is also likely to produce consistent results by incorporating with panel analysis, which can effectively control for the endogeneity. In a cross-sectional analysis, it might deliver false results as shown from our results. MP approach is suggested since it allows the separate identification of a complementarity and the unexplained correlation between the error terms. 


\section{Appendix 4A Likelihood function}

$$
l_{i}\left(y_{b i}, y_{m i}\right)=\int_{S\left(y_{b i}, y_{m i}\right)} \phi_{2}\left(\frac{\varepsilon_{b i}}{\sigma_{b}}, \frac{\varepsilon_{m i}}{\sigma_{m}} ;-s_{i} \rho_{b m}\right) d \frac{\varepsilon_{m i}}{\sigma_{m}} d \frac{\varepsilon_{b i}}{\sigma_{b}}
$$

We normalize the standard deviations of $y_{b i}$ and $y_{m i}$ to be equal to $1, \sigma_{b}=\sigma_{m}=1$. Hence, the likelihood function can be written as follows:

1) when $\delta=0$, the likelihood function will be correspond to the likelihood function of a standard bivariate probit

$$
\begin{aligned}
l_{i}\left(y_{b i}=1, y_{m i}=1\right)= & \int_{\frac{-\lambda_{b i}}{\sigma_{b}}}^{+\infty} \int_{\frac{-\lambda_{m i}}{\sigma_{m}}}^{+\infty} \phi_{2}\left(\frac{\varepsilon_{b i}}{\sigma_{b}}, \frac{\varepsilon_{m i}}{\sigma_{m}} ;-s_{i} \rho_{b m}\right) d \frac{\varepsilon_{m i}}{\sigma_{m}} d \frac{\varepsilon_{b i}}{\sigma_{b}} \\
& =\Phi_{2}\left(\frac{\lambda_{b i}}{\sigma_{b}}, \frac{\lambda_{m i}}{\sigma_{m}} ; \rho_{b m}\right) \\
l_{i}\left(y_{b i}=0, y_{m i}=0\right)= & \int_{\frac{\lambda_{b i}}{\sigma_{b}}}^{+\infty} \int_{\frac{\lambda_{m i}}{\sigma_{m}}}^{+\infty} \phi_{2}\left(\frac{\varepsilon_{b i}}{\sigma_{b}}, \frac{\varepsilon_{m i}}{\sigma_{m}} ;-s_{i} \rho_{b m}\right) d \frac{\varepsilon_{m i}}{\sigma_{m}} d \frac{\varepsilon_{b i}}{\sigma_{b}} \\
= & \Phi_{2}\left(\frac{-\lambda_{b i}}{\sigma_{b}}, \frac{-\lambda_{m i}}{\sigma_{m}} ; \rho_{b m}\right) \\
l_{i}\left(y_{b i}=1, y_{m i}=0\right)= & \int_{\frac{-\lambda_{b i}}{\sigma_{b}}}^{+\infty} \int_{\frac{\lambda_{m i}}{\sigma_{m}}}^{+\infty} \phi_{2}\left(\frac{\varepsilon_{b i}}{\sigma_{b}}, \frac{\varepsilon_{m i}}{\sigma_{m}} ;-s_{i} \rho_{b m}\right) d \frac{\varepsilon_{m i}}{\sigma_{m}} d \frac{\varepsilon_{b i}}{\sigma_{b}} \\
= & \Phi_{2}\left(\frac{\lambda_{b i}}{\sigma_{b}}, \frac{-\lambda_{m i}}{\sigma_{m}} ;-\rho_{b m}\right) \\
l_{i}\left(y_{b i}=0, y_{m i}=1\right)= & \int_{\frac{\lambda_{b i}}{\sigma_{b}}}^{+\infty} \int_{\frac{-\lambda_{m i}}{\sigma_{m}}}^{+\infty} \phi_{2}\left(\frac{\varepsilon_{b i}}{\sigma_{b}}, \frac{\varepsilon_{m i}}{\sigma_{m}} ;-s_{i} \rho_{b m}\right) d \frac{\varepsilon_{m i}}{\sigma_{m}} d \frac{\varepsilon_{b i}}{\sigma_{b}} \\
& =\Phi_{2}\left(\frac{-\lambda_{b i}}{\sigma_{b}}, \frac{\lambda_{m i}}{\sigma_{m}} ;-\rho_{b m}\right)
\end{aligned}
$$

2) when $\delta<0$, inequalities marked with asterisks of $\mathrm{D}(1,0)$ and $\mathrm{D}(1,0)$ in $(10)$ are binding. The probability distribution will no longer be rectangular as the case of a bivariate probit.

$$
\begin{gathered}
l_{i}\left(y_{b i}=1, y_{m i}=1\right)=\int_{\frac{-\lambda_{b i}-2 \delta}{\sigma_{b}}}^{+\infty} \int_{\frac{-\lambda_{m i}-2 \delta}{\sigma_{m}}}^{+\infty} \phi_{2}\left(\frac{\varepsilon_{b i}}{\sigma_{b}}, \frac{\varepsilon_{m i}}{\sigma_{m}} ;-s_{i} \rho_{b m}\right) d \frac{\varepsilon_{m i}}{\sigma_{m}} d \frac{\varepsilon_{b i}}{\sigma_{b}} \\
=\Phi_{2}\left(\frac{\lambda_{b i}+2 \delta}{\sigma_{b}}, \frac{\lambda_{m i}+2 \delta}{\sigma_{m}} ; \rho_{b m}\right) \\
l_{i}\left(y_{b i}=0, y_{m i}=0\right)=\int_{\frac{\lambda_{b i}}{\sigma_{b}}}^{+\infty} \frac{\lambda_{m i}^{+\infty}}{\sigma_{m}} \phi_{2}\left(\frac{\varepsilon_{b i}}{\sigma_{b}}, \frac{\varepsilon_{m i}}{\sigma_{m}} ;-s_{i} \rho_{b m}\right) d \frac{\varepsilon_{m i}}{\sigma_{m}} d \frac{\varepsilon_{b i}}{\sigma_{b}} \\
=\Phi_{2}\left(\frac{-\lambda_{b i}}{\sigma_{b}}, \frac{-\lambda_{m i}}{\sigma_{m}} ; \rho_{b m}\right)
\end{gathered}
$$




$$
\begin{aligned}
& l_{i}\left(y_{b i}=1, y_{m i}=0\right)=\int_{\frac{-h_{i j}}{\sigma_{b}}}^{+\infty} \int_{\frac{\lambda_{m i}+2 \delta}{\sigma_{m}}}^{+\infty} \phi_{2}\left(\frac{\varepsilon_{b i}}{\sigma_{b}}, \frac{\varepsilon_{m i}}{\sigma_{m}} ;-s_{i} \rho_{b m}\right) d \frac{\varepsilon_{m i}}{\sigma_{m}} d \frac{\varepsilon_{b i}}{\sigma_{b}}-\int_{\frac{-\lambda_{b i}-2 \delta}{\sigma_{b}}}^{\frac{-\lambda_{b i}}{\sigma_{b}}} \int_{\frac{-\lambda_{m i}-2 \delta}{\sigma_{m}}}^{\frac{\lambda_{b i}-\lambda_{m i}+\varepsilon_{b_{i}}}{\sigma_{m}}} \phi_{2}\left(\frac{\varepsilon_{b i}}{\sigma_{b}}, \frac{\varepsilon_{m i}}{\sigma_{m}} ;-s_{i} \rho_{b m}\right) d \frac{\varepsilon_{m i}}{\sigma_{m}} d \frac{\varepsilon_{b i}}{\sigma_{b}} \\
& =\Phi_{2}\left(\frac{\lambda_{b i}}{\sigma_{b}}, \frac{-\lambda_{m i}-2 \delta}{\sigma_{m}} ;-\rho_{b m}\right)-\int_{\frac{-\lambda_{b i}-2 \delta}{\sigma_{b}}}^{\frac{-\lambda_{b i}}{\sigma_{b}}} \Phi\left(\frac{\varepsilon_{b i}}{\sigma_{b}}\right)\left[\Phi\left(\frac{\lambda_{b i}-\lambda_{m i}+\varepsilon_{b i}}{\sigma_{m}}\right)-\Phi\left(\frac{-\lambda_{m i}-2 \delta}{\sigma_{m}}\right)\right] d \frac{\varepsilon_{b i}}{\sigma_{b}} \\
& l_{i}\left(y_{b i}=0, y_{m i}=1\right)=\int_{\frac{\lambda_{i i}+2 \delta}{\sigma_{b}}}^{+\infty} \int_{\frac{-\lambda_{m i}}{\sigma_{m}}}^{+\infty} \varphi_{2}\left(\frac{\varepsilon_{b i}}{\sigma_{b}}, \frac{\varepsilon_{m i}}{\sigma_{m}} ;-s_{i} \rho_{b m}\right) d \frac{\varepsilon_{m i}}{\sigma_{m}} d \frac{\varepsilon_{b i}}{\sigma_{b}}+\int_{\frac{\lambda_{b i}-2 \delta}{\sigma_{b}}}^{\frac{-\lambda_{b i}}{\sigma_{b}}} \int_{\frac{-\lambda_{m i}}{\sigma_{m}}}^{\lambda_{b i}-\lambda_{m i}+\varepsilon_{b i}} \varphi_{2}\left(\frac{\varepsilon_{b i}}{\sigma_{b}}, \frac{\varepsilon_{m i}}{\sigma_{m}} ;-s_{i} \rho_{b m}\right) d \frac{\varepsilon_{m i}}{\sigma_{m}} d \frac{\varepsilon_{b i}}{\sigma_{b}} \\
& =\Phi_{2}\left(\frac{-\lambda_{b i}-2 \delta}{\sigma_{b}}, \frac{\lambda_{m i}}{\sigma_{m}} ;-\rho_{b m}\right)+\int_{\frac{-\lambda_{b i}-2 \delta}{\sigma_{b}}}^{\frac{-\lambda_{b i}}{\sigma_{b}}} \Phi\left(\frac{\varepsilon_{b i}}{\sigma_{b}}\right)\left[\Phi\left(\frac{\lambda_{b i}-\lambda_{m i}+\varepsilon_{b i}}{\sigma_{m}}\right)-\Phi\left(\frac{-\lambda_{m i}}{\sigma_{m}}\right)\right] d \frac{\varepsilon_{b i}}{\sigma_{b}}
\end{aligned}
$$

3) when $\delta>0$, inequalities marked with asterisks of $\mathrm{D}(1,1)$ and $\mathrm{D}(0,0)$ in (4.10) are binding.

$$
\begin{aligned}
& l_{i}\left(y_{b i}=1, y_{m i}=1\right)=\int_{\frac{-\infty}{\lambda_{i j}-2 \delta}}^{+\infty} \int_{\frac{\lambda_{m i}-2 \delta}{\sigma_{m}}}^{+\infty} \phi_{2}\left(\frac{\varepsilon_{b i}}{\sigma_{b}}, \frac{\varepsilon_{m i}}{\sigma_{m}} ;-s_{i} \rho_{b m}\right) d \frac{\varepsilon_{m i}}{\sigma_{m}} d \frac{\varepsilon_{b i}}{\sigma_{b}}-\int_{\frac{-\lambda_{i n}-2 \delta}{\sigma_{b}}}^{\frac{-\lambda_{i j}}{\sigma_{b}}} \int_{\frac{\lambda_{m i}-2 \delta}{\sigma_{m}}}^{\frac{-\lambda_{i b}-\lambda_{m i}-2 \delta-\varepsilon_{i j}}{\sigma_{m}}} \phi_{2}\left(\frac{\varepsilon_{b i}}{\sigma_{b}}, \frac{\varepsilon_{m i}}{\sigma_{m}} ;-s_{i} \rho_{b m}\right) d \frac{\varepsilon_{m i}}{\sigma_{m}} d \frac{\varepsilon_{b i}}{\sigma_{b}} \\
& =\Phi_{2}\left(\frac{\lambda_{b i}+2 \delta}{\sigma_{b}}, \frac{\lambda_{m i}+2 \delta}{\sigma_{m}} ; \rho_{b m}\right)-\int_{\frac{-\lambda_{b i}-2 \delta}{\sigma_{b}}}^{\frac{-\lambda_{b i}}{\sigma_{b}}} \Phi\left(\frac{\varepsilon_{b i}}{\sigma_{b}}\right)\left[\Phi\left(\frac{-\lambda_{b i}-\lambda_{m i}-2 \delta-\varepsilon_{b i}}{\sigma_{m}}\right)-\Phi\left(\frac{-\lambda_{m i}-2 \delta}{\sigma_{m}}\right)\right] d \frac{\varepsilon_{b i}}{\sigma_{b}} \\
& l_{i}\left(y_{b i}=0, y_{m i}=0\right)=\int_{\frac{\lambda_{b i}}{\sigma_{b}}}^{+\infty} \int_{\frac{\lambda_{m i}}{\sigma_{m}}}^{+\infty} \varphi_{2}\left(\frac{\varepsilon_{b i}}{\sigma_{b}}, \frac{\varepsilon_{m i}}{\sigma_{m}} ;-s_{i} \rho_{b m}\right) d \frac{\varepsilon_{m i}}{\sigma_{m}} d \frac{\varepsilon_{b i}}{\sigma_{b}}+\int_{\frac{-\lambda_{b i}-2 \delta}{\sigma_{b}}}^{\frac{-\lambda_{b i}}{\sigma_{b}}} \int_{\frac{-\lambda_{m i}}{\sigma_{m}}}^{\frac{-\lambda_{b i}-\lambda_{m i}-2 \delta-\varepsilon_{b i}}{\sigma_{m}}} \varphi_{2}\left(\frac{\varepsilon_{b i}}{\sigma_{b}}, \frac{\varepsilon_{m i}}{\sigma_{m}} ;-s_{i} \rho_{b m}\right) d \frac{\varepsilon_{m i}}{\sigma_{m}} d \frac{\varepsilon_{b i}}{\sigma_{b}} \\
& =\Phi_{2}\left(\frac{-\lambda_{b i}}{\sigma_{b}}, \frac{-\lambda_{m i}}{\sigma_{m}} ; \rho_{b m}\right)+\int_{\frac{-\lambda_{b i}-2 \delta}{\sigma_{b}}}^{\frac{-\lambda_{b i}}{\sigma_{b}}} \Phi\left(\frac{\varepsilon_{b i}}{\sigma_{b}}\right)\left[\Phi\left(\frac{-\lambda_{b i}-\lambda_{m i}-2 \delta-\varepsilon_{b i}}{\sigma_{m}}\right)-\Phi\left(\frac{-\lambda_{m i}}{\sigma_{m}}\right)\right] d \frac{\varepsilon_{b i}}{\sigma_{b}} \\
& l_{i}\left(y_{b i}=1, y_{m i}=0\right)=\int_{\frac{-\lambda_{b i}}{\sigma_{b}}}^{+\infty} \int_{\frac{\lambda_{m i}+2 \delta}{\sigma_{m}}}^{+\infty} \phi_{2}\left(\frac{\varepsilon_{b i}}{\sigma_{b}}, \frac{\varepsilon_{m i}}{\sigma_{m}} ;-s_{i} \rho_{b m}\right) d \frac{\varepsilon_{m i}}{\sigma_{m}} d \frac{\varepsilon_{b i}}{\sigma_{b}} \\
& =\Phi_{2}\left(\frac{\lambda_{b i}}{\sigma_{b}}, \frac{-\lambda_{m i}-2 \delta}{\sigma_{m}} ;-\rho_{b m}\right) \\
& l_{i}\left(y_{b i}=0, y_{m i}=1\right)=\int_{\frac{\lambda_{b i}+2 \delta}{\sigma_{b}}}^{+\infty} \int_{\frac{-\lambda_{m i}}{\sigma_{m}}}^{+\infty} \phi_{2}\left(\frac{\varepsilon_{b i}}{\sigma_{b}}, \frac{\varepsilon_{m i}}{\sigma_{m}} ;-s_{i} \rho_{b m}\right) d \frac{\varepsilon_{m i}}{\sigma_{m}} d \frac{\varepsilon_{b i}}{\sigma_{b}} \\
& =\Phi_{2}\left(\frac{-\lambda_{b i}-2 \delta}{\sigma_{b}}, \frac{\lambda_{m i}}{\sigma_{m}} ;-\rho_{b m}\right)
\end{aligned}
$$

Alternatively, the likelihood function can be written as:

$$
\begin{aligned}
& q_{j i}=2 y_{j i}-1(j=b, m) \\
& s_{i}=q_{b i} q_{m i} \\
& v_{i}=\left(s_{i}+1\right) / 2 \\
& l_{i}\left(y_{b i}, y_{m i}\right)=\int_{\frac{-q_{b i}\left(\lambda_{b i}+2 \delta_{y_{m i}}\right)}{\sigma_{b}}}^{+\infty} \int_{\frac{-q_{m i}\left(\lambda_{m i}+2 \delta_{y_{b i}}\right)}{\sigma_{m}}}^{+\infty} \phi_{2}\left(\frac{\varepsilon_{b i}}{\sigma_{b}}, \frac{\varepsilon_{m i}}{\sigma_{m}} ; s_{i} \rho_{b m}\right) d \frac{\varepsilon_{m i}}{\sigma_{m}} d \frac{\varepsilon_{b i}}{\sigma_{b}}-q_{b i}
\end{aligned}
$$

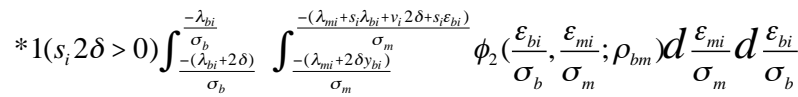




$$
\begin{aligned}
=\Phi_{2}\left(\frac{q_{b i}\left(\lambda_{b i}+2 \delta y_{m i}\right)}{\sigma_{b}}, \frac{q_{m i}\left(\lambda_{m i}+2 \delta y_{b i}\right)}{\sigma_{m}} ; s_{i} \rho_{b m}\right) \\
-q_{b} * 1\left(s_{i} 2 \delta>0\right) \int_{\frac{-\left(\lambda_{b i}+2 \delta\right)}{\sigma_{b}}}^{\frac{-\lambda_{b i}}{\sigma_{b}}} \int_{\frac{-\left(\lambda_{m i}+2 \delta y_{b i}\right)}{\sigma_{m}}}^{\frac{-\left(\lambda_{m i}+s_{i} \lambda_{b i}+v_{i} 2 \delta+s_{i} \varepsilon_{b i}\right)}{\sigma_{m}}} \varphi_{2}\left(\frac{\varepsilon_{b i}}{\sigma_{b}}, \frac{\varepsilon_{m i}}{\sigma_{m}} ; \rho_{b m}\right) d \frac{\varepsilon_{m i}}{\sigma_{m}} d \frac{\varepsilon_{b i}}{\sigma_{b}}
\end{aligned}
$$




\section{Appendix 4B Truncated bivariate probit with upper and lower bounds and the GHK simulator}

$\left(\begin{array}{l}\varepsilon_{1} \\ \varepsilon_{2}\end{array}\right)--T N\left(\mu, \sum ; a, b\right) \equiv N\left(\mu, \sum\right)$ s.t. $a<\varepsilon<b$

$\mathrm{L}$ be the lower triangular Cholesky factorization of $\Sigma$ with elements

$\left(\begin{array}{ll}l_{11} & 0 \\ l_{21} & l_{22}\end{array}\right)$

Let $\left(\mathrm{v}_{1}, \mathrm{v}_{2}\right)$ denote a vector of independent truncated standard normal random variables with upper truncation and lower truncation point. Then we can derive (4.b1) as:

$$
\left\{\begin{array}{c}
\frac{a_{1}-\mu_{1}}{l_{11}}<v_{1}<\frac{b_{1}-\mu_{1}}{l_{11}} \\
\frac{a_{2}-\mu_{1}-l_{21} v_{1}}{l_{22}}<v_{2}<\frac{b_{2}-\mu_{1}-l_{21} v_{1}}{l_{22}}
\end{array}\right.
$$

The above suggests that we can draw $\left(\mathrm{v}_{1}, \mathrm{v}_{2}\right)$ recursively. In order to do so, we first use $z_{\mathrm{i}}$ $(i=1,2)$ to represent the draw from truncated standard normal random variables $(\mu=$ $0)$, and

$z_{1}=\Phi_{i}\left(\frac{b_{1}}{l_{11}}\right)-\Phi_{i}\left(\frac{a_{1}}{l_{11}}\right)$. Then we can generate $\mathrm{v}_{1}$ from

$v_{1}=\Phi_{i}^{-1}\left(z_{1}\right)$. And we can draw $z_{2}$ in the same way,

$z_{2}=\Phi_{i}^{-1}\left(\frac{b_{2}-l_{21} v_{1}}{l_{22}}\right)-\Phi_{i}^{-1}\left(\frac{a_{2}-l_{21} v_{1}}{l_{22}}\right)$

Hence, the truncated bivariate probability can be written as:

$\operatorname{Pr} o b\left(a_{1}<\varepsilon_{1}<b_{1}\right) \operatorname{Pr} o b\left(a_{2}<\varepsilon_{2}<b_{2} \mid a_{1}<\varepsilon_{1}<b_{1}\right)$

$=\operatorname{Pr} o b\left(\frac{a_{11}}{l_{11}}<v_{1}<\frac{b_{11}}{l_{11}}\right) \operatorname{Pr} o b\left(\frac{a_{2}-l_{21} v_{1}}{l_{22}}<v_{2}<\frac{b_{2}-l_{21} v_{1}}{l_{22}}\right)$

$\operatorname{Pr} o b_{G H K}=\frac{1}{D}\left[\Phi\left(\frac{b_{1}}{l_{11}}\right)-\Phi\left(\frac{a_{1}}{l_{11}}\right)\right] *\left[\Phi\left(\frac{b_{2}-l_{21} *\left[\Phi_{i}^{-1}\left(z_{1}\right)\right]}{l_{22}}\right)-\Phi\left(\frac{a_{2}-l_{21} *\left[\Phi_{i}^{-1}\left(z_{1}\right)\right]}{l_{22}}\right)\right]$ 



\section{Chapter 5}

\section{Statistical inference with multiple inequality restrictions}

\subsection{Introduction}

Statistical inferences with inequality (one-sided) restrictions arise frequently in complementarity studies. Inequality restrictions are often imposed on model parameters due to the potential complementary or substitutive relationships between explanatory variables.

When one tries to test complementarity among three or more activities in a linear model, multiple inequality restrictions are imposed to the estimated parameters and the corresponding statistical inference will be based on multivariate one-sided hypotheses. Tests of complementarity based on inequality restrictions have been discussed in several previous studies (Mohnen and Röller, 2005; Lokshin et al., 2007; Carree et al., 2011). However, little has been written regarding the validity of these hypotheses. In particular, very little research has been done on the one-sided restricted inferences for models with more than two potential complementary/substitutive activities. This chapter attempts to fill this gap.

The empirical analysis uses simulated datasets to demonstrate how different types of hypotheses are used for testing complementarity. The findings reveal the biases that potentially exist in different types of multivariate one-sided tests of complementarity. The results try to explain which hypothesis is preferable across different sample sizes and values of goodness of fit. 
The next section reviews previous relevant studies and explains the one-sided tests of hypotheses in models with multiple inequality constraints. Section 5.3 introduces the data drawing process and compares the results generated from different types of hypotheses. The conclusion will be drawn in the last section.

\subsection{Complementarity with more than two activities}

\subsubsection{Definition of pairwise complementarity}

Suppose there are two activities $x_{i}, x_{j}$ and $Z$ is a vector of exogenous variables. The objective function $f\left(x_{i}, x_{i}, Z\right)$ is supermodular if for all values of $x_{1, \ldots,} x_{n}$, at least one of the following inequality holds:

$\frac{\partial^{2} f\left(x_{i}, x_{j}, Z\right)}{\partial x_{i} \partial x_{j}}>0$ (if $\mathrm{x}$ is continuous term)

$f\left(x_{i}=1, x_{j}=1 \mid Z\right)+f\left(x_{i}=0, x_{j}=0 \mid Z\right)-f\left(x_{i}=1, x_{j}=0 \mid Z\right)-f\left(x_{i}=0, x_{j}=1 \mid Z\right)>0$

(if $\mathrm{x}$ is dichotomous term)

$\mathrm{x}_{\mathrm{i}}$ and $\mathrm{x}_{\mathrm{j}}$ are complements if one activity $\mathrm{x}_{\mathrm{i}}$ in the objective function increases conditional on the increase of another activity $\mathrm{x}_{\mathrm{j}}$, for inequality function (5.1), or the presence of one activity $x_{i}$ increases the marginal return of another activity $x_{j}$, for inequality function (5.2), in both cases controlling for other exogenous effects. In the case of substitutability, the inequality signs are reversed.

In order to build up a clear methodology to empirically test the complementary relationship among two or more economic activities, two types of complementarity are distinguished: "objective complementarity" and "behavioral complementarity" (see chapter 2 for more details). Regarding the testing methods, two approaches have been adopted $^{51}$. The "Production approach" (PROD) is broadly used in estimating "objective complementarity" by looking at the estimated cross-term coefficients in the objective function (Mohnen and Röller, 2005; Belderbos, 2004; Cassiman and Veugelers, 2006). The "Correlation approach" (CORR) uses the pairwise correlation coefficients after controlling for the firm specificities to identify the complementary/substitutive relationship between two activities. This approach is adopted to test the "behavioral

${ }^{51}$ Here we only look at the complementarity among activities that are dichotomous choices. 
complementarity" since the estimation is only based on the adoption decisions without involving an objective function. A recently developed approach introduced by Miravete and Pernías (Miravete and Pernías, 2006; Kretschmer, et al., 2012) has been adopted to test for "behavioral complementarity" and can be classified somewhere between the PROD approach and CORR approach. The authors try to estimate the choice equations together with an objective function (see chapter 4.3 for more details).

When one tries to test complementarity among three or more activities, the CORR approach can be implemented in a multivariate framework (Arora and Gambardella, 1990; Belderbos et al., 2006; Tether and Tajar, 2008; Schmiedeberg, 2008). For the PROD approach, it is more complicated because it involves estimation with multiple inequality restrictions imposed on coefficients. Incorporating only the cross-term of two activities one by one in the objective equation (Single cross-term) $)^{52}$ or including all pairwise cross-terms (All cross-term) ${ }^{53}$ is likely to generate biased estimation due to the fact that these two structures ignore the cross-partial effects between extra activities and the cross-terms of higher-order interactions (e.g. the third-order, the fourth-order etc. ${ }^{54}$.

\subsubsection{Studies of complementarity with more than two activities}

The nature of complementarity makes it appealing to researchers who intend to investigate synergies among economic activities, strategies and policies. The methodology of testing for complementarity has been broadly applied in empirical studies after it was first introduced in economics by Edgeworth (1881) and further developed by Milgrom and Roberts (1990a; 1995). Table 5.1 below summarizes representative empirical innovation related studies in testing complementarity for cases of more than two activities or strategies. As shown in column 6, most previous studies are either using the "All cross-term" or the "Single cross-term" approach by ignoring the full cross-term specification, which are the interaction terms of third- or higher-order.

The study of complementarity between innovation policies conducted by Mohnen and Röller (2005) adopted the full cross-term function. Similarly, Belderbos et al. (2006) adopted the same specification in testing complementarity among four co-operative activities of a firm. The difference between these two studies lies in the statistical

\footnotetext{
52 See example from Bresnahan et al. (2002); Black and Lynch (2001); Lokshin et al. (2007)

53 See example from Caroli and Van Reenen (2001); Lokshin et al. (2010)

${ }^{54}$ Lokshin et al. (2007) and Carree et al. (2011) provide an excellent review.
} 
inference with multiple inequality restrictions. The multivariate one-sided hypotheses are defined differently. The former study uses strictly complementarity hypothesis $H_{1}: R \beta>r$ vs $H_{1}: R \beta !>r$ (! denotes "not") while the latter uses non-strictly complementarity hypothesis $H_{0}: R \beta=r$ vs $H_{1}: R \beta \geq r$. The hypothesis testing methods adopted in these two studies are Wald test and Likelihood Ratio test respectively. Gourieroux et al. (1982) explained these two methods in linear model with inequalities constraints, and they found out that the relationship between the likelihood ratio test and the Wald test are the same as in the equality constrained case.

Table 5. 1 Complementarity in innovation studies with more than two activities or strategies

\begin{tabular}{|c|c|c|c|c|c|c|}
\hline Study by & Data & $\begin{array}{l}\text { Dependent } \\
\text { variables }\end{array}$ & $\begin{array}{l}\text { Activities/strateg } \\
\text { ies }\end{array}$ & $\begin{array}{l}\text { No of } \\
\text { activities }\end{array}$ & Method & Findings \\
\hline $\begin{array}{l}\text { Arora and } \\
\text { Gambardella, } \\
1990\end{array}$ & $\begin{array}{l}\text { US, European, and } \\
\text { Japanese chemical and } \\
\text { pharmaceutical } \\
\text { producers, 1978-1988 }\end{array}$ & $\begin{array}{l}\text { External } \\
\text { linkages }\end{array}$ & $\begin{array}{l}\text { External linkages } \\
\text { (firm, university, third } \\
\text { party and external } \\
\text { sourcing) }\end{array}$ & 4 & $\begin{array}{l}\text { CORR } \\
\text { (conditional } \\
\text { correlation) }\end{array}$ & $\begin{array}{l}\text { The strategies are } \\
\text { positively correlated even } \\
\text { after controlling for firm- } \\
\text { specific characteristics. }\end{array}$ \\
\hline $\begin{array}{l}\text { Parthasarthy } \\
\text { and Sethi, } \\
1993\end{array}$ & $\begin{array}{l}87 \text { Flexible automation } \\
\text { user }\end{array}$ & $\begin{array}{l}\text { Flexible } \\
\text { automation }\end{array}$ & $\begin{array}{l}\text { Various strategy and } \\
\text { structure choices }\end{array}$ & 6 & $\begin{array}{l}\text { PROD } \\
\text { (Single } \\
\text { cross-term) }\end{array}$ & $\begin{array}{l}\text { Some complements while } \\
\text { some substitutes }\end{array}$ \\
\hline $\begin{array}{l}\text { Ichniowski, } \\
\text { Shaw and } \\
\text { Prennushi, } \\
1997\end{array}$ & $\begin{array}{l}36 \text { homogeneous steel } \\
\text { production lines, } \\
\text { monthly panel data }\end{array}$ & Productivity & $\begin{array}{l}\text { Organizational and } \\
\text { human resource } \\
\text { practices }\end{array}$ & 5 & $\begin{array}{l}\text { PROD (All } \\
\text { cross-term) }\end{array}$ & Complementary \\
\hline $\begin{array}{l}\text { Love and } \\
\text { Roper, 1999; } \\
2001\end{array}$ & $\begin{array}{l}\text { Product Development } \\
\text { Survey (PDS): UK, } \\
\text { German and Irish } \\
\text { plants, } 1994\end{array}$ & $\begin{array}{l}\text { Innovation } \\
\text { intensity; } \\
\text { Innovation } \\
\text { success }\end{array}$ & $\begin{array}{l}\text { R\&D, tech transfer } \\
\text { and network }\end{array}$ & 3 & $\begin{array}{l}\text { PROD } \\
\text { (Single } \\
\text { cross-term) }\end{array}$ & $\begin{array}{l}\text { Complementarity found } \\
\text { in the case of UK and } \\
\text { Ireland }\end{array}$ \\
\hline $\begin{array}{l}\text { Damijan et } \\
\text { al., } 2003\end{array}$ & $\begin{array}{l}\text { Firm-level data for eight } \\
\text { transition countries, } \\
\text { 1994-1998 }\end{array}$ & $\begin{array}{l}\text { Total factor } \\
\text { productivity }\end{array}$ & $\begin{array}{l}\text { FDI, R\&D and tech } \\
\text { importing }\end{array}$ & 3 & $\begin{array}{l}\text { PROD (All } \\
\text { cross-term) }\end{array}$ & \\
\hline $\begin{array}{l}\text { Yannis et al., } \\
2004\end{array}$ & $\begin{array}{l}\text { Greece, Italy, Denmark, } \\
\text { UK, France, Germany } \\
\text { and the Netherlands, } \\
558 \text { innovative firms, } \\
2000\end{array}$ & $\begin{array}{l}\text { Innovation } \\
\text { intensity }\end{array}$ & $\begin{array}{l}\text { Openness, } R \& D \text { and } \\
\text { human resources } \\
\text { training }\end{array}$ & 3 & $\begin{array}{l}\text { PROD (All } \\
\text { cross-term) }\end{array}$ & $\begin{array}{l}\text { Both internal capabilities } \\
\text { and openness are } \\
\text { complementary for } \\
\text { innovative performance }\end{array}$ \\
\hline $\begin{array}{l}\text { Mohnen and } \\
\text { Röller, } 2005\end{array}$ & $\begin{array}{l}\text { CIS }^{55} 1 \text { survey data from } \\
\text { four countries: Ireland, } \\
\text { Denmark, Germany, } \\
\text { and Italy. }\end{array}$ & $\begin{array}{l}\text { Innovation } \\
\text { intensity; } \\
\text { Innovation } \\
\text { success }\end{array}$ & $\begin{array}{l}\text { Four kinds of } \\
\text { obstacles to } \\
\text { innovation }\end{array}$ & 4 & $\begin{array}{l}\text { PROD (Full } \\
\text { cross-term } \\
\text { Wald test) }\end{array}$ & $\begin{array}{l}\text { A package of policies will } \\
\text { make firms innovate. }\end{array}$ \\
\hline $\begin{array}{l}\text { Hu et al., } \\
2005\end{array}$ & $\begin{array}{l}\text { Large and medium size } \\
\text { enterprises, 1995-1999 }\end{array}$ & Productivity & $\begin{array}{l}\mathrm{R} \& \mathrm{D} \text {, technology } \\
\text { transfer and FDI }\end{array}$ & 3 & $\begin{array}{l}\text { PROD (All } \\
\text { cross-term) }\end{array}$ & $\begin{array}{l}\text { R\&D complements } \\
\text { technology transfer }\end{array}$ \\
\hline $\begin{array}{l}\text { Belderbos et } \\
\text { al., } 2006\end{array}$ & $\begin{array}{l}\text { Netherlands CIS, } 1996 \\
\text { and } 1998\end{array}$ & $\begin{array}{l}\text { Productivity } \\
\text { growth }\end{array}$ & $\begin{array}{l}\text { Four types of } \\
\text { cooperation partners }\end{array}$ & 4 & $\begin{array}{l}\text { PROD ( } \\
\text { Full cross- } \\
\text { term LR } \\
\text { test) }\end{array}$ & $\begin{array}{l}\text { The joint adoption of } \\
\text { cooperation strategies is } \\
\text { preferred. }\end{array}$ \\
\hline Li, 2011 & $\begin{array}{l}\text { Large and Medium size } \\
\text { SOEs in high-tech } \\
\text { industry, 1995-2004 }\end{array}$ & $\begin{array}{l}\text { Number of } \\
\text { patent }\end{array}$ & $\begin{array}{l}\text { R\&D, domestic } \\
\text { technology and } \\
\text { foreign technology }\end{array}$ & 3 & $\begin{array}{l}\text { PROD } \\
\text { (Single } \\
\text { cross-term) }\end{array}$ & $\begin{array}{l}\text { Imported technology } \\
\text { leveraged by R\&D }\end{array}$ \\
\hline
\end{tabular}

55 Community Innovation Surveys. 


\subsubsection{Modeling complementarity in a linear function}

Consider the linear model

$y=X \beta+u$

where $\mathrm{y}$ is a $(n \times 1)$ vector, $\mathrm{X}$ is a $(n \times k)$ matrix, and $\beta$ is a $(k \times 1)$ vector. $\mathrm{u}$ is an $(n \times 1)$ dimension vector following a normal distribution $N(0, \Omega)$, where $\Omega$ is the variance-covariance matrix. Let $\mathrm{q}$ denote the number of activities. A full cross-term specification for 3 and 4 activities is expressed respectively ${ }^{56}$ as

$$
\begin{aligned}
& y_{q=3}=\beta_{0}+\beta_{1} x_{1}+\beta_{2} x_{2}+\beta_{3} x_{3}+\beta_{12} x_{1} x_{2}+\beta_{13} x_{1} x_{3}+\beta_{23} x_{2} x_{3}+\beta_{123} x_{1} x_{2} x_{3}+u \\
& y_{q=4}=\beta_{0}+\beta_{1} x_{1}+\beta_{2} x_{2}+\beta_{3} x_{3}+\beta_{4} x_{4}+\beta_{12} x_{1} x_{2}+\beta_{13} x_{1} x_{3}+\beta_{14} x_{1} x_{4}+\beta_{23} x_{2} x_{3} \\
& +\beta_{24} x_{2} x_{4}+\beta_{34} x_{3} x_{4}+\beta_{123} x_{1} x_{2} x_{3}+\beta_{124} x_{1} x_{2} x_{4}+\beta_{234} x_{2} x_{3} x_{4}+\beta_{1234} x_{1} x_{2} x_{3} x_{4}+u
\end{aligned}
$$

For the case where $\mathrm{x}$ is continuous, the cross derivative $\partial^{2} y / \partial x_{1} \partial x_{2}$ will be used to test for complementarity between $x_{1}$ and $x_{2}$. It equals to $\beta_{12}+\beta_{123} x_{3}$ for equation (5.4) and $\beta_{12}+\beta_{123} x_{3}+\beta_{124} x_{4}+\beta_{1234} x_{3} x_{4}$ for equation (5.5).

The current study focuses on cases where $\mathrm{x}$ is dichotomous. According to (5.2), $x_{1}$ and $x_{2}$ are complementary activities only if at least one of the inequality conditions holds for each

$$
\begin{aligned}
& \mathrm{q}=3\left\{\begin{array}{l}
f_{\text {complement }}\left(x_{1}, x_{2} \mid x_{3}=0\right)=\beta_{12} \geq 0 \\
f_{\text {complement }}\left(x_{1}, x_{2} \mid x_{3}=1\right)=\beta_{12}+\beta_{123} \geq 0
\end{array}\right. \\
& \mathrm{q}=4\left\{\begin{array}{l}
f_{\text {complement }}\left(x_{1}, x_{2} \mid x_{3}=0, x_{4}=0\right)=\beta_{12} \geq 0 \\
f_{\text {complement }}\left(x_{1}, x_{2} \mid x_{3}=1, x_{4}=0\right)=\beta_{12}+\beta_{123} \geq 0 \\
f_{\text {complement }}\left(x_{1}, x_{2} \mid x_{3}=0, x_{4}=1\right)=\beta_{12}+\beta_{124} \geq 0 \\
f_{\text {complement }}\left(x_{1}, x_{2} \mid x_{3}=1, x_{4}=1\right)=\beta_{12}+\beta_{123}+\beta_{124}+\beta_{1234} \geq 0
\end{array}\right.
\end{aligned}
$$

\footnotetext{
${ }^{56}$ We only give example of $\mathrm{q}=3$ and $\mathrm{q}=4$. For cases where $\mathrm{q}>4$, the specification can be easily expanded based on the definition given.
} 
The inverse inequality sign for (5.6) and (5.7) will indicate a substitutive relationship between $x_{1}$ and $x_{2}{ }^{57}$.

The procedure of testing for complementarity follows three steps ${ }^{58}$. First, construct the objective function. Whether the objective function is well specified will directly influence the power of the test. The indicator R-square (goodness of fit) in OLS can be used to measure the quality of the model specification. The linear specification (5.3) will be used for the current study. Another important factor influencing the statistical power of the test is the number of observations. A larger sample is likely to generate more precise results.

Second, once the objective function is specified, one can define estimators associated with inequality constraints (5.6) and (5.7) for $\mathrm{q}=3$ and $\mathrm{q}=4$ respectively. We assume the unconstrained estimator is $\bar{\beta}$ and the inequality constrained estimator $\hat{\beta}_{r}$ is the solution of

$\max -(y-X \beta)^{\prime} \Omega^{-1}(y-X \beta)$

subject to (5.6) or (5.7)

where $\Omega$, the variance-covariance matrix of the error term, can be consistently estimated by $\bar{\Omega}^{59}$. Function (5.8) is a quadratic form which can be solved by several algorithms (e.g Judge and Takayama, 1966; Liew, 1976; Gourieroux et al., 1982).

The third step uses either the likelihood ratio test (Gourieroux, Holly et al., 1982) or the Wald test (Kodde and Palm, 1986) to check the statistical significance of coefficients with inequality constraints.

\subsubsection{The multivariate one-sided hypotheses}

In the following discussions, we assume that the error term in the linear equation (5.3) follows a normal distribution. The different types of one-sided hypotheses in connection with complementarity are (“"” denotes "not") ${ }^{60}$ :

\footnotetext{
${ }^{57}$ The prior literature (Athey and Stern, 1998; Mohnen and Röller, 2005) denotes $x_{1}$ and $x_{2}$ as "strictly complementarity" if the inequalities in (5.6) and (5.7) are strict inequalities.

58 These procedures only apply for testing "objective complementarity".

${ }_{59} \bar{\Omega}$ and $\bar{\beta}$ can be obtained by ML, OLS or GLS.
} 


$\begin{array}{lll}\text { Hypothesis Test } 1 \text { (HT1) } & H_{0}: R \beta=0 \quad \text { vs } & H_{1}: R \beta \geq 0 \\ \text { Hypothesis Test 2 (HT2) } & H_{0}: R \beta \geq 0 \quad \text { vs } & H_{1}: R \beta ! \geq 0\end{array}$

$\mathrm{R}$ is a matrix with dimension of $(p \times k)$ which defines the imposed inequality restrictions on the estimated parameters, $\mathrm{p}$ being the number of inequality constraints that have to be tested simultaneously. In the case of more than two activities, $\mathrm{p}$ will be equal to $2^{q-2}$. HT1 (Hypothesis Test 1) tests equality against at least one inequality holding. Rejecting the null of HT1 suggests the existence of complementarity. HT2 (Hypothesis Test 2) tests if all $R \beta$ are greater or equal to zero against at least one violation in the null hypothesis (not all $R \beta$ are bigger or equal to zero). The complementarity will be concluded if we accept the null of HT2.

The potential problem with HT1: Non-exhaustiveness

One important thing should be noted here is that the HT1 is not exhaustive. It is adopted if one believes that the return of adopting activities simultaneously should be at least as high as adopting them individually. In the absence of exhaustiveness, what happens if the true parameter value is in the region which is not covered by either the null or the alternative hypothesis? For example, $R \beta<0$. In this case, HT1 would be misleading and the test at the $\alpha$ level of confidence will be biased in favour of the null. Grömping (2010) explained the potential problem as: "interpretation of test results in multiple inequality restrictions should take into account the a-priori nature of the restriction, and one must realize that the only guaranteed null hypothesis is the stated null hypothesis" ${ }^{61}$. In the current research of complementarity between economic activities, rejecting HT1 indicates at least one violation of the equality conditions. It does not guarantee that all inequalities are positive. The first row from Table 5.2 illustrates all possible directions of $R \beta$. In the second row of Table 5.2, the results (accepting or rejecting the null hypothesis) based on the HT1 are given. If $R \beta$ falls into the nondefining space of HT1 - " $R \beta<0 ”$, then the test results would suggest accepting the null.

\footnotetext{
${ }^{60}$ It is worthwhile to mention that, in general, the null hypothesis is based on one of these three signs: = (equal to), $\leq$ (less than or equal to), or $\geq$ (greater than or equal to). In particular, the equality is always a part of the null hypothesis and the alternative hypothesis can never include an equal sign.

${ }^{61}$ Some other studies also addressed this issue, such as Cohen, Kemperman, and Sackrowitz (2000), Perlman and Wu (2003), and Silvapulle (1997).
} 
Even though the conclusion drawn based on this results is correct (no complementary relationship between the explanatory variables), it is somehow a result biased in favour of the null because the acceptance of the null hypothesis is not due to the equality $(R \beta=0)$. In the last column with at least one inequality holding for both " $R \beta \leq 0$ " and " $R \beta \geq$ 0 " respectively, the test result would suggest rejecting the null even if there is no existence of complementarity. In these circumstances, HT1 is misleading because it can reject the null even in cases there is no complementarity. Hence, we suggest adopting the HT1 in complementarity studies if only one has adequate reasons to believe that the values of $R \beta$ are in one direction (all non-negative or non-positive). Lokshin et al. (2007) suggested that comparing the log-likelihood ratio of different specifications would avoid the potential the non-exhaustiveness error. Firstly, this method firstly requires the model to be estimated three times: unconstrained, less or equal (“ $\leq$ ”) and greater or equal (" $\geq$ "). Then the one that produced the highest log-likelihood value will be used as alternative in HT1 against the equality restriction ${ }^{62}$.

Table 5. 2 Conditions for accepting or rejecting the Null of HT1 and HT2 in testing for complementarity

\begin{tabular}{l|l|l|l|l}
\hline & All “=” & All “ $\leq{ }^{*}$ & All “ $\geq{ }^{*}$ & $\begin{array}{l}\text { Both " } \leq " \text { and “ } \\
\text { * }\end{array}$ \\
\hline HT1 Null & Accept & Accept & Reject & Reject \\
\hline HT2 Null & Accept & Reject & Accept & Reject \\
\hline
\end{tabular}

Situations with $*$ indicates: at least one inequality holds.

Both " $\leq$ " and " $\geq$ " indicates: the results are falling into both negative and positive parts of p-dimensional space, specifically, at least one inequality holds for both " $\leq$ " and " $\geq$ ".

Superscription "F" indicates: the false conclusion in terms of complementarity.

The potential problem with HT2: there are only equality restrictions

Another important point which needs to be noted is that the null hypothesis in HT2 does not rule out the possibility of all equalities holding. Therefore, accepting the null of HT2 cannot give a concrete conclusion either. The third row of Table 5.2 describes the acceptance or rejection of the null of HT2 for different values of $R \beta$. HT2 is defined to

\footnotetext{
${ }^{62}$ This method indeed simplifies the testing procedure in the sense that it does not require us to use HT2 to solve the potential bias induced by non-exhaustiveness. However, the tradeoff here is that it imposes more computation by estimating the model four times (unconstrained, less or equal (" $\leq$ "), greater or equal (" $\geq$ ") and with equality constrained). In the procedure we proposed later, which takes into account both TH1 and TH2, the model only needs to be estimated only three times (unconstrained, greater or equal (" $\geq ")$ and with equality constrained).
} 
be exhaustive and all possible values of $R \beta$ are covered either in the null or in the alternative hypothesis. If one concludes complementarity based on the acceptance of the null in HT2, then the results are false when all values of $R \beta$ are equal to zero.

We suggest that a test procedure derived by a method that takes into account both TH1 and $\mathrm{TH} 2{ }^{63}$ has a higher statistical power ${ }^{64}$ than test procedures which take only one of the two into account. The main purpose of this chapter is to check whether TH1 or TH2 individually will also produce a satisfactory statistical power. TH1 individually means that we only take account three restrictions (unconstrained, greater or equal and equality constrained) whereas TH2 individually means only two restrictions (unconstrained, greater or equal). Focusing on only one hypothesis test will reduce the computation work substantially, especially the later one. The Monte Carlo experiment shows that, in some situations, only conducting TH1 or TH2 may generate satisfactory results. Situations associate with the sample size and the model specification.

\subsubsection{The hypothesis test method: likelihood ratio test}

For one-sided hypotheses, various testing methods such as likelihood ratio, Wald and score tests have been proposed ${ }^{65}$. In the following, we provide a brief review of multivariate one-sided hypothesis testing (HT1 and HT2) for complementarity studies by using the likelihood ratio test ${ }^{66}$.

The likelihood ratio test statistic (LRT) is defined (Greene, 2003) as

$$
\xi_{L R}=-2 \log \Lambda=2\left(\hat{L}_{1}-\hat{L}_{0}\right)
$$

\footnotetext{
${ }^{63}$ More efficient results can be drawn by accepting the null hypothesis of HT2 and rejecting the null hypothesis of HT1 in testing for complementarity. Another way to produce exactly the same results is by testing either HT1 or HT2 twice, with respect to complementarity and substitutability respectively. The same as in the study by Lokshin et al. (2007), it requires the model to be estimated four times, once unconstrained, with equality constrained, with complementary restrictions and with substitutive restrictions. Specifically, two activities are complementary only if the following two conditions are satisfied: 1) rejecting (accepting) the null of HT1 (HT2) in the complementarity test; 2) accepting (rejecting) the null of HT1 (HT2) in the substitutability test. It only requires us to look at HT1 or HT2 individually. We have tried these three ways of hypothesis testing in our empirical analysis; exactly the same results were generated.

${ }^{64}$ The higher statistical power here indicates a higher value of sensitivity, which is used as an indicator to measure the test performance. See section 5.3.1 for more details.

65 See Silvapulle and Sen (2004) for a detailed review.

${ }^{66}$ Gourieroux (1982) conducted detail comparisons of the LRT, the Wald test and the score test. The result revealed that these three hypothesis tests methods generate roughly the same results.
} 
where $\hat{L}_{1}$ and $\hat{L}_{0}$ are the maximum value of the logarithm of the likelihood function under the alternative hypothesis $H_{1}$ and the null hypothesis $H_{0}$. Obtaining $\hat{\beta}_{1}$ by maximizing (5.8), it is verified that $\xi_{L R}$ is the optimum value of the objective function of the minimization problem (see Gourieroux, 1982),

HT1: $\xi_{L R}=\min \left[\left(\bar{\beta}-\hat{\beta}_{0}\right)^{\prime}\left(X^{\prime} \Omega^{-1} X\right)\left(\bar{\beta}-\hat{\beta}_{0}\right)-\left(\bar{\beta}-\hat{\beta}_{1}\right)^{\prime}\left(X^{\prime} \Omega^{-1} X\right)\left(\bar{\beta}-\hat{\beta}_{1}\right)\right]$

HT2: $\xi_{L R}=\min \left(\bar{\beta}-\hat{\beta}_{1}\right)^{\prime}\left(X^{\prime} \Omega^{-1} X\right)\left(\bar{\beta}-\hat{\beta}_{1}\right)$

where $\bar{\beta}$ and $\hat{\beta}_{0}$ are unconstrained estimator and the estimator under equality constraints. $\hat{\beta}_{1}$ are the estimators subject to constraints (5.6) or (5.7) and $R \hat{\beta}_{1}$ represents the point in the nonnegative orthant that is closest to $R \bar{\beta}$ - orthogonal projection of $R \bar{\beta}$ to the null parameter space (5.6) or (5.7). Similar to the Wald-type statistic, the LRT statistics here also measures the squared "distance" between $R \hat{\beta}_{1}$ and $R \bar{\beta}$. Figure 5.1 is an example of three activities $(\mathrm{p}=2)$ for HT2, when $\left(X^{\prime} \Omega^{-1} X\right)^{-1}=\mathrm{I}$ (identity matrix), the projection of $R \bar{\beta}$ to the null parameter space varies depending on the location where the $R \bar{\beta}$ falls. Then $R \hat{\beta}_{1}$ is given as

$(0,0)$

$$
\text { if } R \bar{\beta} \in Q_{1}
$$

$\left(\beta_{12}, 0\right)$

if $R \bar{\beta} \in Q_{2}$

$\left(\beta_{12}, \beta_{12}+\beta_{123}\right) \quad$ if $R \bar{\beta} \in Q_{3}$

$\left(0, \beta_{12}+\beta_{123}\right) \quad$ if $R \bar{\beta} \in Q_{4}$

The conditional distribution is a mixture of chi-squared distributions (Gourieroux et al., 1982; Kudo, 1963; Perlman, 1969; Kodde and Palm, 1986) which can be written respectively as

$$
\operatorname{Pr}(\xi \geq c)=\sum_{i=0}^{p} \operatorname{Pr}\left[\chi^{2}(i) \geq c\right] w(p, i)
$$


where $w(p, i)$ denotes the probability that i of the p elements of $R \hat{\beta}$ are strictly positive. $\chi^{2}(0)$ is the unit at the origin ${ }^{67}$. c represents the critical value of the probability of the test statistics at a given level of significance ${ }^{68}$.

Figure 5.1 Orthogonal projection of $R \bar{\beta}$ to the Null parameter space for HT2 (equation 5.6)

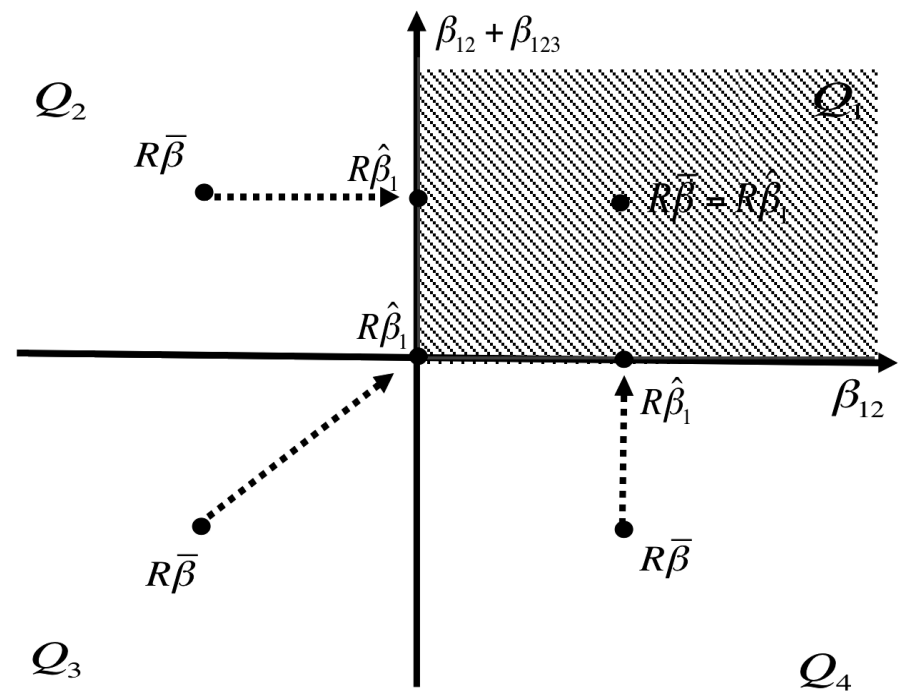

\subsection{A comparison of HT1 and HT2 in simulation experiments}

\subsubsection{Data drawing process}

In order to easily compare the statistical power of HT1 and HT2 in case of complementarity, the estimation will be performed on simulated data. We would like to verify (1) that HT1 yields biased results in testing complementarity and tends to overestimate the potential complementarities if one has no support to believe that the values of $R \beta$ are in one direction (all non-negative or non-positive); (2) that a test

${ }^{67}$ The geometrical proof can be found in Gourieroux et al. (1982).

${ }^{68}$ The simulations are done with statistical program $\mathrm{R}$. The programming code is available upon request. 
procedure that accounts for both HT1 and HT2 has a better performance; (3) that in some situations, using only one test of hypothesis can also generate satisfactory results.

Since most of the empirical studies that investigate pairwise complementarity among multiple activities use dichotomous data, the model adopted in the analysis will be based on equation (5.4) and (5.5) where $\mathrm{X}$ are discrete choice variables. The criteria for $x_{1}$ and $x_{2}$ to be complementary are the inequality constraints (5.6) and (5.7) for respectively 3 and 4 activities.

The sample size of the simulation experiment is set to 500, 1000 and 5000. The data generation follows the process proposed by Lokshin et al. (2007). First, elements in $(k \times 1)$ dimension vector $\beta$ which follow a standard normal distribution $\sim \mathrm{N}(0,1)$ are randomly and independently drawn. Second, construct a discrete variable matrix X composed of vector $x_{1} \ldots x_{123}{ }^{69}$, which elements are set to 1 if the corresponding element in a standard multivariate random draw is positive. Third, use equation (5.4) and (5.5) to construct values of y based on $x_{i}$ and $\beta$. A normally distributed residual vector will be used to indicate the explanatory power of the model specification. The variance of the residual vector is set to values $0.025,1$ and 3.25 to represent a desired $R^{2}{ }^{70}$.

The above processes will be repeated 10,000 times. Each time, we categorize $x_{1}$ and $x_{2}$ as complementary if randomly drawn coefficients satisfy $\beta_{12} \geq 0$ and $\beta_{12}+\beta_{123} \geq 0$ with at least one inequality restriction holding strictly. It will be classified in the substitutive group if $\beta_{12} \leq 0$ and $\beta_{12}+\beta_{123} \leq 0$ with at least one inequality restriction holding strictly. The rest will be put in the inconclusive group. The inequality conditions (5.7) will be applied in the case of 4 activities.

Results of testing pairwise complementarity/substitutability among 3 activities are presented in Table 5.3 with sample size 500, 1000 and 5000 respectively. Table 5.4 gives the results for 4 activities. Statistics are generated by using the $\mathrm{LRT}^{71}$. After the regression on each draw (repetition), one set of estimated coefficients will be given.

\footnotetext{
${ }^{69}$ In the case of 4 activities, $x_{i}$ is composed of $x_{1} \ldots x_{1234}$.

${ }^{70}$ Lokshin et al. (2007) has shown that variances of the residual equal to $0.025,1$ and 3.25 respectively represent R-squares of $0.9,0.5$ and 0.1 .

${ }^{71}$ The significant level of both tests is set at 90 per cent. We have tried with 95 and 99 per cent significant levels. Only limited change has been found. We have also performed the estimation with the Wald test. Results are almost equivalent to those with LRT.
} 
Three types of hypotheses - HT1, HT2 and HT1\&HT2 - are applied in the estimated coefficient for testing the complementarity/substitutability between two activities and hence, the conclusion will be drawn three times. The statistical results are decomposed according to their actual and tested relationships. Take the upper left panel of Table 5.3 as an example, it presents the results of 3 activities with 500 observations and R-square value of 0.9. Columns give the number of actual relationships whereas rows give the number of tested relationships after 10,000 repetitions. Statistical results are given for subcategories HT1, HT2, and HT1\&HT2 respectively. Before the estimation, the actual relationship for each repetition is observed. There are in total $3740(3722+18)$ estimations are actual complementary, 3767(6+3761) estimations are actually substitutive and 2493(2149+344) estimations are actually neither complementary nor substitutive (None $)^{72}$. After repeating the estimations by 10,000 times, As the row "Complem.*" and "Complem.**" shows, there are $5877(3722+6+2149){ }^{73}$ repetitions that concluded in favor of complementarity by using HT1 and 4066(3738+24+304) cases for HT2. By using HT1\&HT2, there are $3987(3720+1+266)$ repetitions that concluded in favor of complementarity.

Two statistical measurements are used to compare HT1, HT2 and HT1\&HT2. Tables 5.5 and 5.6 are the statistics with respect to these two measurements: sensitivity and accuracy. Sensitivity measures the proportion of actual complementarities which are correct identified after 10,000 repetitions. It is calculated as True Positives ${ }^{74}$ divided by the summation of True Positives plus False Positives. Accuracy measures the proportion of correct conclusions divided by the number of repetitions. It is calculated as the summation of True Positives plus True Negatives divided by 10,000. Take the upper left panel of Table 5.3 as an example. Under the subcategory HT1\&HT2, there are in total 3987 (of which 3720 cases of actual complementarity, 1 case of actual substitutability and 266 cases of actually no relationship) out of 10,000 estimations that are concluded to have complementarity for 3 strategies with an R-square of 0.9 and 500 observations. The

\footnotetext{
${ }^{72}$ The number of actual complementarity, substitutability and None are the same for the subcategory of HT1, HT2 and HT1\&HT2.

${ }^{73}$ In a binary classification test, 3722 is the number of True Positives. They measure the number of actual complementarities that are correctly identified. $2155(6+2149)$ is defined as False Positives. It is the number of substitutability (6) and no relationships (2149) that are incorrectly concluded as complementarity. 18 is defined as False Negative: actual complementarities incorrectly identified as "no complementarity". $5932(3743+2189)$ is defined as True Negative: "no complementarity" correctly identified as "no complementarity".

${ }^{74}$ See footnote 73 for the definitions of True Positive, False Positive, True Negative and False Negative.
} 
number of actual cases of complementarity is 3740 (the True Positives, 3720, plus the False Negatives, 20). The sensitivity is $99.47 \%(3720 / 3740)$ and the accuracy is $97.13 \%((3720+3738+1921+28+306) / 10000)^{75}$.

Despite sensitivity is a commonly used statistical indicator to measure the performance of binary classification test, it only account for the proportion of actual positives which are correctly identified as such. For the present study, accuracy is more preferable in the sense that it takes into account both True Positives and True Negatives. For example, there are only slight differences in sensitivity for HT1 and HT2 in the upper left panel of Table 5.5. However, the accuracy shows that, compared with HT1, there is a much higher probability for HT2 to generate a correct conclusion. A preferable hypothesis would be described as $100 \%$ sensitive and $100 \%$ accurate. However, there is sometimes a trade-off between the measures. For instance in the lower left panel of Table 5.5, one would conclude that HT2 is better compared with HT1 based on the sensitivity whereas others might prefer HT1 rather than HT2 due to the relatively higher level of accuracy in HT1. Under such circumstances, we would prefer the hypothesis that generates higher value of accuracy.

One thing should be noted here is that the sensitivity and accuracy of "None" are not given for HT1 and HT2 because the binary classification tests have only be done with respect to complementarity/substitutability. The rejection of such relationships does not provide further information on whether there is actually no relationship.

\subsubsection{Interpretation of the results}

The statistical power of LRT in testing multivariate one-sided hypotheses varies with sample sizes and R-square values. As the sensitivities show in Table 5.5 and Table 5.6 more than $90 \%$ actual complementarities/substitutabilities are correctly identified for the sample with $\mathrm{R}$-square above 0.5 . The sensitivity declines with the decreasing R-square values. The positive correlations between the sensitivity and the R-square are observed for all three types of hypothesis settings. The same relationship is shown for the sensitivity and the number of observations - a larger sample accommodates more consistent results if the sensitivity is used as the measurement.

\footnotetext{
${ }^{75}$ In order to generate comparable results between HT1\&HT2 and the others, the accuracy is calculated based on a binary classification test. Specifically, a complementarity test by using HT1\&HT2 will only give results on "complementarity" or "no complementarity". Therefore, there are in total 9713 cases that are classified as correct conclusions: 3720 true positives and 5993(3738+1921+28+306) true negatives.
} 
Table 5. 3 Monte Carlo results of testing pairwise complementarity in 3 activities $(10,000$ repetitions): decomposition statistics

\begin{tabular}{|c|c|c|c|c|c|c|c|c|c|}
\hline \multirow{3}{*}{$\begin{array}{l}\text { R2 }= \\
\text { Test } \\
\end{array}$} & \multicolumn{9}{|l|}{$90 \%$} \\
\hline & \multicolumn{3}{|c|}{ No.Obs $=500$} & \multicolumn{3}{|c|}{ No.Obs $=1000$} & \multicolumn{3}{|c|}{ No.Obs $=5000$} \\
\hline & \multicolumn{2}{|c|}{ Complem. Substit. } & \multirow{2}{*}{ None } & \multicolumn{2}{|c|}{ Complem. Substit. } & \multirow{2}{*}{ None } & \multirow{2}{*}{ Complem. } & \multirow{2}{*}{ Substit. } & \multirow{2}{*}{ None } \\
\hline HT1 & & & & & & & & & \\
\hline Complem.* & 3722 & 6 & 2149 & 3731 & 3 & 2227 & 3738 & 1 & 2394 \\
\hline $\begin{array}{l}\text { No Complem. } \\
\text { HT2 }\end{array}$ & 18 & 3761 & 344 & 9 & 3764 & 266 & 2 & 3766 & 99 \\
\hline Complem.** & 3738 & 24 & 304 & 3737 & 11 & 214 & 3737 & 2 & 96 \\
\hline $\begin{array}{l}\text { No Complem. } \\
\text { HT1\&HT2 }\end{array}$ & 2 & 3743 & 2189 & 3 & 3756 & 2279 & 3 & 3765 & 2397 \\
\hline Complem. ${ }^{* * *}$ & 3720 & 1 & 266 & 3728 & 0 & 178 & 3734 & 0 & 86 \\
\hline Substit. & 0 & 3738 & 306 & 0 & 3749 & 225 & 0 & 3763 & 90 \\
\hline None & 20 & 28 & 1921 & 12 & 18 & 2090 & 6 & 4 & 2317 \\
\hline $\mathrm{R} 2=$ & \multicolumn{3}{|c|}{$50 \%$} & \multirow{2}{*}{\multicolumn{3}{|c|}{ No.Obs $=1000$}} & \multirow{2}{*}{\multicolumn{3}{|c|}{ No.Obs $=5000$}} \\
\hline True & & Obs $=$ & & & & & & & \\
\hline Test $\longrightarrow$ & \multicolumn{2}{|c|}{ Complem. Substit. } & None & \multicolumn{2}{|c|}{ Complem. Substit. } & \multirow{4}{*}{$\begin{array}{c}\text { None } \\
1580 \\
913\end{array}$} & Complem. & \multicolumn{2}{|c|}{ Substit. $\quad$ None } \\
\hline HT1 & & & & & & & & & \\
\hline Complem.* & 3372 & 24 & 1353 & 3562 & 14 & & 3709 & 6 & 2037 \\
\hline $\begin{array}{l}\text { No Complem. } \\
\text { HT2 }\end{array}$ & 368 & 3743 & 1140 & 178 & 3753 & & 31 & 3761 & 456 \\
\hline Complem. ${ }^{* *}$ & 3722 & 375 & 1112 & 3728 & 195 & 875 & 3735 & 39 & 426 \\
\hline $\begin{array}{l}\text { No Complem. } \\
\text { HT1\&HT2 }\end{array}$ & 18 & 3392 & 1381 & 12 & 3572 & 1618 & 5 & 3728 & 2067 \\
\hline Complem.*** & 3359 & 9 & 666 & 3564 & 10 & 562 & 3705 & 2 & 335 \\
\hline Substit. & 5 & 3377 & 694 & 4 & 3591 & 611 & 0 & 3722 & 368 \\
\hline None & 376 & 381 & 1133 & 172 & 166 & 1320 & 35 & 43 & 1790 \\
\hline $\mathrm{R} 2=$ & $10 \%$ & & & & & & & & \\
\hline $\begin{array}{l} \\
\end{array}$ True & & Obs $=$ & & No. & $\mathrm{ss}=10$ & & & Obs $=50$ & \\
\hline Test & Complem & Substit. & None & Complen & Substit. & None & Complem. & Substit. & None \\
\hline HT1 & & & & & & & & & \\
\hline Complem.* & 1914 & 85 & 477 & 2366 & 60 & 646 & 3340 & 24 & 1260 \\
\hline $\begin{array}{l}\text { No Complem. } \\
\text { HT2 }\end{array}$ & 1826 & 3682 & 2016 & 1374 & 3707 & 1847 & 400 & 3743 & 1233 \\
\hline Complem. ${ }^{* *}$ & 3658 & 1938 & 2014 & 3676 & 1366 & 1886 & 3715 & 425 & 1216 \\
\hline $\begin{array}{l}\text { No Complem. } \\
\text { HT1\&HT2 }\end{array}$ & 82 & 1829 & 479 & 64 & 2401 & 607 & 25 & 3342 & 1277 \\
\hline Complem.*** & 1900 & 71 & 415 & 2388 & 69 & 570 & 3337 & 18 & 391 \\
\hline Substit. & 68 & 1815 & 417 & 48 & 2551 & 537 & 12 & 3393 & 717 \\
\hline None & 1772 & 1881 & 1661 & 1304 & 1147 & 1386 & 391 & 356 & 1078 \\
\hline
\end{tabular}

Notes:

Complementarity with one asterisk (Complem.*) is concluded if the test rejects the null of HT1 in testing for complementarity.

Complementarity with two asterisks (Complem.**) is concluded if the test accepts the null of HT2 in testing for complementarity.

Complementarity with three asterisks (Complem.***) is concluded by using one of the following methods: 1) accepting the null hypothesis of HT2 and rejecting the null hypothesis of HT1 in testing the complementarity; 2) rejecting the null of HT1 in the complementarity test and accepting the null of HT1 in the substitutability test; 3) accepting the null of HT2 in the complementarity test and rejecting the null of HT2 in the substitutability test. We have tried these three ways of hypothesis testing in our empirical analysis, exactly the same results are generated. 
Table 5. 4 Monte Carlo results of testing pairwise complementarity in 4 activities $(10,000$ repetitions): decomposition statistics

\begin{tabular}{|c|c|c|c|c|c|c|c|c|c|}
\hline \multirow{3}{*}{$\begin{array}{ll}\text { R2 }= & \\
\text { Test } & \text { True } \\
\end{array}$} & \multicolumn{9}{|l|}{$90 \%$} \\
\hline & \multicolumn{3}{|c|}{ No.Obs $=500$} & \multicolumn{3}{|c|}{ No.Obs $=1000$} & \multicolumn{3}{|c|}{ No.Obs $=5000$} \\
\hline & \multicolumn{2}{|c|}{ Complem. Substit. } & \multirow[t]{2}{*}{ None } & \multicolumn{2}{|c|}{ Complem. Substit. } & \multirow[t]{2}{*}{ None } & \multirow[t]{2}{*}{ Complem. } & \multirow[t]{2}{*}{ Substit. } & \multirow[t]{2}{*}{ None } \\
\hline HT1 & & & & & & & & & \\
\hline Complem.* & 2569 & 0 & 4342 & 2570 & 1 & 4491 & 2570 & 0 & 4692 \\
\hline $\begin{array}{l}\text { No Complem. } \\
\text { HT2 }\end{array}$ & 1 & 2603 & 485 & 0 & 2602 & 336 & 0 & 2603 & 135 \\
\hline Complem.** & 2569 & 0 & 500 & 2569 & 1 & 347 & 2569 & 0 & 133 \\
\hline $\begin{array}{l}\text { No Complem. } \\
\text { HT1\&HT2 }\end{array}$ & 1 & 2603 & 4327 & 1 & 2602 & 4480 & 1 & 2603 & 4694 \\
\hline Complem.*** & 2566 & 0 & 475 & 2569 & 0 & 334 & 2569 & 0 & 128 \\
\hline Substit. & 0 & 2592 & 456 & 0 & 2593 & 315 & 0 & 2588 & 127 \\
\hline None & 4 & 11 & 3896 & 1 & 10 & 4178 & 1 & 15 & 4572 \\
\hline $\mathrm{R} 2=$ & \multicolumn{3}{|l|}{$50 \%$} & & \\
\hline True & \multicolumn{3}{|c|}{ No.Obs $=500$} & \multicolumn{3}{|c|}{ No.Obs $=1000$} & \multicolumn{3}{|c|}{ No.Obs $=5000$} \\
\hline Test & \multicolumn{3}{|c|}{ Complem. Substit. None } & \multicolumn{2}{|c|}{ Complem. Substit. } & None & \multirow[t]{2}{*}{ Complem. } & \multicolumn{2}{|c|}{ Substit. None } \\
\hline HT1 & & & & & & & & & \\
\hline Complem.* & 2514 & 5 & 3041 & 2556 & 5 & 3512 & 2568 & 1 & 4224 \\
\hline $\begin{array}{l}\text { No Complem. } \\
\text { HT2 }\end{array}$ & 56 & 2598 & 1786 & 14 & 2598 & 1315 & 2 & 2602 & 603 \\
\hline Complem.** & 2560 & 51 & 1802 & 2566 & 11 & 1328 & 2569 & 0 & 616 \\
\hline $\begin{array}{l}\text { No Complem. } \\
\text { HT1\&HT2 }\end{array}$ & 10 & 2552 & 3025 & 4 & 2592 & 3499 & 1 & 2603 & 4211 \\
\hline Complem.*** & 2508 & 0 & 1421 & 2553 & 0 & 1172 & 2567 & 0 & 583 \\
\hline Substit. & 5 & 2551 & 1399 & 0 & 2579 & 1166 & 0 & 2589 & 567 \\
\hline None & 57 & 52 & 2007 & 17 & 24 & 2489 & 3 & 14 & 3677 \\
\hline $\mathrm{R} 2=$ & $10 \%$ & & & & & & & & \\
\hline True & & Obs $=$ & & No. & $s=10$ & & & $\mathrm{Obs}=50 \mathrm{c}$ & \\
\hline Test & Complem & ubstit. & None & Complem & ubstit. & None & Complem. & Substit. & None \\
\hline HT1 & & & & & & & & & \\
\hline Complem.* & 1616 & 37 & 1201 & 2071 & 24 & 1649 & 2495 & 8 & 2871 \\
\hline $\begin{array}{l}\text { No Complem. } \\
\text { HT2 }\end{array}$ & 954 & 2566 & 3626 & 499 & 2579 & 3178 & 75 & 2595 & 1956 \\
\hline Complem.** & 2525 & 976 & 3661 & 2547 & 536 & 3210 & 2561 & 59 & 1960 \\
\hline $\begin{array}{l}\text { No Complem. } \\
\text { HT1\&HT2 }\end{array}$ & 45 & 1627 & 1166 & 23 & 2067 & 1617 & 9 & 2544 & 2867 \\
\hline Complem.*** & 1640 & 34 & 1125 & 2085 & 22 & 1373 & 2486 & 3 & 1483 \\
\hline Substit. & 36 & 1703 & 1116 & 15 & 2115 & 1347 & 3 & 2539 & 1485 \\
\hline None & 894 & 866 & 2586 & 470 & 466 & 2107 & 81 & 61 & 1859 \\
\hline
\end{tabular}

Notes:

Complementarity with one asterisk (Complem.*) is concluded if the test rejects the null of HT1 in testing for complementarity.

Complementarity with two asterisks (Complem.**) is concluded if the test accepts the null of HT2 in testing for complementarity.

Complementarity with three asterisks (Complem.***) is concluded by using one of the following methods: 1) accepting the null hypothesis of HT2 and rejecting the null hypothesis of HT1 in testing the complementarity; 2) rejecting the null of HT1 in the complementarity test and accepting the null of HT1 in the substitutability test; 3) accepting the null of HT2 in the complementarity test and rejecting the null of HT2 in the substitutability test. We have tried these three ways of hypothesis testing in our empirical analysis, exactly the same results are generated. 
Table 5. 5 Monte Carlo results of testing pairwise complementarity/substitutability in 3 activities (10,000 repetitions): Sensitivity and Accuracy

\begin{tabular}{|c|c|c|c|c|c|c|c|c|c|}
\hline \multicolumn{10}{|c|}{$\mathrm{R} 2=\quad 90 \%$} \\
\hline True & \multicolumn{3}{|c|}{ No.Obs $=500$} & \multicolumn{3}{|c|}{ No.Obs $=1000$} & \multicolumn{3}{|c|}{ No.Obs $=5000$} \\
\hline Test & Complem. & Substit. & None & Complem. & Substit. & None & Complem. & Substit. & None \\
\hline \multicolumn{10}{|l|}{ TH1 } \\
\hline Sensitivity & $99.52 \%$ & $99.36 \%$ & & $99.76 \%$ & $99.71 \%$ & & $99.95 \%$ & $99.95 \%$ & \\
\hline Accuracy & $78.27 \%$ & $77.85 \%$ & & $77.61 \%$ & $77.07 \%$ & & $76.03 \%$ & $75.98 \%$ & \\
\hline \multicolumn{10}{|l|}{ TH2 } \\
\hline Sensitivity & $99.95 \%$ & $99.84 \%$ & & $99.92 \%$ & $99.92 \%$ & & $99.92 \%$ & $99.97 \%$ & \\
\hline Accuracy & $96.70 \%$ & $96.32 \%$ & & $97.72 \%$ & $97.22 \%$ & & $98.99 \%$ & $98.98 \%$ & \\
\hline \multicolumn{10}{|l|}{ HT1\&HT2 } \\
\hline Sensitivity & $99.47 \%$ & $99.23 \%$ & $77.06 \%$ & $99.68 \%$ & $99.52 \%$ & $83.83 \%$ & $99.84 \%$ & $99.89 \%$ & $92.94 \%$ \\
\hline Accuracy & $97.13 \%$ & $96.65 \%$ & $93.80 \%$ & $98.10 \%$ & $97.57 \%$ & $95.67 \%$ & $99.08 \%$ & $99.06 \%$ & $98.14 \%$ \\
\hline \multicolumn{10}{|c|}{$\begin{array}{ll}\mathrm{R} 2= & 50 \% \\
\end{array}$} \\
\hline True & \multicolumn{3}{|c|}{ No.Obs $=500$} & \multicolumn{3}{|c|}{ No.Obs $=1000$} & \multicolumn{3}{|c|}{ No.Obs $=5000$} \\
\hline Test & Complem. & Substit. & None & Complem. & Substit. & None & Complem. & Substit. & None \\
\hline \multicolumn{10}{|l|}{ HT1 } \\
\hline Sensitivity & $90.16 \%$ & $90.05 \%$ & & $95.24 \%$ & $94.82 \%$ & & $99.17 \%$ & $98.96 \%$ & \\
\hline Accuracy & $82.55 \%$ & $82.26 \%$ & & $82.28 \%$ & $81.75 \%$ & & $79.26 \%$ & $78.89 \%$ & \\
\hline \multicolumn{10}{|l|}{ HT2 } \\
\hline Sensitivity & $99.52 \%$ & $99.36 \%$ & & $99.68 \%$ & $99.63 \%$ & & $99.87 \%$ & $99.84 \%$ & \\
\hline Accuracy & $84.95 \%$ & $84.68 \%$ & & $89.18 \%$ & $88.95 \%$ & & $95.30 \%$ & $95.07 \%$ & \\
\hline \multicolumn{10}{|l|}{ HT1\&HT2 } \\
\hline Sensitivity & $89.81 \%$ & $89.65 \%$ & $45.45 \%$ & $95.29 \%$ & $95.33 \%$ & $52.95 \%$ & $99.06 \%$ & $98.81 \%$ & $71.80 \%$ \\
\hline Accuracy & $89.44 \%$ & $89.11 \%$ & $78.83 \%$ & $92.52 \%$ & $92.09 \%$ & $84.89 \%$ & $96.28 \%$ & $95.87 \%$ & $92.19 \%$ \\
\hline \multicolumn{10}{|c|}{$\mathrm{R} 2=\quad 10 \%$} \\
\hline True & \multicolumn{3}{|c|}{ No.Obs $=500$} & \multicolumn{3}{|c|}{ No.Obs $=1000$} & \multicolumn{3}{|c|}{ No.Obs $=5000$} \\
\hline Test & Complem. & Substit. & None & Complem. & Substit. & None & Complem. & Substit. & None \\
\hline \multicolumn{10}{|l|}{ HT1 } \\
\hline Sensitivity & $51.18 \%$ & $48.55 \%$ & & $63.26 \%$ & $63.74 \%$ & & $89.30 \%$ & $88.72 \%$ & \\
\hline $\begin{array}{l}\text { Accuracy } \\
\text { HT2 }\end{array}$ & $76.12 \%$ & $75.01 \%$ & & $79.20 \%$ & $79.63 \%$ & & $83.16 \%$ & $82.73 \%$ & \\
\hline Sensitivity & $97.81 \%$ & $97.74 \%$ & & $98.29 \%$ & $98.41 \%$ & & $99.33 \%$ & $99.36 \%$ & \\
\hline $\begin{array}{l}\text { Accuracy } \\
\text { HT1\&HT2 }\end{array}$ & $59.66 \%$ & $60.73 \%$ & & $66.84 \%$ & $67.19 \%$ & & $83.34 \%$ & $83.43 \%$ & \\
\hline Sensitivity & $50.80 \%$ & $48.18 \%$ & $66.63 \%$ & $63.85 \%$ & $67.72 \%$ & $55.60 \%$ & $89.22 \%$ & $90.07 \%$ & $43.24 \%$ \\
\hline Accuracy & $76.74 \%$ & $75.63 \%$ & $55.15 \%$ & $80.09 \%$ & $81.99 \%$ & $64.42 \%$ & $88.81 \%$ & $85.90 \%$ & $78.38 \%$ \\
\hline
\end{tabular}

Notes:

The sensitivity indicates the proportion of actual complementarities that are correctly identified after 10000 repetitions.

The accuracy is the proportion of correct conclusions (true positives plus true negatives) after 10000 repetitions. 
Table 5. 6 Monte Carlo results of testing pairwise complementarity in 4 activities (10,000 repetitions): Sensitivity and Accuracy

\begin{tabular}{|c|c|c|c|c|c|c|c|c|c|}
\hline \multicolumn{10}{|c|}{$\mathrm{R} 2=\quad 90 \%$} \\
\hline True & \multicolumn{3}{|c|}{ No.Obs $=500$} & \multicolumn{3}{|c|}{ No.Obs $=1000$} & \multicolumn{3}{|c|}{ No.Obs $=5000$} \\
\hline Test & Complem. & Substit. & None & Complem. & Substit. & None & Complem. & Substit. & None \\
\hline \multicolumn{10}{|l|}{ HT1 } \\
\hline Sensitivity & $99.96 \%$ & $100.00 \%$ & & $100.00 \%$ & $99.96 \%$ & & $100.00 \%$ & $100.00 \%$ & \\
\hline Accuracy & $56.57 \%$ & $56.72 \%$ & & $55.08 \%$ & $55.18 \%$ & & $53.08 \%$ & $53.05 \%$ & \\
\hline \multicolumn{10}{|l|}{ HT2 } \\
\hline Sensitivity & $99.96 \%$ & $100.00 \%$ & & $99.96 \%$ & $99.96 \%$ & & $99.96 \%$ & $100.00 \%$ & \\
\hline Accuracy & $94.99 \%$ & $95.14 \%$ & & $96.51 \%$ & $96.63 \%$ & & $98.66 \%$ & $98.65 \%$ & \\
\hline \multicolumn{10}{|l|}{ HT1\&HT2 } \\
\hline Sensitivity & $99.84 \%$ & $99.58 \%$ & $80.71 \%$ & $99.96 \%$ & $99.62 \%$ & $86.55 \%$ & $99.96 \%$ & $99.42 \%$ & $94.72 \%$ \\
\hline Accuracy & $95.21 \%$ & $95.33 \%$ & $90.54 \%$ & $96.65 \%$ & $96.75 \%$ & $93.40 \%$ & $98.71 \%$ & $98.58 \%$ & $97.29 \%$ \\
\hline \multicolumn{10}{|c|}{$\begin{array}{ll}\mathrm{R} 2= & 50 \% \\
\end{array}$} \\
\hline$\times$ True & \multicolumn{3}{|c|}{ No.Obs $=500$} & \multicolumn{3}{|c|}{ No.Obs $=1000$} & \multicolumn{3}{|c|}{ No.Obs $=5000$} \\
\hline Test & Complem. & Substit. & None & Complem. & Substit. & None & Complem. & Substit. & None \\
\hline \multicolumn{10}{|l|}{ HT1 } \\
\hline Sensitivity & $97.82 \%$ & $98.04 \%$ & & $99.46 \%$ & $99.58 \%$ & & $99.92 \%$ & $100.00 \%$ & \\
\hline Accuracy & $68.98 \%$ & $69.14 \%$ & & $64.69 \%$ & $64.86 \%$ & & $57.73 \%$ & $57.88 \%$ & \\
\hline \multicolumn{10}{|l|}{ HT2 } \\
\hline Sensitivity & $99.61 \%$ & $99.81 \%$ & & $99.84 \%$ & $99.81 \%$ & & $99.96 \%$ & $99.96 \%$ & \\
\hline Accuracy & $81.37 \%$ & $81.53 \%$ & & $86.57 \%$ & $86.66 \%$ & & $93.83 \%$ & $93.94 \%$ & \\
\hline \multicolumn{10}{|l|}{ HT1\&HT2 } \\
\hline Sensitivity & $97.59 \%$ & $98.00 \%$ & $41.58 \%$ & $99.34 \%$ & $99.08 \%$ & $51.56 \%$ & $99.88 \%$ & $99.46 \%$ & $76.18 \%$ \\
\hline Accuracy & $85.17 \%$ & $85.44 \%$ & $70.71 \%$ & $88.11 \%$ & $88.10 \%$ & $76.21 \%$ & $94.14 \%$ & $94.19 \%$ & $88.33 \%$ \\
\hline \multicolumn{10}{|c|}{$\mathrm{R} 2=10 \%$} \\
\hline True & \multicolumn{3}{|c|}{ No.Obs $=500$} & \multicolumn{3}{|c|}{ No.Obs $=1000$} & \multicolumn{3}{|c|}{ No.Obs $=5000$} \\
\hline Test & Complem. & Substit. & None & Complem. & Substit. & None & Complem. & Substit. & None \\
\hline \multicolumn{10}{|l|}{$\overline{\text { HT1 }}$} \\
\hline Sensitivity & $62.88 \%$ & $62.50 \%$ & & $80.58 \%$ & $79.41 \%$ & & $97.08 \%$ & $97.73 \%$ & \\
\hline Accuracy & $78.08 \%$ & $78.13 \%$ & & $78.28 \%$ & $78.24 \%$ & & $70.46 \%$ & $70.65 \%$ & \\
\hline \multicolumn{10}{|l|}{ HT2 } \\
\hline Sensitivity & $98.25 \%$ & $98.58 \%$ & & $99.11 \%$ & $99.08 \%$ & & $99.65 \%$ & $99.69 \%$ & \\
\hline Accuracy & $53.18 \%$ & $53.83 \%$ & & $62.31 \%$ & $62.99 \%$ & & $79.72 \%$ & $79.61 \%$ & \\
\hline \multicolumn{10}{|l|}{ HT1\&HT2 } \\
\hline Sensitivity & $63.81 \%$ & $65.42 \%$ & $53.57 \%$ & $81.13 \%$ & $81.25 \%$ & $43.65 \%$ & $96.73 \%$ & $97.54 \%$ & $38.51 \%$ \\
\hline Accuracy & $79.11 \%$ & $79.48 \%$ & $59.99 \%$ & $81.20 \%$ & $81.50 \%$ & $63.44 \%$ & $84.30 \%$ & $84.48 \%$ & $68.90 \%$ \\
\hline
\end{tabular}

Notes:

The sensitivity indicates the proportion of actual complementarities which are correctly identified as much after 10000 repetitions.

The accuracy is the proportion of correct conclusions (true positives plus true negatives) after 10000 repetitions. 
With respect to the accuracy, the increasing of sample size results in higher values of accuracy. However, this positive correlation is only observed for HT1\&HT2 and HT2. For HT1, there is rather a negative correlation between accuracy with the sample sizes and the R-square values. The sensitivity declines and the accuracy increases in HT1 when the R-square falls. Increasing the sample size manifests the fluctuation of the accuracy across different R-square values. The same pattern can be observed for both 3 and 4 activities in testing pairwise complementarity/substitutability.

As we discussed in section 5.2.4, the non-exhaustive property of HT1 causes the failure of generating consistent results on complementarity (substitutability) if the vector $R \beta$ contains a negative (positive) value. Table 5.3 and 5.4 decompose the estimated results with respect to the true relationship between two activities. As both Tables shown, HT1 is biased and likely to conclude to complementarity when in fact it belongs to category "None", especially in situations with R-square values above 0.5. It rejects the null hypothesis to conclude to complementary when there are both negative and positive values in $R \beta$. This bias also explains why the accuracy for HT1 is relatively lower when the R-square is above 0.5. Nevertheless, the bias becomes less severe as the R-square values declines. On the other hand, HT2 gives more accurate results when the model is better specified and with a larger sample size. However, as Table 5.3 shows, the number of false conclusions on complementarity made by HT2 is much higher when the sample size is small and the R-square value is low. So far, we can conclude that HT1 is likely to misjudge "None" as complementarity when the number of observations and the Rsquare value rise. When the sample size is small and R-square value is low, HT2 tends to conclude to complementarity (accept the null hypothesis) when the true relationship is in fact substitutive and no relationship exists.

The next question is which type of hypothesis test is preferred across different sample sizes and model quality. The findings show that combing HT1\&HT2 always gives a better outcome in light of the relatively higher accuracy. Table 5.7 presents the preferable hypothesis between HT1 and HT2 across three different sample sizes and R-square values based on the accuracy. 
Table 5. 7 The preferable hypothesis between HT1 and HT2 across different sample sizes and R-square values (conclusions are based on the values of accuracy)

\begin{tabular}{l|c|c|c}
\hline 3 STRATEGIES & 0.1 & 0.5 & 0.9 \\
\hline No. Observations & HT1 & HT2 & HT2 \\
500 & HT1 & HT2 & HT2 \\
1000 & HT1 & HT2 & HT2 \\
5000 & & & \\
\hline 4 STRATEGIES & 0.1 & 0.5 & 0.9 \\
\hline No. Observations & HT1 & HT2 & HT2 \\
500 & HT1 & HT2 & HT2 \\
5000 & HT2 & HT2 & HT2 \\
\hline
\end{tabular}

HT1 is preferred when the sample size is small and the R-square value is low. Take the lower left panel of Table 5.6 as an example (the number of observations equals 500 and the R-square equals 10 per cent). For TH1, only 62.88 per cent true complementary relationships are tested corrected ${ }^{76}$ and the accuracy is about 78.08 per cent. For HT2, the accuracy is 53.18 per cent while about 98.25 per cent complementary relationships are judged correctly. Under these circumstances, HT1 is more consistent with the results generated with HT1\&HT2 and has a higher accuracy. As shown in Table 5.6, HT1 always performs better when the R-square equals 10 per cent except for the case of 4 strategies and 5000 observations. When the sample size is bigger and the R-square value is higher, HT2 becomes more powerful and accurate. Especially at 90 per cent of the Rsquare with 5000 observations, HT2 and HT1\& HT2 generate nearly equivalent results. As we can see from Table 5.7, HT2 performs in general better than HT1 in testing complementarity/substitutability. HT1 becomes more statistically powerful only when the $\mathrm{R}$-square value is about 0.1 .

\subsection{Final remarks}

By using simulated datasets, this chapter elaborates how to implement the multivariate one-sided tests of complementarity. Two types of hypotheses and their potential problems are discussed. The simulation results verify the potential bias that might exist in the non-exhaustive hypothesis setting. Conclusions based on such hypotheses are likely

\footnotetext{
${ }^{76}$ Interpretations are based on the results generated from the LRT.
} 
to be misleading if the nature of the inequalities are not taken into account. The findings also show that HT1 always performs better when the R-square equals 0.1 except for the case of 4 strategies and 5000 observations. When the sample size is bigger and the Rsquare at a higher level, HT2 becomes more powerful and accurate. Even though combining two tests of hypothesis always guarantees a higher value of accuracy in testing for complementarity, the process of conducting two hypotheses test would cause a loss of efficiency if one does not adjust the level of significance. Our results has shown that, in some situations, only one hypothesis testing can also draw a satisfactory conclusion. For example, with a sample size larger than 5000 and R-square values above 0.9, HT2 is almost equivalent to HT1\&HT2. 



\section{Chapter 6}

\section{Innovation obstacles: evidence from Eastern European and Central Asian countries}

\subsection{Introduction}

In developing countries, most firms engage in innovation by imitating or adapting existing production techniques to local conditions rather than by creating new technologies (Cooper, 1989). Innovation studies in this context have paid particular attention to examining the determinants, sources and capability of innovation and their contributions to firms' performance (Basant and Fikkert, 1996). Few studies, however, investigate which obstacles block innovation or cause innovation failures.

An innovation obstacle is perceived as a factor that potentially prevents an innovation decision or increases the difficulties, timeframe and cost of the process (Hadjimanolis, 2003). Due to inadequate experiences and limited resources, firms in developing countries are more likely to face barriers to innovation. Having a good understanding of the nature of innovation obstacles and their interactive effects is critical for the firm and the government to instigate efficient innovation strategies and policy responses (Hadjimanolis, 2003; Ferriani et al., 2008).

The current chapter helps us to gain a deeper understanding of the innovation obstacles and the potential interplay relationships between them. A firm level dataset - the Investment Climate Survey 2009 (ICS) in Eastern European and Central Asian countries 
(EECA) - is used in the empirical analysis. The results reveal the potential obstacles faced by firms and provide policy suggestions on why some obstacles should be removed simultaneously and others should be tackled individually.

The next section outlines the nature of obstacles to innovation and their impact on the innovation decision and output. Section 6.3 specifies the model underlying the empirical analysis. Data and descriptive statistics are introduced in section 6.4. Section 6.5 reports and discusses the empirical findings. Section 6.6 concludes and draws policy suggestions.

\subsection{Obstacles in innovation}

An obstacle (or barrier) to innovation is defined as any factor that undermines the innovation process (Piatier, 1984). The obstacles faced by firms are perceived differently throughout the innovation process (Hadjimanolis, 2003). Obstacles may represent a major determinant of the decision to abandon ongoing innovation projects or simply delay the innovation outcomes (Baldwin and Hanel, 2003). Even after the firm successfully becomes an innovator, obstacles may emerge and limit the innovation intensity (Mohnen and Röller, 2005).

The potential interactive effects among obstacles are particularly appealing from a policy perspective. For example, if there exists complementary among obstacles, a policy that focuses only on one obstacle will be assumed to be insufficient. A policy package will be more effective and necessary in this context. Mohnen and Röller (2005) use the Community Innovation Survey (CIS) from four European countries to prove that a policy package is necessary to increase the propensity of becoming innovator due to the identified complementarity, whereas a more individually targeted choice of policies is suggested to eliminate obstacles in order to improve the innovation output for those who are already innovators. Another study regarding the complementary between innovation obstacles was written by Galia and Legros (2004). The authors investigated innovation obstacles faced by French manufacturing firms by using CIS2 French data. Their findings suggest that there might be interactions and reinforcement among obstacles, and a more targeted choice among policies is expected to improve the innovation performance. 


\subsection{Model specification}

\subsubsection{Complementarity between obstacles versus complementarity between policies}

Regarding complementarity in obstacles and their corresponding policy responses, two notations need to be clarified: the 'positive complementarity' and the 'negative complementarity'. The former is applied in the situation where the complementary activities are expected to have positive effects on the outcomes. For instance the complementarity between human resource practices and IT infrastructure, product and process innovation or internal and external innovation acquisition sourcing strategies in fostering innovation. The presence of these activities is expected to positively enhance the innovation performance and the complementary effects will be shown as a significantly positive sign of the interaction term. The 'negative complementarity' describes an interactive effect between activities that exacerbate the undermining effects to an economic outcome. The sign of the interaction term is expected to be negative. A good example is the complementarity between innovation obstacles. However, if complementarity is strictly interpreted as "the presence of one factor increases the marginal return of the other factor", which is based on the standard notation given by Milgrom and Roberts (1990a), then complementarity between obstacles indicates a positive interactive effect. The 'negative complementarity' would be interpreted as substitutability in this conventional understanding. Differences between these two interpretations are critical for formulating our economic model and interpreting the results. In the current study, we use the second definition: if one obstacle is present and hampers innovation, the second obstacle's hampering effect is alleviated.

Figure 6.1 geometrically depicts the complementarity between obstacles and also the complementarity between corresponding policies. As the figure shows, the complementarity between two obstacles can be depicted in two different ways, which can accordingly lead to two different interpretations in terms of policy responses. On the one hand, in the presence of both obstacles (-O1 and -O2), if the undermining effect of one obstacle (-O1) reinforces the other obstacle (-O2) by worsening the total effect on the outcome (point D), we define it as 'negative complementarity'. The policy instruments (O1 and O2) should at least remove one of the obstacles to avoid them appearing together. The complementarity between these two obstacles reflects a substitutive relation between two corresponding policies (point B in figure 6.1). On the other hand, 
according to the conventional definition, the complementary relation between -O1 and O2 can be interpreted as: the presence of one obstacle (-O1) increases the marginal return of the other obstacle (-O2) by mitigating the negative effects (shifting to point E). The complementarity of obstacles then reflects a complementary relationship between two corresponding policies since solving only one obstacle would consequently magnify the deterring effect from the other. The conventional definition of complementarity is adopted in the following analysis.

Figure 6.1 Positive complementary versus negative complementary

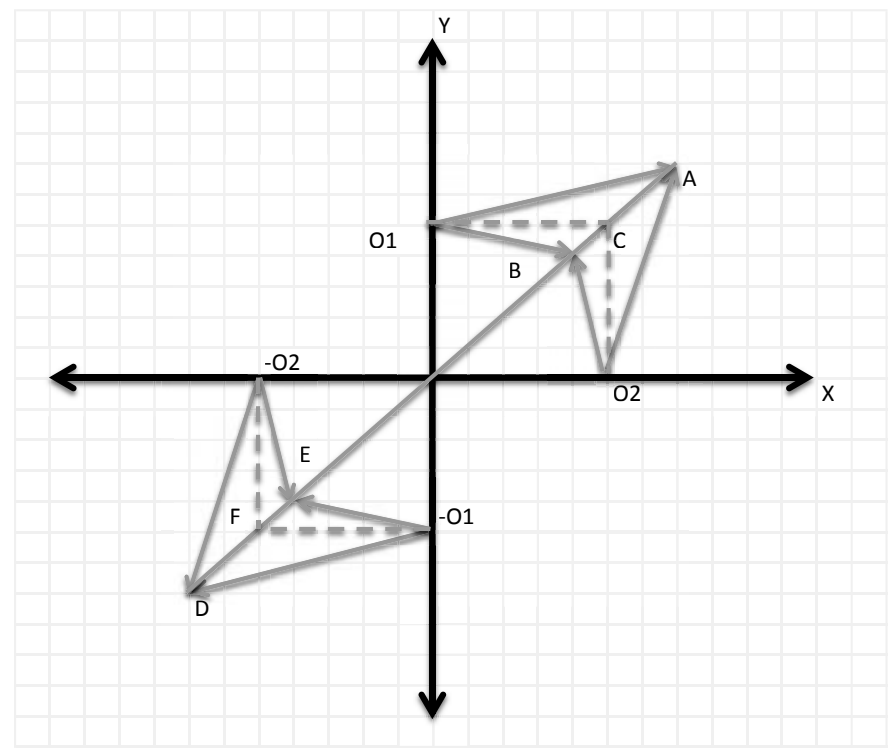

\subsubsection{Model specification: obstacles in innovation function}

Considering there might be other technological acquisition strategies to make firms become innovators, such as acquiring knowledge through licensing, embedded machinery or scientists, we do not exclude firms without $\mathrm{R} \& \mathrm{D}$ investment in our analysis. The Tobit type II model (Heckman-type Selection model or Heckit model, see Amemiya, 1984, 1985) will be employed to measure the intensity of new product sales. It incorporates a selection equation to correct the potential selection bias - firms who are treated may be different from the rest of the observations - caused by the censored data since the innovative sales of new products will only be observed if a firm has achieved 
new products or services innovation (Heckman, 1976, 1979; Johnston and DiNardo, 1997; Verbeek, 2000; Greene, 2003; Kleinknecht and Mohnen, 2002; Mohnen and Röller, 2005). Ordinary Least Squares may fail to generate consistent estimates in this case. A dichotomous variable indicating whether a firm has gained new products or services during the period under review is used as the selection indicator. By including obstacles and their interactions in the innovation function, we will be able to systematically examine the potential complementarity.

$$
\begin{aligned}
& P D_{i}^{o}=A+\beta_{f} \text { Firmspecifics }_{i}+\beta_{s} \text { Size }_{i}+\beta_{c} \text { Country }_{i}+\beta_{i} \text { Industry }_{i}+\varepsilon_{i} \\
& P D_{i}^{o}=\left\{\begin{array}{cc}
0 i f & P D_{i}^{*}<0 \\
P D_{i}^{o} & \text { otherwise }
\end{array}\right. \\
& P D_{i}^{*}=A+\phi_{f} \text { Firmspecifics }_{i}+\phi_{s} \text { Size }_{i}+\phi_{c} \text { Country }_{i}+\phi_{i} \text { Industry }_{i}+\eta_{i} \\
& P D_{i}=\left\{\begin{array}{ccc}
1 & \text { if } & P D_{i}^{*}>0 ; \\
0 & \text { if } & P D_{i}^{*} \leq 0
\end{array}\right. \\
& A=\delta_{1} x_{1}+\delta_{2} x_{2}+\delta_{3} x_{3}+\delta_{4} x_{4}+\delta_{12} x_{1} x_{2}+\delta_{13} x_{1} x_{3}+\delta_{14} x_{1} x_{4}+\delta_{23} x_{2} x_{3}+\delta_{24} x_{2} x_{4}+ \\
& +\delta_{34} x_{3} x_{4}+\delta_{123} x_{1} x_{2} x_{3}+\delta_{124} x_{1} x_{2} x_{4}+\delta_{134} x_{1} x_{3} x_{4}+\delta_{234} x_{2} x_{3} x_{4}+\delta_{1234} x_{1} x_{2} x_{3} x_{4}
\end{aligned}
$$

where $P D_{i}^{o}$ in equation (6.1) indicates the outcome of innovation: sales of new products or services ${ }^{77}$. A is composited of four types of obstacles ${ }^{78}, x_{l}, l=(1,2,3,4)$. "Firmspecifics" captures a vector of firm characteristics that influence firms' innovation and $\delta$ is a vector of estimated coefficients (for detailed explanation of variables, see next section). Size, Country and Industry are three sets of dummies to control for size, location and industry specificities of firm i. $e_{i}$ denotes the disturbance term.

Equation (6.2) specifies the selection equation. $P D_{i}^{*}$ is the latent value of the selection for firm $\mathrm{i}$ in (6.2). It tells whether a firm produces any new products or services during the period under review. We observe the outcome $P D_{i}^{o}$ only if the latent selection

\footnotetext{
${ }^{77}$ Due to the fact that R\&D is not the only technological sourcing to innovation, other sourcing channels such as technology licensing, embedded machinery and imitation (these information are not available from the current data source) may also present and contribute to innovation output, R\&D will not be used as indicator for the selection equation in the Heckman model. Based on the data in the empirical part, there are about $36.55 \%$ of firms which claims to be product innovators without $\mathrm{R} \& \mathrm{D}$ investment.

${ }^{78}$ In equation 6.3, subscript $i$ has been deleted to ease the writing.
} 
variable $P D_{i}^{*}$ is non-negative. It is assumed that the error term $\eta_{i}$ and $\varepsilon_{i}$ follow a joint normal distribution (Heckman, 1979; Greene, 2003). Variables in (6.2) are defined the same as in equation (6.1) except firmspecifics $_{i}$ that should contain at least one extra exogenous variable as instrument in the selection equation, in order to avoid the identification problem (Greene, 2003; Toomet and Henningsen, 2008).

\subsubsection{Testing complementarity between pairs of obstacles}

Turning to the obstacles, $x_{l}, l=(1,2,3,4)$ in $(6.3)$ are dichotomous choice variables which correspond to four types of obstacles in regard to innovation performance. $x_{l}$ equals to one if the corresponding obstacle is reported as a major obstacle by the firm, otherwise zero. $\delta$ is a vector of coefficients that need to be estimated. Obstacles here are treated as exogenous variables that do not correlated with the residual. According to the notion of complementarity (Milgrom, 1990b; 1995), we conclude obstacle $x_{i}$ and $x_{j}$ are complementary if the following condition is satisfied.

$f\left(x_{i}=1, x_{j}=1 \mid Z\right)+f\left(x_{i}=0, x_{j}=0 \mid Z\right) \geq f\left(x_{i}=1, x_{j}=0 \mid Z\right)+f\left(x_{i}=0, x_{j}=1 \mid Z\right)$

In the case of more than two obstacles, testing the complementarity between pairs of obstacles should include the full set of cross-terms in (6.3). For example, the complementarity between $x_{1}$ and $x_{2}$ can only be concluded if all of the following inequalities are satisfied and with at least one inequality holding strictly (for details, see chapter 5.3).

$$
\left\{\begin{array}{l}
f_{1,2}\left(x_{1,} x_{2} \mid x_{3}=0, x_{4}=0\right)=\delta_{12} \geq 0 \\
f_{1,2}\left(x_{1,} x_{2} \mid x_{3}=1, x_{4}=0\right)=\delta_{12}+\delta_{123} \geq 0 \\
f_{1,2}\left(x_{1,} x_{2} \mid x_{3}=0, x_{4}=1\right)=\delta_{12}+\delta_{124} \geq 0 \\
f_{1,2}\left(x_{1,} x_{2} \mid x_{3}=1, x_{4}=1\right)=\delta_{12}+\delta_{123}+\delta_{124}+\delta_{1234} \geq 0
\end{array}\right.
$$

If all inequalities have the inverse sign in (6.5), then we have a substitutability ${ }^{79}$. The same formula can be adopted for testing pairwise complementarity for $x_{1}$ and $x_{3} ; x_{1}$ and $x_{4}$; $x_{2}$ and $x_{3} ; x_{2}$ and $x_{4} ; x_{3}$ and $x_{4}$. In the case of more than two obstacles, estimation without controlling for the full cross-terms (the third- and fourth-order interactions) is

\footnotetext{
${ }^{79}$ Previous studies of Athey and Stern (1998) and Mohnen and Röller (2005) refer $x_{1}$ and $x_{2}$ as "strictly complementary" if the " $\geq$ " is replaced by " $>$ ".
} 
inconclusive. Specifically, only looking at $\delta_{12}$ by ignoring the third and the fourth-order interactions in (6.3) may lead to a biased conclusion (Mohnen and Röller, 2005; Lokshin et al., 2007; Carree et al., 2011). With multiple inequality restrictions imposed on $\delta$, the one-sided multivariate hypotheses used for testing complementarity are

Hypothesis Test $1 \quad H_{0}: R \delta=0 \quad$ vs $\quad H_{1}: R \delta \geq 0$

Hypothesis Test $2 \quad H_{0}: R \delta \geq 0 \quad$ vs $\quad H_{1}: R \delta ! \geq 0$

$\mathrm{R}$ is a matrix with a dimension of $(p \times k)$ which defines the inequality restrictions imposed on the estimated parameters. $\mathrm{p}$ is the number of inequality constraints that have to be tested simultaneously. HT1 (Hypothesis Test 1) tests equality against at least one inequality strictly holding. HT2 (Hypothesis Test 2) tests if all $R \delta$ are larger or equal to zero against at least one violation in the null hypothesis (not all $R \delta$ are larger or equal to r) ${ }^{80}$. "!" sign denotes "not". We emphasize a test procedure that takes into account both HT1 and HT2 herein, which have better statistical power than the test procedures that only consider one of them. A likelihood ratio test (Gourieroux, 1982) is used as the hypothesis testing method. In our empirical analysis, the testing reference for a multivariate distribution is derived by the method discussed in chapter $5^{81}$.

\subsection{Data and variables}

\subsubsection{Data}

The firm-level data Investment Climate Survey (ICS) ${ }^{82}$ conducted by World Bank covers a broad range of topics including infrastructure, economic performance and investment environment.

\footnotetext{
${ }^{80}$ HT1 is not defined to be exhaustive. The null hypothesis of HT1 is equality only. See more details in chapter 5.2.4.

${ }^{81}$ For details with respect to the test statistics, please see chapter 5 . The empirical estimation was done by using statistical program $\mathrm{R}$. The programming code is available upon request.

82 Enterprise Surveys (http://www.enterprisesurveys.org), The World Bank.
} 
Table 6. 1 Variables definition and summary (mean and SD)

\begin{tabular}{|c|c|c|c|c|c|c|}
\hline Variable & & Mean & Std. Dev. & Min & Max & obs. \\
\hline Fin_obs & $\begin{array}{l}\text { Binary variable equals to } 1 \text { if "Access to } \\
\text { finance" is recognized as a major or } \\
\text { serious obstacle in a firm }\end{array}$ & 0.29 & 0.45 & 0 & 1 & 7712 \\
\hline Lab_obs & $\begin{array}{l}\text { Binary variable equals to } 1 \text { if } \\
\text { "Inadequately educated workforce" is } \\
\text { recognized as a major or serious } \\
\text { obstacle in a firm }\end{array}$ & 0.34 & 0.47 & 0 & 1 & 7712 \\
\hline Com_obs & $\begin{array}{l}\text { Binary variable equals to } 1 \text { if "Practices } \\
\text { of competitors in the informal sector" } \\
\text { is recognized as a major or serious } \\
\text { obstacle in a firm }\end{array}$ & 0.29 & 0.46 & 0 & 1 & 7712 \\
\hline Tax_obs & $\begin{array}{l}\text { Binary variable equals to } 1 \text { if "Tax rates: } \\
\text { is recognized as a major or serious } \\
\text { obstacle in a firm }\end{array}$ & 0.47 & 0.50 & 0 & 1 & 7712 \\
\hline Prodsales & $\begin{array}{l}\text { Per cent of annual sales accounted for } \\
\text { by new products or services in } 2007 \text {, in } \\
\text { percentage }\end{array}$ & 0.28 & 0.25 & 0.0001 & 0.99 & 4508 \\
\hline PROD & $\begin{array}{l}\text { In the last three years, has this } \\
\text { establishment introduced new products } \\
\text { or services? }\end{array}$ & 0.58 & 0.49 & 0 & 1 & 7712 \\
\hline RnDdum & $\begin{array}{l}\text { Did this establishment spend on } \\
\text { research and development activities, } \\
\text { either in-house or contracted with } \\
\text { other companies (outsourced)? }\end{array}$ & 0.27 & 0.44 & 0 & 1 & 7712 \\
\hline Discont & $\begin{array}{l}\text { In the last three years, has this } \\
\text { establishment discontinued at least one } \\
\text { product line or service? }\end{array}$ & 0.26 & 0.44 & 0 & 1 & 7712 \\
\hline Upgrade & $\begin{array}{l}\text { In the last three years, has this } \\
\text { establishment upgraded an existing } \\
\text { product line or service? }\end{array}$ & 0.80 & 0.40 & 0 & 1 & 7712 \\
\hline lnsale 2007 & Turn over of 2007 , in logarithm (USD) & 6.79 & 2.25 & -0.568 & 18.197 & 7712 \\
\hline Sizedum2 & $\begin{array}{l}\text { Binary variable equals to } 1 \text { if total } \\
\text { employees of a firm }>25 \text { and }<100\end{array}$ & 0.29 & 0.46 & 0 & 1 & 7712 \\
\hline Sizedum 3 & $\begin{array}{l}\text { Binary variable equals to } 1 \text { if total } \\
\text { employees of a firm }>100\end{array}$ & 0.24 & 0.43 & 0 & 1 & 7712 \\
\hline Expercent & $\begin{array}{l}\text { Export as percentage in total sales of } \\
2007 \text {, in percentage }\end{array}$ & 11.75 & 26.41 & 0 & 100 & 7712 \\
\hline Forown & $\begin{array}{l}\text { Percentage of foreign ownership of } \\
\text { firm, in percentage }\end{array}$ & 7.24 & 23.84 & 0 & 100 & 7712 \\
\hline ISO & $\begin{array}{l}\text { Does this establishment have an } \\
\text { internationally recognized quality } \\
\text { certification? Some examples are: ISO } \\
9000,9002 \text { or } 14000 \text {. }\end{array}$ & 0.26 & 0.44 & 0 & 1 & 7712 \\
\hline Age & Age of the firm by the end of 2007 & 17.19 & 16.37 & 1 & 184 & 7712 \\
\hline Subsidy & $\begin{array}{l}\text { Over the last three years has this } \\
\text { establishment received any subsidies } \\
\text { from the national, regional or local } \\
\text { governments or European Union } \\
\text { sources? }\end{array}$ & 0.10 & 0.30 & 0 & 1 & 7712 \\
\hline Regu_time & $\begin{array}{l}\text { Senior management's time spent on } \\
\text { dealing with regulations }\end{array}$ & 13.39 & 19.82 & 0 & 100 & 7712 \\
\hline Hi-tech & $\begin{array}{l}\text { Binary variable equals to } 1 \text { if a firm } \\
\text { belongs to High technology industry } \\
\text { according to OECD High-Technology } \\
\text { industry classification. }\end{array}$ & 0.08 & 0.27 & 0 & 1 & 7712 \\
\hline
\end{tabular}


Table 6. 2 Mean values of variables across countries

\begin{tabular}{|c|c|c|c|c|c|c|c|c|c|c|c|c|c|}
\hline Country & Income & Freq. & $\begin{array}{l}\text { RnD } \\
\text { dum }\end{array}$ & $\begin{array}{c}\text { PRO } \\
\text { D }\end{array}$ & $\begin{array}{l}\mathrm{Ln}_{-} \\
\text {Sale } \\
2007\end{array}$ & $\begin{array}{l}\mathrm{Ln}_{-} \\
\text {size }\end{array}$ & $\begin{array}{c}\mathrm{Ex}_{-} \\
\text {perce } \\
\text { nt }\end{array}$ & $\begin{array}{l}\text { For_- } \\
\text { own }\end{array}$ & ISO & Age & $\begin{array}{c}\text { Subsi } \\
\text { dy }\end{array}$ & $\begin{array}{c}\text { Regu } \\
\text { time }\end{array}$ & $\begin{array}{l}\text { Hi- } \\
\text { tech }\end{array}$ \\
\hline Albania & Upper-Middle & 84 & 0.25 & 0.27 & 6.61 & 2.99 & 11.00 & 16.13 & 0.21 & 11.82 & 0.01 & 16.42 & 0.02 \\
\hline Belarus & $\begin{array}{l}\text { Upper-Middle } \\
\text { Low/Lower- }\end{array}$ & 187 & 0.22 & 0.70 & 6.80 & 3.75 & 8.58 & 6.22 & 0.12 & 18.22 & 0.05 & 17.30 & 0.05 \\
\hline Georgia & $\begin{array}{l}\text { Middle } \\
\text { Low/Lower- }\end{array}$ & 205 & 0.15 & 0.35 & 5.49 & 3.26 & 6.98 & 3.34 & 0.16 & 11.55 & 0.04 & 1.92 & 0.01 \\
\hline Tajikistan & Middle & 249 & 0.12 & 0.51 & 4.55 & 3.16 & 3.60 & 4.69 & 0.14 & 15.74 & 0.04 & 13.29 & 0.06 \\
\hline Turkey & $\begin{array}{l}\text { Upper-Middle } \\
\text { Low/Lower- }\end{array}$ & 736 & 0.30 & 0.51 & 8.42 & 3.84 & 25.52 & 2.19 & 0.47 & 18.97 & 0.10 & 27.47 & 0.14 \\
\hline Ukraine & $\begin{array}{l}\text { Middle } \\
\text { Low/Lower- }\end{array}$ & 492 & 0.20 & 0.60 & 5.93 & 3.52 & 9.84 & 5.89 & 0.12 & 18.18 & 0.03 & 11.74 & 0.22 \\
\hline Uzbekistan & Middle & 264 & 0.03 & 0.29 & 5.35 & 3.60 & 3.91 & 9.25 & 0.09 & 20.81 & 0.03 & 16.52 & 0.08 \\
\hline Russia & Upper-Middle & 680 & 0.39 & 0.71 & 7.73 & 4.18 & 4.41 & 3.85 & 0.20 & 19.24 & 0.08 & 19.28 & 0.24 \\
\hline Poland & High & 211 & 0.27 & 0.63 & 7.65 & 3.42 & 12.97 & 7.60 & 0.27 & 20.08 & 0.18 & 12.83 & 0.04 \\
\hline Romania & Upper-Middle & 263 & 0.26 & 0.51 & 7.31 & 3.74 & 9.90 & 12.00 & 0.43 & 14.59 & 0.13 & 11.67 & 0.04 \\
\hline Serbia & Upper-Middle & 310 & 0.36 & 0.67 & 7.64 & 3.74 & 10.69 & 10.07 & 0.28 & 25.90 & 0.08 & 15.33 & 0.07 \\
\hline Kazakhstan & $\begin{array}{l}\text { Upper-Middle } \\
\text { Low/Lower- }\end{array}$ & 359 & 0.13 & 0.49 & 6.76 & 3.71 & 1.58 & 3.44 & 0.17 & 10.51 & 0.04 & 5.84 & 0.05 \\
\hline $\begin{array}{l}\text { Moldova } \\
\text { Bosnia and }\end{array}$ & Middle & 284 & 0.31 & 0.54 & 6.13 & 3.54 & 10.74 & 7.81 & 0.12 & 12.88 & 0.07 & 9.53 & 0.01 \\
\hline Herze & Upper-Middle & 238 & 0.51 & 0.64 & 7.53 & 3.54 & 17.06 & 5.55 & 0.35 & 22.78 & 0.17 & 12.74 & 0.04 \\
\hline $\begin{array}{l}\text { Azerbaijan } \\
\text { Fyr }\end{array}$ & $\begin{array}{l}\text { Upper-Middle } \\
\text { Low/Lower- }\end{array}$ & 262 & 0.08 & 0.51 & 5.72 & 3.08 & 2.37 & 7.94 & 0.16 & 16.99 & 0.05 & 3.44 & 0.03 \\
\hline Macedonia & $\begin{array}{l}\text { Middle } \\
\text { Low/Lower- }\end{array}$ & 253 & 0.42 & 0.64 & 6.92 & 3.45 & 23.85 & 8.40 & 0.25 & 17.80 & 0.05 & 15.10 & 0.03 \\
\hline $\begin{array}{l}\text { Armenia } \\
\text { Kyrgyz }\end{array}$ & $\begin{array}{l}\text { Middle } \\
\text { Low/Lower- }\end{array}$ & 224 & 0.22 & 0.64 & 5.80 & 2.97 & 6.64 & 5.82 & 0.23 & 11.84 & 0.01 & 11.33 & 0.06 \\
\hline Republic & $\begin{array}{l}\text { Middle } \\
\text { Low/Lower- }\end{array}$ & 158 & 0.16 & 0.48 & 5.18 & 3.33 & 8.84 & 10.66 & 0.18 & 16.94 & 0.09 & 5.51 & 0.05 \\
\hline Mongolia & Middle & 330 & 0.24 & 0.72 & 5.59 & 3.36 & 6.07 & 4.83 & 0.16 & 14.69 & 0.09 & 12.75 & 0.02 \\
\hline Estonia & $\begin{array}{l}\text { High } \\
\text { Low/Lower- }\end{array}$ & 203 & 0.37 & 0.70 & 7.87 & 3.64 & 18.21 & 15.39 & 0.29 & 17.01 & 0.22 & 6.89 & 0.04 \\
\hline $\begin{array}{l}\text { Kosovo } \\
\text { Czech }\end{array}$ & Middle & 166 & 0.29 & 0.59 & 5.67 & 2.60 & 4.46 & 0.00 & 0.14 & 14.82 & 0.02 & 9.77 & 0.01 \\
\hline Republic & High & 146 & 0.34 & 0.64 & 7.94 & 3.50 & 18.12 & 10.34 & 0.51 & 13.82 & 0.29 & 12.36 & 0.09 \\
\hline Hungary & High & 254 & 0.17 & 0.43 & 8.32 & 3.79 & 12.39 & 14.93 & 0.52 & 15.07 & 0.19 & 16.06 & 0.05 \\
\hline Latvia & Upper-Middle & 207 & 0.18 & 0.59 & 7.75 & 3.67 & 16.22 & 14.83 & 0.27 & 14.04 & 0.14 & 9.42 & 0.01 \\
\hline $\begin{array}{l}\text { Lithuania } \\
\text { Slovak }\end{array}$ & Upper-Middle & 215 & 0.23 & 0.72 & 7.30 & 3.47 & 18.93 & 8.16 & 0.20 & 13.43 & 0.17 & 11.21 & 0.04 \\
\hline Republic & High & 150 & 0.19 & 0.59 & 7.66 & 3.55 & 14.74 & 9.51 & 0.41 & 14.92 & 0.15 & 7.89 & 0.05 \\
\hline Slovenia & High & 240 & 0.43 & 0.76 & 3.13 & 3.68 & 24.72 & 10.80 & 0.43 & 24.62 & 0.25 & 9.13 & 0.06 \\
\hline Bulgaria & Upper-Middle & 161 & 0.40 & 0.55 & 6.90 & 3.33 & 12.24 & 10.88 & 0.29 & 15.93 & 0.03 & 12.00 & 0.04 \\
\hline Croatia & High & 116 & 0.55 & 0.74 & 8.39 & 3.80 & 17.49 & 8.59 & 0.29 & 26.60 & 0.34 & 14.79 & 0.06 \\
\hline Montenegro & Upper-Middle & 65 & 0.32 & 0.75 & 7.50 & 3.20 & 7.02 & 6.91 & 0.25 & 14.28 & 0.03 & 8.00 & 0.02 \\
\hline Total & & 7,712 & 0.27 & 0.58 & 6.79 & 3.57 & 11.75 & 7.24 & 0.26 & 17.19 & 0.10 & 13.39 & 0.08 \\
\hline
\end{tabular}

In this chapter, we use the data from Eastern Europe and Central Asia 2008 (EECA 2008) because it is based on the same questionnaire across 31 countries in this region, 
yielding comparable information on innovation and firm-specific variables. It collects information on whether a firm recently had new product or services innovation, R\&D activities, and the strength of different sets of obstacles to firm's production and performance. Table 6.1 defines variables and presents the summary statistics. After cleaning the missing values ${ }^{83}$, our final sample includes 7,712 firms and distributes across a wide range of manufacturing and service industries in 31 countries. Table 6.2 summarizes the variables by country.

\subsubsection{Measures for innovation performance}

The dependent variable of the selection equation (6.2) is measured by a dichotomous variable $\mathrm{PD}$, which takes the value 1 if a firm introduced new products or services during the period under review ${ }^{84}$. Innovation performance (the dependent variable of equation (6.1)) is measured by the percentage of new products and services sales in total turnover. This share-in-sales indicator is the direct link between the innovation effort and the commercial success and has been widely used as output indicator in recent years (Klomp and Van Leeuwen, 1999; Mairesse and Mohnen, 2001). Dichotomous choice variable $\mathrm{RnD}$ equals to 1 if a firm has invested in $\mathrm{R} \& \mathrm{D}$ during the period under review. Table 6.3 describes the R\&D and innovativeness across firms in different sectors, income levels ${ }^{85}$ and size groups ${ }^{86}$.

As shown in Table 6.3, firms in manufacturing, higher-income and larger-sized groups are more likely to succeed in innovation. In view of the new product sales, manufacturing firms have a higher value compared with firms in the service sector, 29 per cent and 26 per cent. However, the lower-income and smaller-sized firms tend to be higher in proportion of commercialized innovation in the total turnover. In total, 58 per cent of the sampled firms engage in product innovation and the average level of innovation sales is about 0.28 per cent. It is important to note that the product

\footnotetext{
${ }^{83}$ First, firms with fewer than 5 employees are deleted (3.6\%) from our sample. Second, firms that do not aim at innovating are also filtered out from sample (D'Este et al., 2008, Savignac, 2008). Specifically, firms that are not aiming at innovating do not carry out innovation activities at all. So they do not observe the potential obstacles to innovation. Last, we assume that non-innovative firms which experienced unsuccessful innovation would encounter at least one of the obstacles. Therefore, we drop firms which have not had any new or updated products/services and, at the same time, report that none of the obstacles is important. It accounts for $6.2 \%$ of the total sample.

84 Process innovation related measurements are not covered by the current questionnaire, so the influence of obstacles to process innovation will not be studied here.

85 The income-group definition and classification is based on the World Bank country classification. For detail definition, please see: http://data.worldbank.org/about/country-classifications.

${ }^{86}$ As shown in table 6.3, there are about 76 per cent of firms with a size of smaller than 100 employees. The total sample is divided into three groups according to the distribution of the size of firms: $5-25$ (47\% of total sample), 26-100 (29\% of total sample) and above 100 ( $24 \%$ of total sample).
} 
innovation in developing countries may be new products or services which are only new to the firm itself, not necessarily new to the market.

Table 6. 3 R\&D and innovation output status of all and across each group (mean values)

\begin{tabular}{lcccccc}
\hline & RnDdum & Prodinno & Prodsales & $\begin{array}{c}\text { Logit- } \\
\text { prod }\end{array}$ & Freq. & Percentage \\
\hline Sector & & & & & & \\
Service & 0.22 & 0.58 & 0.26 & -1.35 & 3,414 & 44.27 \\
Manufacturing & 0.31 & 0.59 & 0.29 & -1.19 & 4,298 & 55.73 \\
& & & & & & \\
Income & 0.22 & 0.55 & 0.29 & -1.18 & 2,625 & 34.04 \\
Low and lower-middle & 0.29 & 0.59 & 0.28 & -1.22 & 3,767 & 48.85 \\
Upper-middle & 0.32 & 0.63 & 0.24 & -1.52 & 1,320 & 17.12 \\
High & & & & & & \\
Size & 0.19 & 0.54 & 0.29 & -1.15 & 3,595 & 46.62 \\
$5<\mathrm{x}<25$ & 0.29 & 0.60 & 0.28 & -1.25 & 2,263 & 29.34 \\
$26<\mathrm{x}<100$ & 0.40 & 0.64 & 0.25 & -1.46 & 1,854 & 24.04 \\
$>100$ & & & & & & \\
& & & & & & \\
Total & 0.27 & 0.58 & 0.28 & -1.26 & 7712 & 100 \\
\hline
\end{tabular}

\subsubsection{Obstacle measures}

Definition: Obstacles in ICS and Obstacles in CIS

There are in total fifteen different obstacles investigated in the ICS-EECA2008. All respondents were asked how intensely each obstacle has affected their firm during the period under review. We have chosen four most important barriers based on the question: which is the biggest obstacle faced by firm? (see Appendix 6A). They are obstacles in the category of finance, skilled labor, informal competition and tax respectively. Four dichotomous variables are constructed to indicate whether the firm assesses each as a major impediment. Questions are asked about obstacles to innovation on a four-point Likert scale. The corresponding obstacle variable takes the value 1 if the answer is marked as a major or very severe obstacle (scores 3 and 4), and takes the value zero otherwise.

The obstacles defined in the ICS are impediments faced by a firm in their entire operation process, which is different from the obstacles defined in the Community 
Innovation Survey (CIS). The CIS addresses obstacles as the barriers faced by firms particularly to their innovation. The obstacles in ICS are characterized by having a broad range and various categories. We expect that obstacles to a firm's operation will also undermine its innovation performance, especially when a firm intends to become an innovator ${ }^{87}$.

\section{Classification: Internal and external obstacles}

Obstacles can be classified in different ways. The most common one is to differentiate between obstacles internal and external to the firm (Piatier, 1984; Hadjimanolis, 2003). Internal obstacles refer to factors that are generated internally and related to the organization characteristics, employees' quality and the management structure. External obstacles are related to supply, demand and the environment (Hadjimanolis, 1999), for example, difficulties in acquiring external technological information, incorrect perception of target market, and government regulations.

Difficulty in securing finance is recognized as one of the most severe internal barriers to innovation. Financial constraints as internal hampering factors to innovation have been extensively dealt with in previous literature. Himmelberg and Petersen (1994) use small firms in the high-tech industries to show a significant positive relationship between internal finance and firms' R\&D. Stockdale (2002) reports that financial constraints are the second most important impeding factor for innovation for active firms in UK, after the high innovation costs. Similar results also have been obtained by other studies (e.g. Mulkay, Hall and Mairesse, 2001; Savignac, 2006; Tiwari et al., 2008).

Lack of skilled labor is another major internal obstacle that hampers innovation (Hadjimanolis, 1999). Innovation cannot be achieved without efficient utilization of $\mathrm{R} \& \mathrm{D}$ by qualified human capital. Skilled labor is also required in the production process to absorb and transfer ideas into new products. The concept of "absorptive capacity" proposed by Cohen and Levinthal (1990) also suggests that high levels of skills are necessary within a firm in order to appropriate external knowledge.

Considered as an external obstacle, competition from the informal sector is ranked as one of the biggest obstacles by firms in our sample (10.76 per cent). Informal competition may damage innovation since the cost advantage informal firms enjoy is a

\footnotetext{
${ }^{87}$ By filtering out firms that do not intend to become an innovator (see footnote 77 ), it helps us to rule out the potential non-innovation related obstacles that are perceived by firms.
} 
result of ignoring regulations (e.g. intellectual property regulations). While regulation is a major determinant of the intensity of competition from the informal sector, severe obstacles caused by competition from the informal sector may indicate the poor regulatory and institutional quality that prevails in the market. Estimates by Schneider (2005) over 145 countries across the globe show that informality is an issue correlated with low-income countries.

Corporate taxation may influence firms' investment decisions and profits. Classified as another external obstacle, the tax rate has been ranked as the biggest obstacle to firms' production in EECA countries in 2008. High corporate taxes may reduce incentives for innovations by reducing their post-tax returns. Hence, a negative effect of corporate taxes on firm level innovation is expected (Arrow, 1962). The issue of taxation and innovation is complex in the sense that innovative activity of firms is associated with many aspects and levels of taxation. Favorable taxation regimes are expected to create additional and important incentives for innovation (Mohnen, 2000).

Savignac (2008) suggests that a positive correlation between the obstacles and innovation performance might be raised by firms that are not willing to innovate. Hence, it is important to distinguish between firms which opted not to become innovators and those who could not because of obstacle standing in their way. We try to filter out the former by excluding firms that do not aim at innovation and, at the same time, perceive no obstacles in their production and innovation process (Savignac, 2008) ${ }^{88}$.

Table 6.4 shows the percentage of the presence of obstacles across different innovativeness. Generally, innovation active and product innovation oriented firms are more likely to be burdened by competition from the informal sector and by tax rates, while non-innovation active and non-product innovating firms tend to be hampered more by inadequate finance and skilled labor.

\footnotetext{
88 This is done in order to correct for a sample selection problem (Mohnen and Röller, 2005; Savignac, 2008). In particular, the survey includes two questions asking whether the firm has achieved new products/service innovation and upgraded their products/services during the period under review. If a firm responds negatively to these two questions, we classified him as non-potential products innovator. The underlying rationale is that non-innovating firms that did not experience any obstacle to innovation are unlikely to have the intention to innovate.
} 
Table 6. 4 Obstacles in innovators and non-innovators (mean values and percentages)

\begin{tabular}{lcccccc}
\hline & Fin_obs & Lab_obs & Com_obs & Tax_obs & Freq. & Percent \\
\hline R\&D investor & & & & & & \\
No & 0.28 & 0.33 & 0.29 & 0.48 & 5,634 & 73.05 \\
Yes & 0.30 & 0.37 & 0.29 & 0.44 & 2,078 & 26.95 \\
& & & & & & \\
New products or services & & & & & & \\
No & 0.27 & 0.31 & 0.30 & 0.49 & 3,204 & 41.55 \\
Yes & 0.30 & 0.37 & 0.29 & 0.45 & 4,508 & 58.45 \\
Total & 0.29 & 0.34 & 0.29 & 0.47 & 7712 & 100 \\
\hline
\end{tabular}

\subsubsection{Patterns of obstacles}

Sector. The sector in which a firm operates may influence the barriers it faces because different sectors are characterized by the nature of their products, market structure and legislation (Preissl, 1990). Hadjimanolis (2003) suggests that firms in different sectors perceive barriers to innovation differently. In EECA countries, firms in the manufacturing sector are in general more active in innovation. As shown in Table 6.5, 31 per cent of the manufacturing firms invest in $R \& D$, compared with 22 per cent in the service sector. It also shows that obstacles appear more frequent in the manufacturing sector except for the informal competition. This might be due to the fact that manufacturing firms start recognizing the obstacles through innovation. Service firms are more likely to struggle with informal competition since more than 30 per cent report it as a major obstacle while the financial barrier is more serious for manufacturing firms.

Income level. Firms from less developed countries have to face more severe constraints in innovation due to their relatively weak infrastructure, inadequate resources and government supports (Hadjimaonolis, 1999). Table 6.5 suggests that fewer firms from high-income countries encounter obstacles during their production compared with firms from the low and low-middle income groups. The low and low-middle income groups are pressured by inadequate finance and more than 17 per cent of the firms rate it as a severe obstacle, which is about 5 and 17 percentage points higher compared with uppermiddle income and high-income groups. The informal competition also seems to seriously hamper firms' production and innovation in low and middle-income countries. The labor and tax related obstacles more often appear in firms from upper-middle countries. Half of the firms from upper-middle income countries perceive high tax rates 
as a major obstacle and the percentages are 44 per cent and 41 per cent respectively for low-income and high-income group.

Firm size. Piatier (1984) explained that the patterns of obstacles faced by firms differ greatly associating with their size as well. Small firms generally perceive impediments as more severe (Hadjimanolis, 2003). Statistics in Table 6.5 exhibit that bigger size firms (the number of employees above 100) are less likely to encounter obstacles except for the lack of skilled labor. Informal competition seems to severely constrain small firms (with number of employees between 5 and 25). Firms with employees between 26 and 100 have the highest frequency of reporting the tax rate as an obstacle, 49 per cent.

Table 6. 5 Obstacles across different sector, income and size groups (mean values and percentages)

\begin{tabular}{|c|c|c|c|c|c|c|}
\hline & Fin_obs & Lab_obs & Com_obs & Tax_obs & Freq. & Percent \\
\hline \multicolumn{7}{|l|}{ Sector } \\
\hline Service & 0.27 & 0.31 & 0.30 & 0.44 & 3,414 & 44.27 \\
\hline Manufacturing & 0.30 & 0.36 & 0.29 & 0.49 & 4,298 & 55.73 \\
\hline \multicolumn{7}{|l|}{ Income } \\
\hline Low and lower-middle & 0.34 & 0.34 & 0.36 & 0.44 & 2,625 & 34.04 \\
\hline Upper-middle & 0.29 & 0.38 & 0.28 & 0.50 & 3,767 & 48.85 \\
\hline High & 0.17 & 0.24 & 0.19 & 0.41 & 1,320 & 17.12 \\
\hline \multicolumn{7}{|l|}{ Size } \\
\hline $5<x<25$ & 0.29 & 0.30 & 0.32 & 0.45 & 3,595 & 46.62 \\
\hline $26<x<100$ & 0.29 & 0.36 & 0.30 & 0.49 & 2,263 & 29.34 \\
\hline$>100$ & 0.28 & 0.39 & 0.23 & 0.47 & 1,854 & 24.04 \\
\hline Total & 0.29 & 0.34 & 0.29 & 0.47 & 7712 & 100 \\
\hline
\end{tabular}

\subsubsection{Firm specificities}

A set of control variables that captures the firm characteristics will be included in the innovation equation. Sales_log is the logarithm of total turnover in 2002 (in USD). It denotes the scale of the firm. Firms with a higher turnover are expected to have more financial resources to allocate to innovation. Age indicates the number of years a firm has been operating since it started. On the one hand, Age is expected to adversely affect innovation outcome (Tushman and Anderson, 1986; Henderson, 1993; Katrak, 1997) because younger firms are more creative and entrepreneurial dynamic. On the other 
hand, longer operation experience gives a firm prior expertise, already-established financial resources and other complementary assets. Accordingly, older firms are more likely to tackle obstacles that stand in their way (Schoonhoven et al., 1990; Tripsas, 1997). Ex_percent indicates the share of export (indirect and direct) in the total turnover during the period under review. Exporting firms face fiercer competition on the international market. It stimulates firms to be more innovative. However, in the case of EECA countries, firms might compete in the international market with a price advantage of already-existing products due to cheap material and labor. This might inhibit innovation, especially innovation in new products. Therefore, the sign of Ex_percent here is ambiguous. For_percent indicates the percentage of foreign ownership. Foreign owned firms are characterized by higher capital intensity, high quality of human capital and efficient management. Many previous studies suggest that foreign owned firms are more productive (Globerman et al., 1994; Doms and Jensen, 1998; Kimura and Kiyota, 2007). However, it is also argued that foreign owned firms tend to concentrate their R\&D in their home countries (OECD, 2003).

Regu_time records the percentage of time the senior manager spends in dealing with government regulations. It measures how burdensome it is for firms to comply with government regulations. On the one hand, each hour spent in dealing with government regulations is an hour not devoted to making the business more productive. A higher burden of regulations causes less willingness to expand production and innovation. On the other hand, the more time a manager spends also indicates a better understanding of government regulation and consequently benefits both internal (in-house R\&D) and external (co-operative innovation or licensing) innovative activities. 
Table 6. 6 Generalized Tobit estimation results: full sample and across different sectors

\begin{tabular}{|c|c|c|c|c|c|c|}
\hline \multirow{3}{*}{$\begin{array}{c}\text { Dependent } \\
\text { variable: New } \\
\text { products sales }\end{array}$} & \multirow{2}{*}{\multicolumn{2}{|c|}{ Full Sample }} & \multicolumn{4}{|c|}{ Sectors } \\
\hline & & & \multicolumn{2}{|c|}{ Manufacturing } & \multicolumn{2}{|c|}{ Services } \\
\hline & Outcome & Selection & Outcome & Selection & Outcome & Selection \\
\hline Fin_obs & $\begin{array}{c}0.242 \\
(0.153)\end{array}$ & $\begin{array}{c}-0.296 * * * \\
(0.074)\end{array}$ & $\begin{array}{l}0.353^{*} \\
(0.203)\end{array}$ & $\begin{array}{c}-0.295^{* * *} \\
(0.098)\end{array}$ & $\begin{array}{c}0.010 \\
(0.238)\end{array}$ & $\begin{array}{c}-0.303 * * * \\
(0.114)\end{array}$ \\
\hline Lab_obs & $\begin{array}{c}0.092 \\
(0.117)\end{array}$ & $\begin{array}{c}-0.158^{* *} \\
(0.063)\end{array}$ & $\begin{array}{c}0.228 \\
(0.171)\end{array}$ & $\begin{array}{c}-0.255^{* * *} \\
(0.085)\end{array}$ & $\begin{array}{l}-0.030 \\
(0.167)\end{array}$ & $\begin{array}{l}-0.037 \\
(0.097)\end{array}$ \\
\hline Com_obs & $\begin{array}{c}0.075 \\
(0.145)\end{array}$ & $\begin{array}{c}-0.281 * * * \\
(0.068)\end{array}$ & $\begin{array}{l}0.372^{*} \\
(0.214)\end{array}$ & $\begin{array}{c}-0.288^{* * *} \\
(0.100)\end{array}$ & $\begin{array}{l}-0.264 \\
(0.201)\end{array}$ & $\begin{array}{c}-0.286 * * * \\
(0.095)\end{array}$ \\
\hline Tax_obs & $\begin{array}{c}0.172 \\
(0.128)\end{array}$ & $\begin{array}{c}-0.350 * * * \\
(0.052)\end{array}$ & $\begin{array}{c}0.183 \\
(0.168)\end{array}$ & $\begin{array}{c}-0.342^{* * *} \\
(0.071)\end{array}$ & $\begin{array}{c}0.037 \\
(0.197)\end{array}$ & $\begin{array}{c}-0.363 * * * \\
(0.078)\end{array}$ \\
\hline Fin_Lab & $\begin{array}{l}-0.082 \\
(0.255)\end{array}$ & $\begin{array}{c}0.476^{* * * *} \\
(0.135)\end{array}$ & $\begin{array}{l}-0.437 \\
(0.357)\end{array}$ & $\begin{array}{c}0.631 * * * \\
(0.185)\end{array}$ & $\begin{array}{c}0.387 \\
(0.372)\end{array}$ & $\begin{array}{c}0.304 \\
(0.202)\end{array}$ \\
\hline Fin_Com & $\begin{array}{l}-0.322 \\
(0.283)\end{array}$ & $\begin{array}{c}0.410^{* * *} \\
(0.141)\end{array}$ & $\begin{array}{c}-0.823^{* *} \\
(0.398)\end{array}$ & $\begin{array}{l}0.384^{*} \\
(0.200)\end{array}$ & $\begin{array}{c}0.304 \\
(0.417)\end{array}$ & $\begin{array}{c}0.469 * * \\
(0.203)\end{array}$ \\
\hline Fin_Tax & $\begin{array}{c}-0.390^{*} \\
(0.230)\end{array}$ & $\begin{array}{c}0.449 * * * \\
(0.109)\end{array}$ & $\begin{array}{l}-0.483 \\
(0.298)\end{array}$ & $\begin{array}{c}0.365^{* *} \\
(0.146)\end{array}$ & $\begin{array}{l}-0.061 \\
(0.375)\end{array}$ & $\begin{array}{c}0.585^{* * * *} \\
(0.167)\end{array}$ \\
\hline Lab_Com & $\begin{array}{l}-0.342 \\
(0.255)\end{array}$ & $\begin{array}{c}0.458 * * * \\
(0.128)\end{array}$ & $\begin{array}{c}-0.898^{* *} \\
(0.373)\end{array}$ & $\begin{array}{c}0.658^{* * *} \\
(0.178)\end{array}$ & $\begin{array}{c}0.297 \\
(0.352)\end{array}$ & $\begin{array}{c}0.203 \\
(0.186)\end{array}$ \\
\hline Lab_Tax & $\begin{array}{l}-0.223 \\
(0.194)\end{array}$ & $\begin{array}{c}0.346^{* * * *} \\
(0.097)\end{array}$ & $\begin{array}{l}-0.283 \\
(0.260)\end{array}$ & $\begin{array}{c}0.328^{* *} \\
(0.128)\end{array}$ & $\begin{array}{l}-0.075 \\
(0.292)\end{array}$ & $\begin{array}{c}0.338^{* *} \\
(0.150)\end{array}$ \\
\hline Com_Tax & $\begin{array}{l}-0.035 \\
(0.214)\end{array}$ & $\begin{array}{c}0.316^{* * *} \\
(0.102)\end{array}$ & $\begin{array}{l}-0.132 \\
(0.297)\end{array}$ & $\begin{array}{c}0.206 \\
(0.143)\end{array}$ & $\begin{array}{c}0.188 \\
(0.324)\end{array}$ & $\begin{array}{c}0.441^{* * *} \\
(0.150)\end{array}$ \\
\hline Fin_Lab_Com & $\begin{array}{c}0.593 \\
(0.447)\end{array}$ & $\begin{array}{c}-0.494^{* *} \\
(0.245)\end{array}$ & $\begin{array}{c}1.393 * * \\
(0.614)\end{array}$ & $\begin{array}{l}-0.554 \\
(0.342)\end{array}$ & $\begin{array}{l}-0.474 \\
(0.675)\end{array}$ & $\begin{array}{l}-0.458 \\
(0.359)\end{array}$ \\
\hline Fin_Lab_Tax & $\begin{array}{l}-0.084 \\
(0.333)\end{array}$ & $\begin{array}{c}-0.367 * * \\
(0.184)\end{array}$ & $\begin{array}{c}0.072 \\
(0.444)\end{array}$ & $\begin{array}{l}-0.326 \\
(0.248)\end{array}$ & $\begin{array}{l}-0.356 \\
(0.520)\end{array}$ & $\begin{array}{l}-0.438 \\
(0.280)\end{array}$ \\
\hline Fin_Com_Tax & $\begin{array}{c}0.425 \\
(0.390)\end{array}$ & $\begin{array}{c}-0.519 * * * \\
(0.195)\end{array}$ & $\begin{array}{c}0.787 \\
(0.525)\end{array}$ & $\begin{array}{l}-0.264 \\
(0.269)\end{array}$ & $\begin{array}{l}-0.294 \\
(0.635)\end{array}$ & $\begin{array}{c}-0.917 * * * \\
(0.288)\end{array}$ \\
\hline Lab_Com_Tax & $\begin{array}{c}0.317 \\
(0.335)\end{array}$ & $\begin{array}{l}-0.286 \\
(0.179)\end{array}$ & $\begin{array}{c}0.709 \\
(0.459)\end{array}$ & $\begin{array}{l}-0.256 \\
(0.244)\end{array}$ & $\begin{array}{c}-0.303 \\
(0.510)\end{array}$ & $\begin{array}{l}-0.316 \\
(0.271)\end{array}$ \\
\hline Fin_Lab_Com_Tax & $\begin{array}{l}-0.602 \\
(0.568)\end{array}$ & $\begin{array}{c}0.449 \\
(0.314)\end{array}$ & $\begin{array}{l}-1.178 \\
(0.761)\end{array}$ & $\begin{array}{c}0.024 \\
(0.430)\end{array}$ & $\begin{array}{c}0.587 \\
(0.934)\end{array}$ & $\begin{array}{c}1.097 * * \\
(0.474)\end{array}$ \\
\hline Lnsale2007 & $\begin{array}{l}-0.024 \\
(0.029)\end{array}$ & $\begin{array}{c}0.083^{* * * *} \\
(0.012)\end{array}$ & $\begin{array}{l}-0.047 \\
(0.037)\end{array}$ & $\begin{array}{c}0.064^{* * *} \\
(0.017)\end{array}$ & $\begin{array}{c}0.038 \\
(0.048)\end{array}$ & $\begin{array}{c}0.104 * * * \\
(0.017)\end{array}$ \\
\hline Expercent & $\begin{array}{c}0.003^{* *} \\
(0.001)\end{array}$ & $\begin{array}{c}-0.002 * * * \\
(0.001)\end{array}$ & $\begin{array}{c}0.003 * * \\
(0.002)\end{array}$ & $\begin{array}{c}-0.002 * * \\
(0.001)\end{array}$ & $\begin{array}{c}0.001 \\
(0.002)\end{array}$ & $\begin{array}{l}-0.001 \\
(0.001)\end{array}$ \\
\hline Forown & $\begin{array}{c}0.001 \\
(0.001)\end{array}$ & $\begin{array}{c}0.002^{* *} \\
(0.001)\end{array}$ & $\begin{array}{c}0.001 \\
(0.002)\end{array}$ & $\begin{array}{c}0.000 \\
(0.001)\end{array}$ & $\begin{array}{l}0.004 * \\
(0.002)\end{array}$ & $\begin{array}{c}0.003 * * * \\
(0.001)\end{array}$ \\
\hline ISO & & $\begin{array}{c}0.103 * * \\
(0.041)\end{array}$ & & $\begin{array}{c}0.111^{* *} \\
(0.052)\end{array}$ & & $\begin{array}{l}0.118^{*} \\
(0.068)\end{array}$ \\
\hline RnDdum & $\begin{array}{c}0.200 \\
(0.182)\end{array}$ & $\begin{array}{c}0.787 * * * \\
(0.040)\end{array}$ & $\begin{array}{c}0.070 \\
(0.250)\end{array}$ & $\begin{array}{c}0.862 * * * \\
(0.051)\end{array}$ & $\begin{array}{c}0.506^{* *} \\
(0.238)\end{array}$ & $\begin{array}{c}0.683^{* * *} \\
(0.064)\end{array}$ \\
\hline Age & $\begin{array}{c}-0.010^{* * *} \\
(0.002)\end{array}$ & $\begin{array}{l}-0.001 \\
(0.001)\end{array}$ & $\begin{array}{c}-0.008^{* * *} \\
(0.002)\end{array}$ & $\begin{array}{l}-0.000 \\
(0.001)\end{array}$ & $\begin{array}{c}-0.015^{* * *} \\
(0.004)\end{array}$ & $\begin{array}{l}-0.002 \\
(0.002)\end{array}$ \\
\hline Subsidy & & $\begin{array}{c}0.240^{* * * *} \\
(0.057)\end{array}$ & & $\begin{array}{c}0.228^{* * *} * \\
(0.072)\end{array}$ & & $\begin{array}{c}0.256^{* * *} * \\
(0.096)\end{array}$ \\
\hline Regu_time1 & $\begin{array}{c}0.005^{* * *} \\
(0.002)\end{array}$ & $\begin{array}{l}-0.000 \\
(0.001)\end{array}$ & $\begin{array}{c}0.006 * * * \\
(0.002)\end{array}$ & $\begin{array}{l}-0.001 \\
(0.001)\end{array}$ & $\begin{array}{c}0.006^{* *} \\
(0.003)\end{array}$ & $\begin{array}{c}0.001 \\
(0.001)\end{array}$ \\
\hline Hitech & $\begin{array}{l}-0.098 \\
(0.364)\end{array}$ & $\begin{array}{l}-0.053 \\
(0.253)\end{array}$ & $\begin{array}{c}0.346 \\
(0.378)\end{array}$ & $\begin{array}{c}0.888^{* * * *} \\
(0.172)\end{array}$ & & \\
\hline Sizedum2 & $\begin{array}{l}-0.100 \\
(0.076)\end{array}$ & $\begin{array}{l}-0.024 \\
(0.042)\end{array}$ & $\begin{array}{l}-0.016 \\
(0.106)\end{array}$ & $\begin{array}{l}-0.031 \\
(0.057)\end{array}$ & $\begin{array}{l}-0.168 \\
(0.114)\end{array}$ & $\begin{array}{l}-0.036 \\
(0.063)\end{array}$ \\
\hline Sizedum 3 & $\begin{array}{c}-0.198^{*} \\
(0.108)\end{array}$ & $\begin{array}{c}-0.159 * * * \\
(0.057)\end{array}$ & $\begin{array}{l}-0.082 \\
(0.155)\end{array}$ & $\begin{array}{c}-0.199 * * \\
(0.079)\end{array}$ & $\begin{array}{c}-0.313^{* *} \\
(0.155)\end{array}$ & $\begin{array}{l}-0.074 \\
(0.087)\end{array}$ \\
\hline Constant & $\begin{array}{l}-0.267 \\
(0.498)\end{array}$ & $\begin{array}{c}0.302 \\
(0.272)\end{array}$ & $\begin{array}{l}-0.705 \\
(0.790)\end{array}$ & $\begin{array}{c}-0.513^{*} \\
(0.306)\end{array}$ & $\begin{array}{l}-0.791 \\
(0.682)\end{array}$ & $\begin{array}{c}0.137 \\
(0.322)\end{array}$ \\
\hline Observations & 7,712 & 4,508 & 4,298 & 2,537 & 3,414 & 1,971 \\
\hline
\end{tabular}

Standard errors in parentheses

*** $\mathrm{p}<0.01, * * \mathrm{p}<0.05,{ }^{*} \mathrm{p}<0.1$ 
Table 6. 7 Generalized Tobit estimation results: across different income levels

\begin{tabular}{|c|c|c|c|c|c|c|}
\hline \multirow{3}{*}{$\begin{array}{l}\text { Dependent variable: } \\
\text { New products sales }\end{array}$} & \multicolumn{6}{|c|}{ Income pattern } \\
\hline & \multicolumn{2}{|c|}{ Low and Low-middle } & \multicolumn{2}{|c|}{ Upper-middle } & \multicolumn{2}{|c|}{ High } \\
\hline & Outcome & Selection & Outcome & Selection & Outcome & Selection \\
\hline \multirow[t]{2}{*}{ Fin_obs } & $0.550^{* *}$ & $-0.249^{* *}$ & 0.242 & $-0.352 * * *$ & -0.296 & -0.173 \\
\hline & $(0.259)$ & $(0.118)$ & $(0.234)$ & $(0.110)$ & $(0.329)$ & (0.203) \\
\hline \multirow[t]{2}{*}{ Lab_obs } & 0.161 & -0.135 & 0.076 & $-0.173^{*}$ & 0.085 & -0.212 \\
\hline & $(0.229)$ & $(0.113)$ & (0.173) & $(0.092)$ & $(0.232)$ & $(0.146)$ \\
\hline \multirow[t]{2}{*}{ Com_obs } & $0.500^{*}$ & $-0.344 * * *$ & -0.165 & $-0.303^{* * *}$ & 0.209 & -0.036 \\
\hline & $(0.272)$ & $(0.108)$ & $(0.218)$ & $(0.101)$ & $(0.304)$ & $(0.200)$ \\
\hline \multirow[t]{2}{*}{ Tax_obs } & 0.500 & $-0.526^{* * *}$ & 0.174 & $-0.299 * * *$ & -0.025 & $-0.270^{* *}$ \\
\hline & $(0.321)$ & $(0.099)$ & $(0.171)$ & $(0.075)$ & $(0.209)$ & $(0.115)$ \\
\hline \multirow[t]{2}{*}{ Fin_Lab } & -0.318 & 0.156 & -0.234 & $0.721 * * *$ & $1.365^{* *}$ & 0.473 \\
\hline & $(0.449)$ & $(0.223)$ & $(0.385)$ & $(0.193)$ & $(0.611)$ & $(0.420)$ \\
\hline \multirow[t]{2}{*}{ Fin_Com } & -0.713 & 0.344 & 0.042 & $0.533^{* *}$ & $-1.310^{*}$ & 0.182 \\
\hline & $(0.459)$ & $(0.213)$ & $(0.438)$ & $(0.211)$ & $(0.759)$ & $(0.475)$ \\
\hline \multirow[t]{2}{*}{ Fin_Tax } & -0.713 & $0.468^{* *}$ & -0.517 & $0.430 * * *$ & 0.298 & $0.664 * *$ \\
\hline & $(0.440)$ & $(0.184)$ & $(0.328)$ & $(0.158)$ & $(0.507)$ & $(0.306)$ \\
\hline \multirow[t]{2}{*}{ Lab_Com } & -0.768 & $0.592^{* * *}$ & -0.232 & $0.503^{* * *}$ & -0.135 & -0.208 \\
\hline & $(0.485)$ & $(0.209)$ & $(0.374)$ & $(0.182)$ & $(0.670)$ & $(0.407)$ \\
\hline \multirow[t]{2}{*}{ Lab_Tax } & -0.290 & $0.515^{* * *}$ & -0.337 & $0.288^{* *}$ & -0.008 & $0.421 *$ \\
\hline & $(0.448)$ & $(0.184)$ & $(0.261)$ & $(0.132)$ & $(0.413)$ & $(0.249)$ \\
\hline \multirow[t]{2}{*}{ Com_Tax } & -0.504 & $0.564 * * *$ & 0.048 & 0.202 & -0.046 & 0.180 \\
\hline & $(0.453)$ & $(0.174)$ & $(0.312)$ & $(0.149)$ & $(0.441)$ & $(0.269)$ \\
\hline \multirow[t]{2}{*}{ Fin_Lab_Com } & 1.195 & -0.257 & 0.240 & $-0.769^{* *}$ & -1.255 & -0.402 \\
\hline & $(0.733)$ & $(0.372)$ & $(0.679)$ & $(0.366)$ & $(1.628)$ & $(0.900)$ \\
\hline \multirow[t]{2}{*}{ Fin_Lab_Tax } & -0.218 & -0.093 & 0.345 & $-0.495^{*}$ & $-1.938^{* *}$ & $-1.133^{* *}$ \\
\hline & $(0.640)$ & $(0.319)$ & $(0.468)$ & $(0.255)$ & $(0.906)$ & $(0.572)$ \\
\hline Fin_Com_Tax & 0.591 & $-0.522^{*}$ & 0.529 & -0.420 & 1.263 & -0.954 \\
\hline & $(0.674)$ & $(0.306)$ & $(0.574)$ & $(0.290)$ & $(1.032)$ & (0.603) \\
\hline Lab_Com_Tax & 0.366 & $-0.592^{*}$ & 0.677 & -0.232 & -0.817 & 0.301 \\
\hline & $(0.670)$ & $(0.309)$ & $(0.481)$ & $(0.251)$ & $(0.879)$ & $(0.536)$ \\
\hline Fin_Lab_Com_Tax & -0.547 & 0.355 & -1.056 & 0.388 & 1.779 & 1.454 \\
\hline Fin_obs & $(0.991)$ & $(0.501)$ & $(0.826)$ & $(0.459)$ & $(1.946)$ & $(1.097)$ \\
\hline Lnsale2007 & -0.087 & $0.098^{* * *} *$ & 0.003 & $0.081 * * *$ & $-0.109^{*}$ & $0.056^{*}$ \\
\hline & $(0.060)$ & $(0.019)$ & $(0.040)$ & $(0.018)$ & $(0.058)$ & $(0.033)$ \\
\hline Expercent & -0.000 & -0.000 & 0.003 & $-0.003^{* * *}$ & $0.005^{* *}$ & -0.002 \\
\hline & $(0.002)$ & $(0.001)$ & $(0.002)$ & $(0.001)$ & $(0.003)$ & $(0.002)$ \\
\hline Forown & 0.002 & -0.001 & 0.001 & 0.002 & 0.001 & $0.005^{* * *}$ \\
\hline & $(0.002)$ & $(0.001)$ & $(0.002)$ & $(0.001)$ & $(0.002)$ & $(0.002)$ \\
\hline ISO & & $0.133^{*}$ & & 0.091 & & 0.146 \\
\hline & & $(0.081)$ & & $(0.056)$ & & $(0.099)$ \\
\hline RnDdum & -0.077 & $0.817^{* * *}$ & 0.299 & $0.809^{* * *}$ & -0.157 & $0.744 * * *$ \\
\hline & $(0.348)$ & $(0.074)$ & $(0.247)$ & $(0.055)$ & $(0.281)$ & $(0.098)$ \\
\hline Age & $-0.009^{* *}$ & 0.000 & $-0.012 * * *$ & $-0.003^{* *}$ & $-0.007^{* *} *$ & -0.000 \\
\hline & $(0.004)$ & $(0.002)$ & $(0.003)$ & $(0.001)$ & $(0.004)$ & $(0.003)$ \\
\hline Subsidy & & 0.162 & & $0.311 * * *$ & & $0.225^{* *}$ \\
\hline & & $(0.131)$ & & $(0.084)$ & & $(0.104)$ \\
\hline Regu_time1 & 0.005 & $-0.004 * * *$ & $0.006^{* * *}$ & 0.001 & $0.010^{* *}$ & 0.003 \\
\hline & $(0.004)$ & $(0.002)$ & $(0.002)$ & $(0.001)$ & $(0.004)$ & $(0.003)$ \\
\hline Hitech & -0.322 & 0.333 & -0.104 & $-0.832^{*}$ & 0.030 & 0.549 \\
\hline Lnsale2007 & $(0.926)$ & $(0.457)$ & $(0.587)$ & $(0.476)$ & $(0.580)$ & $(0.529)$ \\
\hline Sizedum2 & -0.108 & 0.005 & -0.077 & -0.028 & -0.059 & -0.111 \\
\hline & $(0.140)$ & $(0.071)$ & $(0.109)$ & $(0.060)$ & $(0.178)$ & $(0.110)$ \\
\hline Sizedum 3 & -0.181 & $-0.245^{* *}$ & -0.149 & $-0.138^{*}$ & -0.072 & -0.108 \\
\hline & $(0.232)$ & $(0.102)$ & (0.153) & $(0.082)$ & $(0.231)$ & $(0.148)$ \\
\hline Constant & -0.340 & -0.554 & -0.584 & $0.920 * *$ & 0.338 & 0.288 \\
\hline & $(1.176)$ & $(0.366)$ & $(0.612)$ & $(0.465)$ & $(0.746)$ & $(0.434)$ \\
\hline Observations & 2625 & 1,442 & 3,670 & 2,233 & 1,320 & 8,33 \\
\hline
\end{tabular}

Standard errors in parentheses

*** $\mathrm{p}<0.01, * * \mathrm{p}<0.05, * \mathrm{p}<0.1$ 
Table 6. 8 Generalized Tobit estimation results: across different size groups

\begin{tabular}{|c|c|c|c|c|c|c|}
\hline \multirow{3}{*}{$\begin{array}{c}\text { Dependent } \\
\text { variable: New } \\
\text { products sales }\end{array}$} & \multicolumn{6}{|c|}{ Size pattern } \\
\hline & \multicolumn{2}{|c|}{ Small (5-25) } & \multicolumn{2}{|c|}{ Medium (26-100) } & \multicolumn{2}{|c|}{ Large $(>100)$} \\
\hline & Outcome & Selection & Outcome & Selection & Outcome & Selection \\
\hline \multirow[t]{2}{*}{ Fin_obs } & 0.010 & $-0.264 * *$ & 0.278 & -0.187 & 0.468 & $-0.397 * *$ \\
\hline & $(0.208)$ & (0.104) & $(0.286)$ & $(0.147)$ & $(0.329)$ & $(0.161)$ \\
\hline \multirow[t]{2}{*}{ Lab_obs } & -0.030 & $-0.293^{* * *}$ & -0.010 & -0.036 & 0.308 & -0.008 \\
\hline & $(0.200)$ & $(0.096)$ & $(0.222)$ & $(0.121)$ & $(0.202)$ & $(0.128)$ \\
\hline \multirow[t]{2}{*}{ Com_obs } & 0.195 & $-0.426 * * *$ & 0.117 & -0.125 & -0.240 & -0.074 \\
\hline & $(0.237)$ & $(0.092)$ & $(0.263)$ & $(0.137)$ & $(0.286)$ & $(0.178)$ \\
\hline \multirow[t]{2}{*}{ Tax_obs } & 0.014 & $-0.407 * * *$ & 0.170 & $-0.250^{* *}$ & 0.287 & $-0.329 * * *$ \\
\hline & $(0.203)$ & $(0.077)$ & $(0.218)$ & $(0.097)$ & $(0.227)$ & (0.112) \\
\hline \multirow[t]{2}{*}{ Fin_Lab } & 0.083 & $0.559 * * *$ & 0.089 & 0.382 & -0.455 & 0.304 \\
\hline & (0.403) & $(0.208)$ & $(0.461)$ & $(0.248)$ & $(0.472)$ & $(0.272)$ \\
\hline \multirow[t]{2}{*}{ Fin_Com } & -0.070 & $0.566^{* * *}$ & $-0.975^{*}$ & -0.002 & -0.216 & 0.285 \\
\hline & $(0.403)$ & $(0.187)$ & $(0.558)$ & $(0.275)$ & $(0.659)$ & $(0.390)$ \\
\hline \multirow[t]{2}{*}{ Fin_Tax } & -0.237 & $0.338^{* *}$ & -0.541 & 0.259 & -0.462 & $0.880^{* * *}$ \\
\hline & $(0.310)$ & $(0.156)$ & $(0.414)$ & $(0.207)$ & $(0.516)$ & $(0.248)$ \\
\hline \multirow[t]{2}{*}{ Lab_Com } & -0.392 & $0.564 * * *$ & -0.213 & 0.281 & -0.289 & 0.432 \\
\hline & $(0.407)$ & $(0.181)$ & $(0.455)$ & $(0.241)$ & $(0.487)$ & $(0.307)$ \\
\hline \multirow[t]{2}{*}{ Lab_Tax } & -0.198 & $0.537 * * *$ & -0.010 & 0.014 & -0.377 & 0.285 \\
\hline & $(0.330)$ & $(0.148)$ & $(0.352)$ & $(0.181)$ & $(0.336)$ & (0.194) \\
\hline \multirow[t]{2}{*}{ Com_Tax } & -0.185 & $0.501 * * *$ & 0.071 & 0.022 & 0.202 & 0.143 \\
\hline & $(0.333)$ & $(0.142)$ & $(0.396)$ & $(0.196)$ & $(0.434)$ & $(0.251)$ \\
\hline \multirow[t]{2}{*}{ Fin_Lab_Com } & 0.187 & $-0.745^{* *}$ & $1.584^{*}$ & -0.195 & 0.061 & -0.199 \\
\hline & $(0.672)$ & $(0.348)$ & $(0.835)$ & $(0.465)$ & $(0.950)$ & $(0.586)$ \\
\hline \multirow[t]{2}{*}{ Fin_Lab_Tax } & 0.217 & $-0.583^{* *}$ & -0.472 & 0.260 & 0.048 & $-0.644^{*}$ \\
\hline & $(0.527)$ & $(0.282)$ & $(0.616)$ & $(0.342)$ & $(0.662)$ & $(0.375)$ \\
\hline \multirow[t]{2}{*}{ Fin_Com_Tax } & 0.219 & $-0.779 * * *$ & 0.985 & 0.250 & 0.526 & -0.512 \\
\hline & $(0.568)$ & $(0.265)$ & $(0.755)$ & $(0.376)$ & $(0.872)$ & $(0.503)$ \\
\hline \multirow[t]{2}{*}{ Lab_Com_Tax } & 0.456 & $-0.451 *$ & 0.242 & 0.287 & 0.105 & -0.608 \\
\hline & $(0.509)$ & $(0.260)$ & $(0.641)$ & $(0.336)$ & $(0.687)$ & $(0.408)$ \\
\hline Fin_Lab_Com_Tax & -0.676 & $0.965^{* *}$ & -1.077 & -0.678 & -0.263 & 0.456 \\
\hline & $(0.873)$ & $(0.453)$ & $(1.109)$ & $(0.595)$ & $(1.213)$ & $(0.730)$ \\
\hline Lnsale2007 & -0.006 & $0.072^{* * *}$ & -0.003 & $0.062^{* * *}$ & -0.092 & $0.121^{* * *} *$ \\
\hline & $(0.041)$ & $(0.017)$ & $(0.052)$ & $(0.023)$ & $(0.057)$ & $(0.025)$ \\
\hline Expercent & 0.003 & -0.001 & 0.000 & $-0.003 * * *$ & 0.003 & -0.001 \\
\hline & $(0.002)$ & $(0.001)$ & $(0.002)$ & $(0.001)$ & $(0.002)$ & $(0.001)$ \\
\hline Forown & -0.003 & $0.003^{* *}$ & 0.003 & 0.001 & 0.003 & 0.001 \\
\hline & $(0.002)$ & $(0.001)$ & $(0.002)$ & $(0.001)$ & $(0.002)$ & $(0.001)$ \\
\hline ISO & & $0.153^{* *}$ & & $0.154^{* *}$ & & 0.063 \\
\hline & & $(0.071)$ & & $(0.072)$ & & $(0.076)$ \\
\hline RnDdum & 0.324 & $0.768^{* * *}$ & 0.438 & $0.846^{* * *}$ & -0.336 & $0.836^{* * *}$ \\
\hline & $(0.277)$ & $(0.064)$ & $(0.340)$ & $(0.072)$ & $(0.270)$ & $(0.076)$ \\
\hline Age & $-0.015^{* * *}$ & -0.001 & $-0.019 * * *$ & -0.001 & -0.003 & -0.001 \\
\hline & $(0.005)$ & $(0.002)$ & $(0.004)$ & $(0.002)$ & $(0.002)$ & $(0.002)$ \\
\hline Subsidy & & $0.280^{* * *}$ & & 0.149 & & $0.326^{* * *}$ \\
\hline & & $(0.101)$ & & $(0.101)$ & & $(0.103)$ \\
\hline Regu_time1 & $0.007^{* * *}$ & 0.001 & $0.006^{* *}$ & -0.000 & $0.005^{*}$ & -0.002 \\
\hline & $(0.002)$ & $(0.001)$ & $(0.003)$ & $(0.001)$ & $(0.003)$ & $(0.002)$ \\
\hline Hitech & -0.677 & -0.122 & 0.133 & $0.583^{*}$ & -0.119 & 0.341 \\
\hline & $(0.620)$ & $(0.386)$ & $(0.798)$ & $(0.315)$ & $(0.640)$ & $(0.449)$ \\
\hline Constant & -0.293 & 0.373 & -1.056 & -0.013 & 1.215 & $-1.305^{* *}$ \\
\hline & $(0.668)$ & $(0.358)$ & $(1.090)$ & $(0.444)$ & $(1.302)$ & $(0.617)$ \\
\hline Observations & 3,595 & 1,959 & 2,263 & 1,365 & 1,854 & 1,184 \\
\hline
\end{tabular}

Standard errors in parentheses

*** $\mathrm{p}<0.01, * * \mathrm{p}<0.05, * \mathrm{p}<0.1$

Additional variables are included in the selection equation (6.2) to avoid specification problems. These variables are expected to influence the probability of product 
innovation but not the new products sales. In reality, such variables are difficult to define (Puhani, 2000; Vella, 1998). ISO and Subsidies will be used to indicate if a firm has an internationally recognized quality certification and received any subsidies from the national, regional or local governments or European Union sources during the period under review. These two factors are used to capture part of the technological capability and additional financial resources of the firms. They are expected to positively influence the probability of participating in and achieving innovation. However, these proxies may not affect the intensity of innovation, as they are mainly determined by the quality of products and services. Finally, three sets of dummies are included to control for size, industry and country specific effects.

\subsection{Obstacles to innovation: empirical results}

This section discusses the empirical evidence for firms from CEEA countries and elaborates how patterns of obstacles are presented differently across sectors, income levels and size groups.

The complementary/substitutive relationships between pairs of obstacles are tested in the innovation output function with control for firm, industry and country specific effects. A firm's innovation output intensity is measured by the logit transformation of the percentage of sales due to new products and services.

Large volume of sales indicates large scale of production and relatively adequate resources to allocate in production. Firms with a higher turnover are expected to be more innovative compared with firms with small scales of turnover. The estimated coefficients for turnover are significant at 99 per cent for all sub-groups in the selection equation. It suggests that a relatively higher turnover increases the probability of a firm to become an innovator. This effect is more profound in the service sector and the largesized group, as shown by higher estimated coefficients. However, this positive correlation does not hold with respect to the intensity of innovation. As shown in Table 6.6, Table 6.7 and Table 6.8, the estimated coefficients for variables Lnsale2007 are insignificant. A firm's age does not affect the innovation propensity and undermines the innovation intensity except for large-sized firms. It is consistent with the argument that old firms are expected to be less dynamic and innovative (Katrak, 1997). This negative effect is strengthened in the service sector and also for firms with fewer than 100 
employees. The negative sign of Ex_percent in the selection equation implies that exporting firms are less innovative in terms of the new products innovation for manufacturing, upper-middle income and medium size firms. In contrast, positive effects are found for the intensity of innovation. Foreign ownership plays a significant role in stimulating innovation propensity, especially for firms in the service sector and highincome group. These effects are not significant to the innovation sales except for the service sector. The probability for firms with foreign ownership to become successful innovators is higher than for firms with non-foreign ownership.

The R\&D dummy indicates whether a firm engages in $R \& D$ activities and is included in the innovation output equation. As one of the most important sources of innovation, engaging in $\mathrm{R} \& \mathrm{D}$ is expected to create critical contributions to a firm's innovation performance. The significant coefficients shown in all sub-groups of our study confirm that $R \& D$ investment significantly fosters innovator propensity. It is also found that in the service sector, engaging in $\mathrm{R} \& \mathrm{D}$ also strengthens the sales of new products. Firms in high-tech industries have a higher propensity to become innovators in the manufacturing sector. The size of a firm appears to be negative correlated with innovation outcome. Smaller firms are more likely to achieve new products innovation. The estimated coefficients for size dummies are negative and significant in both selection and outcome equation across all groups. The technological capability variable (ISO) and external finance variable (Subsidies) that are included only in the selection equation appear both as positive and significant.

To sum up, the findings present a clear pattern of the determinants to innovation across sectors. Due to the different nature and operation mechanism between manufacturing and service sector, firm-specific variables have shown rather heterogeneous effects on innovation performance. For instance, foreign ownership plays a more critical role in the service sector in promoting both innovation propensity and innovation intensity. One possible explanation is that new products in the service sector are difficult to succeed without incorporating local culture and customs. Therefore, foreign firms have to carry out innovation activities locally instead of in their home countries. Hence, combined with their adequately skilled labor and efficient management mechanism, the probability of becoming an innovator is likely to be higher for foreign owned firms in the service sector. Meanwhile, we also find out that export intensity only fosters innovation for manufacturing firms. Because it is easy to transfer and imitate, products in the service 
sector are less likely to become a tangible product for exporting purposes compared with products in the manufacturing sector. Therefore, the significantly positive effect of the export intensity to innovation is only observed for manufacturing firms.

Table 6. 9 Summary of complementary/substitutive relationships between pairs of obstacles (at 95\% significant level)

\begin{tabular}{|c|c|c|c|c|c|c|c|c|c|}
\hline \multirow{2}{*}{$\begin{array}{l}\text { Depen } \\
\text { dent } \\
\text { variable } \\
\text { : R\&D }\end{array}$} & \multirow[b]{2}{*}{$\begin{array}{l}\text { Full } \\
\text { Sample }\end{array}$} & \multicolumn{2}{|c|}{ Sectors } & \multicolumn{3}{|c|}{ Income groups } & \multicolumn{3}{|c|}{ Size groups } \\
\hline & & $\begin{array}{l}\text { Manufact } \\
\text { uring }\end{array}$ & Service & $\begin{array}{l}\text { Low \& } \\
\text { Low- } \\
\text { middle }\end{array}$ & $\begin{array}{l}\text { Upper- } \\
\text { Middle }\end{array}$ & $\begin{array}{l}\text { High- } \\
\text { income }\end{array}$ & $\begin{array}{l}\text { Small } \\
(5-25)\end{array}$ & $\begin{array}{l}\text { Medium } \\
(26-100)\end{array}$ & $\begin{array}{l}\text { Large } \\
(>100)\end{array}$ \\
\hline \multicolumn{10}{|c|}{$\begin{array}{l}\text { Innovation } \\
\text { Propensity }\end{array}$} \\
\hline Fin_Lab & $\begin{array}{c}\text { Compleme } \\
\text { ntary }\end{array}$ & $\begin{array}{c}\text { Compleme } \\
\text { ntary }\end{array}$ & $\begin{array}{c}\text { Compleme } \\
\text { ntary }\end{array}$ & None & $\begin{array}{c}\text { Compleme } \\
\text { ntary }\end{array}$ & None & $\begin{array}{l}\text { Compleme } \\
\text { ntary }\end{array}$ & $\begin{array}{c}\text { Compleme } \\
\text { ntary }\end{array}$ & None \\
\hline $\begin{array}{l}\text { Fin_Co } \\
\mathrm{m}\end{array}$ & $\begin{array}{c}\text { Compleme } \\
\text { ntary }\end{array}$ & None & None & None & $\begin{array}{c}\text { Compleme } \\
\text { ntary }\end{array}$ & None & $\begin{array}{l}\text { Compleme } \\
\text { ntary }\end{array}$ & $\begin{array}{l}\text { Substitutiv } \\
\text { e }\end{array}$ & None \\
\hline Fin_Tax & $\begin{array}{l}\text { Compleme } \\
\text { ntary }\end{array}$ & $\begin{array}{c}\text { Compleme } \\
\text { ntary }\end{array}$ & $\begin{array}{l}\text { Compleme } \\
\text { ntary }\end{array}$ & $\begin{array}{l}\text { Compleme } \\
\text { ntary }\end{array}$ & $\begin{array}{c}\text { Compleme } \\
\text { ntary }\end{array}$ & None & None & $\begin{array}{l}\text { Compleme } \\
\text { ntary }\end{array}$ & $\begin{array}{c}\text { Compleme } \\
\text { ntary }\end{array}$ \\
\hline $\begin{array}{l}\text { Lab_Co } \\
\mathrm{m}\end{array}$ & $\begin{array}{l}\text { Compleme } \\
\text { ntary }\end{array}$ & $\begin{array}{c}\text { Compleme } \\
\text { ntary }\end{array}$ & None & $\begin{array}{l}\text { Compleme } \\
\text { ntary }\end{array}$ & $\begin{array}{c}\text { Compleme } \\
\text { ntary }\end{array}$ & None & $\begin{array}{l}\text { Compleme } \\
\text { ntary }\end{array}$ & $\begin{array}{c}\text { Compleme } \\
\text { ntary }\end{array}$ & None \\
\hline $\begin{array}{l}\text { Lab_Ta } \\
x\end{array}$ & $\begin{array}{l}\text { Compleme } \\
\text { ntary }\end{array}$ & $\begin{array}{l}\text { Compleme } \\
\text { ntary }\end{array}$ & $\begin{array}{l}\text { Compleme } \\
\text { ntary }\end{array}$ & $\begin{array}{l}\text { Compleme } \\
\text { ntary }\end{array}$ & None & $\begin{array}{l}\text { Compleme } \\
\text { ntary }\end{array}$ & $\begin{array}{l}\text { Compleme } \\
\text { ntary }\end{array}$ & None & None \\
\hline $\begin{array}{l}\text { Com_T } \\
\text { ax }\end{array}$ & $\begin{array}{c}\text { Compleme } \\
\text { ntary }\end{array}$ & None & $\begin{array}{c}\text { Compleme } \\
\text { ntary }\end{array}$ & $\begin{array}{c}\text { Compleme } \\
\text { ntary }\end{array}$ & None & None & $\begin{array}{c}\text { Compleme } \\
\text { ntary }\end{array}$ & None & None \\
\hline \multicolumn{10}{|c|}{ New product sales } \\
\hline Fin_Lab & None & None & None & None & None & $\begin{array}{c}\text { Compleme } \\
\text { ntary }\end{array}$ & None & None & None \\
\hline $\begin{array}{l}\text { Fin_Co } \\
\mathrm{m}\end{array}$ & None & None & None & $\begin{array}{l}\text { Compleme } \\
\text { ntary }\end{array}$ & None & None & None & None & None \\
\hline Fin_Tax & $\begin{array}{c}\text { Substitutiv } \\
\mathrm{e}\end{array}$ & $\begin{array}{c}\text { Substitutiv } \\
\text { e }\end{array}$ & None & $\begin{array}{c}\text { Substitutiv } \\
\text { e }\end{array}$ & None & None & None & $\begin{array}{c}\text { Substitutiv } \\
\text { e }\end{array}$ & None \\
\hline Lab_Co & None & $\begin{array}{c}\text { Substitutiv } \\
\mathrm{e}\end{array}$ & None & None & None & None & None & None & None \\
\hline $\begin{array}{l}\text { Lab_Ta } \\
\mathrm{x} \\
\text { Com_T }\end{array}$ & None & None & None & None & None & $\begin{array}{l}\text { Compleme } \\
\text { ntary }\end{array}$ & None & None & None \\
\hline$a x$ & None & None & None & None & None & None & None & None & None \\
\hline
\end{tabular}

Turning to the intrinsic relationships between pairs of obstacles, Table 6.9 presents the complementarity/substitutability test results. The test results are based on the likelihood ratio test at the 90 per cent significant level ${ }^{89}$. Four types of obstacles are found to be pairwise complementary with respect to the propensity of innovation when all firms are included. Except for Fin_Com and Com_Tax (at significance level of 95 per cent), other pairwise complementary relationships are all above 99 per cent significant level. The finding is in line with the study from Mohnen and Röller (2005), which confirms the complementarity between financial, labor and tax related obstacles in innovation

\footnotetext{
${ }^{89}$ A multivariate one-sided hypothesis test is used in testing complementarity versus substitutability between two obstacles. The test procedure is based on the method introduced in chapter 5. Since the simulation results in chapter 5 show that a method combing HT1 and HT2 in general gives more efficient conclusion, the results in table 6.9 are based on both HT1 and HT2. Specifically, complementarity between two obstacles can be concluded only when one rejects the null hypothesis in HT1 and at the same time accepts the null hypothesis in HT2.
} 
propensity. A complementary relationship suggests that the presence of one obstacle attenuates the deterring effect of the other obstacle. A more intuitive interpretation here would be an additional obstacle does not matter anymore if existing obstacles are already preventing a firm to become a product innovator in EECA countries. Corresponding policy that is on target for removing this additional obstacle would not help the firm to become an innovator. A policy package that is on target for removing all complementary obstacles is favored. Substitutive relations are uncovered between finance and tax obstacles for the sales of new products. Specifically, the existence of finance obstacle worsens the hampering effect of tax obstacles, which begets a lower level of new product sales. In this case, policy instruments that remove only one obstacle individually are preferred because two substitutive obstacles existing simultaneously would aggravate their deterring effects.

\section{Complementarity/substitutability across sectors}

With respect to the innovation propensity, a complementary relation is more likely to be confirmed among finance, labor and tax related obstacles for firms in both manufacturing and service sectors. Informal competition is found to be complementary with labor obstacles for manufacturing firms whereas it shows a complementary relationship with tax obstacles for service firms. There is no complementary or substitutive effect found for firms in the service sector with respect to the intensity of innovation. In the manufacturing sector, substitutability is exhibited among finance and tax, and tax and labor obstacles. In regard to the pattern of these inter-connected patterns (see figure 6.1), labor and tax tend to be connected with other obstacles in forming a complementary relationship.

\section{Complementarity/substitutability across Income levels}

As shown in Table 6.9 (column 5 to 7), in the light of the innovation propensity, the tax obstacle complements the other three obstacles for firms in low- and lower-middle income countries whereas the finance obstacle has the most complementary relationships for firm in middle-income group. Labor and informal competitions are complementary obstacles except for firms in the high-income group. The findings also show that the interactions between obstacles become less intensive as the income level increases. Only labor and tax are found to be connected as complementary factors in the high-income group. Turning to the innovation intensity, relatively few interactions are observed. 
Finance and informal competition are complementary for firms in low and lower-middle income countries. And a substitutive relationship is found between finance and tax obstacles for the same group. The labor obstacle appears to be more active for highincome group because it forms complementary relationships with both finance and tax.

\section{Complementarity/substitutability across firm size}

Except for finance and tax, other types of obstacles are confirmed to be complementary to innovation propensity for firms with 5 to 25 employees. Finance obstacle seems to have a complementary relationship with both labor and tax while it exhibits a substitutive relationship with informal competition for firms with 26 to 100 employees. Furthermore, labor and informal competition are observed as complementary obstacles in this group. Only one complementary relationship is found for firms with more than 100 employees, which is between finance and tax. Looking at the pattern of connections between obstacles, less intensive interactions are shown with respect to the innovation intensity. Only one interaction is observed substitutability between finance and tax for mediumsized firms.

Overall, there seems to be a clear picture concerning the patterns of obstacles in different sectors, income levels and size groups. First, based on the number of connections, complementary relationships between obstacles dominate the pattern with respect to the propensity of product innovation. Fin_Tax appears most frequently across all sub-groups compared with other pairs of obstacles. It is followed by Fin_Lab, Lab_Com and Lab_Tax. Considering the innovation intensity, substitutability tends to be formed, especially by Fin_Tax. Secondly, complementary or substitutive relationships between obstacles are less frequent for firms from higher income countries or with larger number of employees. One possible explanation is that firms from high-income countries or with many employees are comparatively more resource abundant, either financial-wise, in skilled labor or through their past experience. They are less likely to encounter obstacles in the innovation process, as well as interactions between obstacles. Last, the estimated coefficients for obstacles in the outcome equation most often have a positive sign. Such a finding might turn up because firms learn about obstacles as they become more innovative. Thus, as the intensity of innovation increases (a higher percentage of sales due to new products or services), the firm is expected to perceive more obstacles. 
Figure 6.2 Complementarity/substitutability between obstacles to innovation propensity
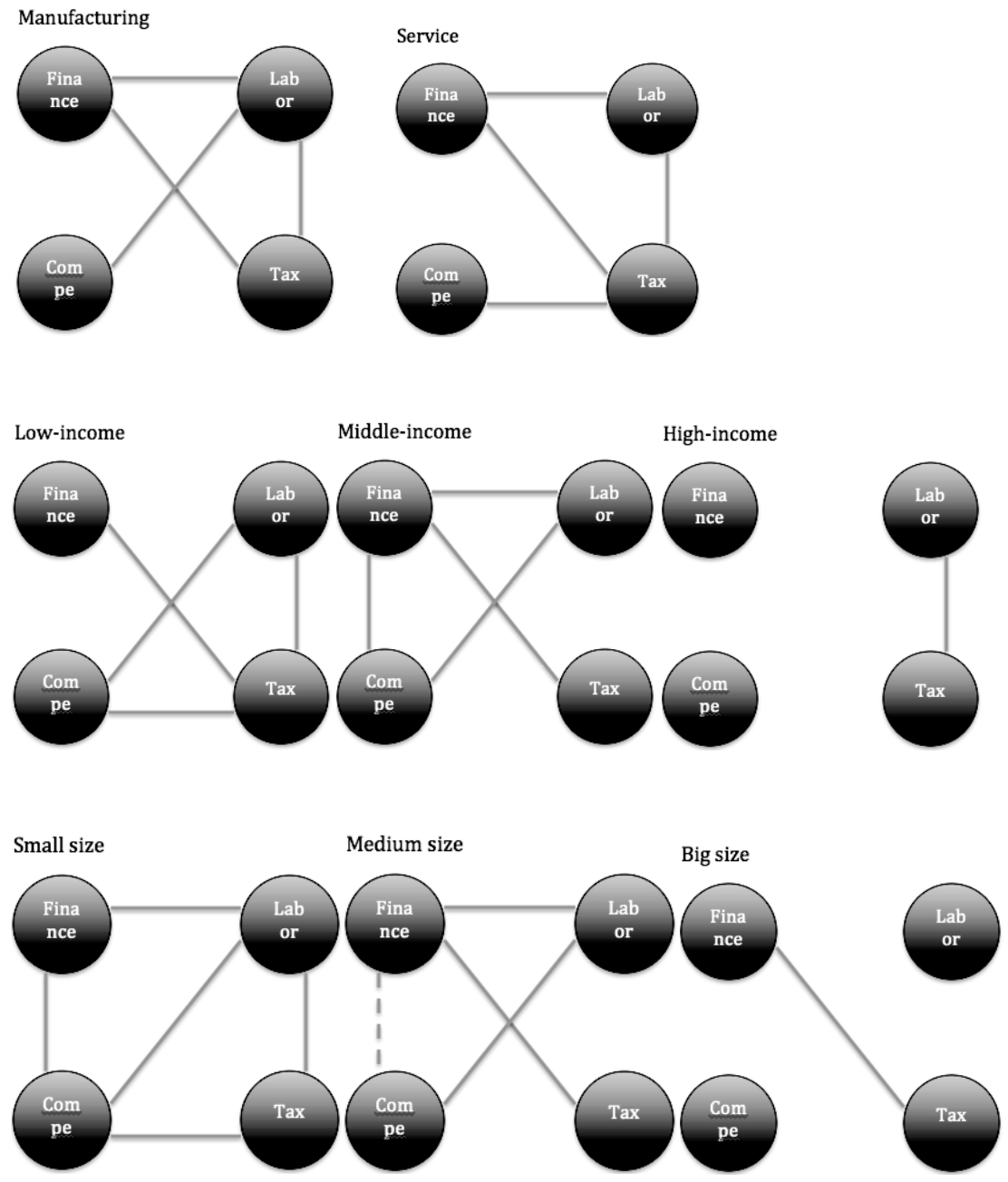

\subsection{Conclusion and policy remarks}

By investigating the potential complementarity and substitutability between obstacles, we are able to obtain a clear picture on how obstacles interact with each other in determining firms' innovation performance. With inadequate resources to eliminate all barriers together, especially for firms in developing countries, understanding the intrinsic relationships between obstacles is essential to formulate efficient strategies and policies. 
Despite the fact that $\mathrm{R} \& \mathrm{D}$ is often seen as the key source to a firm's technological upgrading, not all firms are willing to engage in $\mathrm{R} \& \mathrm{D}$ activities. There are about 73 per cent of EECA firms in our sample that do not engage in $\mathrm{R} \& \mathrm{D}$. The estimation confirms that R\&D investments foster a firm to become an innovator. Furthermore, we adopted the generalized Tobit model, which enables us to differentiate obstacles to innovation propensity from obstacles to innovation intensity. The findings show that four types of obstacles are complementary with respect to the propensity of innovation. It suggests that an additional obstacle does not matter anymore if existing obstacles are already preventing a firm to become a product innovator. Hence, policy instruments should be designed to eliminate them together rather than removing them individually. In contrast, a substitutive relation in which mainly exist between finance related and tax related obstacles plays a dominant role regarding the innovation intensity. Under these circumstances, the presence of one obstacle (e.g. high tax rate) would exacerbate the undermining effects induced by the other obstacle (e.g. inadequate internal finance). Policies that intend to remove them individually would be preferred.

Without obtaining the full information on process innovation, the current study is constrained to look only at product innovation. Other technological sourcing is also critical for firms in EECA countries since only 27 per cent of firms engage in R\&D and there are about 58 per cent of firms that claims to have product innovation. At least 29 per cent of sampled firms adopt other channels as technological sourcing than R\&D investment, which might cause a potential missing variable bias in estimating the innovation function. Another limitation of this study is that some firms might learn to cope with obstacles by innovating instead of realizing obstacles beforehand, which could explain the positive coefficients for obstacle variables in the innovation intensity function. Last, without computing the marginal effects of each obstacle by taking the potential complementarity into account, we cannot give concrete policy suggestions on the sequence of removing obstacles. 


\section{Appendix 6A}

\begin{tabular}{lll}
\hline Type of obstacles & No. & Percentage \\
\hline Access to finance & $\mathbf{1 , 2 9 3}$ & $\mathbf{1 6 . 7 7}$ \\
Access to land & 178 & 2.31 \\
Business licensing and permits & 231 & 3 \\
Corruption & 459 & 5.95 \\
Courts & 96 & 1.24 \\
Crime, theft and disorder & 146 & 1.89 \\
Customs and trade regulations & 184 & 2.39 \\
Electricity & 352 & 4.56 \\
Inadequately educated workforce & $\mathbf{8 9 1}$ & $\mathbf{1 1 . 5 5}$ \\
Labor regulations & 183 & 2.37 \\
Political instability & 778 & 10.09 \\
Practices of competitors in the informal sector & $\mathbf{8 3 0}$ & $\mathbf{1 0 . 7 6}$ \\
Tax administration & 270 & 3.5 \\
Tax rates & $\mathbf{1 , 3 4 9}$ & $\mathbf{1 7 . 4 9}$ \\
Transport & 96 & 1.24 \\
Does not apply & 376 & 4.88 \\
Total & & \\
\hline
\end{tabular}

No.: The number of firms which report the biggest obstacle faced by the establishment 



\section{Chapter 7}

\section{Conclusion}

\subsection{Summary}

The present thesis sheds light on the potential synergistic effects of innovation strategies and policies in developing countries. The findings have contributed to expanding our understanding of complementarity assets that potentially exist in innovation. Our main concerns are placed on investigating the interdependent relationships between technological sourcing strategies, and also the potential interactions between innovation obstacles. Furthermore, this thesis also contributes to the methodology in testing complementarity in the case of more than two activities. By comparing two commonly used one-sided multivariate hypotheses, we provide a detailed discussion of their potential problems and statistical power, and also give implications on which hypothesis should be adopted based on different model specifications. The Investment Climate Survey from the World Bank has been used as the main data source for the empirical analyses. Here we highlight our findings.

\section{Technological sourcing}

The lack of advanced technological competencies in developing countries requires innovation to occur through the imitation or adoption of already existing technologies. Especially in low-income countries, the low levels of technological capability severely constrain firms to close their distance from the technological frontier. Most of them rely on external knowledge acquisitions to engage in innovation activities from a basic level. 
By using firm-level data across 24 developing countries, chapter 4 examines the significant contribution of external technological sourcing exert to productivity growth in low-income countries. In this context, firms tend to rely on acquiring technology externally such as licensing, imported machinery and the like. The technological sourcing trajectory changes as the level of development goes up. In the context of middle-income countries, firms have already built up certain parts of innovation capabilities and also have gained innovation experience. In-house $R \& D$ activities start paying off in terms of generating higher level of productivity. The findings also exhibit that in-house R\&D strengthens the benefits of external technological sourcing. A synergistic effect is uncovered when firms adopt both internal and external technological sourcing simultaneously.

Considering the different development paths and country specificities, innovation behaviors and technological sourcing trajectories vary across countries. Chapter 3 takes a closer look at the technological sourcing in Chinese manufacturing firms. Classified as a middle-income country, China has accumulated basic innovation capabilities through external and internal channels. Firms are found to benefit from doing both R\&D and technology purchasing in raising the sales of new products per employee, but the complementarity is only observed in small-sized Chinese manufacturing firms with 100 to 300 employees. The findings confirm that in-house $R \& D$ accelerates the assimilation of external know-how while external technology sourcing enhances the efficiency of inhouse innovation activities, which is consistent with the conclusion drawn from Chapter 4.

In relation to complementarity, there might have to be a minimum of technological capability for it to work out. Without a basic level of absorptive capacity or certain accumulation of R\&D, importing technology does not pay off in terms of productivity improvement. Therefore, government and corporate policies should be formulated on the basis of specific learning mechanisms underlying different levels of development. At a low level of development, external technological sourcing is essential for firms to gain a basic capability accumulation. Governments should draw up policies that encourage firms to acquire technology externally, such as providing technological information and financial support for technology import. In middle-income countries where firms have built up certain level of technological capabilities and gathered some innovation 
experience, government policies should stimulate firms to invest in innovation by both internal and external channels.

\section{Innovation obstacles}

Studies with respect to innovation have devoted great emphasis to the determinants, capability and consequence of innovation in both advanced and developing economies. Less attention has been paid to which barriers block innovation or cause innovation failures at the firm level. Such neglect is particularly notorious in the context of developing countries. Due to relatively severe institutional, resource and affordability constraints, firms from developing countries are likely to face more barriers in the learning process. By investigating the potential interdependent relationships between pairs of obstacles on the ICS EECA 2008 data, Chapter 6 tries to identify factors that severely constraint innovation in Eastern European and Central Asian countries. The empirical analysis uncovers the potential complementary between innovation obstacles. It helps us to obtain a clearer picture about how obstacles interact with each other in determining firms' innovation performance and consequently provide policy implications.

The findings show that four types of obstacles (finance, tax, skilled labor and competition from the informal sector) are found to be pairwise complementary with respect to the propensity of innovation for firms from EECA countries. A complementary relation suggests that policy packages that attempt to eliminate them together are preferred. Only removing one of them would amplify the deterring effects of the other. When it comes to the innovation intensity, substitutive relations are uncovered between finance and tax, labor and tax obstacles in terms of new product sales. A substitutive relationship suggests us removing at least one obstacle because its presence would magnify the undermining effects induced by the other. Policies that attempt to avoid obstacles appearing simultaneously would be preferred in this case.

\section{Complementarity with more than two activities}

The perspective of complementarity is intriguing, yet it lacks the specificity about its definition, classification and testing approach framework. Chapter 2 reviews the general definition of complementarity and it gives a clear hierarchy classification. Based on different types of complementarity, different testing approaches are also given. Chapter 4 
compares the behavioral complementarity and objective complementarity by distinguishing complementary effects from the correlation caused by unobserved heterogeneity. When one tries to test complementarity among three or more activities in a linear model, multiple inequality restrictions are imposed on the estimated parameters and the corresponding statistical inferences are provided by multivariate one-sided hypotheses. Chapter 5 explains how to implement the PROD approach in an objective function with more than two activities. It focuses on the different hypotheses used for testing coefficients under multiple inequality constraints. A simulation experiment is employed and the findings reveal the potential biases which may exist in different types of multivariate one-sided hypotheses in testing for complementarity. The result also highlights that combining two hypotheses together always guarantees a more accurate conclusion. However, for a better-specified model with a relatively large sample size (e.g. larger than 1000), only one individual hypothesis will also perform consistently and generate an efficient result.

\subsection{Limitations and further research}

The contextual conditions, main technological activities and the nature of innovation output differ significantly between innovation in developed countries and developing countries. As a result, firms in these country groups adopt technology for different purposes and use it rather differently. Empirical studies of firms' innovation behavior usually require the availability of relatively sound datasets. Even though the Investment Climate Survey from World Bank provides us a unique opportunity to conduct comparison analysis, yet information with respect to innovation behavior at firm level is still limited, especially for the latest waves. Apart from having limited innovation information, observations are also largely unbalanced across each wave, which rules out the possibility of conducting panel data analysis. Systematic surveys with standard methodology and survey instruments (e.g. Community Innovation Survey in Europe) across developing countries are needed for future research.

Due to the inaccessibility of more advanced innovation data in developing countries, cross-sectional analyses are adopted in most parts of this thesis. The potential problem is the endogeneity of input variables such as capital, labor and knowledge inputs, which may be correlated with unobserved factors in the residual. Additionally, without 
longitudinal analysis, the time-invariant individual effects may also produce inconsistent estimations.

With respect to complementarity studies, an important point worth mentioning is that significant differences in results are found by adopting different testing approaches (e.g. chapter 2, chapter 4 and chapter 5). For example, conclusions based on the Correlation approach and Production approach are most likely to be different because the former is formulated to test "behavioral complementarity" and the latter is to test "objective complementarity" (see chapter 2.3), the same for the Miravete/Pernías approach and the Production approach (see chapter 4.3). In the cases of testing complementarity with more than two activities, results are also significantly different by using single-cross term, all-cross term and full-cross term approaches (see Chapter 5). Future studies should be aware of distinguishing these testing approaches.

The notion of complementarity has a potentially major application in explaining consistency in economic performance and organizational stability. As mentioned by Ennen et al. (2009), complementarities arise in a complex environment involving various elements. Those elements include not only activities, which are complementing each other, but also factors that accommodate or inhibit the emergence of complementarities. Relatively fewer studies try to investigate the condition or the cause of complementarity. Future studies should try to pay more attention to the preconditions and contextual factors, both internal and external, which accommodate complementarity instead of merely concentrating on the synergistic outcomes. Another challenge for future research is to identify which sub-group of activities plays the core role in connecting a complementary system and which activities can be broken off without influencing the performance? Moreover, most empirical studies on complementarity are based on a cross-sectional perspective. Further research should pay greater attention to outcomes based on longitudinal analysis. 



\section{References}

Ackerberg, D., K. Caves and G. Frazer (2006). Structural identification of production functions, mimeo.

$\mathrm{Ai}, \mathrm{C}$ and E. Norton (2003). Interaction terms in logit and probit models, Economics Letters 80(1):123-129.

Aggarwal, A. (2000). Deregulation, technology imports and in-house R\&D efforts: an analysis of the Indian experience. Research Policy 29(9):1081-1093.

Aghion, P. and P. Howitt (1998). Endogenous Growth Theory. Cambridge.

Almeida, R. and A. Fernandes (2008). Openness and Technological Innovation in Developing Countries: Evidence from Firm-Level Surveys. Journal of Developing Studies, 44(5):701-727.

Amemiya, T. (1984). Tobit models: a survey. Journal of Econometrics 24:3-61.

Amemiya, T. (1985). Advanced econometrics. Basil Blackwell, Oxford, UK.

Arellano, M. and S. Bond (1991). Some tests of specification for panel data: Monte Carlo evidence and an application to employment equations, Review of Economic Studies 58(2):277-297.

Arellano, M. and O. Bover (1995). Another Look at the Instrumental Variable Estimation of Error Component Models. Journal of Econometrics 68:29-51.

Arora, A., and A. Gambardella (1990). Complementarity and external linkages: the strategies of the large firms in biotechnology. The Journal of Industrial Economics 38:361-379.

Arrow, J. (1962). The economic implications of learning by doing. The review of economic studies 29(3):155-173.

Athey, S. and S. Stern (1998). An empirical framework for testing theories about complementarity in organizational design. NBER Working Paper No. W6600. NBER, Cambridge.

Audretsch, D., A. Menkveld and R. Thurik (1996). The decision between internal and external R\&D, Journal of Institutional and Theoretical Economics 152(3):519-530.

Baer, M., \& M. Frese (2003). Innovation is not enough: Climates for initiative and psychological safety, process innovations, and firm performance. Journal of Organizational Behavior 24:45-68.

Baldwin, J. and P. Hanel (2003). Innovation and Knowledge Creation in an Open Economy. Cambridge, Cambridge University Press.

Basant, R. and B. Fikkert (1996). The effects of R\&D, foreign technology purchase, and domestic and international spillovers on productivity in Indian firms. The Review of Economics and Statistics 78(2):187-199.

Beckerman, W. (1962). Projecting Europe’s growth. Economic Journal 72:912-925.

Belderbos, R., M, Carree and B, Lokshin (2006). Complementarity in R\&D Cooperation Strategies. Review of Industrial Organization 28(4):401-426.

Belderbos, R., B. Lokshin and M. Carree (2008). The productivity effects of internal and external R\&D: Evidence from a dynamic panel data model, Oxford Bulletin of Economics and Statistics 70(3):399-413.

Belderbos, R., I. Banri and W. Ryuhei (2008). Intra-firm technology transfer and R\&D in foreign affiliates: Substitutes or Complements? Evidence from Japanese multinational firms, Journal of the Japanese and International Economies 22(3):310-319.

Bhagwati, J. (1988). Export-promoting trade strategy: issues and evidence. The World Bank Research Observer 3(1): $27-57$.

Bin, G. (2008). Technology acquisition channels and industry performance: An industry-level analysis of Chinese large-and medium-size manufacturing enterprises. Research Policy 37(2):194-209. 
Black, S. and M. Lynch (2004). What's driving the new economy?: the benefits of workplace innovation. Royal Economic Society 114(493):97-116.

Blundell, R. and S. Bond (1998). Initial conditions and moment restrictions in dynamic panel data models, Journal of Econometrics, 87(1):115-143.

Brickley, J. (1995). Incentive Contracts and Contracting: Evidence from Franchising. Bradley Policy Research Center Working Paper 95-26, Simon School of Business.

Boeing, P., E. Mueller and P. Sandner (2012). What makes Chinese firms productive? - Learning from indigenous and foreign sources of knowledge. Mimeo.

Blonigen, B. and C. Taylor (2000). R\&D intensity and acquisitions in high-technology industries: Evidence from the U.S. electronic and electrical equipment industries, Journal of Industrial Economics 48(1):47-70.

Bocquet, R. and O, Brossard (2007). Complementarities in organizational design and the diffusion of information technologies: An empirical analysis. Research Policy 36(3):367-386.

Bonaccorsi, A. (2007). Institutional complementarity and inventive performance in nano science and technology. Research Policy 36(6):813-831.

Bönte, W. (2003). R\&D and productivity: Internal vs. external R\&D - Evidence from West-German manufacturing industries, Economics of Innovation and New Technology 12(4):343-360.

Braga, H. and L. Willmore (1991). Technology imports and technological efforts: an analysis of the determinants in Brazilian firms, The Journal of Industrial Economics 39(4):421-437.

Bresnahan, T., E. Brynjolfsson and L. Hitt (2002). Information technology, workplace organization and the demand for skilled labor: A firm-level evidence. The Quarterly Journal of Economics 117:339-376.

Carree, M., B, Lokshin and R. Belderbos (2011). A note on testing for complementarity and substitutability in the case of multiple practices. Journal of Productivity Analysis 35(3):263-269.

Caroli, E. and J. Van Reenen (2001). Skill-Biased Organizational Change? Evidence from A Panel of British and French Establishments. The Quarterly Journal of Economics 116(4):1449-1492.

Cassiman, B. and R. Veugelers (2006). In search of complementarity in innovation strategy: Internal R\&D and external knowledge acquisition. Management Science 52(1):68-82.

Child, J. (1994). Management in China during the Age of Reform, Cambridge, England: Cambridge University Press.

Chesbrough, W. (2003). Open Innovation, The New Imperative for Creating and Profiting from Technology. Harvard Business School Press.

Choi, B. and S. Poon (2008). Effects of knowledge management strategy on organizational performance: a complementarity theory-based approach. The International Journal of Mnagement Science 36:235-251.

Chung, S. and H. Singh (2000). Complementarity, status similarity and social capital as drivers of alliance formation. Strategic Management Journal 21(1):1-22.

Coase, R. (1998). The New Institutional Economics, American Economic Review, 88(2):72-74.

Cohen, A., J. Kemperman and H. Sackrowitz (2000). Properties of Likelihood Inference for Order Restricted Models. Journal of Multivariate 72(1):50-77.

Cohen, W. and D. Levinthal (1989). Innovation and learning: the two faces of R\&D, The Economic Journal, 99(397):569-596.

Cohen, W. and D. Levinthal (1990). Absorptive Capacity: A New Perspective on Learning and Innovation. Administrative Science Quarterly 35(1):128-152.

Colombo, M. and R. Mosconi (1995). Complementarity and Cumulative Learning Effects in the Early Diffusion of Multiple Technologies. Journal of Industrial Economics 43(1):13-48.

Colombo, M. (2005). Founders' human capital and the growth of new technology-based firms: A competence-based view. Research Policy 34(6):795-816.

Colombo, G. Massimo, L. Grilli and E. Piva (2006). In search of complementary assets: The determinants of alliance formation of high-tech start-ups. Research Policy 35(8):1166-1199.

Cooper, C. (1989). Technology and Innovation in International Economy. United Nation University Press, The Netherlands. 
Criscuolo., C., J. Haskel, and M. Slaughter (2005). Why are some firms more innovative? Knowledge inputs, knowledge stocks and the role of global engagement. NBER Working paper 11479.

D'Este, P., S. Iammarino and M. Savona (2008). What hampers innovation? Evidence from the UK CIS4. University of Sussex \& School of Management, Cranfield University.

Desai, A. (1989). Indian Technology Imports from SMEs. National Council for Applied Economic Research, New Delhi.

Deolalikar, A. and E. Evenson (1989). Technology production and technology purchase in Indian industry and econometric analysis, Review of Economics and Statistics 71(4):687-692.

Damijan, P., K. Mark, M. Boris and R. Matija (2003). The role of FDI, R\&D accumulation and trade in transferring technology to transition countries: evidence from firm panel data for eight transition countries. Economic Systems 27(2):189-204.

Doms, M. and J. Jensen (1998). Comparing wages, skills and productivity between domestically and foreign-owned manufacturing establishments in the United States. In: Baldwin, R.E., R.E., Lipsey, and J.D., Richardson, (Eds), Geography and Ownerships as Basis for Economic Accounting, University of Chicago Press, Chicago.

Drazin, R. and A. Van de Ven (1985). Alternative forms of fit in contingency theory. Administrative Science Quarterly 30(4):514-539.

Dussauge, P., B. Garrette, and W. Mitchell (2000). Learing From Competing Partners: Outcomes and duration of Scale and Link Alliances in Europe, North America and Asia. Strategic Management Journal 21(2):99-126.

Edgeworth, F. Y. (1881). Mathematical Psychics. An Essay on the Appli- cation of Mathematics to the Moral Sciences, Augustus M. Kelley, New York, 1967.

Ennen E., and A. Richter (2010). The Whole is More Than the Sum of Its Parts - Or is It? A Review of the Empirical Literature on Complementarities in Organizations, Journal of Management 36:1207-233.

Evangelista, R., T. Sandven, G. Sirilli, and K. Smith (1997). Innovation expenditures in European Indusstry. Final Report to the European Commission DG-XIII, Project EIMS No.93/54.

Ferriani, S., E. Garnsey and D. Probert (2008). Sustaining breakthrough innovation in large established firms: learning traps and counteracting strategies, in Bessant, J. and Venables, T. (eds.) Creating wealth from knowledge. Cheltenham: Edward Elgar.

Fikkert, B. (1993). An open or closed technology policy? The effects of technology licensing, foreign direct investment and technology spillovers on R\&D in Indian industrial sectors' firms, Unpublished $P h D$ Dissertation, Yale University, New Haven, CT.

Fransman, M. and K. King (1984). Technological capability in the third world. The Macmillan Press LTD. London.

Freel, M. and R. Harrison (2006). Innovation and Cooperation in the Small Firm Sector: Evidence from 'Northern Britain, Regional Studies 40(4):289-305.

Freeman, C. (1989), The Economics of industrial Innovation, 2nd ed., Francis Pinter, London.

Fu, X., C. Pietrobelli and L. Soete (2010). The role of foreign technology and indigenous innovation in the emerging economies: technological change and catching-up, World Development 39(7)1204-1212.

$\mathrm{Fu}, \mathrm{X}$. and Y. Gong (2010). Indigenous and foreign innovation efforts and drivers of technological upgrading: Evidence from China, World Development 39(7):1213-1225.

Galia, F. and D. Legros (2004). Complementarities between obstacles to innovation: evidence from France. Research Policy 33(8):1185-1199.

Gerschenkron, A. (1962). Economic Backwardness in Historical Perspective, a Book of Essays, Cambridge, Massachusetts: Belknap Press of Harvard University Press.

Gilsing, V, B. Nooteboom, W. Vanhaverbeke, G. Duysters and A. Van Den Oord (2008). Network embeddedness and the exploration of novel technologies: technological distance, betweenness centrality and density. Research Policy 37(10):1717-1731. 
Globerman, S., J. Ries and I. Vertinsky (1994). The economic performance of foreign affiliates in Canada, Canadian Journal of Economics 27(1):143-56.

González, A. and F. Lamanna (2007). Who fears competition from Informal firms?. Policy Research Working Paper 4316. World Bank.

Gourieroux, C., A. Holly and A. Monfort (1982). Likelihood ratio test, Wald test, and Kuhn-Tucker test in linear models with inequality constraints on the regression parameters. Econometrica: journal of the Econometric Society 50(1):63-80.

Greene, W. (2003). Econometric Analysis. 5th ed. Upper Saddle River, NJ: Prentice-Hall.

Griliches, Z. (1984). Productivity, R\&D, and the Data Constraint, American Economic Association 84(1):1-23.

Grömping, U. (2010). Inference with Linear Equality and Inequality Constraints Using R: The Package ic. infer. Journal of Statistical Software 33(10):1-31.

Groves, T., Y. Hong, J. McMillan and B. Naughton (1994). Autonomy and incentives in Chinese state enterprises, Quarterly Journal of Economics 109(1):183-209.

Grossman, G. and E. Helpman (1991). Innovation and Growth in the Global Economy, MIT Press, Cambridge, MA.

Guthrie, D. (1997). Between markets and politics: Organizational responses to reform in China, American Journal of Sociology 102(5):1258-1304.

Hadjimanolis, A. (1999). Technovation - Barriers to innovation for SMEs in a small less developed country (Cyprus). Technovation 19(9):561-570.

Hadjimanolis, A. (2003). The Barriers Approach to Innovation. In Shavinina; The International Handbook on Innovation. Pergaman.

Hahn, J Penner and J. Shaver (2005). Does international research and development increase patent output? An analysis of Japanese pharmaceutical firms. Strategic Management Journal 26(2):121- 140.

Hajivassiliou, V. and P. Ruud (1994). Classical estimation methods for LDV models using simulation. Handbook of Econometrics, eds. R. Engle and D. McFadden, 4(40):2383-2441.

Hall, B. and J. Mairesse (1995). Exploring the relationship between R\&D and productivity in French manufacturing firms, Journal of Econometrics 65(1):263-293.

Hall, B., J. Mairesse and P. Mohnen (2010). Measuring the returns to R\&D, in the Handbook of the Economics of Innovation, B. H. Hall and N. Rosenberg (editors), Elsevier, Amsterdam, 2010, 1034-1082.

Hashai, N. (2008). R\&D intensity, value appropriation and integration patterns within organizational boundaries. Research Policy 37(6-7):1022-1034.

Heckman, J. (1976). The common structure of statistical models of truncation, sample selection and limited dependent variables and a simple estimator for such models. NBER Books, National Bureau of Economic Research.

Heckman, J. (1979). Sample Selection Bias as a Specification Error. Econometrica 47(1):153-161.

Helfat, C. (1997). Know-how and asset complementarity and dynamic capability accumulation: The case of R\&D. Strategic Management Journal 18(5):339-360.

Henderson, R. (1993). Underinvestment and incompetence as responses to radical innovation: evidence from the photolithographic alignment equipment industry. Rand Journal of Economics 24(2):248-70.

Himmelberg, C., and B. Petersen (1994). R\&D and internal finance: A panel study of small firms in hightech industries, Review of Economics and Statistics 76(1):38-51.

Holtz-Eakin, D., W. Newey and H. Rosen (1988). Estimating Vector Autoregressions with Panel Data, Econometrica 56(6):1371-1395.

Holmström, B. and P. Milgrom (1994). The Firm as an Incentive System, American Economic Review, 84(4):972-991.

$\mathrm{Hu}, \mathrm{A}$., G. Jefferson, and Q. Jinchang (2005). R\&D and technology transfer: firm-level evidence from Chinese industry. The Review of Economics and Statistics 87(4):780-786.

Ichniowski, C., K. Shaw and G. Prennushi (2007). The Effects of Human Resource Management Practices on Productivity: A Study of Steel Finishing Lines. International Library of Critical Writings In Economics 203(2):244 
Ichniowski, C., K. Shaw, and G. Prennushi (1997). The effects of human resource practices on manufacturing performance: A study of steel finishing lines. American Economic Review 87: 291-313.

Johnston, J. and J. DiNardo (1997). Econometric Methods. 4th edition. McGraw-Hill.

Judge, G. and T. Takayama (1966). Inequality Restrictions in Regression Analysis. Journal of the American Statistical Association 61(313):166-181.

Katrak, H. (1997). Developing countries' imports of technology, in-house technological capabilities and efforts: an analysis of the Indian experience. Journal of Development Economics 53(1):67-83.

Kim, L. and R. Nelson (2000). Technology, Learning and Innovation: Experience of Newly Industrializing Economies, Cambridge: Cambridge University Press.

Kimura, F. and K. Kiyota (2007). Foreign-owned versus domestically-owned firms: Economic performance in Japan, Review of Development Economics 11(1):31-48.

King, D., R. Slotegraaf and I. Kesner (2008). Performance Implications of Firm Resource Interactions in the Acquisition of R\&D-Intensive Firms. Organization Science 19(2):327-340.

Kleinknecht, A. and P. Mohnen (2002). Innovation and Firm Performance: Econometric Explorations of Survey Data. Palgrave, New York.

Klomp, L. and G. Van Leeuwen (1999). The Importance of Innovation for Company Performance. Statistics Netherlands: Voorburg.

Kodde, D. and F. Palm (1986). Wald criteria for jointly testing equality and inequality restrictions. Econometrica: journal of the Econometric Society 1243-1248.

Kretschmer, T., E. Miravete and J. Pernías (2012). Competitive Pressure and the Adoption of complementary innovations, American Economic Review, 102(4):1540-1570.

Kudo, A. (1963). A multivariate analogue of the one-sided test. Biometrika 50(3-4):403-418.

Lall, S. (1989). Learning to Industrialise: The Acquisition of Technological Capability by India. Macmillan, London.

Lane, P. J., and Lubatkin, M, (1998). Relative Absorptive Capacity and Interorganizational Learning., Strategic Management Journal 19(5):461-477.

Laursen, K. (2003). New human resource management practices, complementarities and the impact on innovation performance. Cambridge Journal of Economics 27(2):243-263.

Lewbel, A. (2007). Coherency and Completeness of Structural Models Containing a Dummy Endogenous Variable. International Economic Review 48(4):1379-1392.

Li, X. (2011). Sources of External Technology, Absorptive Capacity, and Innovation Capability in Chinese State-Owned High-Tech Enterprises. World Development 39(7):1240-1248.

Li, X. and G. Wu (2010). In-house R\&D, technology purchase and innovation: Empirical evidences from Chinese hi-tech industries, 1995-2004. International Journal of Technology Management 51(2/3/4):217-238.

Liew, C. (1976). Inequality-Constrained Least-Squares Estimation. Journal of the American Statistical Association 71(355):746-751.

Liu, H. (1992). A summary of technical trade of China in 1990, Almanac of Foreign Economic Relations in China $55-82$.

Liu, X. and T, Buck (2007). Innovation performance and channels for international technology spillovers: Evidence from Chinese high-tech industries. Research Policy 36(3):355-366.

Liu, X. and White, R. (1997). The relative contributions of foreign technology and domestic inputs to innovation in Chinese manufacturing industries, Technovation 17(3):119-125.

Liu, X. and H. Zou (2008). The Impact of Greenfield FDI and Mergers and Acquisitions on Innovation in Chinese High-tech Industries. Journal of World Business 43:352-364.

Lokshin, B., R. Belderbos and M. Carree (2008). The Productivity Effects of Internal and External R\&D: Evidence from a Dynamic Panel Data Model. Oxford Bulletin of Economics and Statistics 70(3):399-413. 
Lokshin, B., M. Carree and R Belderbos (2007). Testing for complementarity and substitutability in case of multiple practices. Opean Access publications from Katholieke Universiteit Leuven urn:hdl:123456789/120461, Katholieke Universiteit Leuven.

Love, J. and S. Roper (2001). Location and network effects on innovation success: evidence for UK, German and Irish manufacturing plants. Research Policy 30(4):643-661.

Love, J, and S. Roper (1999). The determinants of innovation: R\&D, technology transfer and networking effects. Review of Industrial Organization 15(1):43-64.

Lu, Q. and W. Lazonick (2001). The organization of innovation in a transitional economy: business and government in Chinese electronic publishing, Research Policy 30:55-77.

Lundvall. (1992). National Systems of Innovation: Towards a theory of innovation and interactive learning. Pinter Publishers.

Luo, Y., J. Tan and O. Shenkar (1998). Strategic responses to competitive pressure: The case of township and village enterprises in China, Asia Pacific Journal of Management 15(1):33-50.

Mairesse, J. and P. Mohnen (2001). To be or not to be innovative: An exercise in measurement, Cambridge, MA: NBER, Working paper 8644-35.

Mairesse, J., P. Mohnen, Y. Zhao, and F. Zhen (2012). Globalization, Innovation and Productivity in Manufacturing Firms: A Study of Four Sectors of China, Working Papers DP-2012-10, Economic Research Institute for ASEAN and East Asia (ERIA).

Matsuyama, K. (1995). Economic development as coordination problems. Northwestern University (Evanston, Ill.). Center for Mathematical Studies in Economics and Management Science.

Matusik, S. (2000). Absorptive Capacity and Firm Knowledge: Separating the Effects of Public Knowledge, Flexible Firm Boundaries, and Firm Absorptive Abilities. Paper presented at the Organization Science Winter Conference, Keystone.

Milgrom, P. and J. Roberts (1990a). Rationalizability, learning, and equilibrium in games with strategic complementarities. Econometrica: journal of the Econometric Society 1255-1277.

Milgrom, P. and J. Roberts (1990b). The economics of modern manufacturing: Technology, strategy, and organization. The American Economic Review 511-528.

Milgrom, P. and J. Roberts (1994). Complementarities and systems: Understanding Japanese economic organization. Estudios Economicos 9(1):3-42.

Milgrom, P. and J. Roberts (1995). Complementarities and fit strategy, structure, and organizational change in manufacturing. Journal of accounting and economics 19(2):179-08.

Miotti, L. (2003). Co-operative R\&D: why and with whom?: An integrated framework of analysis. Research Policy 32(8):1481-1499.

Miravete, E. and J. Pernías. (2006). Innovation complementarity and scale of production. The Journal of Industrial Economics 54(1):1-29.

Miravete E. and C. Pernías (2010). Testing for complementarity when strategies are dichotomous. Economics Letters. 106:28-31.

Mohnen, P. (2000). R\&D tax incentives: Issues and evidence, in The Political Economy of Industrial Policy in Europe and the Member States, Damien Neven and Lars-Hendrik Röller (eds.). Berlin : Ed. Sigma:183-199.

Mohnen, P. and L. Röller (2005). Complementarities in innovation policy. European Economic Review 49(6):1431-1450.

Monjon, S. and P. Waelbroeck (2003). Assessing Spillovers from Universities to Firms: Evidence from French firm-level data, International Journal of Industrial Organization 21(9):1255-1270.

Moorman, C. (1999). The contingency value of complementary capabilities in product development. Journal of Marketing Research 36(2):236-257.

Mowery, D. and J. Oxley (1995). Inward technology transfer and competitiveness: the role of national innovation system. Cambridge Journal of Economics 19(1):67-93.

Mulkay, B., B. Hall and J. Mairesse (2001). Firm level investment and R\&D in France and the United States, in Deutsche Bundesbank (ed.), Investing Today for the World of Tomorrow, Springer Verlag, Berlin. 
Mytelka, L. (1987). Licensing and technology dependence in the Andean group, World Development 6(4):447459.

Nelson, R. (1993). National Innovation Systems; a comparative analysis. Oxford University Press.

Nerkar, A. and P. Roberts (2004). Technological and product-market experience and the success of new product introductions in the pharmaceutical industry. Strategic Management Journal 25(89):779-799.

OECD (2003). Towards a knowledge-based economy, OECD Publishing. Paris.

OECD (2006). Main Science and Technology Indicators, OECD Publishing. Paris.

OECD (2007). Reviews of Innovation Policy China, OECD. http://www.oecd.org/publishing/corrigenda.

OECD (2011), Main Science and Technology Indicators, OECD Publishing. Paris.

Oehlert, G. (1992). A note on the delta method. American Statistician 46:27-29.

Olley, S. and A. Pakes (1996). The dynamics of productivity in the telecommunications equipment industry, Econometrica, 64(6):1263-98.

Parthasarthy, R. and S. Sethi (1993). Relating strategy and structure to flexible automation: a test of fit and performance implications. Strategic Management Journal 14(7):529-549.

Perlman, M. and L. Wu (2003). On the validity of the likelihood ratio and maximum likelihood methods. Journal of Statistical Planning and Inference 117:59-81.

Perlman, Michael. (1969). One-sided problems in multivariate analysis. Institute of Mathematical Statistics.

Piatier (1984). Barriers to innovation. London. Frances Pinter Publishers Ltd.

Preissl (1998).Barriers to innovation in services SI4S Topical Paper STEP Group.

Puhani, P. (2000). The Heckman Correction for Sample Selection and its Critique. Journal of Economic Surveys 14(1):53--68.

Powell, T. (1997). Information technology as competitive advantage: The role of human, business, and technology resources. Strategic Management Journal 18(5):375-405.

Rawski, T. (1994). Chinese industrial reform: Accomplishments, prospects and implications, American Economic Association Papers and Proceedings 84(2):271-275.

Roodman, D. (2006). How to do xtabond2: an introduction to "Difference" and "System" GMM in Stata. Center for Global Development Working Paper Number 103.

Roper, S. and J. Du (2008). Modeling the innovation value chain. Research Policy 37(6-7):961-977.

Rothaermel, F. (2007). Building dynamic capabilities: Innovation driven by individual-, firm-, and networklevel effects." Organization Science 18(6):898-921.

Rothaermel, F. (2001). Complementary assets, strategic alliances, and the incumbent's advantage: an empirical study of industry and firm effects in the biopharmaceutical industry. Research Policy 30:1235-1251.

Rothaermel, F. (2005). Technological discontinuities and complementary assets: A longitudinal study of industry and firm performance. Organization Science 16(1):52-70.

Saliola, F. and M. Seker (2011). Total factor productivity across the developing world. Enterprise Note Series 2011(NO. 23). World Bank.

Salmon, R. and J. Shaver (2005). Learning by Exporting: New Insights from Examining Firm Innovation. Journal of Economics \& Management Strategy 14:431-460.

Sasidharan, S. and V. Kathuria (2011). Foreign direct investment and R\&D: Substitute or complements: A case of Indian Manufacturing after 1991 reforms, World Development 39(7):1226-1239.

Savignac, F. (2006). The impact of financial constraints on innovation: Evidence from French manufacturing firms, Cahiers de la Maison des Sciences Économiques v06042, Université Panthéon-Sorbonne (Paris I).

Savignac, F. (2008). Impact of financial constraints on innovation: What can be learned from a direct measure?, Economics of Innovation and New Technology 17(6):553-569. 
Schmidt, T. (2005). What Determines Absorptive Capacity, Paper presented at the DRUID Tenth Anniversary Summer Conference on 'Dynamics of Industry and Innovation: Organisations, Networks and Systems'.

Schmiedeberg, Claudia. (2008). Complementarities of innovation activities: An empirical analysis of the German manufacturing sector. Research Policy 37(9):1492-1503.

Schneider, F. (2005). Shadow Economies around the World: What do we really know? European Journal of Political Economy 23(1):598-642.

Schoonhoven, C., K. Eisenhardt and K. Lyman (1990). Speeding Products to. Market: Waiting Time to First Product. Administrative Science 35(1):177-207.

Silvapulle, J. (1997). A curious example involving the likelihood ratio test against one-sided hypotheses. American Statistician 51(2):178-180.

Silvapulle, M. and P. Sen (2004). Constrained statistical inference: Order, inequality, and shape constraints. London: Wiley.

Song, M., C. Droge and S. Hanvanich (2005). Marketing and technology resource complementarity: an analysis of their interaction effect in two environmental contexts. Strategic Management Journal 26:259 276.

Steinfeld, E. (1998). Forging Reform in China: The Fate of State-Owned Industry, Cambridge: Cambridge University Press.

Stockdale, B. (2002). UK Innovation Survey 2001, Economic Trends 580:36-42.

Tether, B. (2002). Who Co-operates for Innovation, and Why: An Empirical Analysis. Research Policy, 31(6):947-967.

Tether, B. (2008). Beyond industry-university links: Sourcing knowledge for innovation from consultants, private research organisations and the public science-base. Research Policy 37(6-7):1079-1095.

Tiwari, A., P. Mohnen, F. Palm and S. van der Loeff (2008). Financial constraints and R\&D investment; Evidence from CIS, forthcoming in Kleinknecht, A., Ott, R., van Beers, C., and R. Verburg, eds., Determinants of Innovative Behaviour: A Firm's Internal Practices and its External Environments, Palgrave Publishers, London.

Toomet, O. and A. Henningsen (2008). Sample Selection Models in R: Package sample Selection. Journal of Statistical Software 27(7):1-23.

Toole, A. (2007). Does public scientific research complement private investment in research and development in the pharmaceutical industry?. Journal of Law and Economics 50(1):81-104.

Topkis, M. (1978). Minimizing a submodular function on a lattice. Operations Research 26(2):305-321.

Topkis, M. (1998). Supermodularity and Complementarity. Princeton University Press.

Tripsas, M. (1997). Unravelling the process of creative destruction: complementary assets and incumbent survival in the typesetter industry. Strategic Management Journal, Summer Special Issue 18(S1):119-42.

Tushman, M. and P. Anderson (1986). Technological discontinuities and organizational environments. Administrative Science Quarterly 31(3):439-65.

Vella, F. (1998). Estimating Models with Sample Selection Bias: A Survey. Journal of Human Resources 33(1):127-- 172 .

Verbeek, M. (2000). A Guide to Modern Econometrics. John Wiley \& Sons, Hoboken, NJ.

Veugelers, R. (1997). Internal R\&D expenditures and external technology sourcing, Research Policy 26(3):303-315.

Vives, X. (1990). Nash equilibrium with strategic complementarities. Journal of Mathematical Economics 19(3):305-321.

Von Hippel (1988). The Sources of Innovation. New York: Oxford University Press.

Walder, A. G. (2003). Elite Opportunity in Transition Economies. American Sociological Review 68, 899-916.

White, S. and X. Liu (1998). Organizational processes to meet new performance criteria: Chinese pharmaceutical firms in transition. Research Policy 27(4):369- 383. 
White, S. (2000). Competition, capabilities, and the make, buy, or ally decisions of Chinese state-owned firms, Academy of Management Journal 43(3):324-341.

Wooldridge, J. (2002). Econometric Analysis of Cross Section and Panel Data, Cambridge: MIT Press.

Zahra, S. and G. George (2002). Absorptive Capacity: A Review and Reconceptualisation and Extension, Academy of Management Review 27(2):185-203.

Zhang, X. (1990). Survey of technology import and export in China, Almanac of Foreign Economic Relations in China 54-78.

Zhao, H. (1995). Technology imports and their impacts on the enhancement of China's indigenous Technological capability, The Journal of Development Studies 31(4):585-602.

Zhou K., C. Yim and D. Tse (2005). The effects of strategic orientations on technology- and market based breakthrough innovations, Journal of Marketing 69(2):42-60.

Zhu, K. (2004). The complementarity of information technology infrastructure and e-commerce capability: A resource-based assessment of their business value. Journal of Management Information Systems 21(1):167-202. 



\section{Samenvatting}

Deze samenvatting introduceert het onderwerp van dit proefschrift en beschrijft de data die zijn gebruikt voor de empirische analyse. Het geeft vervolgens een beknopte weergave van de resterende hoofdstukken.

Het tweede hoofdstuk poogt het concept van complementariteit te begrijpen en beschouwt eerdere studies over innovatie in de bestaande literatuur die de complementariteit benadering toepassen. Het geeft een inzichtelijke interpretatie weer van complementariteit tussen paarsgewijze economische activiteiten door een hiërarchische classificatie te gebruiken. Complementariteit wordt over het algemeen ingedeeld in twee categorieën die gebaseerd zijn op al of geen inkadering in een specifieke objectieve afhankelijkheidsrelatie: objectieve complementariteit en gedragsbepalende complementariteit. Een nadere classificering in de lagere hiërarchie wordt tevens gedefinieerd. Naast het uitwerken van verschillende typen complementariteit introduceert hoofdstuk 2 ook de benaderingen zoals die in empirische studies worden toegepast om complementariteit en substitutie te toetsen. Drie benaderingen worden onderscheiden: CORR (correlatie benadering), MP (Miravete en Pernías benadering) en PROD (productie benadering). Bovendien komt uit de bestudering van de studies, die complementariteit in innovatieprocessen trachten te onderzoeken, de problemen en beperkingen naar voren die thans in de literatuur bestaan. Het hoofdstuk betrekking hebbende op het literatuuroverzicht verstrekt een gedetailleerde discussie over deze problemen en beperkingen. Het verklaart ook op welke wijze deze in dit proefschrift zullen worden behandeld.

Hoofdstuk 3 onderzoekt het bestaan van complementariteit tussen in-house R\&D en externe technologische acquisitie door panel data van Chinese productiebedrijven te gebruiken. Het tracht het effect te onderzoeken van interne en externe technologie 
inkoop op de bedrijfsinnovatie en productiviteit in kleine en middelgrote Chinese productiebedrijven. Het voorspelt in het bijzonder de opbrengst van R\&D en de aankoop van externe technologie en de mogelijke complementariteit of substitutie ertussen. Dat doet het door onderscheid te maken tussen twee prestatiemaatstaven, te weten innovatie in producten of processen en arbeidsproductiviteit. Omdat grootte in dit geval relevant is, schatten wij afzonderlijk de relaties voor bedrijven met minder dan 100 , tussen 100 en 300 en meer dan 300 werknemers. De resultaten laten zien dat in-house R\&D de assimilatie van externe knowhow lijkt te versnellen terwijl de inkoop van externe technologie de efficiëntie van in-house innovatie versterkt. De resultaten laten ook enig bewijs zien voor het bestaan van complementariteit van in-house $\mathrm{R} \& \mathrm{D}$ en de aankoop van externe technologie in de toename van de verkoop van nieuwe producten per werknemer in kleinschalige Chinese productiebedrijven tussen de 100 en 300 werknemers, terwijl R\&D en de aankoop van externe technologie substituten zijn als het gaat om de toename van de arbeidsproductiviteit.

Het vierde hoofdstuk beschrijft een andere empirische studie die potentiële synergetische effecten tussen technologische strategieën toetst, gebruikmakend van cross-sectional data van bedrijven uit 24 ontwikkelings- en minst ontwikkelde landen. In dit hoofdstuk pogen wij factoren te identificeren die de keuze voor de inkoop van specifieke technologie bepalen alsmede factoren die potentiële complementariteit bevorderen. Het bestudeert de functies van interne $R \& D$ inspanningen en de inkoop van externe technologie met betrekking tot het bevorderen van de productiviteit van productiebedrijven. Drie benaderingen worden vergeleken en toegepast in de empirische analyse, zijnde CORR, PROD en MP (Miravete en Pernías benadering, zie hoofdstuk 4). De analyse benadrukt dat in een cross-sectional analyse de MP benadering ten opzichte van de andere twee benaderingen opvalt omdat het een structureel kader verschaft dat op effectieve wijze de afwijking corrigeert die veroorzaakt wordt door de correlatie tussen zgn. unobservables. De empirische bevinding laat de kritische rol zien van de acquisitie van externe technologie voor fabricage industrieën in ontwikkelingslanden en toont tekenen van complementariteit in alleen midden-inkomenslanden. De bevindingen geven ook aan dat verschillende benaderingen verschillende resultaten voortbrengen.

Hoofdstuk 5 bediscussieert de verschillende vormen van multivariate eenzijdige hypothese gedefinieerd om paarsgewijze complementariteit tussen drie of vier activiteiten te toetsen. Dit hoofdstuk gebruikt gesimuleerde datasets om de validiteit en efficiëntie te 
vergelijken van twee type hypothesen met verschillende modelspecificaties en steekproefgrootte. De simulatieresultaten bevestigen the potentiële afwijking die zou kunnen bestaan in het formuleren van een non-exhaustive hypothese. Conclusies die gebaseerd zijn op dergelijke hypothesen, neigen af te wijken indien geen rekening wordt gehouden met de aard van de ongelijkheden. Resultaten uit dit hoofdstuk suggereren ook dat het combineren van twee hypothesen altijd een meer accurate conclusie in het toetsen van complementariteit garandeert. In een enkele situatie, specifiek in het geval van een grote steekproefomvang en een hoge waarde van R-square voor lineaire modellen, kan ook het testen van slechts één hypothese adequate informatie geven voor het trekken van juiste conclusies.

Teneinde de barrières voor innovatie beter te kunnen begrijpen, past hoofdstuk 6 de complementariteitsbenadering toe op bedrijfsniveau gegevens uit de Investment Climate Survey 2009 Eastern European and Central Asian countries (EECA) om te onderzoeken in hoeverre er complementariteit dan wel substitutie bestaat tussen vier categorieën van innovatie-obstakels in verschillende sectoren, over inkomensniveaus en groepsgrootte. De benadering van de paarsgewijze complementariteitstoets, indien er sprake is van meer dan twee activiteiten, is ontleend aan hoofdstuk 5. De resultaten uit dit hoofdstuk geven een duidelijke verklaring voor de complementariteit tussen barrières voor innovatie: de aanwezigheid van een obstakel verzacht het belemmerende effect van het andere obstakel voor innovatie. De bevinding suggereert dat beleidsmaatregelen die beide obstakels trachten aan te pakken, de voorkeur genieten. Beleid dat slechts één obstakel wegneemt, zal het tegenwerkende effect van de ander vergroten. Een substitutie relatie tussen obstakels, aan de andere kant, suggereert dat het verwijderen van één obstakel voldoende is omdat het niet wegnemen ervan de negatieve effecten veroorzaakt door het andere obstakel zou versterken.

Het laatste hoofdstuk sluit dit proefschrift af met het duiden van enkele beleidsimplicaties en het adviseren over richtingen voor toekomstig onderzoek. 



\section{Curriculum vitae}

Jun Hou was born on February 1982 in Guiyang, China. He finished his bachelor course in Agricultural Economics at Southern China University of Tropical Agriculture (Hainan University). In 2007, he obtained his MA in Economics of Development at the Institute of Social Studies, Erasmus University, Rotterdam, and later that year, joined the $\mathrm{PhD}$ program at UNU-MERIT, Maastricht University. Jun Hou is currently employed as a research officer at the TMD center, Oxford Department of International Development, Oxford University. 

UNITED NATIONS

UNIVERSITY

\section{UNU-MERIT}

2013

\section{Jun Hou}

Complementarity in Innovation and Development: A Cross-country Comparison

\section{Rufin Baghana}

Impacts of Government Incentives to R\&D, Innovation and Productivity:

A Microeconometric Analysis of the Québec Case

\section{Lilia I. Stubrin}

High-Tech Activities in Emerging Countries: A Network perspective on the Argentinean biotech activity

2012

\section{Abdul Waheed}

Innovation Determinants

and Innovation as a Determinant:

Evidence from Developing Countries

\section{Bilal Mirza}

Energy Poverty and Rural Energy Markets in Pakistan

\section{Benjamin Engelstätter}

Enterprise Software and Video Games: An Empirical Analysis

\section{Fulvia Farinelli}

Natural Resources, Innovation and Export Growth: The Wine Industry in Chili and Argentina

\section{Rodolfo Lauterbach}

Innovation in Manufacturing: From Product Variety and Labor Productivity Growth to Economic Development in Chile

\section{Kirsten Wiebe}

Quantitative Assessment of Sustainable Development and Growth in Sub-Saharan Africa.

\section{Julio Miguel Rosa}

Organizational Strategies, Firms' Performance and Spatial Spillovers. The Canadian Case in Research and Development.

Johannes Wilhelmus Marie Boels

Joseph Schumpeter, honderd jaar economische ontwikkeling. Een historisch-theoretische beschouwing.

\section{1}

\section{Daniel Vertesy}

Interrupted Innovation: Emerging economies in the structure of the global aerospace industry.
71. Tina Saebi

Successfully managing alliance portfolios: an alliance capability view.

\section{Nora Engel}

Tuberculosis in India - A case of innovation and control.

\section{Evans Mupela}

Connectivity and growth in Sub-Saharan Africa: The role of communication satellites

\section{Nantawan Kwanjai}

Cross cultural intelligence amid intricate cultural webs - A tale of the UnDutchables in the land of 1002 smiles

\section{Lina Sonne}

Innovation in Finance to Finance Innovation: Supporting pro-poor entrepreneur-based innovation

2010

\section{Fernando Santiago}

Human Resources Management Practices and Learning for Innovation in Developing Countries: Pharmaceutical Firms in Mexico

\section{Zakaria Babutsidze}

Essays on Economies with Heterogenous Interacting Consumers

\section{Bertha Vallejo}

Learning and Innovation Under Changing Market Conditions: The Auto Parts Industry in Mexico

\section{Donatus Ayitey}

Technical Change, Competitiveness and Poverty Reduction: A Study of the Ghanaian Apparel Industry

\section{Sergey Fillipov}

Multinational Subsidiary Evolution: Corporate Change in New EU Member States

\section{Asel Doranova}

Technology Transfer and Learning under the Kyoto regime; Exploring the Technological Impact of CDM projects in developing countries

2009

\section{Alexis Habiyaremye}

From Primary Commodity Dependence to Diversification and Growth". "Absorptive Capacity and Technological Catch Up in Botswana and Mauritius".

59. Yoseph Getachew

The Role of Public Capital in Economic Development 


\section{Sandra Leitner}

Embodied Technological Change and Patterns of Investment in Austrian Manufacturing

\section{Semih Akçomak}

The Impact of Social Capital on Economic and Socia Outcomes

\section{Abraham Garcia}

The Role of Demand in Technical Change

\section{Saurabh Arora}

Coherence in socio-technical systems: a network

perspective on the innovation process

$$
2008
$$

\section{Rutger Daems}

Medicines for the developing world

\section{Johannes Hanel}

Assessing Induced Technology - Sombart's Understanding of Technical Change in the History of Economics

\section{Rifka Weehuizen}

Mental Capital: the economic significance of mental health

\section{Danielle Clood}

The relationship between R\&D partnership formation, social embeddedness and innovative performance

\section{Sabine Fuss}

Sustainable Energy Development under Uncertainty

2007

\section{Tobias Kronenberg}

Reconciling Environmental Conservation with Economic Prosperity: The Feasibility of Double Dividends in the Short and Long Run

\section{Viktoria Kravtsova}

Assessing the Impact of Foreign Direct Investment in Transition Economies

\section{Suhail Sultan}

The Competitive Advantage of Small and Medium Sized Enterprises: The Case of Jordan's Natural Stone Industry

2006

\section{Bulat Sanditov}

Essays on Social Learning and Imitation

\section{Mamata Parhi}

Dynamics of New Technology Diffusion: A Study of the Indian Automotive Industry

\section{Andreas Reinstaller}

Social structures and the innovation process: Their role in the demand of firms and consumers

\section{Rose Kiggundu}

Innovation systems and development : the journey of a Beleaguered Nile Perch Fishery in Uganda

\section{Thomas Pogue}

The Evolution of Research Collaboration in South African Gold Mining: 1886-1933

\section{Geoffrey Gachino}

Foreign Direct Investment, Spillovers and Innovation: The Case of Kenyan Manufacturing Industry

\section{0. Önder Nomaler}

Technological Change, International Trade and Growth An Evolutionary, Multi-Agents-Based Modeling Approach

2005

39. Samia Satti Osman Mohamed-Nour

Change and Skill Development in the Arab Gulf Countries

\section{Elad Harison}

Intellectual Property Rights: Economics and Policy

Analysis

\section{Daniel Dalohoun}

The relationship between $R \& D$ partnership formation, social embeddedness and innovative performance: a multi-level approach of social embeddedness

\section{Müge Ozman}

Networks, Organizations and Knowledge

\section{Bas Straathof}

Product variety and economic growth - The counteracting effects of scale and idiosyncrasy

\section{Wilfred Schoenmakers}

Knowledge Flows between Multinational Companies: A Patent Data Analysis

\section{Myriam Cloodt}

Mergers and Acquisitions (M\&As) in High-Tech Industries: Measuring the Post-M\&A Innovative Performance of Companies

2004

\section{Paola Criscuolo}

R\&D Internationalisation and Knowledge Transfer. Impact on MNEs and their Home Countries

31. Maarten Verkerk

Trust and Power on the Shop Floor

\section{Gottfried Leibbrandt}

Adoption, harmonization and succession of network technologies across countries

\section{Mark Sanders}

Skill Biased Technical change - Its Origins, the Interaction with the Labour Market and Policy Implications

2003

28. Nadine Roijakkers

Inter-firm cooperation in high-tech industries: a study of R\&D partnerships in pharmaceutical biotechnology 


\section{Viki Sonntag}

Speed, Scale and Sustainability

\section{Masaru Yarime}

From End-of-Pipe Technology to Clean Technology

\section{Stéphane Malo}

The combinatorial Chemistry Revolution - Sustaining a Superior Performance Position through Technological Learning

2002

\section{Annelies Hogenbirk}

Determinants of Inward Foreign Direct Investment: the Case of the Netherlands

2001

\section{John Adeoti}

Technology Investment in Pollution Control in SubSaharan Africa: The Case of the Nigerian Manufacturing Industry

\section{Edward Huizenga}

Innovation Management: How Frontrunners Stay Ahead. An Empirical Study on Key Success Factors in the ICT sector

2000

\section{Machiel van Dijk}

Technological Change and the Dynamics of Industries.

Theoretical Issues and Empirical evidence from Dutch Manufacturing

1999

\section{Jan Cobbenhagen}

Managing Innovation at the Company Level: A Study on Non-Sector-Specific Success Factors

\section{Marjolein Caniëls}

Regional Growth Differentials: The Impact of Locally

Bounded Knowledge Spillovers

1998

\section{Aldo Geuna}

Resource allocation and knowledge production: Studies in the economics of university research

1996

\section{Reinoud Joosten}

Dynamics, Equilibria, and Values

\section{Hugo Kruiniger}

Investment, R\&D, and the Financing Decisions of the Firm
1995

\section{Hans van Meijl}

Endogenous Technological Change: The Case of Information Technology. Theoretical Considerations and Empirical Results

\section{René Kemp}

Environmental Policy and Technical Change. A Comparison of the Technological Impact of Policy Instruments

\section{Rohini Acharya}

The Impact of New Technologies on Economic Growth and Trade. A Case Study of Biotechnology

\section{Geert Duysters}

The Evolution of Complex Industrial Systems. The Dynamics of Major IT Sectors

\section{Marjan Groen}

Technology, Work and Organisation, A Study of the Nursing Process in Intensive Care Units

1994

\section{Huub Meijers}

On the Diffusion of Technologies in a Vintage Framework Theoretical Considerations and Empirical Results

\section{Theon van Dijk}

The Limits of Patent Protection. Essays on the Economics of Intellectual Property Rights

\section{Hans Voordijk}

Naar Integrale Logistiek in Bedrijfsketens, Ontwikkelingen in de Bouw

1993

\section{Paul Diederen}

Technological Progress in Enterprises and Diffusion of Innovations. Theoretical Reflections and Empirica Evidence.

\section{Ben Dankbaar}

Economic Crisis and Institutional Change. The crisis of Fordism from the perspective of the automobile industry

\section{Hanno Roberts}

Accountability and Responsibility: The Influence of Organisation Design on Management Accounting

1992

\section{Bart Verspagen}

Uneven Growth Between Interdependent Economies. An Evolutionary View on Technology Gaps, Trade and Growth

3. Sjoerd Romme

A Self-organization Perspective on Strategy Formation 
1989

2. John Spangenberg

Economies of Scale, and Atmosphere in Research

Organisations

1988

1. John Hagedoorn

Evolutionary and heterodox innovation analysis : a study

of industrial and technological development in process

control and information technology 